\title{
Republic of Moldova: Poverty Reduction Strategy Paper
}

Poverty Reduction Strategy Papers (PRSPs) are prepared by member countries in broad consultation with stakeholders and development partners, including the staffs of the World Bank and the IMF. Updated every three years with annual progress reports, they describe the country's macroeconomic, structural, and social policies in support of growth and poverty reduction, as well as associated external financing needs and major sources of financing. This country document for the Republic of Moldova, dated May 2004, is being made available on the IMF website by agreement with the member country as a service to users of the IMF website.

To assist the IMF in evaluating the publication policy, reader comments are invited and may be sent by e-mail to publicationpolicy@imf.org.

Copies of this report are available to the public from

International Monetary Fund $\bullet$ Publication Services

$70019^{\text {th }}$ Street, N.W. $\bullet$ Washington, D.C. 20431

Telephone: (202) 623-7430 • Telefax: (202) 623-7201

E-mail: publications@imf.org • Internet: http://www.imf.org

Price: $\$ 15.00$ a copy

\section{International Monetary Fund Washington, D.C.}



GOVERNMENT OF THE REPUBLIC OF MOLDOVA

\section{Economic Growth and Poverty Reduction Strategy Paper (2004-2006)}




\section{THE LIST OF ACRONYMS}

ACSA

ADMV

ADP

AESM

ASM

CCI

CD

CEDS

CFM

CIS

CLC

CMEA

CPA

CPAB

CPI

CSCA

CSR

DAIMES

DCTD

DFCR

DOTS

DSA

DTD

EC

e-Economy

e-Government

EFF

EGPRSP

ERCPOR

EU

FDI

FPSS

GDP
- Agency for Consultancy and Education in Agriculture

- Agro-industrial Department „Moldova-Vin”

- Association of Domestic Producers

- Academy of Economic Studies from Moldova

- Academy of Sciences of Moldova

- Chamber of Commerce and Industry

- Customs Department

- Children Facing Extremely Difficult Situations

- Railroads of Moldova

- Community of Independent States

- Center of Legislative Creation

- Council of Mutual Economic Aid

- Central Public Administration

- Central Public Administration Bodies

- Consumption Price Index

- Citizen's savings and credit associations

- Chamber of State Registration

- Development, Adoption, Implementation, Monitoring and Evaluation of the Strategy

- Department for Construction and Territorial Development

- Department of Financial Control and Revision

- TBC Control Program

- Department of Social Assistance

- Department for Tourism Development

- European Commission

- electronic economy

- electronic Government

- Extended Fund Facility

- Economic Growth and Poverty Reduction Strategy paper

- Experimental Republican Center Prosthesis, Orthopedics and Rehabilitation

- European Union

- Foreign Direct Investments

- Republican Fund of Population's Social Support

- Gross Domestic Product 


\begin{tabular}{|c|c|}
\hline GIU & - PRSTF Grant Implementation Unit \\
\hline GPC & - General Practitioner's Center \\
\hline GRP & - Gross Regional Product \\
\hline GS & - Group of synthesis of the final EGPRSP version \\
\hline HBS & - Household Budget Survey \\
\hline HDI & - Human Development Index \\
\hline HPP & - Heating and Power Plant \\
\hline HIV/AIDS & - Acquired Immunodeficiency Syndrome \\
\hline $\mathrm{HU}$ & - Health Unit \\
\hline ICT & - Information and Communication Technologies \\
\hline \multirow[t]{2}{*}{ ICSDPR } & - Interministerial Committee for Sustainable Development and \\
\hline & Poverty Reduction \\
\hline IEASM & - Institute of Energetic of the ASM \\
\hline ILO & - International Labor Organization \\
\hline IMF & - International Monetary Fund \\
\hline InfSoc & - Informational Society \\
\hline IT & - Information Technologies \\
\hline ITD & - Information Technologies Department \\
\hline JIT & - "Just in Time" principles \\
\hline LPA & - Local Public Administration \\
\hline LPAB & - Local Public Administration Bodies \\
\hline MAFI & - Ministry of Agriculture and Food Industry \\
\hline $\mathrm{MC}$ & - Ministry of Culture \\
\hline MD & - Migration Department \\
\hline ME & - Ministry of Economy \\
\hline MEd & - Ministry of Education \\
\hline MENR & - Ministry of Environment and Natural Resources \\
\hline MEnerg & - Ministry of Energy \\
\hline MF & - Ministry of Finance \\
\hline MFA & - Ministry of Foreign Affairs \\
\hline MIA & - Ministry of Internal Affairs \\
\hline $\mathrm{MH}$ & - Ministry of Health \\
\hline MHI & - Mandatory Health Insurance \\
\hline MI & - Ministry of Industry \\
\hline MJ & - Ministry of Justice \\
\hline MLSP & - Ministry of Labor and Social Protection \\
\hline
\end{tabular}


MR

MTC

MTEF

NACS

NALFE

NARE

NBM

NCEAM

NCEI

NCSDPR

NGO

NHIC

NIEI

NPAA

NSIH

NTDP

OECD

MEPO

OSCE

PAR

PC

PCA

PD

PHARE

PISA

PB

PPMU

PRSTF

IPRSP

R\&D

RENUS

RISP

SAAR

SAIPP

SALRC

$\mathrm{SC}$
- Ministry of Reintegration

- Ministry of Transports and Communications

- Medium term expenditures framework

- National Anti- Corruption Strategy

- National Agency for Labor Force Employment

- National Agency for Regulation in Energy

- National Bank of Moldova

- National Council for Evaluation and Accreditation in Medicine

- National Commission for European Integration

- National Council for Sustainable Development and Poverty Reduction

- Non-governmental organization

- National Health Insurance Company

- National Institute of Economy and Information

- National Public Acquisition Agency

- National Social Insurance House

- National Territorial Development Plan

- Organization for Economic Cooperation and Development

- Moldovan Export Promotion Organization

- Organization for Security and Cooperation in Europe

- Public Administration Reform

- Participatory Council

- Partnership and Cooperation Agreement

- Privatization Department

- Technical Assistance to Central and East European Countries

- Project for International Students Appraisal

- Polichlor Biphenyl

- Poverty and Policy Monitoring Unit

- Poverty Reduction Strategy Trust Fund

- Interim Poverty Reduction Strategy paper

- Research \& Development

- National Registry of Statistical Units

- Rural Sector Investment Support Project

- State Agency for Authors Rights

- State Agency for Industrial Property Protection

- State Agency for Land Relations and Cadastre

- State Chancellery 
SCSTD

SD

SDR

SEN

SIFM

SMD

SME

SPAI

SPFI

SSIB

SS

SStr.

SSD

TACIS

TIMSS

TQM

UCTE

UNDP

UNICEF

USAID

VOC

WB

WTO

YSD
- Supreme Council for Science and Technological Development

- Sustainable Development

- Special Drawing Rights

- Special educational needs

- Social Investment Fund in Moldova

- Standards and Metrology Department

- Small and medium enterprises

- Initiative regarding the fight against corruption

- State Principal Fiscal Inspectorate

- State Social Insurance Budget

- State Securities

- Sectoral Strategies

- Statistics and Sociology Department

- Technical Assistance to CIS

- International Mathematics and Science Study

- Total system of Quality Management

- Union for Energy Transport Coordination

- United Nations Development Program

- United Nations Children's Fund

- US Agency for International Development

- Vehicle Operation Costs

- World Bank

- World Trade Organization

- Youth and Sports Department 


\section{TABLE OF CONTENTS}

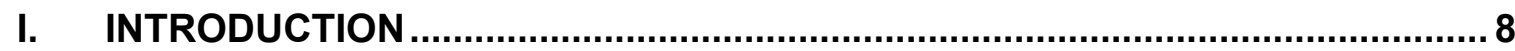

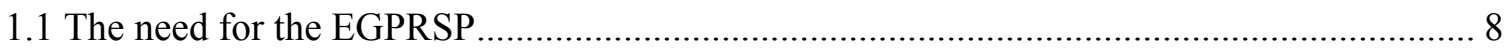

1.2 The principles of EGPRSP development and implementation .............................................. 9

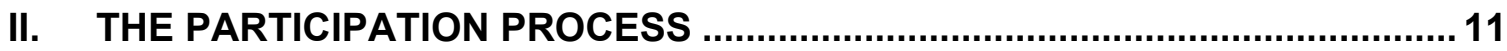

2.1 The principles and objectives of the participation process .............................................. 11

2.2 The institutional framework of the participation process ................................................... 11

2.3. Development of communication campaign and public consultations .................................. 13

III. SOCIAL AND ECONOMIC EVOLUTION: ACHIEVEMENTS AND PROBLEMS17

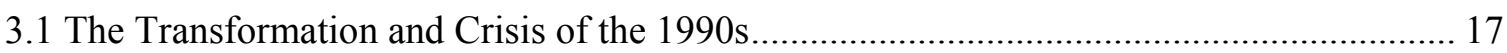

3.2 Economic Growth, Imbalances and Constraints ............................................................. 19

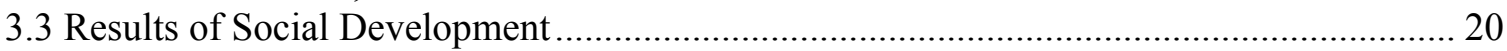

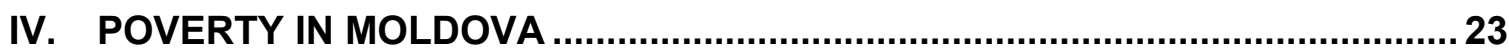

4.1 The Main Features of Poverty ....………………………………………………….... 23

4.2 Definition and Measurement of Poverty …………………………………………….... 24

4.3 Poverty Indicators and the Dynamics of Poverty ……………………………………..... 26

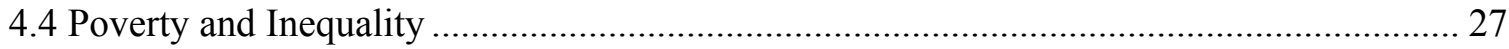

4.5 The Poverty Profile and Main Reasons for Poverty ………………………………............ 28

4.6 Income and Consumption Expenditures of the Poor ………………………………........ 29

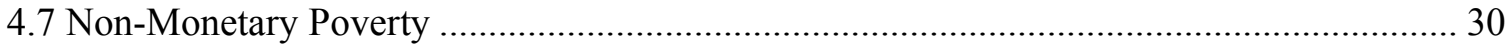

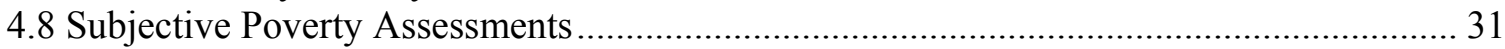

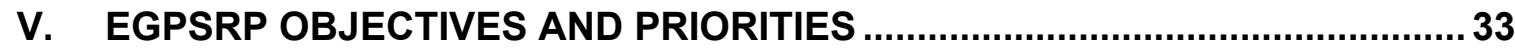

5.1 Long-term development objectives............................................................................... 33

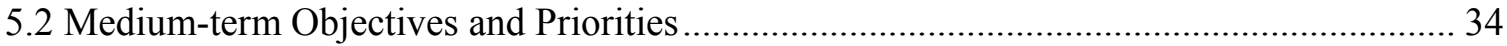

5.3. EGPSP and Millennium Development Goals ................................................................. 36

VI. STRATEGY MEASURES FOR POVERTY REDUCTION..................................38

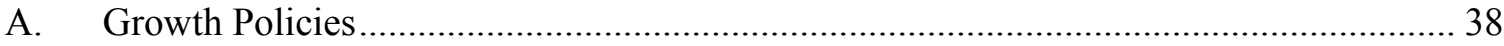

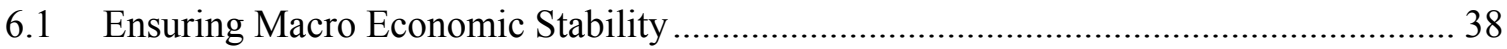

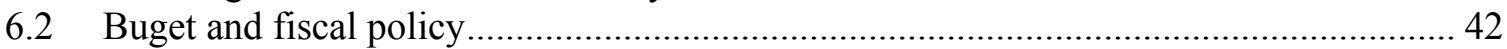

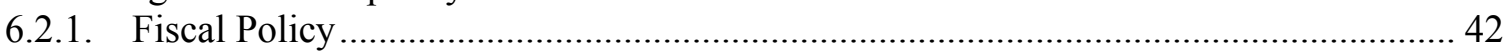

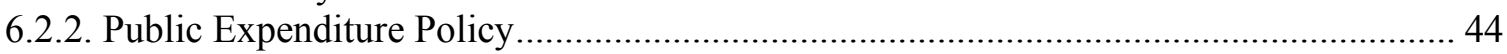

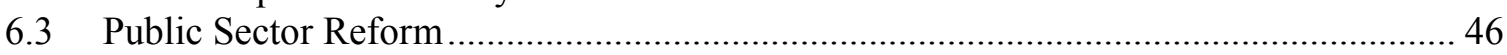

6.3.1. Reform of Public Administration............................................................................... 46

6.3.2. Public Finance Management ................................................................................. 52

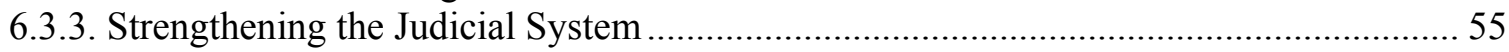

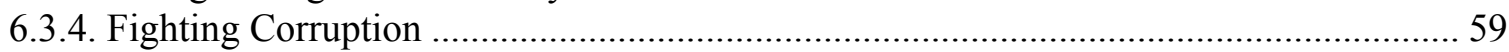

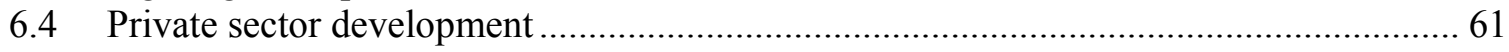

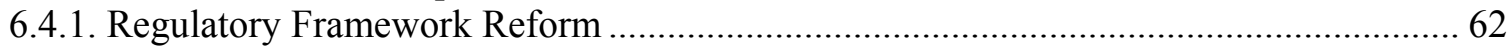

6.4.2. Competition Promotion and Protection ......................................................................... 63

6.4.3. The Optimization and Improvement of Corporate Management ...................................... 64

6.4.4. Suport and Development of Small and Medium-Scale Enterprises................................. 65

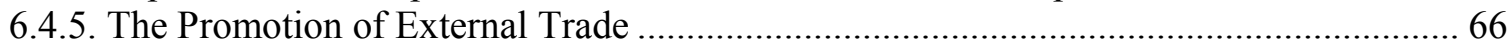

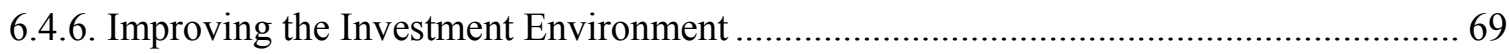




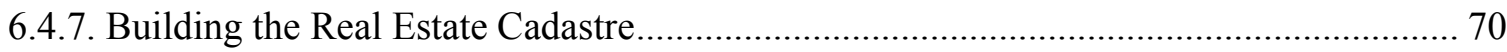

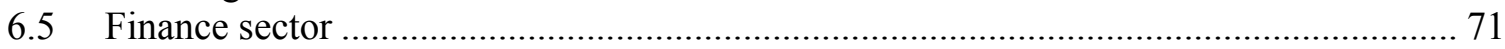

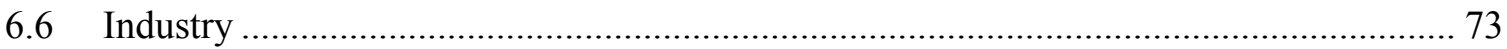

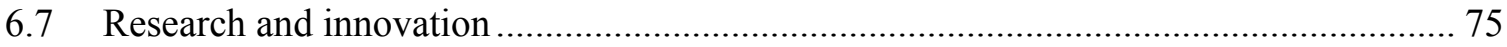

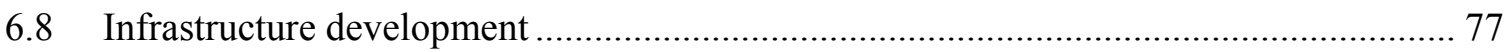

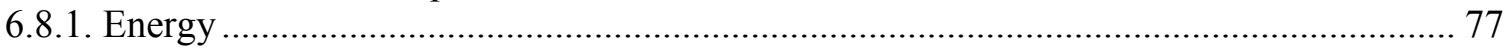

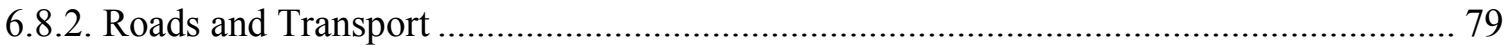

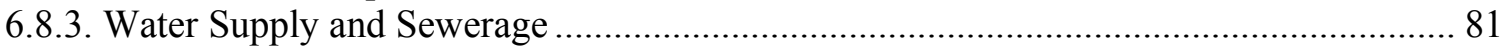

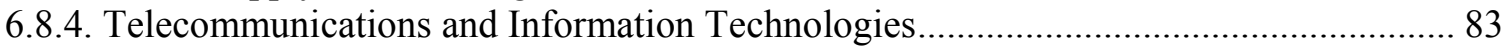

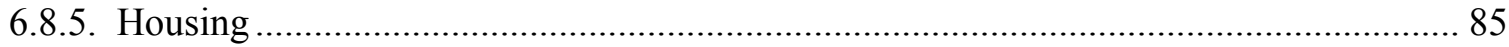

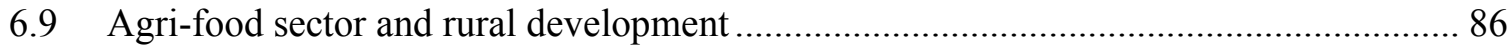

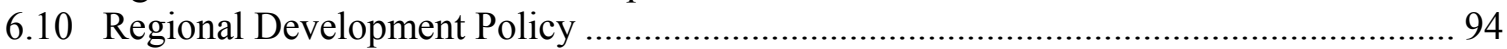

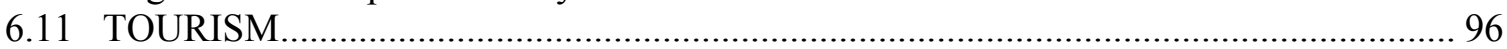

6.12. ENVIRONMENTAL PROTECTION AND SUSTAINABLE USE OF NATURAL

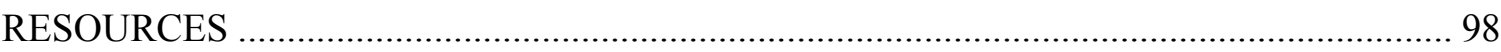

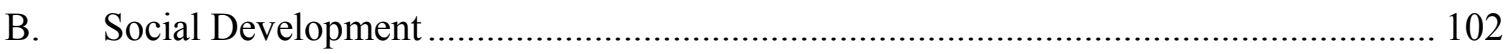

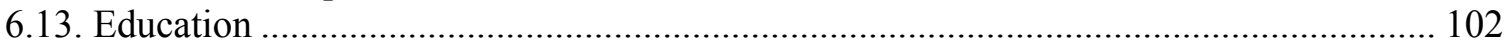

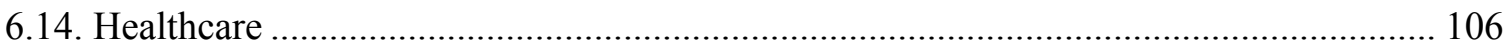

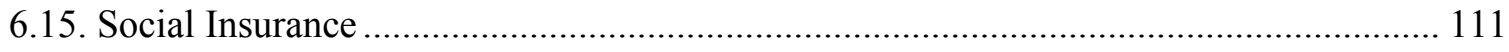

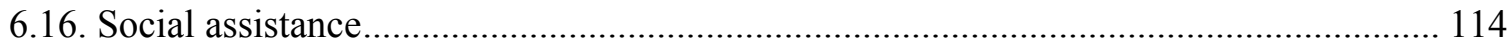

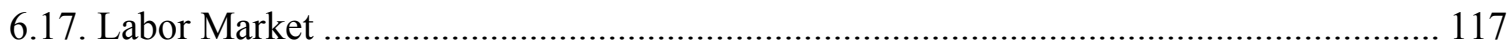

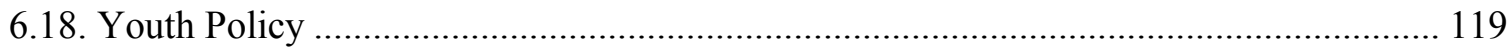

VII. EXPECTED OUTCOMES AND RISKS IN STRATEGY IMPLEMENTATION .... 122

VIII. EGPRSP IMPLEMENTATION, MONITORING AND EVALUATION ................123

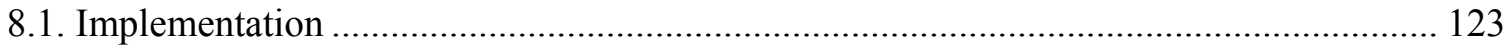

8.2. Monitoring and Evaluation ....................................................................................... 124

8.3 Sources of information for monitoring and evaluation ................................................. 128

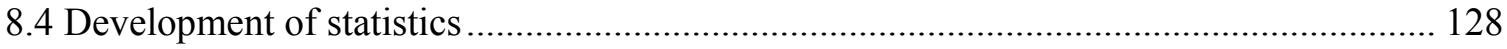

IX. ACTIONS, COSTS, AND LINKAGE TO MTEF ……........................................ 130

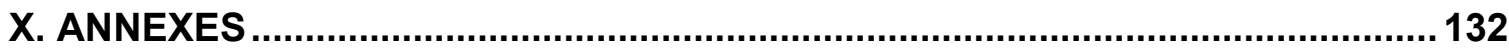

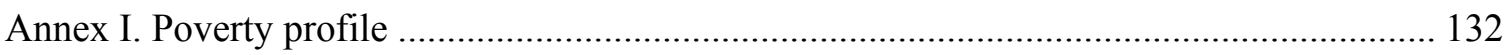

Annex 2. Methodological principles for the evaluation of the absolute poverty line............. 139

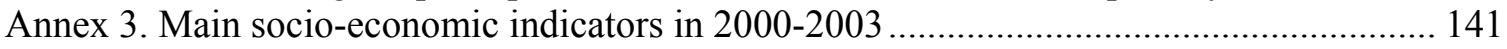

Annex 4. The forecast of macroeconomic indicators for 2004-2006 ................................... 144

Annex 5. Indicators for monitoring the EGPRSP implementation ..................................... 146

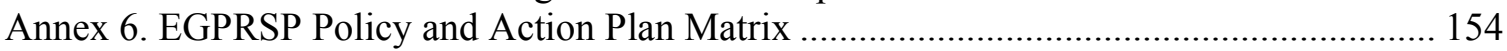

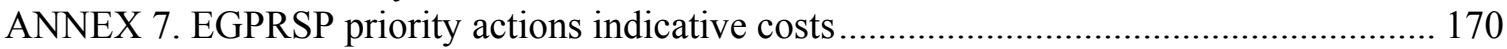

ANNEX 8. Structure of public reactions In the debates process on EGPRSP $\ldots \ldots \ldots \ldots \ldots \ldots \ldots \ldots . . . . . . . .190$ 


\section{INTRODUCTION}

\subsection{THE NEED FOR THE EGPRSP}

1. The Economic Growth and Poverty Reduction Strategy Paper (EGPRSP) is the overarching policy framework for the sustainable development of the Republic of Moldova in the medium term. It should serve as the basis for developing and implementing new assistance strategies by international financial organizations and donor countries, as well as for the preparation of the annual state budgets for 2005 and 2006.

2. The need for a more strategic approach to economic growth and poverty reduction is determined by the country's recent experience. During the first ten years of independence, the GDP dropped by three times, the real income of the population contracted by $72 \%$ and the average pension in terms of purchasing power declined by $75 \%$.

3. Despite significant efforts made to establish the basic institutions of the market economy, as well as to promote democratic values, the Moldovan society was unable to achieve the strategic objectives defined in 1990, according to which the creation of a market economy and the improvement in the population's living standards were the main priorities of state policy.

4. During the period of 2001-2003, a sizable improvement in economic and social indicators was registered: GDP grew by $21.6 \%$ in real terms, the monthly average wage by $71.2 \%$ and the average monthly pension by $93 \%$. Nevertheless, poverty remains a major concern.

5. In 2002 over $40 \%$ of the population lived below the absolute poverty line. Poverty has generated a range of social problems, including an exodus of $35-40 \%$ of the economically active population abroad. Despite some improvement during the last three years, the Republic of Moldova, measured by GDP per capita (US\$542 in 2003), continues to be the last but one among the ex-soviet countries, and the last among the countries of Central and South-Eastern Europe.

6. This situation occurred mainly due to: (a) the lack of a coherent, long term and comprehensive vision among the political class during the 1990s regarding the future of the country and of the economy; (b) the ineffectiveness of the economic and social policies adopted, and especially of the tools used for their implementation; (c) the fast pace of economic reforms compared with the rate of institutional change and changes in social protection mechanisms; (d) the divergence between the economic priorities of the governing bodies of the '90s and the social priorities of the majority of the population.

7. The country's negative experience emphasizes the need for major changes in social and economic policies, with the aim to improve the environment for business, provide employment, and upgrade public administration at all levels. It is necessary to replace some components of the institutional framework with new structures able to ensure sustainable and well-balanced socioeconomic development. The need to address current deficiencies determined the leadership of the country to develop a strategic, systemic and participative vision for socioeconomic development and launch it for discussions and contributions to the entire society.

8. The need for this Strategy is also imposed by the necessity of consolidating the society around a set of objectives which are transparent and shared by the entire society, as well as by groups with a direct interest in accomplishing these objectives - the poor, business community 
and public administration. The Economic Growth and Poverty Reduction Strategy will provide a basis for this consolidation over the medium term. The support of society is critical for successful EGPRSP elaboration and implementation. This will not be forthcoming without ensuring extensive, informed and well-focused participation of all segments of society in the process of developing the strategy.

9. EGPRSP has the potential to become an effective tool for continuous strategic planning, and for providing for the prioritization of strategic objectives and the implementation of related actions. It is also a tool for the efficient and transparent allocation of available resources, and for the harmonization of medium and long-term objectives. Annual review of the Strategy will be required to adjust its parameters to changing realities.

10. The EGPRSP also represents a framework for the coordination of sectoral strategies, directing them towards the accomplishment of the higher-level EGPRSP objectives.

11. The EGPRSP offers a thorough view of the needs of the country for international technical assistance and external resources. It allows for effective allocation of resources offered by international financial organizations and donors to address the most important socio-economic and ecological problems.

12. The first step in EGPRSP development was the approval in October 2000 of the Interim Strategy for Poverty Reduction, followed by the approval of an updated version of the paper on April 24, 2002 (Government Decree No. 524). According to this decree, line ministries have developed sectoral strategies, which formed the basis for the present EGPRSP version.

\subsection{THE PRINCIPLES OF EGPRSP DEVELOPMENT AND IMPLEMENTATION}

13. The Government considers that: (i) poverty reduction is a special effort, which needs a special arrangement and an unconditional commitment by the Government, in the first place, but also by the entire society and (ii) sustainable economic growth is fundamental for poverty reduction.

14. Guided by the social orientation of Government economic policies, the priority focus of EGPRSP is to improve the living standards of the nation's citizens and the social protection of the poorest including the system of social guarantees, to create new job opportunities especially for poor, to provide access to good quality medical services, and to build high quality human capital through educational and scientific development.

15. Achieving these objectives will only be possible by maintaining the high rates of economic growth achieved during the last three years, and by integrating domestic financial and human flows into regional, European and world structures. In addition, there is a need to build a coherent and stable legal framework, harmonized with European principles and standards, and oriented towards the creation of a favorable entrepreneurial and investment climate.

16. EGPRSP has also been inspired by the global concern of poverty reduction, embodied in the "United Nations Millennium Guidelines: Human Development - Objective of Prime Importance", signed by the Republic of Moldova in New York in 2000, together with 146 countries. By signing this document, the country demonstrated its commitment to the 
fundamental human values expressed therein: liberty, equality, solidarity, tolerance, peace affirmation, human rights, and sustainable development.

17. Given the context and the need for the EGPRSP, and its place and role in the development of the Republic of Moldova, the following general principles have guided its design:

a) The objectives and the actions of the EGPRSP provide an inclusive and comprehensive vision on (i) economic and social issues faced by the country, especially by the most vulnerable groups, (ii) the ways to use the available resources for solving these problems;

b) The EGPRSP promotes the fundamental aspirations of the Moldovan people for the next 15 years, aiming at harmonizing the medium term and the long term objectives;

c) The EGPRSP actions focus on obtaining tangible results during the next 3 years, to improve the welfare of the population;

d) It provides for the prioritization of objectives and actions to maximize the benefits from available resources, in order to: (i) ensure significant impact on the main vulnerable groups; (ii) lead to tangible results in the short term governed by the EGPRSP;

e) It reflects in its objectives, measures and actions the desires, social interests and the capacities of the participants and key beneficiaries of the Strategy - the poor, business community and public administration at all levels - ensuring the full involvement of all mentioned groups in developing and implementing the EGPRSP, as well as in monitoring and evaluating its implementation process.

18. The application of these principles will help ensure the commitment of the society to EGPRSP objectives. At the same time it should: (i) contribute to the improvement of governance, including for assigning the Government responsible for EGPRSP implementation (ii) capitalize on the relations with the country's development partners, and (iii) stimulate the wide and active participation of civil society in the EGPRSP planning and implementation.

19. The Government will promote the country's strategic involvement into globalization processes. Having the aspiration to join the European Union, the Strategy stipulates the actions and measures for implementing the Copenhagen criteria, which include building an efficient market economy and the capacity to support competition, to respond to other market economy requirements, and to provide the state capacity to fulfill the relevant legislation and to honor its future obligations as a member of the European Union.

20. In order to ensure the competitiveness of the national economy on the world market, it is planned that the country capitalizes on the positive aspects of globalization, and on the advantages and opportunities offered by its membership of the World Trade Organization and the Pact for Stability in the South-Eastern Europe.

21. It is of vital importance for the Republic of Moldova to create, through a deep reform process, a public administration system, which is modern, responsible, predictable, transparent, and resistant to corruption. Better governance and a more efficient activity of the public sector in partnership with the civil society constitute the basis for the insurance of sustainable economic growth and the reduction of poverty.

22. In order to implement the stipulations of the Strategy, the challenge is to join together in partnership the efforts of public administration, civil society, the business community and international partners to achieve the common goal of improving the lives of the country's people. 


\section{THE PARTICIPATION PROCESS \\ 2.1 THE PRINCIPLES AND OBJECTIVES OF THE PARTICIPATION PROCESS}

23. The EGPRSP represents the result of a wide and well-focused participatory process, drawing on the commitment of all stakeholders to reach the EGPRSP objectives. Those involved are (a) representatives of civil society, (b) poor, (c) representatives of the business community (d) central and local public authorities, and (e) international donors.

24. The participatory approach of developing the EGPRSP has the following advantages:

i) A better understanding of the changing nature and distribution of poverty;

ii) An improvement in the interaction between the Government and society as a whole;

iii) A meaningful dialogue as regards the prioritization of public actions;

iv) Better allocation and use of resources;

v) Perception of the EGPRSP by the society as being conducive to improving the lives of people.

25. In order to capitalize on these advantages, the participation process is based on the following principles:

1) Providing transparency and relevancy in promoting the views of state bodies and civil society;

2) The documentation of the activities of all the forums - from the working groups up to the decision making and approval bodies - in order to ensure their coherence, continuity, responsibility and transparency;

3) Making explicit the nature of the decisions, proposals, initiatives, requests etc. as regards their motivation and rationale;

4) The accurate reporting and dissemination through the mass-media of the activity of participatory forums, and the positions promoted by different participants in preparing, discussing, implementing and monitoring EGPRSP.

26. The participatory process facilitates the realization of its goals of ensuring: (a) the reflection of the interests and values of the EGPRSP target-groups, (b) the transparency for the entire development-implementation process, (c) the internal coherence of the content and process of the EGPRSP (d) and the responsibility and commitment of participants for the EGPRSP actions. The process also enhances the status of the EGPRSP document as the intellectual property of the Republic of Moldova, demonstrating that it belongs not only to the public bodies, but also to the whole society.

\subsection{THE INSTITUTIONAL FRAMEWORK OF THE PARTICIPATION PROCESS}

27. The EGPRSP process includes the following steps - development, adoption, implementation, monitoring and evaluation of the Strategy (DAIMES).

28. The institutional framework for the EGPRSP consists of two major components. The first component deals with the preparation and development process. It comprises different 
interest groups and state institutions- the Presidency, Parliament and Government, specialized agencies on the one hand, and opinion leaders, reference persons from civil society and especially from the business and scientific communities on the other hand.

29. This institutional arrangement for EGPRSP has as its oversight body the National Council for Sustainable Development and Poverty Reduction (NCSDPR). This Council is chaired by the President of the country and represents the main coordinating body for strategic planning activities in the field of social-economic policy focused on sustainable development of the country and on improving the population's living standards.

30. The Interministerial Committee for Sustainable Development and Poverty Reduction (ICSDPR) was appointed as the executive body of the NCSDPR through a Government decree. According to its regulations, the ICSDPR “...ensures the development, promotion and implementation of the National Plan for Sustainable Development and Poverty Reduction, of the Economic Growth and Poverty Reduction Strategy Paper, the Millennium Development Goals and of other strategic planning documents".

31. The second component of the institutional framework focuses on ensuring the participation of all segments of the civil society in EGPRSP development. The component is represented by the Participation Council for EGPRSP development (PC), which was established in September 2002. The Government approved the nominal constituency of the Council, as well as its guidelines.

32. The members of the Participation Council are representatives of the Parliament, the Presidency, Government, civil society (NGOs activating in areas relevant for the EGPRSP goals of economic growth and poverty reduction), the business and scientific communities, and international organizations that operate in the Republic of Moldova and donors.

33. The EGPRSP development Grant Implementation Unit (GIU), which started operating on 1 May 2003, was assigned as the executive body of the Participatory Council. The GIU administers international trust funds to support the development of the EGPRSP.

34. According to the Participation Plan developed and approved by the Participation Council in September 2003, the process is to be organized in three stages: (i) general information campaign and needs assessment; (ii) participation in defining strategic objectives and specific policies to address the needs; and (iii) identification of mechanisms of stakeholders' participation at the implementation and monitoring phase. The Participation Plan was implemented through 80 public events throughout the country, with utilization of social communication instruments These instruments are: national surveys and surveys focused on EGPRSP target-groups, group interviews, seminars, round tables, forums, informational campaigns, etc. They are meant to ensure an exhaustive and transparent dialogue with all the participants in the EGPRSP development process.

35. The magnitude and volume of activities envisaged in the Participation Plan required the selection and employment of a Facilitating Organization, which possessed well-trained human resources, a network of branches throughout the republic and experience in deployment of activities at the national and local levels. Following a transparent selection process organized in July-September 2003 under the coordination of the Participation Council, the Network of Nongovernmental Organizations that are active in the social area was appointed as the Facilitating Organization. The Network operates through the Forum of Women Organizations of the Republic of Moldova. 
36. It was widely recognized that poor people are less "organized", in successfully addressing their problems. The Participation Council accepted this and as a result a scheme to directly consult the poor through specific methods was designed and submitted. In order to successfully implement this scheme a sociologic agency was selected through a transparent process, and performed a qualitative analysis of the poor.

37. A communication strategy, supported by the participation plan, was developed and approved. It aims at: (1) providing comprehensive information on all EGPRSP relevant aspects, and (2) contributing to the active involvement of stakeholders' groups in the dialogue. In October 2003 the EGPRSP web page was launched (http://www.scers.md/). It allows stakeholders to access the latest version of the overall paper and sectoral strategies, and provides information about the timetable and location of public discussions, as well as summaries of these discussions. The information is available in three languages: Romanian, English and Russian.

\subsection{Development of communication campaign and public consultations}

38. The communication campaign had the following main goals:

- Informing the public on the importance of public participation in EGPRSP development;

- Encouraging public debates on the participatory development of the EGPRSP;

- Promoting the participation of civil society in order to ensure the wide ownership of the process by all interested parties;

39. During the campaign, communication techniques related to administrative and social mobilization, advertising, interpersonal interaction and promotion of information services were actively used.

40. The media played a crucial role in the communication process. Initially, a media list was created, comprising all the media institutions that exist in the country, their contact information and journalists. The media list is an efficient tool of rapid communication with journalists, for distributing press communiqués, invitations and information notes. Also, in the context of cooperation with journalists, a contest of materials on EGPRSP priority topics was announced. Another tangible result of the announced contest is the large number of publications that appeared in the printed and electronic media regarding the EGPRSP participatory process, the document itself and the activities undertaken in order to approve the EGPRSP.

41. An important target-group comprised public authorities at all levels. The communication with public authorities was done through direct interaction and through round-tables and seminars. All local public authorities received an envelope with a motivating message and promotional publications edited by EGPRSP GIU. Overall, the information reached around all 900 mayoralties and local public authorities.

42. An important role within the communication strategy was played by non-governmental organizations, first as audience and then as a channel for information dissemination. Having access to a socially active public, the cooperation with NGOs is of paramount importance for the involvement of the public in the decision-making process, as well as in the monitoring of 
public policies. Therefore a list of electronic addresses of non-governmental organizations was created, through which NGOs received periodic information on the development of the EGPRSP and the participatory process. The electronic addresses database comprises over 800 addresses of non-governmental organizations and initiative groups from various areas. This information was also sent to donors and media institutions.

43. The organizations' networks were involved in the process of information dissemination and collecting feedback from the public. The emphasis placed on existing networks and coalitions of non-governmental specialized organizations is still relevant, as they are more productive and represent reliable channels of information dissemination and feedback collection.

44. In addition to the EGPRSP development and the promotion of the participation process, as an objective of the communication strategy was set the promotion of the participation idea itself and the emphasis on individual responsibility to facilitate the process at the national and local levels. For this group a national essay contest was organized named "A solution for my country". Youngsters were encouraged to illustrate in the essay the importance of everyone in solving existing problems and offer their own solutions to overcome the problems of the country. This technique proved to be efficient. As a result 560 essays were submitted to the contest. According to estimative calculations, each participating pupil involved at least 4 other persons in the writing process (parents, fellow pupils, teachers, etc.). Thus, the process succeeded in mobilizing around 2500-3000 active participants.

45. As far as the publicity and advertising are concerned promotional actions, radio and TV shows were organized and a TV spot was displayed for three months on national television, the station with largest coverage. Also, leaflets (totaling 10,000 copies) and posters (totaling 3,000 copies) on EGPRSP were edited and distributed through the information points of the facilitator, through direct promotion during organized events and via mail.

46. Four publications of the bulletin in the official and Russian languages were published, each with a circulation of 77,200 copies, totaling 308,800 copies. The bulletins were distributed via raion newspapers and through a number of local publications from the left bank of river Nistru. The bulletin purpose was to reflect the process of strategy's development and discussion. It promoted sound poverty reduction policies at individual and local levels, included materials from actions carried out within the EGPRSP participatory process, and generated comments to improve the strategy's content.

47. The development and maintenance of the web page www.scers.md was another related activity. Although access to Internet is not so spread on the territory of the republic, (except for the capital and some raion centers), it was proposed to place on this web page an electronic version of EGPRSP and sectoral strategies. Presently versions of the strategy are posted and accessible on the www.scers.md page in the official, Russian and English languages. Posting the English version on the Internet was appreciated by the donors' community from inside and outside of the country.

48. The Participation Plan, approved by the Participation Council, envisages the organization of seminars, conferences, roundtables at national and local levels, press conferences and other social communication events, amounting to 80 events. 
49. The entire participation process for discussing the draft strategy can be divided in two components:

i) The first component includes the participation in discussions on draft documents of ministerial officials, which are related to the EGPRSP. Their participation in discussions is important in order to ensure a common and clear understanding of strategy priorities, sector goals and tasks that are set to each ministry. Moreover there is a clear interdependency among EGPRSP sector components (for example, the realization of goals of ensuring the access to health, education and social services of the population from rural areas, greatly depends on the development of infrastructure, and the development of infrastructure depends to the same extent on the flow of investments into the private sector, etc.).

ii) The second component envisages the participation of representatives of trade unions, non-governmental organizations, academic circles, donors, media, local public administration, etc. This has ensured the transparency of the process of EGPRSP finalization and offered them the possibility to get involved in the next stages, which comprise the strategy' implementation, evaluation and monitoring.

50. At the local level a total of 25 round-tables were organized in 23 localities, with 890 participants out of which representatives of raion and local public administrations accounted for $24.3 \%$, entrepreneurs for $14.7 \%$, representatives of local NGOs for $20.1 \%$, trade-unions for $1.7 \%$, and public institutions employees for $23.8 \%$ (from schools, hospitals, policlinics, libraries, kindergarten, social assistance centers, higher education institutions, etc.). The local media represented $4.8 \%$ of all participants and, last but not least, were representatives of socially vulnerable persons at $10.2 \%$.

51. Local level round-tables were deployed in a participatory manner facilitating the maximum involvement of participants. Each local level round-table was dedicated to one sector strategy. The participants were selected and invited on the basis of subject, maintaining a balanced representation of participants from raion public administrations, mayoralties, non-governmental organizations from the field, trade unions, media, private sector, public institutions, representatives of the church, higher education institutions, farmers, and other community organizations.

52. The representatives of line ministries and departments presented the draft sectoral strategies, and the respective components of the EGPRSP. The Participation Council has insisted on presenting the draft documents exclusively by representatives of ministries and departments, thus demonstrating and emphasizing the fact that EGPRSP has an intellectual country ownership, and that the public officials have a clear understanding of the priorities and actions that are necessary to be undertaken.

53. The task of ministries' representatives was to present the content and provide answers to questions, criticisms and comments coming from the participants. The remaining time was dedicated to a number of participatory activities and proceedings, such as work in groups and presentation of the discussion results in plenary sessions. This manner of organizing roundtables allowed a maximum involvement of participants, providing them with the opportunity to express themselves on the draft documents. The overall discussion was moderated by a team of trainers with experience in participatory activities.

54. In contrast with local level actions, at the national level, the purpose was to collect contributions and comments from professionally competent persons, think tanks, academic circles, international organizations, donors, and others. In contrast to local level participants 
that shared their views on how measurable and real are the proposed actions and policies, the national level participants expressed their opinion on the correct motivation and problems' identification in relevant areas, on the formulation of objectives, on setting priorities and on the quality of monitoring indicators.

55. At the national level 32 events took place (seminars, round-tables and workshops) with a total presence of 1086 persons, out of which representatives of ministries/departments accounted for $18.4 \%$, public institutions for $23.9 \%$, national NGOs for $21.2 \%$, media - for $14.3 \%$, donors for $11.8 \%$, and local public administration for $3.4 \%$.

56. Within the Participation Council meetings and public discussions a number of donors contributed with the analysis and comprehensive comments for the EGPRSP. Both the synthesis group and the sectoral working groups used these comments to improve the quality of the document.

57. In April 2004 the Government of the Republic of Moldova organized the National Forum for presenting the Economic Growth and Poverty Reduction Strategy. The country's leadership, representatives of the World Bank, IMF, UNDP and other international institutions, as well as representatives of civil society, business environment and academic community, totaling 307 persons, attended the Forum. During the Forum the pre-final draft of the Strategy was presented and discussed. Furthermore during public discussions the interested parties submitted comments and proposals on the EGPRSP draft. Although participants appreciated the fact that a part of proposals and recommendations were reflected in the draft document, they also underlined the need for continuing the public debates.

58. Following the National Forum a series of national level workshops, were organized. The objective of the workshops with participation of key-actors was to finalize the strategy components. A large part of comments and proposals raised during public discussions were reflected in the final version of the EGPRSP. For a more detailed presentation of proposals an analysis will be performed, on the basis of which explanations of the reasons behind the incorporation or rejection of proposals as well as a list of proposals under consideration will be provided. The analysis will be presented to all interested parties in order to assess the level of participation in this process. This is important to ensure the feedback from the Government to the civil society, as a pre-requisite for openness and motivation for continued participation during the implementation, monitoring and evaluation stages. The abovementioned stages are described in Chapter VIII of this Strategy.

59. The total number of direct participants in EGPRSP public consultations reached 2283 persons. Taking into consideration the fact that this number includes only representatives of actively involved NGOs, state institutions, and private sector firms, the total number of those involved indirectly is much higher.

60. With the approval of the document follow-up actions will include (i) The public presentation of EGPRSP components, and (ii) The identification of ways and means to enhance the participation of the interested public in the strategy's implementation stage. All these proposals will be included in the Partnership Matrix, and will serve as a basis for a sustainable partnership throughout the strategy's implementation. 


\section{SOCIAL AND ECONOMIC EVOLUTION: ACHIEVEMENTS AND PROBLEMS}

\subsection{THE TRANSFORMATION AND CRISIS OF THE $1990 \mathrm{~S}$}

61. Transition countries have faced formidable challenges arising from the legacy of the previous socio-economic system and institutional uncertainties and instabilities of the transition period. And reform in transition countries differs from reform in other countries because change should have been systemic, penetrating the foundations of the established institutional setting. The following account shows that Moldova is not an exception to the complexities and difficulties of dealing with recent history.

62. What needs to be underlined in reviewing the post-Soviet evolution of Moldova is that the smaller, highly trade dependent countries of the former Soviet Union - Moldova, Georgia, Armenia and Tajikistan - experienced economic collapse unprecedented in history. In the years immediately after independence, the GDPs of these countries shrank by fully two thirds, compared with up to one third or less in most other countries of the former Soviet Union. The disruption of economic relations and economic decline has left traumatic material and psychological legacies in many areas of social and economic life.

63. With independence, the Republic of Moldova began facing a set of political, economic and social problems, which it had to resolve alone, relying on its own potential and resources. The process of state building and self-determination was going in a context of social and economic crisis, and radical transformation of the economic system. Lack of experience in resisting external "shocks", crises in the economy and social sector, as well as insufficient experience in implementing system reforms, unstable internal political situation, territorial disintegration of the country - all these predetermined the considerable "mistakes and costs" of the transition period.

64. Until independence, the Moldovan economy was highly integrated into the USSR economy through the mechanism of the inter-republican division of labor and economic ties with the other union republics. The high degree of integration was reinforced by an almost complete lack of domestic energy resources, of non-agricultural raw materials, machinery, equipment and components for production, and of subsidies for the country's agrarian sector from the Union budget. The break-up of the USSR's economic zone led to the collapse of the established system of economic ties, to emerging of obstacles to the movement of goods, and restrictions on access to the emerging markets of the newly independent states.

65. The Transnistria conflict has broken economic ties within the country. As a result of the territorial disintegration, Moldova lost control on its eastern border of a considerable part of its energy and industrial sectors.

66. The transformation affected not only economic ties between economic agents, but also banking, monetary and payment systems. Barter transactions and non-payments were growing in number, which undermined the financial stability of both economic agents and the state. Lack of budget resources and the need to support relatively high budget commitments led to a budget deficit, which, in its turn, contributed to rising inflation.

67. The period of adaptation to the collapse of the USSR and internal disintegration coincided with the beginning of the reform and restructuring of the economic system. A switch from the centrally planned economy to the market economy was executed energetically in all main areas, including price liberalization, foreign trade and investment, opening up the internal market, mass privatisation, introduction of the local currency in 1993, and formation of a new banking system. Conditions and rules of economic activity changed fast. However the consequences of the reforms, and their effect on social development were not accurately predicted; no account was taken of the low level of preparedness of the people and of economic agents to live and act in the changing 
environment. In addition, not all the necessary adjustments in the reform measures were made, and the government changed too often. Thus the practical results of the reform to a large extent failed to meet expectations of society and government.

68. The transformation of ownership relations was the key and radical reform. The mass privatization of the state property on the basis of patrimony bonds did not justify the aspiration in the emergence of a new class of owners interested in the development of production by increasing competitiveness, renovating and modernizing fixed assets, attracting investment and quality management. The rights of the new owners were often vague and not protected enough at the legal and institutional levels. The main agrarian reform, the transfer of land into private ownership, was carried out without providing state support to agricultural producers and without infrastructure adequate enough to render informational, technological, commercial, financial, consulting and other services to peasants. As a result the problems of high labor intensity, low productivity, old technologies, small-scale commodity production, and excessive dependency on the weather conditions intensified.

69. Economic and territorial disintegration, as well as errors in the implementation of large-scale reforms resulted in the long, deep crisis of the 1990s. The economic crisis in Moldova lasted 10 years (from 1990 to 1999), during which GDP contracted by two thirds.

70. The crisis of the 1990s evolved unevenly. In the course of 1990-1996 all sectors of the economy experienced continuous decline. Output in industry and agriculture fell by more than half, capital investment fell to only $15 \%$ of its 1990 level. A large-scale decline in production was aggravated by the imbalance of the financial system at the macro- and micro levels, which manifested itself in high and hyper inflation (in 1992-1993), a sizable budget deficit, which in 1996 accounted for $9.7 \%$ of GDP, persistent devaluation of the national currency, growing non-payments and barter transactions, and a growing number of loss-making enterprises.

71. In 1997 there were signs of a weakening of the crisis and growth in the economy - the decline in industry stopped, agriculture registered a rise of $11,4 \%$ in output, and for the first time GDP showed a growth of $1.6 \%$. The inflation rate fell up to $12 \%$, and the budget deficit decreased substantially. However the 1998 crisis in Russia provided an external "shock" to the national economy, which depended substantially on the state of the Russian market whose share in Moldovan exports was almost $60 \%$.

72. A new spiral of the crisis lasted for two years (1998-1999), when GDP output fell by 10\%, industrial output fell by $25 \%$, and agricultural output by $20 \%$. There was an unprecedented decline in foreign economic activity as exports and imports slumped by almost $50 \%$. In many respects the crisis in foreign trade was caused by the strengthening of the real exchange rate of the Leu to the Russian Ruble, as the devaluation of the Moldovan currency against the dollar and other freely convertible currencies was lower than that of the Russian Ruble. The devaluation of the Leu against the dollar, by 2.5 times between December 1997 and December 1999, led to a substantial rise in the expenditures for the servicing of foreign debt, expressed in the national currency. Inflationary processes increased. In the course of 1998 consumer prices rose by $18.3 \%$, and in 1999 by $43.7 \%$. Though inflation is a "universal tax", it hits mostly low-income groups of the population, and, as a result, poverty incidence increased significantly.

73. Total losses of the Moldovan economy in the period of the 1990 crisis turned out to be considerable. In 1999, which was the lowest point of the crisis, GDP output accounted for only $34 \%$ of the 1989 level, industrial output $32 \%$, and agriculture $50 \%$. There was a drastic reduction in fixed assets reinvestment. There was an almost 10-fold cut in investments in fixed capital by 1999 which was only $11 \%$ of the 1989 level. Thus the economy's revival began from extremely unfavorable "starting" conditions. 


\subsection{ECONOMIC GROWTH, IMBALANCES AND CONSTRAINTS}

74. In 2000 the Moldovan economy moved onto a growth trajectory. The factors that contributed were the stabilization of eastern markets, primarily Russia, rising domestic demand due inter alia to increasing money inflows from labor migrants, and restrictions on the growth of money supply, which helped reduce inflation. From 2000 to 2003, GDP rose by $24,1 \%$, industrial output by 54,1\%, and investments in fixed capital by $21,5 \%$.

75. The economy entered the period of upturn with a new structure. As a result of implementation of reforms, the non-state sector became dominant. In 2002 its share in GDP was $75 \%$, with a share of over $80 \%$ in industrial manufacturing, over $95 \%$ in retail trade, almost $100 \%$ in the agrarian sector, and $54 \%$ in the sector of paid services. Thus economic outcomes, including the rate of growth, are now mainly determined by the activity and performance of the private sector. Simultaneously with a rise in the share of the private sector in the structure of the economy, there was also a rise in the share of the service sector, which in 2000-2002 accounted for almost $50 \%$ of GDP. The above structural shifts are indicative of progress in the transformation of the national economy.

76. In spite of the achievements, further advancing the economic development of the country can be hampered by imbalances and constraints triggered during the 1990 crisis. The main of them are: i) the predominantly agrarian structure of the economy with an insufficient share of processing industry; ii) low ratios of saving, accumulation of fixed capital and capital investment; iii) excessive dependency of the growth of the economy and domestic consumer demand on the size of labor migration abroad; iv) economic backwardness of regional economies, and a big difference in the level of social and economic development between the country's capital and other regions.

77. During the period of the 1990 crisis, industrial output fell faster than agricultural output. As a result the share and role of the agrarian sector in GDP became bigger than that of the industrial sector. In the years of the economic revival the share of agriculture fell a little, whereas the share of industry rose insignificantly. However, the correlation between these sectors remains unfavorable agriculture in 2002 accounted for $21,0 \%$ of GDP and nearly half of all employed in the economy $(49,6 \%)$, industry accounted for $17,3 \%$ of GDP and a bit more than one tenth of the employed $(11,4 \%)$.

78. The existing structure of production and employment restricts the socio-economic development of Moldova. Labor productivity and the economic impact of agriculture is much lower than in other sectors, including industry. In 2002 gross value added produced by one employee was $50 \%$ lower in agriculture than on average in the economy, and $72 \%$ lower than in industry. Thus, the income gained by farmers and agricultural workers, as well as the tax revenues for the budget obtained from the agrarian sector, are relatively small. This prevents the reduction of poverty in rural areas, developing the technical and technological base of the agricultural production, increasing its effectiveness and raising the budget resources of the state.

79. Low gross savings (17,1\% of GDP in 2003) and low investments in fixed capital indicate that the fundamentals for stable and sustainable economic growth are not yet in place. The growth of output is largely based on the improvement of obsolete and outdated equipment. The economic recovery didn't have a considerable impact on the investment climate. The amount of fixed capital investments was only by 4,7\% higher than during the top of the crisis in 90s (1999). The investment process is concentrated in a few sectors - in processing, energy, gas and water supply, communication, which account for about $70 \%$ of all capital investment in the economy. Of these, in the processing industry $60 \%$ of investments are used to produce foodstuffs, alcoholic drinks, and tobacco products. Other forms of production experience an acute lack of investment. The investment processes were to a certain extent supported by flows of foreign capital, whose share in the funding of capital investments reached $37.2 \%$ in 1999 and $25.3 \%$ in 2000 . In recent years the 
share of foreign investments fell dramatically (to $19.5 \%$ in 2001 and $11.9 \%$ in 2002), which is indicative of an unfavorable, unstable environment for investment activity in Moldova. At the same time, limited national saving does not allow to resolve the investment problem with exclusively internal resources.

80. The recent improvement in economic growth has been accompanied by growing imbalances between domestic demand and production. A more than two-fold increase in final demand in 20002002 exceeded the GDP growth rate, as result the final consumption exceeded GDP by 1-3\% annually. The main role in the expansion of demand that encouraged the economy's revival was played by the growth in household consumption, not only due to an increase in pensions, wages, benefits and compensations, but also by inflow of money from people working abroad. Interestingly, the remittances of labor migrants have a significant impact on the growth of domestic demand. According to the National Accounts, in 1997 the remittances of labor migrants accounted for $8.5 \%$ of gross disposable household income, and $19.5 \%$ in 2002 .

81. Rates of growth in the economy and structural transformation have lagged behind those of domestic demand. The gap has been covered at the expense of growing imports, which resulted in an increase in a trade deficit that in 2002 amounted to $24.9 \%$ of GDP. Because of the desynchronization between domestic demand and production, and between exports and imports, the Moldovan economy obtained the status of a net debtor to the rest of the world. A sizable foreign debt $(81.9 \%$ of GDP in 2002) and the need to divert large resources for its servicing are limiting essentially the resources necessary for future development of the country.

82. In a domestic regional context, the economy of Moldova is evolving in an unbalanced way. In the course of the crisis years, a gap between the social and economic development of Chisinau and the rest of the country increased. Differentiation of the economic potentials of the capital and regions is caused by the degradation of industry and infrastructure of smaller cities during the 1990 crisis, and by the low efficiency of the agrarian sector in regional economies, resulting in an absence of necessary conditions and resources for development.

83. More than $80 \%$ of the population of the country live in the regions, which receive less than $20 \%$ of foreign investments, account for less than $40 \%$ of exports, and have wage levels almost half those in the capital.

84. Gross Regional Product per person outside Chisinau is only one third of that in the capital. Agriculture predominates (43\%) in regional output, and its share in the regions is twice as high as in the economy as a whole. The share of services in the economy of regions (37\%) is also almost half that in the economy of the capital (71\%). The regions of Moldova are not self-sufficient. The budgets of all administrative and territorial units (excluding Chisinau region) receive subventions from the state budget. Because of scarcity of resources, local budgets are primarily used to finance current expenditures but not for investment and development.

\subsection{RESULTS OF SOCIAL DEVELOPMENT}

85. The social crisis of the 1990 s was deeper and more dramatic than the economic crisis. With large-scale release of labor from the economy, high inflation and falling real state expenditures for social needs, the losses of the population were limited not only to narrowing income resources and declining purchasing power, but also to a diminished ability to enjoy social assistance from the state, in the form of benefits and free social services. At the lowest point of the crisis (1999) the average wage in real terms was only about $25 \%$ of the 1990 level, the average pension about $17 \%$, and according to the International Labor Organization (ILO) methodology, the unemployment rate reached $11.1 \%$. 
86. The worsening living conditions of the majority of the population of Moldova entailed changes in the demographic movement of the population. In the course of 1990s the birth rate and life expectancy were falling, and the death rate was rising. As a result of these trends, from the mid 1990 s the number of population is falling. Growth in the economy and in real incomes in 20002002 has not yet produced a tangible effect on demographic processes.

87. Economic growth has had a favorable impact on the expenditures and consumption of the population. According to the National Accounts, gross disposable household income increased in real terms by $10.1 \%$ in 2000 , by $12.7 \%$ in 2001 , and by $21.2 \%$ in 2002 . The household gross disposable income growth rate was higher than GDP growth rate. In 2000-2002 practically all sectors of the economy showed growth in real wages - in average wages increased by almost $50 \%$. At the same time, the fastest wage growth rates were registered in the sectors where wages were traditionally the lowest - in agriculture, education, and healthcare. Starting in 2001 there was a rise in pensions, and in 2001-2002 the real average pension increased by almost $64 \%$.

88. Growing budget revenues allowed the state to increase social expenditures, primarily for healthcare and education. From 1999 to 2002 state expenditures for healthcare rose from $2.9 \%$ of GDP to $3.6 \%$ of GDP, and for education from $4.7 \%$ of GDP to $5.6 \%$. However, access of the population to social services remains limited because the level of their pre-crisis state financing has not yet been restored, and a considerable part of services are provided for payment - about $40 \%$ of medical services and over $30 \%$ of services in education.

Table 1. Main Indicators of Social Development

\begin{tabular}{|c|c|c|c|c|c|c|}
\hline & 1997 & 1998 & 1999 & 2000 & 2001 & 2002 \\
\hline \multicolumn{7}{|l|}{ HUMAN REPRODUCTION } \\
\hline $\begin{array}{l}\text { Number of permanent residents as } \\
\text { of } 1 \text { January, thousands of people }\end{array}$ & 3663.7 & 3655.6 & 3649.9 & 3644.1 & 3635.1 & 3627.8 \\
\hline $\begin{array}{l}\text { Population aging rate (individuals } \\
\text { of } 60 \text { and over per } 100 \text { people) }\end{array}$ & 13.3 & 13.5 & 13.6 & 13.6 & 13.6 & 13.9 \\
\hline \multicolumn{7}{|l|}{$\begin{array}{ll} & \text { Average life expectancy, years: } \\
\end{array}$} \\
\hline - male & 62.9 & 64.0 & 63.7 & 63.9 & 64.5 & 64.4 \\
\hline - female & 70.3 & 71.4 & 71.0 & 71.2 & 71.7 & 71.7 \\
\hline$\circ \quad$ Births per 1,000 people & 12.5 & 11.3 & 10.6 & 10.2 & 10.0 & 9.9 \\
\hline o $\quad$ Deaths per 1,000 people & 11.8 & 10.9 & 11.3 & 11.3 & 11.0 & 11.6 \\
\hline$\circ \quad$ Rate of natural increase & 0.7 & 0.4 & -0.7 & -1.1 & -1.0 & -1.7 \\
\hline \multicolumn{7}{|l|}{ INCOME OF POPULATION } \\
\hline$\circ \quad$ GDP per capita, USD & 527.1 & 464.8 & 321.3 & 353.7 & 408 & 459 \\
\hline $\begin{array}{l}\text { Share of population with income } \\
\text { below USD 2,15 per day (by } \\
\text { purchasing power parity), } \% *\end{array}$ & - & 52.7 & 70.8 & 64.5 & 52.4 & 39.8 \\
\hline $\begin{array}{l}\text { Share of poorest population (I } \\
\text { quintile group) in national } \\
\text { consumption, \% }\end{array}$ & 5.8 & 5.9 & 6.2 & 6.7 & 6.6 & 6.8 \\
\hline $\begin{array}{l}\text { Average monthly nominal wage, } \\
\text { USD }\end{array}$ & 47.6 & 46.5 & 29.0 & 32.8 & 42.2 & 51.0 \\
\hline $\begin{array}{l}\text { Growth of real wages, as \% of } \\
\text { previous year }\end{array}$ & 5.1 & 5.8 & -12.6 & 2.2 & 21.2 & 21.0 \\
\hline \multicolumn{7}{|l|}{$\begin{array}{l}\text { EMPLOYMENT AND LABOR } \\
\text { MARKET }\end{array}$} \\
\hline $\begin{array}{l}\text { Number of employed in the } \\
\text { economy, thousands of people }\end{array}$ & 1646 & 1642 & 1495 & 1515 & 1499 & 1505 \\
\hline $\begin{array}{l}\text { Number of employed in agrarian } \\
\text { sector, thousands people }\end{array}$ & 684 & 750 & 731 & 766 & 764 & 747 \\
\hline
\end{tabular}




\begin{tabular}{|c|c|c|c|c|c|c|c|}
\hline & & 1997 & 1998 & 1999 & 2000 & 2001 & 2002 \\
\hline & $\begin{array}{l}\text { Number of hired labor, thousands } \\
\text { of people }\end{array}$ & 1104 & 1003 & 805 & 697 & 692 & 685 \\
\hline & $\begin{array}{l}\text { Rate of officially registered } \\
\text { unemployment, \% }\end{array}$ & 1.5 & 1.9 & 2.1 & 2.1 & 2.0 & 1.9 \\
\hline & $\begin{array}{l}\text { Unemployment rate according to } \\
\text { ILO methodology, } \%\end{array}$ & $\ldots$ & 9.2 & 11.1 & 8.5 & 7.3 & 6.8 \\
\hline
\end{tabular}

Source: Department of Statistics and Sociology and $\left(^{*}\right)$ Policy and Poverty Monitoring Unit

89. The improvement in the economy in 2000-2002 was not accompanied by an adequate increase in employment and jobs. The number of workers employed in the national economy rose by only $0.7 \%$, so the unemployment problem remained acute. The reason for the inconsistency between rates of economic growth and employment growth is that a rise in the economy is more based on the use of available fixed assets and economizing on the labor force to ensure price competitiveness of products, than on a rise in investment and creation of additional jobs.

90. In summary, it can be seen that during the 1990s, various Moldovan governments took a number of measures to respond to the external shocks of the break up of the Soviet Union, the impact of the Russian financial crisis, and to reform and liberalize the economy. The monetary element of macroeconomic policy succeeded in reducing inflation to a level, which provides a stable platform for private investment. However, macro-economic reform and economic restructuring have not yet generated the anticipated benefits in growth and poverty reduction.

91. One reason is that governance systems and structures have not changed as quickly as changes in the macro-economic setting. The progress in creating an enabling environment for market-led growth, or delivering services effectively and efficiently to the people of Moldova has not been adequate. There is general agreement that sustained economic progress depends on public administration and private sector reforms which is why such reforms feature strongly in this Strategy.

92. A balanced interpretation of progress in Moldova today is that the institutional elements of a democratic modern economy have been put in place, and presently are in an incipient stage of development. The perceptions of many experts are that social and economic improvements are slow and sometimes negligible. The critical issues now are not only to make improvements, but also to ensure that improvements are visible and understood by stakeholders. 


\section{POVERTY IN MOLDOVA \\ 4.1 THE MAIN FEATURES OF POVERTY}

93. Poverty in the 1990s grew in association with reductions in national output, investment, employment and the real income of the population. However, as a subject of government policy it was only introduced into Government's agenda in 1997 when financial and technical assistance to build analytical capacity for poverty studies was provided by UNDP and the World Bank.

94. The analysis based on the data from the national Household Budget Survey (HBS) shows a profile of poverty similar to that of other countries in the region. As with many countries in transition, poverty is a multidimensional phenomenon consisting of:

- Reduced income, consumption and employment,

- Insufficient or poor quality nutrition ${ }^{1}$,

- Poor health condition,

- Limited access to education,

- Low levels of participation in decision making,

- Lack of personal empowerment, reflected in the limited possibility to influence one's life situation.

95. Because of its geographical and geo-economic and geo-political location, Moldova has specific features, which have amplified its vulnerability to poverty. These include regional

$\left.{ }^{1}\right)$ Level of food consumption by the poor compared to the minimum and to non-poor households (per person, monthly) - 2002

\begin{tabular}{|c|c|c|c|c|c|c|c|c|c|}
\hline \multirow{3}{*}{$\begin{array}{l}\text { Selected food } \\
\text { items }\end{array}$} & \multicolumn{9}{|c|}{ Consumption (kg, l, pcs.) } \\
\hline & \multicolumn{3}{|c|}{ Total } & \multicolumn{3}{|c|}{ Urban } & \multicolumn{3}{|c|}{ Rural } \\
\hline & $\begin{array}{l}{ }^{*} \text { minimal } \\
\text { standard }\end{array}$ & $\begin{array}{c}\text { extremely } \\
\text { poor }\end{array}$ & $\begin{array}{l}\text { non- } \\
\text { poor }\end{array}$ & $\begin{array}{l}\text { minimal } \\
\text { standard }\end{array}$ & $\begin{array}{c}\text { extremely } \\
\text { poor }\end{array}$ & $\begin{array}{l}\text { non- } \\
\text { poor }\end{array}$ & $\begin{array}{l}\text { minimal } \\
\text { standard }\end{array}$ & $\begin{array}{c}\text { extremely } \\
\text { poor }\end{array}$ & $\begin{array}{l}\text { non- } \\
\text { poor }\end{array}$ \\
\hline $\begin{array}{l}\text { Bead and } \\
\text { bakery } \\
\text { products }\end{array}$ & 11.55 & 10.39 & 13.72 & 10.24 & 7.27 & 9.34 & 10.91 & 11.51 & 16.45 \\
\hline $\begin{array}{l}\text { Meat and meat } \\
\text { products }\end{array}$ & 2.32 & 1.02 & 3.31 & 2.26 & 0.69 & 2.68 & 2.35 & 1.14 & 3.71 \\
\hline $\begin{array}{l}\text { Milk and dairy } \\
\text { products }\end{array}$ & 11.75 & 6.59 & 14.84 & 11.12 & 4.77 & 15.11 & 15.18 & 7.24 & 14.67 \\
\hline Eggs & 19.10 & 9.26 & 14.56 & 17.50 & 6.31 & 14.13 & 20.54 & 10.32 & 14.84 \\
\hline $\begin{array}{l}\text { Sugar and } \\
\text { confectionery }\end{array}$ & 1.47 & 0.62 & 1.57 & 1.48 & 0.69 & 1.43 & 1.47 & 0.60 & 1.66 \\
\hline $\begin{array}{l}\text { Vegetables, } \\
\text { melons, gourds }\end{array}$ & 10.18 & 6.27 & 11.19 & 10.01 & 4.55 & 9.95 & 10.43 & 6.88 & 11.97 \\
\hline $\begin{array}{l}\text { Fruit and } \\
\text { berries }\end{array}$ & 6.62 & 1.56 & 3.21 & 6.62 & 1.24 & 3.30 & 6.70 & 1.67 & 3.16 \\
\hline
\end{tabular}

Source: PPMU based on HBS data.

${ }^{*}$ Monitorul Oficial - $2000-\mathrm{N} 115$ 
economic crises, natural disasters particularly of drought, political and social instability, territorial separation, combined with fear for the future arising from experience of its recent history.

96. Poverty in Moldova affects not only traditionally vulnerable categories of the population such as the less educated and unskilled, the long term unemployed or only periodically employed, it also affects those who are able to work, and who are qualified and healthy.

97. Child poverty persists in the country, especially in rural areas where four out of ten children under ten years of age live in extreme poverty. Child poverty is also widespread in large families with large numbers of children in both rural and urban areas. Children living in households without their parents, as happens where there are high levels of out-migration, are increasingly appearing among those in persistent poverty i.e. amongst those who are poor for at least four consecutive years.

Table 2. Type of panel households in 2002 (percent)

\begin{tabular}{|l|c|c|c|c|c|c|}
\hline \multirow{2}{*}{\multicolumn{1}{c|}{ Type of HH }} & \multirow{2}{*}{$\begin{array}{c}\text { All } \\
\text { HHs }\end{array}$} & \multirow{2}{*}{$\begin{array}{c}\text { Non- } \\
\text { poor }\end{array}$} & \multicolumn{4}{c|}{ Poor for } \\
\cline { 6 - 7 } & 1 year & 2 years & 3 years & 4 years \\
\hline Single member of HH & 28.0 & 26.8 & 35.9 & 30.6 & 24,3 & 17.8 \\
\hline A couple without children & 21.1 & 18.8 & 27.2 & 19.6 & 24.2 & 8.9 \\
\hline A couple with children & 21.2 & 20.6 & 16.9 & 18.7 & 24.7 & 27.7 \\
\hline Single parent with children & 7.2 & 10.0 & 5.1 & 8.6 & 6.3 & 6.0 \\
\hline Other HHs with children & $\mathbf{1 2 . 3}$ & $\mathbf{9 . 4}$ & $\mathbf{1 0 . 3}$ & $\mathbf{1 2 . 3}$ & $\mathbf{1 1 . 7}$ & $\mathbf{2 1 . 8}$ \\
\hline Other HHs without children & 10.2 & 14.4 & 4.6 & 10.2 & 8.8 & 17.8 \\
\hline Total & $\mathbf{1 0 0 . 0}$ & $\mathbf{1 0 0 . 0}$ & $\mathbf{1 0 0 . 0}$ & $\mathbf{1 0 0 . 0}$ & $\mathbf{1 0 0 . 0}$ & $\mathbf{1 0 0 . 0}$ \\
\hline
\end{tabular}

Source: PPMU based on HBS data.

The rate of utilization by the poor of educational, medical and cultural institutions is extremely low, reflecting inequities in access to basic public services.

98. While past studies have portrayed poverty as being mainly associated with the rural areas, the reality is that the highest levels of poverty occur in the urban areas of the country's small towns which have been most affected by the economic crisis. The inhabitants of large cities are most protected from risk of poverty.

\subsection{DEFINITION AND MEASUREMENT OF POVERTY}

99. Conceptual aspects of poverty and its measurement are presented in Box 1 .

\section{Box 1: Definition and Measurement}

Poverty measurement and definition: Poverty is identified with deprivation, which is multidimensional phenomenon comprising both material (monetary) and non-material (non-monetary) aspects of an individual or family welfare. In most cases (e.g. for household survey data based assessments) it is reduced to economic deprivation or, in other words, lack of adequate income. The relevant attributes of non-financial - especially health and education poverty - are also taken into consideration, but separately, since there is no unanimously elaborated and accepted aggregated welfare indicator. Similarly, neither the measurement of a subsistence minimum deficit, included in the concept of absolute poverty, nor the relative positions of welfare that are framed in the relative poverty notion ensure the necessary understanding of poverty (nor its level) for the elaboration of anti-poverty projects and policies. For this purpose consultations with the poor are necessary. Consequently, the qualitative methods that comprise self-evaluation of needs and deficit through the techniques of subjective poverty and through evaluation of participatory poverty complement objective and quantitative methods.

In the research carried out by the Poverty and Policy Monitoring Unit (PPMU), the main indicator of society welfare is consumption per person: a person is considered poor if his/her consumption falls below the poverty threshold. Such a person is identified on the basis of consumption expenditures per equivalent adult person (an equivalence scale is used to adjust the poverty threshold to the composition of the household - implicitly it is assumed that each member of the 
household has the same level of life). If the value of this "equivalent" consumption falls below the poverty threshold the household is considered poor, and its members are considered poor.

Indicators used in poverty research. The FGT (Foster-Greer-Thorbecke) group of indicators measuring poverty (the rate, depth and severity of poverty) is used to characterize the poverty level in a country and among the main groups of population. In Moldova, poverty is valuated annually based on the national Households Budgets Survey data.

Subjective and participatory methods of poverty evaluation, based on the self-appreciation of the level of welfare, play a key role in the understanding of poverty. The subjective poverty threshold is estimated using self-appreciation of material welfare, as well as the necessary amount of money to meet the ends.

100. For a successful poverty reduction policy, there must be accurate and full information on its features i.e. the number, composition, and social and economic status of the poor. For this purpose poverty monitoring is performed where the poor part of the population is identified with the help of a special criterion - the poverty line. That part of the population whose level of welfare is below this line is considered poor.

101. The poverty line is calculated on the basis of actual consumption expenditures rather than of income. In the agrarian economy with its seasonal fluctuations in the income of rural households, as well as with a considerable unofficial sector, assessment of poverty on the basis of the level of consumption expenditures is preferable to that of income.

102. The poverty line is estimated in two stages. At the first stage expenditures are estimated for food products, which ensure daily consumption of the physiologically required number of calories. The estimated amount of the expenditures in monetary terms represents the so-called extreme poverty line. Households whose consumption is below this line are considered extremely poor. At the second stage, essential nonfood expenditures of the least wealthy households are estimated, part of which is added to minimally required food expenditures (the extreme poverty line). As a result the poverty line is estimated as a formula, which states the required minimum for expenditures on food products and nonfood goods and services.

103. Technical tools for the estimation of the poverty line vary. The World Bank and PPMU experts adopt the same method in the estimation of the poverty line on the basis of consumption analysis but, due to differences in technical assumptions, the results do not completely coincide. According to the World Bank, the level of poverty (poverty incidence) in 2001 was $62.3 \%$, and in $200248.3 \%$; according to the PPMU, it was 54.6\% and 40.4\%, respectively. The main differences in the estimation of the poverty line lie in the choice of (World Bank figures quoted first): (i) physiologically required daily consumption of calories (2 100 calories versus 2282 calories); (ii) base groups of households ( $3-5$ deciles and $2-4$ deciles of the consumption profile); (iii) base periods for the indexation of prices and expenditures (4th quarter of 2001 and January 2002); (iv) methods to calculate per capita expenditures, including deflation (arithmetical average expenditures per one household member and on the basis of the OECD equivalent scale).

104. Despite some discrepancies in the poverty measurement tools, the trends and broad results obtained are compatible, both as regards to the identification of the major groups in poverty and of those facing relatively high risk of falling into poverty.

i) Poverty incidence, poverty gap and severity are closely linked to economic dynamics. Poverty rose drastically in 1998 - 1999 as a result of the financial and economic crisis, and then fell in 2001 2002 during the period of the economic recovery;

ii) Geographically, the majority of poor live in rural areas, and the association of households to the agricultural sector increase its risk of poverty. But it is the urban population residing in small towns that face the relatively highest risk of falling into poverty. In terms of socio-economic and demographic characteristics, underemployed (including unemployed and part timers) account for the largest group in poverty, followed by children and the elderly (pensioners). The latter face smaller 
risk than the first two categories, with children in large or foster families facing the biggest risk of either being poor or (while in poverty) having smaller chance of moving out of poverty.

105. For the more accurate poverty diagnostics, three main problems must be solved. The first task is to improve the data base, which will require: (i) conducting a census of the population, so as to allow more representative sampling for the Household Budget Survey; (ii) improving the filling in of diaries and questionnaires by respondents (iii) keeping complete records of consumption by households of previously accumulated stocks. Because of the imperfection of the database, the available information on poverty, which includes poverty incidence, poverty gap and poverty severity indicators is insufficiently accurate and representative. The second task is to adopt an official methodology for the estimation of the poverty line and the identification of the poor. The improvement of poverty diagnosis will allow more explicit and sound social policy.

106. While the HBS, conducted by the Department of Statistics and Sociology constitutes the main input to income poverty assessment, several other data sources are also utilized by the Poverty and Policy Monitoring Unit to analyze and monitor both monetary and non-monetary aspects of poverty. These data sources include administrative records, especially from mayoralties and from central agencies possessing their own reporting systems (especially on health, education, environment, unemployment etc). Also data from other specialized surveys, either conducted on a regular basis - such as the labor force survey and the agricultural sector survey conducted by the DSS, or conducted occasionally by different agencies and scientific institutes are used for poverty assessment.

107. The HBS data are disseminated and accessible to interested data users including those outside the government. Also a multi-source integrated database under development by the PPMU will become accessible for other users for the purpose of poverty analysis.

\subsection{POVERTY INDICATORS AND THE DYNAMICS OF POVERTY}

108. In 2001 - 2002, a growing economy and rising real incomes improved the main poverty indicators - the poverty level (as a share of the poor population), the poverty gap (the difference between the poverty line and consumption by the poor), the severity (inequality among the poor). Improvement was not only due to the growing economy, but also due to a considerable rise in labor migration and associated private money transfers from abroad, which raised the incomes and consumption expenditures of the population. According to the National Accounts, income from labor migration increased in 2002 as compared to 19973.2 times, while the nominal value of the national wage bill rose 2.4 times.

109. From 1999 to 2002 poverty level fell by $45 \%$. The poverty incidence in 2002 was below 50 $\%$, whereas in 1999 it was over $70 \%$ for both sources. Severe poverty i.e. the number and share of families and citizens in extreme difficulty need and destitution fell by half. The poverty gap registered a sharp fall of more than $100 \%$, as well as poverty severity by a similar amount. Though still severe, the situation with the poor in 2002 was not as dramatic as in 1999.

Table 3 Indices of poverty level, depth and severity in 1997 - 2002 (in \%)

\begin{tabular}{|l|c|c|c|c|c|c|}
\hline \multicolumn{1}{|c|}{ Indices and sources } & $\mathbf{1 9 9 7}$ & $\mathbf{1 9 9 8}$ & $\mathbf{1 9 9 9}$ & $\mathbf{2 0 0 0}$ & $\mathbf{2 0 0 1}$ & $\mathbf{2 0 0 2}$ \\
\hline POVERTY LEVEL (POVERTY INCIDENCE) & & & & & & \\
Poverty Line (Lei p.c. per month) & - & $\mathbf{1 2 8 . 9}$ & $\mathbf{1 7 9 . 2}$ & $\mathbf{2 3 4 . 8}$ & $\mathbf{2 5 7 . 3}$ & $\mathbf{2 7 0 . 7}$ \\
Poverty Incidence & - & 52.0 & 73.0 & 67.8 & 54.6 & 40.4 \\
Poverty Gap & - & 19.5 & 32.3 & 27.0 & 19.3 & 12.4 \\
Poverty Severity & - & 9.8 & 17.7 & 13.7 & 9.1 & 5.2 \\
\hline EXTREME POVERTY LEVEL & & & & & & \\
Extreme Poverty Line (Lei p.c. per month) & - & $\mathbf{1 0 1 . 0}$ & $\mathbf{1 4 0 . 4}$ & $\mathbf{1 8 3 . 9}$ & $\mathbf{2 0 1 . 5}$ & $\mathbf{2 1 2 . 0}$ \\
\hline Extreme Poverty Incidence & - & 37.4 & 59.7 & 52.2 & 38.0 & 26.2 \\
Extreme Poverty Gap & - & 12.4 & 22.7 & 17.6 & 11.6 & 6.6
\end{tabular}




\begin{tabular}{|l|c|c|c|c|c|c|}
\hline \multicolumn{1}{|c|}{ Indices and sources } & $\mathbf{1 9 9 7}$ & $\mathbf{1 9 9 8}$ & $\mathbf{1 9 9 9}$ & $\mathbf{2 0 0 0}$ & $\mathbf{2 0 0 1}$ & $\mathbf{2 0 0 2}$ \\
\hline Extreme Poverty Severity & - & 5.9 & 11.4 & 8.2 & 5.1 & 2.4 \\
\hline International Line \$2.15 PPP per day (value in Lei p.c & & & & & & \\
per month) & $\mathbf{8 5 . 0}$ & $\mathbf{9 1 . 6}$ & $\mathbf{1 2 7 . 6}$ & $\mathbf{1 6 7 . 5}$ & $\mathbf{1 8 3 . 9}$ & $\mathbf{1 9 3 . 7}$ \\
Poverty incidence & - & 52.7 & 70.8 & 64.5 & 52.4 & 39.8 \\
\hline
\end{tabular}

Source: PPMU based on HBS

110. The negative social consequences of the Russian financial crisis i.e. the sharp growth of poverty incidence, poverty gap and severity, have been overcome. It appears that poverty after the 1998 - 1999 "shock" has returned to its starting point. However, at the same time, poverty incidence, gap and severity remain unacceptably high.

\subsection{POVERTY AND INEQUALITY}

111. In the perception of the poor, inequality is a major component of the phenomenon of poverty. Implementation of a number of market measures such as the liberalization process and the withdrawal of subsidies, as well as the economic crisis of 1990s, were accompanied by rising inequality. Other factors increasing inequality were mass privatization and property redistribution, employment reduction and falling numbers of hired labor, increasing differentiation in remuneration of labor, the diminishing role of the state in the redistribution of resources, the emergence of a new class of entrepreneurs and self-employed, a growing informal sector and corruption, weak social policy and degradation of regional economies.

112. Income inequality expressed by the Gini coefficient rose since 1990 and reached 0.44 in the late 90s; but in $2000-2002$ the coefficient fell slightly to 0.42 . However, incompatibility of the data for the period before 1997 and since implementing the new HBS in 1997 makes it difficult to compare inequality measures over these two periods. The least wealthy $20 \%$ of the population in recent years accounted for less then $5 \%$ of total income of all households, whereas the wealthiest $20 \%$ of the population accounted for almost $50 \%$. Incomes of the wealthiest families are 10 times higher than those of the least well to do. Consumption inequality (generally lower than of income) has followed a similar trend, decreasing slightly from 0.39 in 1998 to 0.36 in 2002. The interquintiles ratio has also decreased. Economic growth has contributed to a reduction of poverty incidence, poverty gap and severity, yet it does not so far impact sufficiently on inequality.

Table 4 Distribution of total disposable income and expenditures for consumption products of households in 1997 - 2002 (in \%)

\begin{tabular}{|c|c|c|c|c|c|c|c|c|c|c|c|}
\hline \multirow{2}{*}{$\frac{\text { Indicators }}{\text { TOTAL }}$} & \multicolumn{2}{|c|}{1997} & \multicolumn{2}{|c|}{1998} & \multicolumn{2}{|c|}{1999} & \multicolumn{2}{|c|}{2000} & \multicolumn{2}{|c|}{2001} & \multirow{2}{*}{$\frac{2002}{100.0}$} \\
\hline & 100.0 & $\begin{array}{c}100.0 \\
1\end{array}$ & $100.0^{2}$ & 100.0 & 100.0 & 100.0 & 100.0 & 100.0 & 100.0 & 100.0 & \\
\hline \multicolumn{12}{|l|}{$\begin{array}{l}\text { Of which for } \\
\text { quintile (20\%) } \\
\text { groups of } \\
\text { population: }\end{array}$} \\
\hline I & 4.3 & 3.9 & 5.9 & 4.5 & 6.3 & 4.6 & 6.8 & 4.3 & 6.5 & 4.6 & 6.8 \\
\hline II & 9.8 & 9.7 & 10.6 & 9.8 & 10.7 & 10.4 & 11.2 & 10.4 & 10.7 & 10.4 & 11.1 \\
\hline III & 14.8 & 15.0 & 15.2 & 14.7 & 15.0 & 15.1 & 15.3 & 14.8 & 15.0 & 15.0 & 15.6 \\
\hline IV & 22.5 & 22.6 & 22.1 & 22.0 & 21.5 & 21.9 & 21.5 & 21.7 & 21.6 & 21.6 & 22.2 \\
\hline V & 48.7 & 48.8 & 46.2 & 49.0 & 46.5 & 48.0 & 45.2 & 48.8 & 46.2 & 48.4 & 44.3 \\
\hline $\begin{array}{l}\text { Gini } \\
\text { coefficient of } \\
\text { income }\end{array}$ & \multicolumn{2}{|c|}{0.436} & \multicolumn{2}{|c|}{0.443} & \multicolumn{2}{|c|}{0.436} & \multicolumn{2}{|c|}{0.419} & \multicolumn{2}{|c|}{0.428} & 0.421 \\
\hline $\begin{array}{l}\text { Gini } \\
\text { coefficient of } \\
\text { consumption }\end{array}$ & \multicolumn{2}{|c|}{ - } & \multicolumn{2}{|c|}{0.369} & \multicolumn{2}{|c|}{0.391} & \multicolumn{2}{|c|}{0.374} & \multicolumn{2}{|c|}{0.378} & 0.367 \\
\hline
\end{tabular}


Source: ${ }^{1}$ ) Household disposable income: Department of Statistics and Sociology of the Republic of Moldova.

${ }^{2}$ ) Household consumption expenditures: PPMU based on HBS data.

113. The income inequality problem is aggravated by the fact that the poor receive a substantial portion of income in kind and not in monetary form. As a result the poor population's access to goods and services provided for cash is lower than the potential of their aggregate monetary and in-kind income.

114. State programs for social assistance and support of the population do not yet make a positive impact on inequality reduction because of the inadequate targeting of these programs. In 2002 the least wealthy $20 \%$ of the population received only $6.6 \%$ of total social transfers (less pensions), whereas the wealthiest $20 \%$ of the population obtained $46,0 \%$. In order not only to stop the spread of poverty but also to reduce inequality, redistribution of social assistance and the results of economic growth must be made for the benefit of the poor.

Table 5 Distribution of income from social benefits by quintiles of household income, 2002 (percent)

\begin{tabular}{|l|c|c|c|c|c|c|}
\hline \multicolumn{1}{|c|}{ Indices } & \multicolumn{3}{c|}{ Quintiles of disposable income } & I & Total \\
\cline { 2 - 7 } & I & II & III & IV & V & $\mathbf{1 0 0 . 0}$ \\
\hline Disposable income - total & 5.4 & 10.7 & 15.5 & 22.2 & 46.2 & $\mathbf{1 0 0}$ \\
\hline Social transfers and allowances, pensions & 6.9 & 15.4 & 23.7 & 27.8 & 26.2 & $\mathbf{1 0 0 . 0}$ \\
\hline $\begin{array}{l}\text { Social transfers and allowances without } \\
\text { pensions }\end{array}$ & 6.6 & 9.2 & 13.5 & 24.7 & 46.0 & $\mathbf{1 0 0 . 0}$ \\
\hline $\begin{array}{l}\text { Allowances for mothers with many children } \\
\text { and other child allowances }\end{array}$ & 28.4 & 26.5 & 15.0 & 15.1 & 15.0 & $\mathbf{1 0 0 . 0}$ \\
\hline $\begin{array}{l}\text { Compensations offered to participants of the } \\
\text { WWII and their widows }\end{array}$ & 0.0 & 0.7 & 5.6 & 24.9 & 68.8 & $\mathbf{1 0 0 . 0}$ \\
\hline $\begin{array}{l}\text { Compensations for utilities and fuel payment } \\
\text { Social transfers and allowances without child } \\
\text { allowances and nominative compensations }\end{array}$ & 4.5 & 8.4 & 18.9 & 28.6 & 39.6 & $\mathbf{1 0 0 . 0}$ \\
\hline $\begin{array}{l}\text { Social non-monetary and humanitarian } \\
\text { assistance }\end{array}$ & 4.3 & 1.9 & 5.0 & 22.4 & 66.4 & $\mathbf{1 0 0 . 0}$ \\
\hline
\end{tabular}

Source: PPMU based on HBS data.

\subsection{THE POVERTY PROFILE AND MAIN REASONS FOR POVERTY}

115. The profile (structure and composition) of poverty in Moldova corresponds in many respects to the poverty profile in other countries in transition. To a large extent it can be explained by economic and partly by demographic factors, the main of which are low labor productivity in the agrarian sector, weakness of regional economies, increased dependence on the working population because of mass unemployment and the aging of the population, low pensions and social benefits, and substantial differentiation in the amount of salaries and wages by sectors of economy.

116. Poverty is not equally spread among residents of cities, towns and villages. According to the PPMU, the highest poverty level is in small towns (53.2\%), a little less in rural areas (45.1\%) and least of all in big cities (16.5\%). Such territorial differentiation of poverty incidence can be mainly explained by the economic condition of small towns, cities and rural settlements. During the course of the economic crisis, economies of small towns suffered most. The majority of them were monostructural and they depended on the operation of a small number of enterprises located within their territory (including one-factory towns). Closure or considerable cuts in the output of those enterprises resulted in massive lay-offs. Relatively low development of the service sector and infrastructure prevented and continues to prevent small towns from attracting investment and rehabilitating their economies, which predetermines a high poverty level. 
117. Poverty incidence in the rural areas is connected with declining terms of trade in the relative prices for agricultural and nonagricultural products as a result of the liberalization of prices and comparatively low labor productivity and low incomes of the employed. The economies of large cities, especially of the capital of the country, retained and even strengthened their comparative advantages resulting from more diversified production structure, and developed infrastructure and service sector. Residents of large cities have better opportunities for employment, retraining, opening their own businesses, and so on. So risks and poverty incidence here are much lower than in smaller cities and villages.

118. In terms of age, children and the elderly are the poorest. The poverty level among children in 2002 was $45.2 \%$. Yet for all age groups of children (under 5, from 5 to 9 years, from 10 to 14 years, from 15 to 18 years), poverty incidence is higher on average than among the residents of the republic. The more children there are in the family, the higher is the risk of being included in the category of the poor. Poverty is especially widespread among children in rural areas (50\%) due to large family size and relatively low incomes of rural households.

119. Poverty incidence is high among the elderly over 60 (43.7\%), and increases with age, $46.9 \%$ amongst people aged $70-75$, and $52.1 \%$ for those over 75 . The main reason for them to be poor is a small pension, which in 2002 was only $29.9 \%$ of the official minimum cost of living and $21.5 \%$ of the average monthly salary.

120. For households whose main source of income is social transfers (pensions, social benefits and compensations) poverty incidence $(59.1 \%)$ is high. More than half of the unemployed is poor $(54.5 \%)$, as well as a big part of seasonal workers and part-timers $(46.5 \%)$. Loss of a job is very often associated with a higher risk of being poor. Large-scale unemployment and part-time unstable employment are the most significant reasons for the high poverty level in the country as a whole.

121. As with other countries with a large agrarian sector, Moldova has widespread poverty among agricultural hired labor (56.0\%) and farmers $(47.3 \%)$ due to low incomes from agricultural activities.

122. Well-being depends a lot on the level of education. The poverty level among households headed by people with unfinished secondary education is $49.4 \%$ and for those with no education is $59.2 \%$. These households account for $36.1 \%$ of all households. In comparison, only $13.3 \%$ households headed by university graduates are poor. Thus, developing the system and increasing the level of education will decrease risks and poverty incidence.

\subsection{INCOME AND CONSUMPTION EXPENDITURES OF THE POOR}

123. The main source of income for poor households is their agricultural activity. Agricultural income of the poor accounts for $39.8 \%$ of disposable income. The agrarian sector plays an important role in the formation of income of the poor because most of the country's population (58.6\%), including the poor, live in the rural areas and are involved in agricultural activities. However, possessing land does not guarantee well-being - 79.2\% of poor rural families have land plots intended for farming activity. The problem lies in the low productivity of agricultural activity, lack of equipment, small sizes of land plots, which predetermines low incomes. The dependence of income on the weather and climate is a specific and additional risk factor for poor rural households.

Table 6 Structure of disposable income of households in 2002 (as \% of total)

\begin{tabular}{|c|c|c|c|}
\hline & Poor & $\begin{array}{c}\text { of which extremely } \\
\text { poor }\end{array}$ & Not poor \\
\hline $\begin{array}{c}\text { Total } \\
\text { of which incomes from: } \\
\text { - hired labor }\end{array}$ & 100.0 & 100.0 & 100.0 \\
& 25.3 & 24.7 & 40.1
\end{tabular}




\begin{tabular}{|l|c|c|c|} 
- individual agricultural activity & 38.9 & 40.2 & 27.6 \\
- individual non-agricultural & 1.1 & 0.9 & 3.0 \\
activity & & & \\
- ownerships & 0.2 & 0.1 & 0.2 \\
- social benefits & 24.0 & 24.1 & 11.9 \\
- other transfers & 10.5 & 10.0 & 17.2 \\
\hline
\end{tabular}

Source: Poverty and Policy Monitoring Unit based on the Household Budget Survey

124. Income from hired labor accounts for only $25.3 \%$ of the disposable income of poor families due to lower qualifications, wages, as well as widespread seasonal unemployment among the poor. For the non-poor, employment is the most important source of income reflecting the influence of large city economies. Social benefits (pensions, compensations, benefits) play an important role in the income of the poor. A high share of social transfers $(24.0 \%)$ in the structure of disposable incomes of the poor indicates that obtaining these transfers does not guarantee avoiding the status of being poor.

125. "Other transfers" are $10.5 \%$ of the disposable income of poor households. These include remittances from abroad. There are indications from other sources such as the National Bank that the amount and share of such transfers in disposable household income is much higher. Labor migration and remittances from abroad have become one of the most important ways of coping with poverty for poor households.

126. In the structure of consumption expenditures of the poor, expenditures on food predominate (75.8 \%). A considerable part of food products consumed are produced by the households themselves, and typical of rural families that produce half of the food consumed. Access of the poor to other goods and services is very restricted as seen from the low ratio of expenditures for clothes and footwear (2.6\%), health (2.1\%), transport and communication $(2.3 \%)$, education $(0.4 \%)$. Expenditures for the upkeep of houses (10.4\%) are more of a "set" nature, as their size and share in consumption expenditures depend on the tariff rates for public utilities and energy. Tariff policy has a significant impact on the structure of expenditures of the poor and their access to other consumer goods and services.

Table 7 Structure of household consumption expenditures in 2002(\%)

\begin{tabular}{|l|c|c|c|}
\hline & Poor & $\begin{array}{c}\text { of which } \\
\text { extremely poor }\end{array}$ & Not poor \\
\hline $\begin{array}{l}\text { Total } \\
\text { of which: }\end{array}$ & 100.0 & 100.0 & 100.0 \\
\hline - food products & 75.8 & 77.4 & 54.5 \\
\hline - alcoholic drinks, tobacco & 4.6 & 4.3 & 3.4 \\
\hline - clothes and footwear & 2.6 & 2.2 & 9.4 \\
\hline - housing and conveniences & 10.4 & 10.2 & 15.8 \\
\hline - health & 2.1 & 1.8 & 4.4 \\
\hline - transportation and communication & 2.3 & 1.9 & 5.5 \\
\hline - education & 0.4 & 0.4 & 1.6 \\
\hline - other goods and services & 1.8 & 1.8 & 5.4 \\
\hline
\end{tabular}

Source: Poverty and Policy Monitoring Unit based on HBS data.

\subsection{NON-MONETARY POVERTY}

\section{Health}

127. During the transition, people's health has been severely affected. Average life expectancy in Moldova is 68.5 years. Under 5 mortality rate is 18.3 per 1,000 live births and the maternal mortality rate is 28 per 100,000 live births. 
128. To be poor in Moldova means to have limited access to health care services. Studies show the ratio of hospitalization days for poor and non-poor is 1:11. And the average duration of hospitalization per year is 9-13.5 times shorter for the poor compared with the non-poor. Financial constraints are more severe in rural than in urban areas, and the situation worsens as the number of persons in the household increases and the level of household decreases. The education level of the household head also affects access to health services, those with lower levels of education have reduced access.

\section{Education}

129. Education significantly influences the poverty level. Persons without education and illiterates constitute $20 \%$ of the poor, while those with primary and incomplete secondary are a further $42.6 \%$, comprising $61.8 \%$ in total. For the non-poor, these two groups comprise $38.2 \%$.

130. The non-poor have higher levels of net enrolment at all levels of education, but the differences are especially pronounced at the higher level. Enrolments at university level education are three times lower for the poor than for the non-poor. The problem of access to higher education is particularly serious in rural areas where the net enrolment ratio is only 0.10 compared with 0.44 in urban areas. The difference between rural and urban enrolment is even greater amongst poor people. The enrolment ratio of youngsters from poor urban households is seven times higher than for poor rural households.

\subsection{SUBJECTIVE POVERTY ASSESSMENTS}

131. Most households in Moldova (61.2\%) consider themselves poor according to the results of the sample household survey of the Opinions of Poverty Phenomenon (August 2002), conducted by the Department of Statistics and Sociology, with the methodology support of the PPMU. Such "subjective reassessment" of poverty (as compared to the objective data of the World Bank, Poverty and Policy Monitoring Unit) occurs due to the lack of coincidence between the perceptions of the respondents' living standards and level of their actual well-being.

132. The majority of respondents define poverty in the same way, irrespective of their place or residence and whether they consider themselves poor or not. In their opinion the most significant sign of poverty is low income (78.3\% of respondents), the second significant sign is poor health (33.6\%), the third insufficient nutrition (29.9\%). A considerable part of respondents also associate poverty with bad housing conditions and low economic security.

133. The perception of poverty by households that consider themselves poor is based on the realities of their life. Of urban households, $68.6 \%$ consider low incomes to be the main reason for poverty, while $73 \%$ of rural households feel the same. Along with worsening of health of family members they mentioned loss of a job and impossibility to find a job as risk factors.

134. Households that consider themselves poor react sharply to inequality in society. They believe that in comparison with the previous $3-5$ years, inequality processes in this country intensified. Of urban and rural respondents, $50 \%$ pointed out increasing inequality in the area of money distribution. For food consumption, housing conditions, access to medicines and educational services, the figures range from 35 to $48 \%$ in urban areas and from 22 to $43 \%$ in the rural areas.

135. It is alarming that the poor see their prospects for the future as negative. Every third household expects a fall in its well-being, both in the cities and rural areas, whereas only every seventh urban and every twentieth rural family anticipates improvements in material living conditions.

136. In the event of critical financial situation a large majority (almost $90 \%$ - in cities and more than $92 \%$ - in rural areas) of households that consider themselves poor count on the help from outside. Their biggest hopes are for financial aid from their immediate family. In the same context, 
assistance from their neighbors, friends and co-workers is in second place, and private borrowing in the third place. A much smaller number of households count on the support from the social protection authorities, or local public administration bodies, public organizations, and the church.

137. The share of private ("other") transfers in disposable income of low income households showed a decreasing trend since $2000^{2}$. At the same time the share of income from social transfers of income of the same group of households has increased significantly - mostly due to changes made in 2000 , such as the introduction of new benefits for utilities ("targeted compensations") and increased level of pension and child benefit payments. However, the level of these benefits remained still insufficient to help the poor households to escape from poverty.

\begin{tabular}{lccccc}
$\begin{array}{l}\text { 2) The bottom quintile's } \\
\text { share of income from: }\end{array}$ & 1998 & 1999 & 2000 & 2001 & 2002 \\
- other (private) transfers & 13.70 & 15.07 & 19.93 & 11.91 & 13.45 \\
- social benefits & 8.73 & 7.03 & 12.26 & 20.11 & 21.69 \\
\hline
\end{tabular}

Source: Poverty and Policy Monitoring Unit based on HBS data. 


\section{EGPSRP OBJECTIVES AND PRIORITIES}

\subsection{LONG-TERM DEVELOPMENT OBJECTIVES}

138. The preparation and implementation of the EGPRSP is a key stage in the achievement of the long-term objectives of the country's socio-economic development. The Strategy identifies tasks and priorities for implementation in the medium-term. The achievement of these tasks and priorities is necessary to implement long-term objectives. The following objectives, which are derived from Moldova's Constitution and the Government Program "Revival of the economy-Revival of the country", correspond to international, European and domestic conventions:

i) Sustainable socially-oriented development;

ii) The reintegration of the country;

iii) European integration.

139. Sustainable socially oriented development serves simultaneously as a long-term objective and as a medium term development principle. It is enshrined in the UN documents signed by the leadership of the Republic of Moldova. Among the most important are the UN Declaration on Environment and Development (Rio de Janeiro, 1992) and the UN Summit on Millennium Goal Development (New York, 2000).

140. Sustainable economic and social development will be based on the following principles:

- Improved political and economic governance. Good governance is essential for successful development. Increased popular participation in government and respect for the rule of law and human rights is critical. Equally important is the establishment of sound economic management and macroeconomic stability.

- Private sector development. Private ownership of economic assets, a liberalized regime for prices and trade, private sector deregulation, and the promotion of competition constitute the platform for economic growth.

- A modified role for government where the center will ensure the political framework for the (i) efficient delivery of goods and services, (ii) regulation necessary for natural monopolies (energy, telecommunications) and public health and safety, (iii) increased independence of providers in healthcare and education (the center will have the monitoring role) (iv) and insurance of the equitable distribution of the benefits of growth for the welfare of the whole population.

141. Socially oriented development entails a consistent growth in the standards of living especially of the poorest, the speedy resolution of unjustifiably high social differentiation, consistent with the Millennium Development Goals which are: i) to eradicate extreme poverty and hunger; ii) to achieve universal access to primary education; iii) to promote gender equality and empower women; iv) to reduce child mortality; v) to improve maternal health; vi) to combat HIV/AIDS, malaria and other diseases; vii) to ensure environmental sustainability; viii) and to build a global partnership for development.

142. The Reintegration of the country must lay the basis for long term stability without which prospects for Moldova's development will in many respects remain unclear. Territorial reintegration is a complicated process, as the long conflict has led to the disruption of nearly all the important economic systems including the monetary and credit system, the banking sector, infrastructure, customs administration, and systems of education, health care, and social security. The challenge is to restore state unity in the political, legal, economic, social and cultural aspects. 
143. A political solution to this problem is of paramount importance. In the first place, the development and approval of the new Constitution of the Republic of Moldova is required. For this purpose, a long term constructive dialogue between the sides is necessary, as well assistance on behalf of guarantor countries and OSCE. The political settlement of this problem would lay the foundation for the joint settlement of economic and social problems.

144. After the political settlement, the main goal would be to implement the economic reintegration of the country by means of the formation of a common economic zone. This would be aimed at the elimination of internal barriers and obstacles for free movement of goods, capital and people; at the establishment of the environment conducive to stable economic growth; and at social development throughout the country. It will facilitate the development of entrepreneurship and interaction between economic agents within the country, the establishment of a stable investment environment, the integration of the banking systems and, in the long run, the strengthening of the economic potential to reduce poverty.

145. European integration is defined by Moldova as a fundamental development objective, which means the consistent implementation of common European values and standards, living standards and economic development models.

146. The relations between Moldova and the European Union are based on the Partnership and Cooperation Agreement, which was enacted in 1998. This Agreement defines principles of relations and cooperation objectives relating to the development of democracy, the protection of human rights and national minorities, the establishment of the rule of law and the setting up of the market economy in Moldova. The Agreement provides for the gradual harmonisation of national legislation with European legislation in the field of trade, business, customs, banking, tax and social systems, and infrastructure. The prospects for cooperation, including a possibility to enter into a free trade agreement, will depend on Moldova's success in the development of the legal, economic, social and other systems according to EU principles and standards.

147. Expansion of the European Union will create for Moldova new conditions and opportunities in the progress towards integration within the "neighborhood" policy framework. An Action Plan will be prepared and approved in the first half of 2004 that will develop and elaborate on the provisions of the Partnership and Cooperation Agreement.

\subsection{MEDIUM-TERM OBJECTIVES AND PRIORITIES}

148. For the country to move energetically and effectively towards the achievement of the longterm development objectives, the focus in the medium-term period will be on the attainment of the following objectives:

i) Sustainable and inclusive economic growth;

ii) Poverty and inequality reduction, and increased participation of the poor in economic development;

iii) Human resources development.

\section{Sustainable and Inclusive Economic Growth}

149. Current economic growth is based to a large extent on the export of labor. The remittances provided by this labor have led to fast growth in domestic consumption. Because of rigidities in the domestic supply of goods and services, consumption-led growth has attracted imports, widening the trade balance, and contributing to inflation. The quality of economic growth in Moldova is affected by an unbalanced structure of the economy, by monostructural exports, and by low investments in 
fixed capital. Such a growth paradigm does not provide a basis for the sustainable growth needed to reduce poverty.

150. The challenge is to move from the current state of remittance based, consumption- led growth to a more balanced model, emphasizing investment and locally based import substituting and export led growth. The vision for the future involves seeing remittances as a potential source of development finance and an opportunity for investment within an enhanced business environment. Better policy will encourage investment in small and medium enterprises. Import substituting and export led enterprises will generate income and employment, using improved market opportunities opening up in traditional markets, and in new markets. This process will be stimulated by the emphasis being placed in the Strategy on private sector development and an enabling, deregulated business environment, which allows business to prosper.

151. To change the paradigm and quality of growth will require mobilization of new sources and factors of growth by attracting significant investment, primarily, in the processing industry and in infrastructure, for the diversification of the structure of the economy, and the replacement of labor force export with the export of goods and services.

152. The progress and growth rate of the country's economic development will depend mainly on the business and investment environment, which is being formulated at the national and local levels. In the medium-term, it is increasingly important to improve the business and investment climate by pursuing a stable, transparent and efficient regulatory policy, by developing competition, and by supporting small and medium-sized business. This will help mobilize the domestic investment potential of the economy consisting of the labor migrants' savings, the resources of the banking system, of the shadow sector and of capital leaving the country.

153. The improvement of conditions for sustainable growth throughout the country including the recovery and development of infrastructure will be a main focus (infrastructure in this context includes roads, water supplies, heating, electricity and gas, and telecommunications). This will permit the smoothing of socio-economic imbalances between the Center and regions, and the improvement of living standards in smaller cities and villages. The task is to emphasize the development of the economic potential of regions, as well as making business more active in localities, and attracting investments to regions.

154. Based on economic transformation similar to the above, it is estimated that annual economic growth targets of between $5-10 \%$ are feasible, $5 \%$ growth per annum being a moderate scenario, and $8-10 \%$ being an optimistic scenario. Analysis in the macro section below supports the view that these targets are feasible.

\section{Poverty and Inequality Reduction, and Increased Participation of the Poor in Economic Development}

155. Poverty and inequality reduction, and the increased participation of the poor in economic development and its benefits, are the goals of both social and economic policy. In spite of the growth in the economy, the overall level of social development remains extremely low, while levels of poverty and social inequality remain high. Poverty and inequality are not only negative attributes at this stage of the country's development, but also obstacles to sustainable growth. They restrict the participation of a part of the population in wealth production and the use of their skills and working potential.

156. The aim is to improve the living conditions of the poor through better targeted social protection, facilitating access to social services for the poor, as well as to assist families and individuals to mitigate their poverty by developing small business, creating additional jobs, and assisting socially vulnerable groups in employment. 


\section{Human Resources Development}

157. Human resources development represents both a factor for economic growth, and its result. Changing the growth paradigm involves improving the quality of "human capital" participating in development. At the same time, the increasing social orientation of growth suggests maximal orientation of policy and development results towards fostering human development.

158. Today, because of high unemployment and low wages, human resources are underused, resulting in their gradual degradation. The poor strata of society are largely isolated from the system of human resources development. They have extremely limited access to quality health care and education, so that human resources are brought up in unfavorable conditions, which do not further their development.

159. In the medium term, it is expected that there will be considerable improvement in the quality of medical and educational services, as well as in the access of the poor to these services. This will contribute to a sustainable growth of the economy, and will also lead to poverty reduction.

160. In developing its medium term priorities, the Government is conscious of the constraints imposed by scarcity of public financial resources, which will last throughout the period of the Strategy. The following set of policy priorities has been identified based on the considerations inherent in the Strategy objectives, and on those areas where limited resources can be used most efficiently for growth and poverty reduction:

i) private sector;

ii) public administration;

iii) social protection;

iv) health care and education;

v) infrastructure;

vi) regional development;

vii) environment.

\subsection{EGPSP and Millennium Development Goals}

161. The medium and long-term priorities and objectives of the EGPRSP are linked with the Millennium Development Goals. In particular the Strategy sets specific relevant tasks and indicators, which are adapted to Moldova's development conditions. Attaining these targets is necessary in order to successfully achieve national and international objectives. The selected indicators are included in the EGPRSP monitoring system. In the process of EGPRSP implementation the indicators system will be refined and extended in order to improve further the process of monitoring of results, objectives and tasks, set in the EGPRSP and Millennium Development Goals.

162. The successful implementation of the EGPRSP over the period 2004-2006 will be clearly linked to reaching sufficient progress towards the achievement of the Millennium Development Goals by 2015. A number of the MDGs adapted to the Moldovan reality are presented below, along with indicative targets for successful progress by 2006, 2010 and 2015. 
Reduce by half the proportion of persons with daily income below 2,15 USD (evaluated at Purchasing Power Parity) over the period 1997-2015:

- reduce the ratio of this population category from $39.8 \%$ in 2002 , to $28.0 \%$ in $2006,23.0 \%$ in 2010 and $18.0 \%$ in 2015.

Ensure equal opportunities for all children to study in gymnasiums:

- increase the ratio of net enrollment in gymnasium education from $88.0 \%$ in 2002 , to $88.9 \%$ in $2006,93.8 \%$ in 2010 and $100 \%$ in 2015 .

Reduce by 2/3 the under-5 mortality rate over the period 1990-2015:

- reduce the under-5 mortality rate from 18.3 (per 1000 children) in 2002 to 15.0 in $2006,11.9$ in 2010 and to 8.4 in 2015;

- reduce the infant mortality rate from 14.7 (per 1000 new-born) in 2002 to 12.1 in 2006, 9.6 in 2010 and 6.3 in 2015 ;

- increase the proportion of children under 2 years old that are vaccinated against measles from $99.2 \%$ in 2002 to $100 \%$ beginning with 2006 .

Reduce the maternal mortality rate by $3 / 4$ over the period $1990-2015$ :

- reduce the maternal mortality rate from 28.0 (per 100.000 births) in 2002 to 23.0 in 2006, 21.0 in 2010 and to 13.3 in 2015;

- ensure that all births are assisted by qualified medical personnel beginning with 2006 (the relevant ratio is currently $99 \%$ ).

Arrest and reverse by 2015 the spread of HIV/AIDS:

- reduce the incidence of HIV/AIDS from 4.66 (per 100.000 persons) in 2002 to 4.0 in 2006, 3,5 in 2010 and 3,2 in 2015;

- reduce the incidence of HIV amongst the population aged 15-24 from 6,0 in 2002 to 4.9 in 2006, 4.2 in 2010 and 4.0 in 2015.

Arrest and reverse by 2015 the spread of TBC and malaria:

- reduce the TBC-associated mortality rate from 15.8 (per 100.000 persons) in 2002 to 12.0 in 2010 and 7.0 in 2015.

Integrate the principles of sustainable development in the country's policies and programs and reduce the loss of environmental resources:

- increase the relative weight of areas covered with forests from $10.3 \%$ in 2002 to $11.0 \%$ in $2006,12.1 \%$ in 2010 and $13.2 \%$ in 2015 ;

- increase the relative weight of areas protected for the conversation of biodiversity from $1.96 \%$ in 2002 to $2.1 \%$ in $2006,2.2 \%$ in 2010 and $2.4 \%$ in 2015.

Reduce by half the number of persons without sustainable access to improved water sources by 2015:

- increase the share of population with sustainable access to improved water sources from $38.5 \%$ in 2002 to $47.7 \%$ in $2006,57.0 \%$ in 2010 and $68.5 \%$ in 2015.

The share of population with access to improved sanitation is envisaged to increase from $40.0 \%$ in 2001 , to $56.0 \%$ in $2006,73.3 \%$ in 2010 and $90.0 \%$ in 2015 . 


\title{
VI. STRATEGY MEASURES FOR POVERTY REDUCTION
}

\author{
A. Growth Policies
}

\subsection{ENSURING MACRO ECONOMIC STABILITY}

\section{Situation Analysis}

163. As described in Chapter III of this Strategy, in recent years the trends of the main macroeconomic indicators have been quite positive. Between 2000 - 2002, GDP growth increased steadily. In 2003, growth slowed but remained strong at 6,3\%. The industrial sector registered the fastest growth, increasing from $7.7 \%$ in 2000 to $13.6 \%$ in 2003. Meanwhile, agriculture showed a mixture of growth and slowdown. Agricultural output decreased by $3.3 \%$ and $14.1 \%$ in 2000 and 2003 respectively, and increased by $6.4 \%$ in 2001 and by $3.4 \%$ in 2002 .

164. Growth of investment in fixed capital took off only in 2001, a year after the start of GDP growth. The volume of investment grew significantly - 11\% per year in 2001 and 2002, and 16\% in 2003. However, in general the level of investment in fixed capital remains low at about $14 \%$ of GDP in 2003. During the recent period of economic growth, export and import volume also increased. In 2000 , exports increased by only $1.7 \%$, and in 2003 by $22.7 \%$. Over the same period, the volume of imports increased faster than exports. Imports increased at a particularly high rate in 2000 and 2003 - by $32.4 \%$ and $35.1 \%$ respectively. In 2001 imports increased by $15 \%$, and in 2002 by $16.3 \%$. The increase of import as compared to export led to a persistent trade deficit, which increased sharply in 2003 - when the trade balance was twice as high as in 2000.

165. Despite economic growth, and an improvement in the main macroeconomic indicators, some imbalances remain. To reduce them, it will be necessary to improve the conditions for sustainable growth by continuing with structural reforms that will allow the maintenance of high growth rates in industry, exports and investment. Structural reforms will be oriented on increasing the growth potential of different sectors, creating more work places, and increasing incomes which will serve as a basis for reducing poverty.

\section{Objective}

166. In the medium-term perspective policy will be oriented towards ensuring stable conditions for continuing sustainable economic growth and poverty reduction.

167. The main medium term objectives are:

- To reduce inflation in order to provide favorable conditions for business and investment, and to protect the real incomes of the population,

- To maintain a flexible exchange rate policy and provide favorable conditions for external economic activity,

- To stabilize the external debt situation and improve debt management so as to decrease external risk,

- To undertake a budgetary-fiscal policy that would ensure a balanced evolution in incomes and expenditures. 


\section{Medium Term Macroeconomic Forecast}

168. The macroeconomic forecast below is based on the following assumptions:

i. the average annual GDP growth will be driven increasingly by growth in industrial production and services, by export growth and investment in fixed capital,

ii. there will be successful implementation of economic and structural policies aimed at: (i) improving the business environment; (ii) developing an industrial and services sectors based on advanced technologies; (iii) attracting domestic and foreign investment; (iv) restructuring and modernization of enterprises; (v) promoting exports and substituting imports; (vi) improving the management of public and private enterprises.

169. The latest macroeconomic forecast prepared by the Ministry of Economy for 2004-2006 envisages that a slowdown in economic growth will probably take place, which usually occurs after achieving such high growth rates. The growth GDP was of $7.8 \%$ in 2002 , while growth in 2003 was reduced to $6.3 \%$.

170. The base forecasting scenario assumes GDP growth in 2004 of $6 \%$, with an annual increase of $5 \%$ in the next two years. The forecast growth rates are viewed as the minima required for the formation of resources and conditions to reduce poverty over the medium term perspective.

171. The consistent implementation of structural reforms will strengthen the growth potential of the economy. The growth rate of industrial output is projected to be higher than that of GDP. Growth of industrial output is expected to be $12 \%$ in 2004, and an average growth of $10.5 \%$ annually in 2005-2006. The volume of services rendered to the population will increase by $7 \%$ in 2004 , and annually by $6 \%$ in $2005-2007$. It is assumed that the agricultural output will grow but on a declining trend. Agricultural output is projected to increase by $7.5 \%$ in 2004, (compensating for the 2003 decline), by $4 \%$ in 2005, and by $3 \%$ in 2006. In reality, agricultural output in Moldova is highly unpredictable since the main influence on agricultural output is variable weather conditions.

172. The growing industrial output will have an impact on exports. Export growth is projected to be $14 \%$ in $2004,13 \%$ in 2005 , and $12 \%$ in 2006 . It is expected that growing industrial output will facilitate import substitution, which will, to some extent, mitigate the foreign trade balance problem. Imports are projected to grow by $9 \%$ in 2004, $7 \%$ in 2005, and $6 \%$ in 2006.

173. The forecast rates of economic growth will be supported by increasing the volume of investment in fixed assets. An investment growth rate higher than GDP is forecasted. Capital investments are projected to rise by 13\%,10\%, and 9\% in 2004, 2005 and 2006 respectively. At the same time, there is a risk that investment growth might be lower than the projected figures, due to the unpredictability of foreign investment, as well as unfavorable terms for bank credits, including comparatively high interest rates.

174. The promotion of a balanced monetary policy is a priority for the reduction of inflation and creating conditions for sustainable medium-term economic growth. A rise in the inflation rate to $15.7 \%$ in 2003 had a negative impact on investment and business activities. The steep rise of inflation was caused by growing prices for grain and flour, administratively raised tariffs for natural gas and energy, transport and communication services, and an increase in money transfers from Moldovan citizens working abroad.

175. In order to sterilize excessive foreign currency and to replenish its reserves, the National Bank of Moldova (NBM) expanded its purchase of foreign currency with the result that the monetary mass increased by $30.7 \%$ at the end of 2003. The NBM had to tighten credit and monetary policy by raising mandatory reserve requirements and the base interest rate on credits. 
176. The medium-term credit and monetary policy of the NBM will be targeted at reducing inflation and maintaining stability on the monetary markets. This will ensure favorable conditions for the growth of business and investment activities of the private sector, real income and purchasing power of the population.

177. Based on the macroeconomic forecast prepared by the Ministry of Economy for 2004-2007, the NBM has developed a monetary program that provides for:

i) monitoring the inflationary processes with the purpose of reducing the rate of growth of prices from $9 \%$ in 2004 to $5 \%$ in 2007 ;

ii) A gradual re-monetization of the economy (with the broad monetary aggregate M3 increasing as share of GDP from $31.2 \%$ in 2003 to $47.0 \%$ in 2007 );

iii) a moderate growth of commercial credit to the economy (by $34.8 \%$ in 2004 with a subsequent decrease in growth to $19 \%$ in 2007 ).

178. NBM exchange rate policy, as well as credit and monetary policy as a whole, is oriented towards supporting stable economic growth, and provides for:

i) continuation of a floating exchange rate and the determination of the exchange rate on the basis of supply and demand dynamic, the economic situation in the country and on foreign markets;

ii) intervention on the exchange market where excessive fluctuations of the exchange rate need to be mitigated;

iii) maintaining international currency reserves at an adequate level and placing the foreign currency assets of the NBM in investment instruments that meet security and liquidity requirements.

179. It should be noted that under conditions of a persistent deficit in the balance of trade, a devaluation of the national currency might improve the trade balance by increasing the competitiveness of exported products and raising prices of imports. However, this effect of devaluation is likely to be very limited, because a large reduction of the national currency exchange rate will increase inflation due to the heavy dependence of the economy on imports, including the importation of strategic commodities (energy). Besides this, the exchange rate of the Moldovan Leu on the market is much lower than its exchange rate calculated by purchasing power parity. A market exchange rate gradually approximating to its purchasing power parity exchange rate is likely to reduce the considerable depreciation of the Leu. For these reasons, it is anticipated that there will be a moderate downward trend in the Leu's exchange rate, with a decrease of the Leu by 19.3\% from December 2003 to December 2007.

180. The dependence of the economy on external economic factors, coupled with the worsening conditions of external economic activity and the decrease in foreign investment inflows in 2003, makes the improvement of external economic relations crucial. In 2003 the deficit in the trade balance reached $31.3 \%$ of GDP. Despite money transfers from labor migrants increasing to $18.6 \%$ of GDP, these did not compensate for the increase in the trade deficit. As a result there was an increase in the negative balance of the current account to around $10.8 \%$ of GDP. The discontinuation of funding by international financial institutions had an adverse effect on the balance of payments. For the first time in recent years, there was a deficit on the financial account in addition to the deficit on the current account. The problem of adequate volume of international reserves became more acute, as the reserves fell below the equivalent level of three months of imports. 
181. It is worth being mentioned that the transfers from abroad referred to in the previous paragraph are only those financial flows, which are officially registered through the banking system. In reality, remittances sent from abroad involve large sums of money, which pass through non-bank channels.

182. According to the NBM forecast of balance of payments indicators for 2004-2007, there will be some stabilization of the external economic position of the country due to:

i) a growth in exports and a decrease in the balance of trade deficit (from 27.6\% of GDP in 2004 to $20.3 \%$ of GDP in 2007);

ii) the inflow of money transfers from labor migrants, which will, on average, account for about $17 \%$ of GDP annually;

iii) the inflow of means through technical assistance and the renewal of foreign financing by creditors.

183. A gradual decrease in the current account deficit is forecasted, from $7.7 \%$ of GDP in 2004 to $3 \%$ of GDP in 2007.

184. A sustainable settlement of the country's public debt problem is envisaged to be achieved on the basis of the further stabilization of the budgetary-fiscal system, the improvement of the balance of trade and balance of payments, and the more efficient administration of debt. The State Debt Administration Strategy for the medium term (2004-2007), developed by the Ministry of Finance, defines the main directions of the foreign debt stabilization as:

i) enhancement of payment discipline in the service and repayment of accumulated state debts;

ii) attraction of credit resources in accordance with the assessment of their possible repayment and efficient use;

iii) insurance of transparency in the process of placement and use of the attracted resources;

iv) further restructuring of foreign debt on a bilateral basis and search for opportunities to refinance multilateral debt obligations.

185. The maintenance of fiscal equilibrium and the stability in the process of redistributing resources created through the budgetary system will play a significant role in ensuring macroeconomic stability.

186. According to forecasts, in 2004-2006 the total of consolidated public budget revenues in as a share of GDP will decrease insignificantly, from $36.1 \%$ in 2004 , to $35.6 \%$ in 2005 , and $34.6 \%$ in 2006. The rate of consolidated public budget expenditures, as a share of GDP will vary insignificantly: $36.5 \%$ in $2004,36.4 \%$ in 2005 , and $35 \%$ in 2006 . A small annual budget surplus is forecasted throughout the period $(0.3 \%$ in $2004,0,8 \%$ in $2005,0,4 \%$ in 2006$)$. 


\subsection{BUGET AND FISCAL POLICY}

\subsubsection{Fiscal Policy}

187. The main objectives of fiscal policy for the medium and long term are based on the provisions of the Fiscal Reform Concept approved by Parliament, and include:

- ensuring the stability and predictability of public revenues, especially tax collections for full coverage of budgetary obligations,

- ensuring fiscal equity, stability and transparency of fiscal legislation,

- stimulating the economic activity, especially by encouraging the development of small business, by attracting external and domestic investments in the national economy, the creation of new workplaces, etc.

188. These objectives will be carried out through (i) improving the structure of tax rates in order to reduce the tax burden and continuous broadening of the fiscal base, (ii), reducing fiscal exemptions with the aim to maintain only those targeted at efficiently supporting economic growth and poverty reduction, and (iii) increasing the efficiency of fiscal administration.

189. Fiscal policy for 2004-2006 is consistent with the evolution of the national fiscal system reform and does not envisage any radical changes from the policy promoted during the previous years.

190. With economic growth and the improvement of fiscal management, the income tax on legal entities and individuals is seen to become a more and more important source of budget revenues. Also, this tax plays an important role as an economic lever for investment stimulation and equitable distribution of income among different layers of population. Prudent application can also lead to an increase in the overall scale of tax collections by uncloaking taxpayers from the informal economy.

191. To support people with low income and gradually shift the tax burden on the population with average and above average incomes, the tax grid of individuals was changed in 2004, and beginning with 2005 a gradual increase in personal income tax relief is envisaged from Lei 3,600 in 2004 to Lei 3,960 in 2005, and Lei 4,500 in 2006. Income tax relief and deductions for individuals will tend to increase towards raising the minimum subsistence level. At the same time, taking into consideration the financial situation of population, it is envisaged to increase tax relieves granted for supported persons (children, parents, other family members, etc) from Lei 240 in 2004 to Lei 600 in 2005, and to Lei 840 in 2006. Starting with 2005 as non-taxable income sources are proposed the individual state social insurance contributions.

192. At the same time, it is planned to continue reducing the income tax rates for individuals. Thus, for annual income under Lei 16,200 the rate will drop from 10\% in 2004 to $8 \%$ in 2006, for income from Lei 16,200 to 21,000 - the rate will decrease from $15 \%$ in 2004 to $13 \%$ in 2006 and for annual income larger that Lei 21,000 - from $22 \%$ in 2004 to $18 \%$ in 2006 . These fiscal measures will lead to a decrease the financial burden on population's income and, at the same, will stimulate the entrepreneurship activity.

193. In order to continue reducing the fiscal burden and uncloak taxpayers that activate in the informal economy, during the last years the rate of income tax for legal entities has been substantially decreased from $28 \%$ in 2001 to $20 \%$ in 2004 . This tendency will continue in $2005-$ 2006 , with the rate being respectively $18 \%$ and $15 \%$. The income tax reform for legal persons is determined by the need to broaden the fiscal base by legalizing income generated in the informal economy and will be implemented along with measures of fiscal discipline enhancement. 
194. Income tax relief will be maintained during 2004-2006, to encourage economic agents to invest, create new work places, develop small and medium enterprises, especially in agriculture. At the same time, in order to broaden the fiscal base, amendments in the legislation will be proposed, to improve the tax mechanism for non-residents that are conducting business on the territory of the Republic of Moldova.

195. Value added tax. It is planned to maintain the destination method of VAT calculation for all countries, as well as for all agents from the country that have no fiscal relations with the budgetary system. The structure and value of VAT will not be modified. At the same time, the VAT payment fiscal relief will be reviewed to keep only those that are economically efficient or have an increased social role.

196. Excises. For 2004-2006, it is planned to maintain the destination method of excises calculation for exported goods. The list of goods subject to excises and the level of excises share will not be modified.

197. Real estate tax. The progress registered in the decentralization of real estate tax administration at the level of local public authorities will depend on the efforts to design a National Cadastral System. In the EGPRSP reference period is envisaged to develop and implement the Program of real estate goods evaluation. The resulting ascertaining of real estate market value will serve as a basis of taxing the property. Until the end of the property evaluation process, this tax will be applied accordingly to year 2003 registered practice.

Local taxes. Beginning with 2005, the new chapter on "Local taxes" in the Fiscal Code will be implemented, This will simplify the procedure of local taxes encashment and will offer local public authorities possibilities to raise local budgets incomes, increasing their role in the territories.

198. Social Insurance Contributions. To increase social equity and ensure consistency between insured risks, contributions and benefits, starting with 2004 a process of gradual distribution of state social insurance contribution was initiated in order to reduce the rate paid by the employer and to increase the individual rate of the employee, in parallel with the reduction of the overall rate to $30 \%$ in 2004 and $29 \%$ in 2005 . Thus, in 2004 this ratio is $28 \%$ paid by the employer and $2 \%$ by the employee, in 2005 - 27\% and 2\% respectively, and in $2006-26 \%$ and $3 \%$ respectively.

199. For 2005-2006 it is planned to implement the Strategy on the reform of the pension system for those working in agriculture, which stipulates passing from the principle of paying contributions on the basis of land owned and its quality to the principle of paying contributions from the income - for owners of agricultural lands that are employed on the basis of an individual work contract, and on the basis of a fixed contribution - for owners of agricultural land that work their land individually.

200. Contributions to mandatory health insurance. Starting with 2004, the system of mandatory health insurance was extended to cover the whole country. For 2004-2006, the medical insurance premium is to be maintained at $4 \%$, of which $2 \%$ paid by the employer from the salary fund and $2 \%$ by the employee.

201. To improve and increase the efficiency of fiscal administration, the following will be undertaken:

\section{i) Improvement in tax collection mechanism}

This will be carried out through consolidation of taxes and local taxes collection services and by concentration of the Principal State Fiscal Inspectorate efforts on a more efficient collection of other state revenues. Also, it is planned to implement automated record-keeping systems for petroleum and alcohol products. 
This will continue to be implemented through the method of computerized selection of taxpayers to undertake risks' based verification. Simultaneously, the control method will be intensified on the basis of analysis of information from fiscal and financial reports, as well as other sources without leaving the office. This will allow establishing the level of precision of tax diminution by economic agents.

\section{iii) computerization of fiscal procedures}

To realize this it is necessary to:

- develop and implement an information system and taxpayers notification mechanism, present reports in electronic format to the Principal State Fiscal Inspectorate, and self-service of taxpayers through the web site www.FISK.MD ;

- develop the concept, of the mechanism and organization of an informational system for providing state and local public bodies with fiscal information;

- improve the interface mechanisms with other departments' information systems.

iv) popularization of fiscal legislation and education of taxpayers in the spirit of voluntary payment of fiscal obligations, by launching a series of programs and advertising spots on the importance of tax compliance.

The implementation of measures in these areas will contribute to raising the fiscal management efficiency, to a reduction of subjectivism in the process of fiscal management, and to a more operative application of fiscal administration levers.

\subsubsection{Public Expenditure Policy}

202. According to MTEF forecasts, over the next three years the Government will face an acute lack of financial means due to the need to honor external commitments. This will require promotion of a restrictive budgetary policy, with emphasis on rationalization and efficiency of public expenditures, as well as reallocation of existing resources from less important to top-priority programs and that have a substantial impact on the economic growth and poverty alleviation.

203. According to preliminary estimates, total public expenditures will increase from Lei 9 billion in 2003 to Lei 13,5 billion in 2006, with a concomitant increase in all elements of the global framework of expenditures. Despite the increase in nominal value, their weight in GDP has diminishing tendencies, as a result of a decrease of weight of revenues in GDP. This is partially explained by the reduction of the fiscal burden and by the fact that the forecast of certain revenues set at fixed rates are not influenced by GDP growth.

204. Expenditures of the health insurance funds and those of the state social insurance budget will grow more rapidly than expenditures of the consolidated budget, as a result of policy measures in the state social insurance field and in the area of mandatory health assistance insurance, as well as due to the projected growth of the salary fund.

205. Taking account of the direct impact on poverty reduction, public expenditure policy in the next years will place increased emphasis on social transfers to the population and salary expenditures. Transfers to the population, including those made through the system of state social insurance, will be considerably increased following the implementation of measures meant to intensify social protection of both insured and uninsured persons in the public system of social insurance. These measures are related mainly to the implementation of the pensions' indexation 
mechanism, to the increase in the quantum of nominative allowances and compensations, as well as the rationalization of the number of beneficiaries of social assistance.

206. Starting with 2005 and until 2010, it is planned to implement the Law on the system of establishing base salaries in the budgetary sector and allowances for high ranked officials, which is to be approved in 2004. The new salary system will ensure an equitable salary level for all categories of employees, depending on the level of qualification, responsibility, work complexity and will be based on individual professional performances of employees. Salary reform in the budget sector will be implemented in the context of the general reform of the public sector through optimization of the institutional structure and number of staff in the public sector.

207. The allocation of resources by sectors for 2003-2006 will be carried out on the basis of sector expenditures programs, taking into consideration the factors of strategic influence on sector development, as well as the reserves for improving the expenditures for certain sectors identified by the MTEF analysis.

The analysis of public expenditures structure in 2004 shows that circa $66 \%$ of discretionary public expenditures are socio-cultural expenditures, out of which social protection $-30 \%$, education $20 \%$, health protection $-14 \%$. Besides this, circa $18 \%$ of discretionary public expenditures are on general public services, public order and national security, and circa $13 \%$ - expenditures on infrastructure and national economy branches.

208. In the context of strategic priorities for the next three years, the social-cultural expenditures are becoming prominent, due to their social importance and direct impact on poverty reduction.

With the implementation of mandatory health insurance and the creation of respective insurance funds, additional resources will be attracted to the health sector, concomitantly placing an emphasis on their efficient use.

The priorities of resources allocation among sectors and within sectors in the MTEF context will be determined by the following factors:

- intensification of control over administrative expenditures within state services, defense, public order and law;

- rationalization of education system for enhancing the efficiency of resources use, by directing additional allowances for the increase of alimentary norms in pre-school and boarding-school institutions, and well as for increasing the stipends by circa $20 \%$;

- increasing the cost of the medical services package offered through mandatory health insurance and broadening the categories insured by the state;

- ensuring a more efficient directing of expenditures for social protection, that provides: (i) a greater equity in the pension system; (ii) restructuring the social assistance programs, emphasizing the criteria of eligibility based on income and poverty level; (iii) reform of labor market services;

- targeting real sector expenditures to support the agriculture and rural development, public roads infrastructure and energy complex, which have an increased impact on poverty reduction;

- making changes in the amount of expenditures for implementing investment projects, as a result of finalizing some projects or starting other new investment projects, according to EGPRSP priorities. 
Investment projects with foreign financing, as well as extra-budgetary funds and resources are important financing sources for some sector activities and often produce financial fluxes with serious implications for the budget or for the further maintenance of the infrastructure. To ensure the principle of complexity in budgetary planning, as well as to increase budgetary-fiscal transparency and gradual decrease of out-of-budget operations, it is important that both projects with external financing and the extra-budgetary funds and resources are treated as an integral part of the general public expenditures framework by sectors.

209. Given the limited growth prospects for public financial resources for the medium term, prudent economic and budgetary-fiscal management will provide an opportunity to achieve a modest increase of public expenditures, by attracting and maintaining the support from international financial bodies in the implementation of the country's economic reforms.

\subsection{PUBLIC SECTOR REFORM}

\subsubsection{Reform of Public Administration}

\section{Situation Analysis}

210. Since independence, macroeconomic and structural reforms in the production and social sectors have proceeded faster than reforms to the system of state administration. The later were essentially limited to reductions in the numbers of state employees. These reductions were driven by the macroeconomic need to minimize the budget deficit, and by the existing constrains to provide salaries for state employees and state pensions.

211. About 8,500 employees serve in central public administration and around 6,500 in local administration. The number of public officials within central public bodies located in the municipality of Chisinau is relatively low, most of them being concentrated in regional branches of the tax inspectorates, customs and statistics bodies.

212. In general, reform and restructuring of public administration have been led by changes of political administration, rather than by a coherent, consistent, long term reform plan. The number of central administration structures has increased recently and now consists of 16 ministries, 14 departments with autonomous budget and accountability, and over 20 agencies, services, centers and extra-ministerial and extra-departmental inspectorates.

213. The main emphasis of recent reforms in public administration has been to decentralize government functions and responsibilities by reorganizing the local pubic administration bodies. To increase the capacity of public bodies to satisfy the needs of local communities, in the summer of 2003 the former administrative structure based on 10 judets was replaced by an expanded structure of 32 regions.

214. The current situation of public administration is characterized by the following:

(i) insufficient functional and institutional adaptation of pubic administration to the requirements set by the transition from a centrally planned economy to a market economy. Strategic approaches to public administration have been used to a limited extent, being limited only to the development of the Medium term expenditures framework;

(ii) the principles and methods of selection and promotion of public employees are not sufficiently consistent with efficient administration, and developing high quality policy;

(iii) existing capacities are insufficient for using modern management methods; 
(iv) low level of work remuneration has a negative impact on the motivation and efficiency of state employees' activity;

(v) the over-regulation unjustifiably complicates the efficient administration of socioeconomic development processes. This is an impediment for the private sector activity, contributes to extension of corruption, and undermines society's trust in public bodies;

(vi) the current framework of tax collection does not ensure the full and fair contribution of all potential taxpayers to the creation of state revenues, which is increasing the tax burden on honest tax payers;

(vii) the development and implementation of macroeconomic, sector and regional policies is nor based enough on analytic studies, which hinders promotion of high quality policies;

(viii) there persists a low level of openness and transparency in the decision making process of public administration.

215. The actual reforms of local public administration provide conditions for continuing the decentralization process. The rights and responsibilities of local public administration are stipulated in laws regarding the drafting and approval of local budgets, the management of local public finance, guarantees of local autonomy, membership and powers of local councils and public administration authorities, and administration of the property of territorial-administrative units.

216. At the same time, there are multiple serious problems that need to be addressed over the medium term:

(i) imperfection of the legal framework and mechanisms for efficient economic and fiscal decentralization;

(ii) a lack of clear separation of functions and responsibilities between central public administration and local public administrations;

(iii) the insufficient professional level of local administration personnel;

(iv) imperfection of the training and retraining system for managers and local administration bodies' employees;

(v) insufficient consulting of local public administration on drafting and application of laws and regulations;

(vi) insufficient computer facilities and information technologies;

(vii) lack of access to the intergovernmental data base of the Council of Europe regarding local administration.

\section{Objective}

217. To establish a modern, efficient public administration system, which will strengthen democratic processes and the market economy, which is impartial and non-political, and whose principles and operation correspond to best European practice.

\section{Long Term Strategy}


218. The public administration system will be subordinated to the new role of the state as the facilitator of democracy and the market economy. Public administration in this context comprises the totality of organizations, regulations, management systems and principles of public bodies functioning.

219. The strategic framework of public administration reform is correlated with the development objectives and principles followed by the state in its activities. These transpire from the Economic Growth and Poverty Reduction Strategy, where respective measures and actions are being defined. It is envisaged to:

(i) improve political and economic governance;

(ii) develop the private sector;

(iii) modify the role of public bodies, in order to increase the efficiency of administration, service delivery, regulation and equitable distribution of economic growth benefits.

220. Within the overall context of Moldova's governance, the guiding principles for public administration reform are:

(i) clear definitions of core roles and functions of the public administration;

(ii) reasonable delegation to local public administration bodies and the private sector of competences and responsibilities for activities linked with provision of goods and services;

(iii) elimination of overlapping and duplication of functions between public administration bodies, with the purpose of a more efficient use of resources;

(iv) rational use of scarce budget resources and management of resources by concentrating on priority areas;

(v) unified approaches to functional, structural and organizational reforms of public administration;

(vi) separation of policy development and implementation, regulatory and service delivery functions to allow focusing activities according to core competences;

(vii) rationalization of accountability and management systems to avoid wide spans of managerial responsibility;

(viii) establishment of a remuneration scheme which will provide consolidation of managerial capacities and personnel's competences;

(ix) harmonization to EU and Council of Europe standards of public administration.

221. The central public administration reform strategy will concentrate on:

(i) increasing the efficiency of public administration at central level;

(ii) improving the decision making process and its strategic approach;

(iii) increasing efficiency by developing capacity of the institutional and human resource development system; 
(iv) improving the interaction between public administration and civil society.

222. At the level of local public administration bodies, continuing of the decentralization process will involve the establishment of efficient self-government institutions and mechanisms, which will be responsive, transparent and accessible for the public. In promoting the decentralization policy the following priorities will be taken into consideration:

(i) improvement of legislation for local autonomy and self-government;

(ii) clear delimitation of functions and responsibilities between central and local public administrations;

(iii) increase of the fiscal and economic independence of local public administration bodies;

(iv) increase of the efficiency (openness and record-keeping) of the activity of local public administration bodies.

223. The policy of professional development promotion of human resources both for central and local public administration bodies will observe the following principles:

(i) competitive and transparent selection, recruitment and promotion of employees;

(ii) development of job descriptions based on the revised role and functions of public administration bodies;

(iii) professional development of public servants through continuous improvement and systematic in-service training;

(iv) annual performance testing and evaluations;

(v) establishment of an adequate remuneration system, which, in perspective, will be based on performance;

(vi) minimization of political pressures on the activity of public servants.

224. The interaction between the public administration and society will be improved. Civil society, non-government organizations, associations, independent media and the population at large will be able to have increased access to public administration activities. This will be facilitated through electronic distribution of information, including through the Internet and mass media. Public hearings and discussions will be carried in relation to important policy matters, as is the case with EGPRSP. There will be better transparency about public spending in general and for the social protection of the population in particular.

225. Permanent consultation groups will be established to include representatives of public administration, local authorities, public and non-commercial organizations with the aim of summarizing and disseminating experience in social partnership, local self-government and selforganization of the population in territories.

226. Local public administration bodies will be encouraged to explain to the population public policies and activities through the press, TV and radio. 


\section{Priority Actions 2004-2006}

227. First of all the conceptual foundation of public administration reform will be developed. In this context, the priority will be the preparation of a Strategic Plan. The Plan would be based on complex assessment of the roles, responsibilities, functions and activities of central and local public administration, by comparison with the role and functions adequate to a modern democracy and market economy.

228. The complex assessment will be done functionally and organizationally. This would include a review of ministry and departmental responsibilities as set down in official documents (laws and regulations), which currently define roles and responsibilities, then will compare them with those appropriate for a market economy. Also, the current administration systems' organization principles, procedures and practice will be reviewed. They will be compared with those, which have been developed by EU accessing countries with similar parameters of size and population. These actions would provide the basis for restructuring and streamlining functions, procedures and obligations.

229. Following the assessment, proposals for reform and restructuring will be formulated, taking into account the principles set out in the long term strategy and will highlight measures that are to be undertaken by public administration to develop and execute core functions consistent with its role in a modern democracy and market economy.

230. These functions would focus on policy formulation, setting regulatory systems and monitoring of public service delivery. Direct government regulatory activity would be limited.

231. The Strategic Plan will include priority actions, implementation, reporting and monitoring procedures, execution schedules and resources necessary for the public administration reform. The Plan will be based on a general methodology and common principles for the process of internal reorganization and reform of ministries and departments. Self-reorganization will be based on strategic planning principles, implemented through pilot exercises and supported financially, to allow ministries and departments to hire experts that will offer consultations on this process.

232. The preparation and assessment of the Strategic Plan would be supervised and managed by the Public Administration Reform Management Unit. The Unit would need to be directly supported by and accountable to an Inter-ministerial committee chaired by the Prime Minister. This unit might also provide for centralized human resource development and could execute functions of administrative personnel manager.

233. Besides provisions for organizational reform and restructuring, the Strategic Plan will also contain stipulations for creating appropriate capacities for the public administration, including the legal framework, management systems and human resources. These would cover:

- an organization model for a continuous public service, made out of professionals with management and analytical skills;

- legal framework covering the organization of public administration, the public services, administrative procedures, accessibility and transparency of official state information, public procurement, budget management, and publication by public bodies of annual performance reports.;

- management systems, procedures and practices for public administration;

- an effective public service job classification and grading system that would reflect skills requirements; 
- a transparent competitive selection, recruitment and promotion system for the public service;

- an efficient remuneration system that will contribute to the attraction and retention of professionals in the public service, will recognize and motivate activity performance;

- introducing public service accountability through implementing a personnel performance management system (regular performance appraisal linked to remuneration and career);

- a training system to support the reforms in public administration e.g. establishing the internal audit function, developing capacities for strategic planning, and a system that enables civil servants to develop their skills according to the needs of the public service. The new Public Administration Reform Management Unit should determine the field of inclusion and content of the training in the light of reform needs.

234. The preparation of the Strategic Plan would take account of previous work carried out in this area such as that funded by TACIS and the World Bank.

235. In the implementation of the state public administration decentralization the following tasks will be required to be undertaken:

- implementation of a favorable legal and institutional environment to increase the efficiency of the local public administration. This will be done by bringing the regulatory base in line with the European standards in the field of local autonomy, as reflected in the recommendations of the European Charter of Local Autonomy;

- review of the system of transfer of functions to local government based on the principles of subsidiarity and separation of competence among all levels of public administration;

- determination of the procedure for the transfer of functions and delegation of powers of ministries and departments to local administration authorities, and mechanisms of responsibility for their implementation;

- review of the legal framework and measures needed to raise the revenues of local budgets to levels that guarantee long term sustainability and financial independence of self-administration. Also, the processes of development and approval of local budgets will be reviewed and improved, ensuring strict supervision of public finances use;

- development of simple and accessible regulations, rules and procedures for the functioning of local public administration. The development and implementation for local public bodies of improved management systems and procedures for analyzing economic and social development, municipal asset management, and the budget process;

- providing opportunities for professional development of local administration employees within a state system of training, retraining and skill raising for local self-government. The possibilities of ensuring their social and legal protection will be studied;

- disseminating advanced experience and practice in social partnership, efficient use of local and other available resources for addressing local problems;

- ensuring transparency and improving the accountability of local public administration for managing the delivery of public services and improving the business environment at local level, for use of property and finances. 
236. The development of a Strategic Plan will require a general review of the legal and institutional framework based on complex and coordinated studies, done with the support and technical assistance of international donors.

\subsubsection{Public Finance Management}

237. During the transition to market economy, a set of public finance management measures have been initiated to ensure the efficient functioning of the budgetary system in the new economic conditions. At the same time, this area is facing a series of problems and difficulties, such as: (i) a fragmented legal and regulatory framework, (ii) insufficient approach and reflection of sector and inter-sector priorities in resource allocation, (iii) the limited scope of treasury system coverage and drawbacks in accounting and reporting in the budgetary system, (iv) weak and outdated information systems and technologies, (v) inadequate control systems.

238. Insurance of efficient implementation of governmental programs and priorities require further improvement and strengthening of public financial resources management.

239. The long-term objective in this area is building of an efficient and sustainable financial management system, based on modern instruments and mechanisms, adjusted to European standards. To achieve the general objective, the main medium term tasks are the following:

- improving public finance allocation methodology by applying modern practices of budget drafting;

- consolidating the financial discipline by developing the treasury system and improving budget execution procedures;

- improving public debt management methods and mechanisms in order to minimize servicing costs;

- improving fiscal administration and increasing the efficiency of financial control;

- rationalizing and optimizing budgetary management by creating an integrated financial management information system;

- harmonizing the budgetary and fiscal legal and regulatory framework with European Union requirements and standards.

240. To improve the method of resource allocation according to governmental policies and strategies specified in EGPRSP, the drafting of MTEF will continue to be developed as an instrument of strategic budget planning approach and the area of public authorities' scope will be extended, in order to develop budgets on the basis of programs and performance. The development of MTEF will be focused on: (i) the improvement of the quality of projections by using the macrofinancial forecast model, (ii) the consolidation and deepening of sector and inter-sector analyses by extending the development of strategic expenditures plans to sectors beyond those of education, health and social protection, (iii) the improvement of setting sector expenditures ceilings by emphasizing strategic priorities in resources allocation policy. The importance of MTEF in budgetary planning and the link between EGPRSP and MTEF is described in Box 2.

241. In the area of state and local administration budget relations, activities will focus on reducing the financial dependence of local governments and the stimulation of local financial autonomy. This will be done through improving the legislation on financial relations between state budget and administrative-territorial units' budgets, performing fiscal potential analysis from the territorial aspect, undertaking measures for enhancing their fiscal base and through improving the mechanism of budget equalization transfers mechanism. 


\section{Box 2. MTEF and EGPRSP}

To improve the strategic approach to the public revenues and expenditures planning process, starting with 2002 (with the support of the World Bank and UK Department for International Development), the drafting of the Medium Term Expenditures Framework has been introduced as the initial stage of the budgetary cycle. The MTEF is to be the primary instrument in correlating public incomes and expenditures with governmental policies and priorities proposed in EGPRSP.

The general objectives pursued through the introduction of MTEF are the following:

i) improvement of macroeconomic and fiscal forecasting by developing an inclusive and objective framework of resources;

ii) orientating the distribution of methods to inter-sector and intra-sector policies' support;

iii) enhancing budgetary planning possibilities by adopting a medium term multi-year perspective;

iv) identifying and emphasizing main problems in public finance management, in order to establish this area's strategic reform actions, necessary to improve its effectiveness and efficiency;

v) strengthening the responsibility of public authorities for the efficient allocation and use of public resources.

MTEF and EGPRSP constitute two directly correlated but distinct strategic planning processes. EGPRSP is the document that includes baseline policies and priorities for the state's development, and MTEF offers the medium term public finance general framework available for the implementation of proposed measures and actions.

At the same time, EGPRSP also constitutes an instrument of negotiation with donors for additional financing of some priority actions that have no financial coverage in the MTEF, providing that these are considered effective and efficient by donors. The correlation between EGPRSP and MTEF must be based on accurate and objective predictions of external financing.

242. To improve the budget execution process, medium term priorities include: (i) consolidation and development of the treasury system and (ii) improvement of public sector accounting. Treasury system consolidation will be achieved by re-equipping and upgrading existing technologies to develop a performance information system for the state treasury. This system will allow the creation of a single information space between all participants in the budget process at the central and local levels.

243. To improve accounting and financial reporting, a public sector accounting reform concept is to be developed, based on which a single normative framework regulating accounting and national standards of budgetary accounting will be developed. Also, reporting formats on budget execution for all budget levels are to be reviewed in order to supply relevant information for financial analysis.

244. The integration of the state social insurance budget and health insurance funds into a single budgetary classification system, and their operation through the treasury system will essentially improve the quality and promptness of financial reports submitted by respective institutions.

245. Public debt management plays a specific role in public finances management. It is planned to improve in this area the legal and regulatory framework in order to harmonize with international requirements and to apply the new tools and special financial operations in the area of state debt. Also, measures will be undertaken to improve the process of negotiations with external creditors for debt restructuring and the need to distribute information related to the issue and circulation of state securities. Special attention will be given to the development of technical and strategic analysis and 
risk management capacities in the area of state debt, including through the update of the DFMAS debt management application.

246. To consolidate the financial control framework, the strict definition of control functions among different control bodies will be emphasized and efficient cooperation amongst these institutions will be ensured. To exclude overlapping and duplication efficient planning and coordination of controls will be ensured. The same goal will be pursued in developing a strategy for public sector internal audit.

247. To improve budget financial management over the medium and long terms, it is proposed to create an integrated public finance management information system. The goal and benefits of this action are presented in Box 3.

248. To implement the integrated public finances management informational system, the following actions will be undertaken:

i) creation of a single information space, both among subdivisions of the Ministry of Finance, and among these and local level subdivisions: local treasuries and fiscal services, as well as financial directorates of second level local administrative-territorial units and the Balti municipality, with the Customs Department and its subordinated bodies;

ii) creation of a single information environment with budget executors (ministries, departments, public institutions) for the process of state budget preparation and execution, and creation of reports on budget execution in real-time, using Internet technologies and authorized access of information users to this process.

249. Actions will also be taken to adapt the legal and regulatory framework to European Union requirements in the budgetary-fiscal area. During 2004-2006 it is planned to:

i) finalize the Fiscal Code by drafting and promoting its title on local taxes, natural resources use payment, customs taxes and other incomes;

ii) improve and systematize legislation on banking system and process;

iii) review and approve the Budgetary Classification (new version) according to updated international standards;

iv) improve legal and regulatory provisions for public sector accounting record-keeping and the development of a single budgetary system plan of accounts. 


\section{Box 3. Integrated Financial Management System}

Presently the structure of the Ministry of Finances' information system is fragmented and is characterized by a series of technological and functional drawbacks, such as old programming language, limited information processing possibilities, and the use of the telecommunications network in exchange of information.

With the implementation of treasury system the volume of information accumulated and stored on the Central Treasury and territorial treasury servers has increased enormously. Although the information system has been improved and adjusted to information processing needs, it is difficult to ensure the necessary level of information security, as well as satisfactory information processing productivity.

The creation of an integrated financial management system will help solve shortcomings and is one of the main objectives of the public finance management consolidation strategy. The new system will ensure:

(i) correct and timely circulation of documents among budgetary process participants;

(ii) real time reception of accounting balances and other financial accountability reports for the purpose of operative administration of the budgetary cycle and its execution process;

(iii) real-time authorized access to the informational system's data of reports' users;

(iv) organization of automatic real-time accounting and book-keeping in financial bodies, mayoralties and budgetary institutions.

Taking into consideration the amount of activity and the significant costs, the integrated financial management system can only be implemented with donors' financial assistance, dedicated to the procurement of the required software and technical re-equipment, as well as for the upgrading of telecommunications systems and personnel training.

250. A precondition in promotion and achievement of proposed objectives is the development of analytical and institutional capacities both within the Ministry of Finance and its subdivisions and in central and local public authorities involved in public finance management. For this purpose a vast training and retraining program in public finance management staff will be developed. In particular, budget strategic planning and analysis capacities, debt risks analysis and management, and audit and financial control staff retraining will be developed. With the implementation of a single financial management information system, it will be necessary to train information technology specialists to ensure the support of the budgetary process information system.

\subsubsection{Strengthening the Judicial System}

\section{Situation Analysis}

251. The judicial and legal reforms were launched in 1994 following the adoption by the Parliament of the Judiciary and Legal Reform Concept document. The Concept was based on the idea that the transition from a totalitarian system and centralized economy to a democratic state and a market economy requires new legal mechanisms including an independent judiciary, an efficient mechanism of human rights and private property protection. This Concept established priorities relating to the restructuring of courts of law with two detailed aspects: the establishment of an adequate legal framework and institutional reform.

252. The main step in the establishment of the legal framework and the rule of law has been the adoption of the Constitution, which includes a separate chapter dedicated to judiciary authority. This step was followed by the adoption of a series of laws, such as: the Law on the Constitutional 
Court, Law on judiciary organization, Law on the status of judges, Law on the Supreme Council of the Magistrate, Law on the disciplinary college and the disciplinary responsibility of judges.

253. Art. 114 of the Constitution stipulates that justice is an exclusive attribute of the state. Other fundamental constitutional principles include: the provision of justice in the name of the law (Art. 114 of the Constitution), the right to defense (art.26), presumption of innocence (Art.21), equality of citizens in front of the law and public authorities (Art.16), prohibition of extraordinary courts (Art.115), independence and immovability of judges and their obedience only to the law (Art.116), and the guarantee of the right to appeal (Art.119), etc. The Constitutional Court has been created as the only authority of constitutional jurisdiction in the Republic of Moldova, thus implementing the constitutional control at the state level.

254. The judicial reform has caused essential changes with regard to the status, role and functions of courts of law resulting in the introduction of judicial competence in all areas of social and economic relations. The establishment of specialized courts - the economic and military courts has led to the specialization of judges.

255. The central idea has been to focus the judiciary on the protection of personal rights, thereby upholding the principle of free access to justice and the right to satisfaction from competent courts of law. The principle of access to justice is embodied in the Criminal Procedure Code of the Republic of Moldova, according to which in a criminal trial the parties have the right to be assisted or represented by a defending lawyer selected or appointed ex officio. In a case when the suspected, accused and the guilty persons are not able to pay a lawyer, a counsel for the defense appointed by the judge assists them. This procedure is not applied in other categories of cases.

256. The status of judges has been modified based on the principles of independence, impartiality and immovability. Attention has also been given to the restructuring of other important institutions, such as the prosecutor's office, the Bar, the notary offices, criminal prosecution bodies, etc. A new department has been established under the Ministry of Justice, responsible for the enforcement of court decisions, which do not involve deprivation of freedom and decisions of other authorities. This is reported to have led to an insignificant improvement in the situation in this area.

257. The reform process is a comprehensive and a long one, and experience has shown that the judiciary system reformed after 1996 has begun to represent a barrier to the constitutional right to free access to justice. Although judicial and legal reform has been promoted for many years, the need for a new restructuring of the judiciary has transpired. The Law nr.1471-XV of November 21, 2002, on the modification of the Constitution of the Republic of Moldova, provides a new organization of courts system, by exclusion of one tier, because the previous structure proved to be very complex. As a result, the first level courts, courts of appeal and last appeal will examine cases more rapidly and will enhance the access of citizens to the Supreme Court of Justice. The adoption by Parliament on May 8, 2003, of the Law nr.191-XV on the modification and amendment of legislative acts has established the mechanism for the practical implementation of the new courts system.

258. Within the judiciary and legal reforms the most important codes have been adopted: criminal, civil, criminal procedure, civil procedure. The new executive code and administrative offences code are being finalized. 


\section{Objective}

259. The ultimate goal of legal reforms is:

- To revise the legal and institutional frameworks to establish the rule of law and a modern market economy.

\section{Long Term Strategy}

260. The problem of strengthening the judicial system is complex and multi-dimensional, and needs a systemic approach. Although a range of legislative acts have been adopted in this area, and much institutional restructuring has taken place, there are still many unresolved issues that damage not only the image of the justice, but also affect the level of economic, social and politic development of the state in general, and the credibility of the state on the external arena. At this stage, it is necessary to steadily continue the reform implementation process.

261. The priority areas that require review are:

- Improvement of the quality of the drafting of legislative and support acts in general, and especially those regarding economic development;

- development of the legal education system;

- development of the legal services market, and respecting the rights of legal services consumers (implementing quality standards);

- execution of courts decisions.

262. Legislation to support the rule of the law needs to be adequate for the regulation of the entire complex of social and economic relations. The preparation of legal acts will be improved to ensure coherence in general and for each separate area. This process will clearly define the goals of the actions envisaged, which will focus on defending the interests and liberties of the individual and ensuring access to justice, attraction and promotion of investments, deregulation, adjustment of national legislation to the legislation of the Council of Europe and European Union. Another priority of reviewing the standards on drafting normative acts and initiating a legal framework impact evaluation mechanism is the creation of premises for consolidating legal security for economic agents, foreign investors etc.

263. Key problems in this area are: insufficient financing of judicial bodies (which affects the impartiality of judges and the efficiency of justice), inadequate management of courts, noninsurance of the principle of equality of the parties in a trial, lack of information, etc. Also, it is necessary to ensure the recruitment of qualified persons for the positions of judge, prosecutor, attorney, notary, court clerk, etc. and the improvement of their professional competence through the creation of the National Institute of Justice, which will ensure their continuous training. This Institute is subordinated presently to the Ministry of Justice and is to be created on the basis of the Center for training and retraining of staff from the Ministry of Justice and General Prosecutor's Office system,. It will contribute to forming new staff in the justice area, as well as their in-service training, taking into consideration frequent changes in the legal framework.

264. The judicial management organization system is not fully adjusted to present realities. Thus, structures existing in the Ministry of Justice, responsible for the administration of the judicial system, are dispersed and do not activate in common and coherently. Hence, there is a need to create a unified structure. 
265. The reform of the legal education system must begin at the university level with the training of future lawyers. Necessary measures will be taken to ensure high and uniform standards of legal training and morality, which will constitute the premise of admission to the profession. Legal training, including programs of in-service training, will pursue the strengthening of legal capacities, understanding of professional ethics, human rights, as well as the support of an adequate administration of justice. Another objective will be the matching of knowledge received at faculty with the demands of the market economy and/or the labor market and foreign trade. There shall be initiated and developed the promotion of legal knowledge in order to reduce legal nihilism from the society.

266. From the point of view of incidence of justice institute over economic growth and poverty reduction, this one will guarantee that nobody can be stopped by economic barriers from realizing his/her rights in any court. All persons should have the right to necessary legal assistance in a trial. Thus, the aspects of ensuring access to justice must take the shape of a coherent and consequent state policy, within which to be explicitly determined and well delimited the categories of beneficiaries of these services, the types of offered assistance. Given that legal charges constitute a barrier for the application of justice, these shall be reviewed. In this context, the existing system of legal charges (costs of experts, state taxes, attorney fees, etc) will be analyzed in order to create some mechanisms for establishing real and adequate costs of legal charges. Another sensible aspect in ensuring access to justice is the need to ensure the access of general public to legal information sources (accessing electronic versions of regulatory databases, distributing informing materials regarding legal information, continuous development of the Republican Center of Legal Information under the Ministry of Justice etc.)

267. The execution of courts' decisions (both in criminal and civil matters) is also facing serious drawbacks. Despite reforms in this area, the number of non-executed legal decisions is still very large, generating discontent of those involved in this process.

268. The situation of convicts in state prison institutions is alarming. The number of inmates and the period of conviction are rising. Prisons are overpopulated and detention conditions are described by various national and international bodies as inhuman and degrading. At the same time, the annual adoption of laws on the amnesty of certain categories of persons has not been proven to be an efficient remedy.

269. Another aspect that needs to be dealt with is the possibility to institute measures for facilitating or stimulating amiable conciliation or conflict resolution, before hearings in court begin or even during trial. At the present, mediation is applied only in criminal cases. The introduction of this institute will allow for a considerable decrease of expenses for persons that take part in litigation, and will decrease the number of cases examined by courts of law. Thus, the development and further application of alternative disputes resolutions is being imposed.

\section{Priority Actions for the 2004-2006 period}

\section{The legal framework}

- Review of the framework, as well as the standards of developing regulations in the area of justice;

- Establishing an evaluation mechanism for the legal framework's impact on social and economic processes, establishing a number of evaluation indicators, etc.

\section{Access to justice}

- Developing and implementing policies and subsequent laws in the area of legal assistance guaranteed by the state; 
- Developing mechanisms for offering free-of-charge legal assistance for socially-vulnerable persons;

- Ensure frequent application of alternative disputes resolution ways, including mediation and arbitration (courts of arbitration);

- Review of the possibilities for reduction of legal costs;

- Creation of necessary conditions for ensuring the access of the general public to legal information.

\section{The judicial system}

- Undertaking studies and evaluations aimed at different aspects of the organization and functioning of justice, from the aspect of protection of individual rights and perspective of sustainable economic development;

- Improving institutional capacities and adequate organization of legal personnel, performance evaluation;

- Provision of access to performance equipment and information technologies.

\section{Development of the legal education system}

- Review of legal education standards;

- Optimization of education and training curricula;

- Initiation and development of the legal knowledge promotion.

\section{Effective enforcement of court decisions}

- Evaluate the performance and the modalities of the current system of enforcement of court decisions.

\subsubsection{Fighting Corruption}

\section{Situation analysis}

275. Corruption can be broadly defined as abuse of public office. It exists at all levels and is fueled by the opportunities and incentives created by the governance system. Poor public sector wages also contribute to driving corruption at the lower levels of the public administration. The entrenchment of corruption is accompanied by the expansion of the unofficial economy and worsening of public services. A particular concern is raised by the practice of buying work places, a corrupt activity that serves to further entrench corruption within state institutions.

276. As a rule, the most affected by corruption is business activity. The costs of corruption to enterprises are large, and its direct and indirect costs (hiring security personnel) exceed by far the benefits. Corruption disproportionately affects enterprises as they navigate through the web of licensing and inspection, but also affects the rural poor particularly those involved in trade.

277. Corruption is a serious concern to the Government and its elimination is an absolute condition for economic development and poverty alleviation. According to surveys conducted by the international anti-corruption organization Transparency International, Moldova ranks 102 out of 
133 countries from the study. Among most corrupted sectors mentioned by the representatives of the business environment are customs, fiscal authorities and the police. The most corrupt sectors for civil society representatives are the education and health sectors.

\section{Objective}

278. To eliminate corruption with the main emphasis on removing bureaucratic barriers to entrepreneurial activities that provide the main opportunities for corruption.

\section{Long Term Strategy}

279. Removal of corruption will stimulate economic activity in the country. By this, Moldova will become a more attractive country for foreign investors, incomes for the private sector will increase, budgetary resources collection will be more efficient, conditions will be created for better remuneration of civil servants, the quality of services rendered to the population will be improved, and will be possible to promote more efficiently the social, health care and education policies.

280. The Center for Fighting Economic Crimes and Corruption is formally mandated with the task of fighting corruption. To strengthen the activities of this body, the Government of Moldova has recently proposed the drafting of a National Strategy for Corruption Prevention and Fighting (NACS). This strategy is aimed at isolating the underlying causes of corruption, the most affected structures and organizations, and will evaluate corruption in the context of public sector institutional reform. The Center for Fighting Economic Crimes and Corruption will be made responsible for the drafting and implementation of the Strategy. The Court of Accounts will play an important role in identifying cases and causes of corruption.

281. The main provisions of the NACS will be:

(a) minimization of regulation;

(b) free access to information;

(c) elaboration of the code of conduct, to which institutions will adhere to eliminate corruption;

(d) conflict of interest rules prohibiting participation in decision making whenever private interests may be present in the performance of public duties;

(e) declaration of incomes by public office holders and their effective monitoring;

(f) promotion of coalitions among groups with similar interests for preventing corruption;

(g) creating communication channels that will allow the population to inform public bodies on cases of corruption and protection of informers;

(h) establishment of vigilance units;

(i) random integrity testing on those in responsible positions.

282. The control systems in ministries and departments will be strengthened, to make the existing rules and regulations more effective. Looking ahead, greater reliance on informational technologies, public sector reform, and training of legislators and civil servants will form an integral part of the NACS. 


\section{Priority Actions for the 2004-2006 period}

283. A medium term priority will be to reduce and simplify regulations that apply to business and enterprises. This will be primarily addressed through the EGPRSP private sector development strategy.

284. As part of the public administration reform, the Government, with donors' assistance, will implement a public sector capacity consolidation project, which will be focused on professional development and capacity building. This will be done on the basis of the EGPRSP public administration reform strategy.

285. Also, under its public administration reform strategy, the Government will engage in open discussions involving the state, civil society, and development partners, on a medium-term institutional reform agenda.

\subsection{PRIVATE SECTOR DEVELOPMENT}

286. As a result of economic reforms, the private sector became the driving force in the economy. Moldova's medium term socio-economic development is dependent on ensuring stable and favorable conditions for the further development of the private sector, a component of which involves the reduction of the administrative restrictions and barriers that currently impose high costs on the sector. The main constraints facing the sector are:

- an unstable legal and regulatory framework;

- excessive bureaucracy reflected in the large number of permits, licenses and other authorizations, resulting in additional costs in registering and developing private businesses;

- excessive tutelage of control bodies;

- inefficient fiscal administration;

- insufficient working capital and limited access to financial resources;

- difficult access to domestic and external markets and weak marketing services;

- low level of managerial abilities, a business culture which is not yet fully developed along with limited access to information and consulting services;

- persistence of corruption.

287. Improving the business environment to encourage and support of domestic producers will focus on transforming the legal and regulatory environment for business, and eliminating existing restrictions and barriers. The medium term priorities are:

(i) reform of the regulatory framework;

(ii) development and protection of competition;

(iii) rationalization of corporate management;

(iv) support and development of Small and Medium Enterprises (SME);

(v) promotion of external trade;

(vi) improvement of investment environment; 
(vii) creation of real estate cadastre ;

288. Most of these reforms are legislative and administrative in nature thus entailing limited financial costs.

\subsubsection{Regulatory Framework Reform}

289. The existing regulatory framework has an adverse effect on the development of the economy and generates an activity, which is well below the economy's potential, especially with regard to the small and medium enterprise sector and investment.

290. The Government will vigorously promote regulatory reform. Emphasis will be placed on shifting public administration from excessive regulation to assessing and monitoring the impact of regulations on business activity.

291. At the first stage the regulatory framework reform promoted by the Ministry of Economy will focus on:

(i) simplifying and rationalizing business registration and post-registration procedures in the issuing of permits, licenses and similar documents and reducing the public sector's involvement in these processes;

(ii) reducing the number of all state controls, and changing their orientation to facilitating tax collection, and providing training/educational and consulting support;

(iii) increasing the efficiency of paid services rendered by public authorities by setting tariffs for services at the level of costs incurred during their rendering, and providing free services that do not imply additional expenses;

(iv) rationalizing fiscal policies and procedures, especially for SMEs.

292. Regulatory reform will be supported by actions to improve voluntary technical regulation and standards. The objective in this area is to move towards EU and international legislative and administrative practices in order to facilitate the assessment of products conformity. Products conformity assessment and conversion from mandatory to voluntary standards are highlighted in the draft EU/Moldova Action Plan. These interdependent systems act as connectors between the regulatory framework and other dimensions of business and market development, including product safety, public health and consumers rights protection, and market inspection.

293. The products conformity assessment is based on the accreditation and assurance systems that are provided through separate functional and institutional systems. Accreditation provides for state assessment of the competence of conformity assessment bodies, based on the following criteria: impartiality, confidentiality, responsibility for taken decisions, and adherence to their own quality standards. The conformity assurance system and voluntary application of standards based on mandatory technical regulations will contribute to the protection of the internal market, promote Moldovan goods on international markets, and ensure the international competitiveness of domestic products. At present the establishment of the conformity assessment system is at its early stages.

294. The Ministry of Economy will initiate and undertake measures aiming at:

(i) improving the methodological basis and procedures for the assurance of products conformity and accreditation according to international/European criteria and practices;

(ii) enhancing producer's responsibility by establishing legal provisions alongside producers' conformity declaration procedures; 
(iii) de-monopolizing the conformity assurance procedure;

(iv) promoting the voluntary application of standards by developing technical regulations, in accordance with international/European standards;

(v) creating adequate conditions for the introduction of ISO 9000 quality and ISO 14000 environment management systems;

(vi) improving the accreditation and products conformity assurance systems' activity to promote the efficient integration of Moldova's products into the international system;

(vii) creating conditions to promote the mutual recognition of conformity certificates/declarations at the international level.

\subsubsection{Competition Promotion and Protection}

295. Competition policy will comply with the following principles: (i) the right of economic agents to benefit from competition within the law and the rules of correct and honest conduct of business; (ii) the non-admissibility of the limiting competition, abusing a dominant market position, and infringing on the legitimate rights of consumers; (iii) the obligation of central and local public authorities to contribute to the development and protection of competition.

296. The existing situation in the area of competition is unsatisfactory. One of the causes is the lack of an efficient regulation of anti-monopoly and competition protection activities, due to the absence of coherent policy, and the dispersion of anti-monopoly functions amongst many state organizations.

297. The creation of the National Competition Agency is the first step towards the promotion of a coherent state policy in this area. The National Agency will assume anti-monopoly functions including in the area of natural monopolies. This will allow the concentration of anti-monopoly deregulation functions into one body where core skills and competencies will ensure the uniform application of principles and practices promoting competitive and coherent policies in all sectors of the national economy. The development of new competition laws, including those on natural monopolies, for holdings, and for financial services will increase the number of markets on which anti-monopoly policy will be forcefully applied. Business regulation proposed by national and local public authorities will aim to provide incentives for the encouragement of competition reduce costs and protect consumers' rights.

298. The National Agency will create a web page, which will publish special studies and information materials. This will ensure the transparency of the National Agency's activities. The activity of the Agency will provide equitable conditions for all market participants by establishing clear and single rules of behavior that ensure a competitive environment in accordance with the country's obligations including those undertaken with Moldova's WTO membership, 


\subsubsection{The Optimization and Improvement of Corporate Management}

299. Rapid economic reform has been accompanied by the strengthening of the private property framework, and the development of new types of business organizations. At present corporations in Moldova are mostly small and medium size joint stock companies, in which substantial financial and material assets are concentrated. Such companies comprise $2.6 \%$ of all companies, employ $25.7 \%$ of the total number of employees, and generate $34.8 \%$ of net sales. The company's structure is characterized by an enhanced concentration of share capital. Corporations make an essential contribution to the revenues of the budget, promote the exports of goods and services, and have a positive impact on economic policy.

300. There are, nevertheless a series of constraints to the further development of corporations, including:

i. a low ratio of foreign investments in the capital structure of companies; investing in Moldovan companies is perceived as risky;

ii. lack of banking resources in the financial structure, due to the weak legislation and the inefficiency of corporate management;

iii. lack of protection of minority shareholders' rights;

iv. weak management responsibility and lack of a corporate administration code;

v. weak mobilization of domestic savings for investment;

vi. insufficient protection of investors, lack of transparency and insufficient objective information regarding corporations and the stock exchange market.

301. In addition to the above there are a number of organizational problems including: (i) lack of information and incentives for good corporate administration management; (ii) legal, judicial and public entities' personnel is not sufficiently familiar with the role and regulatory methods of the activities of corporations; (iii) the absence of a traditions in corporate behavior; (iv) an insufficient analysis of the problems of the corporate sector.

302. The objectives of corporate management policy in Moldova are:

i. the creation of transparent and stable relations, which are understood and accepted by all parties and are based on the rules of corporate culture;

ii. the promotion of efficient corporate management through the elimination of administrative restrictions;

iii. the strengthening of the competitiveness of Moldovan corporations and of competition among them;

iv. the creation of a domestic corporate structure which is compatible with international corporate systems;

v. the input in the elimination of corruption.

303. To this end, medium term actions will focus on:

i) preparing the Corporate Administration Code in compliance with international and European principles;

ii) improving the present legal framework and the mechanism for its implementation; 
iii) assuring the coherence of the legal and procedural framework with the judicial branches;

(vi) creating a competitive market environment;

(v) undertaking a constructive dialogue between the public and the private sectors in order to achieve balance between the interests of the Government and the business community, including the participants in corporate relations.

\subsubsection{Suport and Development of Small and Medium-Scale Enterprises}

304. SMEs are vital for attracting the population into economic activity, creating new jobs, supplying the market with goods and services, and encouraging entrepreneurship, regional development and the reduction of poverty.

305. The main transformations that occurred in the economy (including the privatization of state enterprises, the restructuring of many large firms, the agricultural reform, and the establishment of the right to undertake business activities) have established the SME sector as one of the leading sectors of the economy. SMEs employ $29 \%$ of the overall number of employees and account for around $30 \%$ of national sales. Small and micro-enterprises are characterized by relatively high levels of economic efficiency. From the total number of profit making companies, $85 \%$ are small companies, of which $60 \%$ are micro-enterprises.

306. SMEs have particularly consolidated their position in the trade sector, where small capital investments are suitable, and working capital requirements more manageable. In 2003, small trading companies covered $45 \%$ of total national sales and accounted for $96 \%$ of all trading companies. In the processing industry, the share of small businesses in total sales amounts to $16 \%$. Small enterprises account for $87 \%$ of all industrial enterprises and employ $21 \%$ of salaried staff.

307. SMEs are constrained by the difficulties of transition, such as:

(i) the incoherence of policies and the lack of a state strategy regarding SMEs;

(ii) significant administrative barriers (registration, authorization, licensing, large number of controls, based on applying penalties, inefficient leasing/rental relations' regulation, etc.);

(iii) an excessive fiscal burden and a system requiring accounting reports which are cumbersome and expensive;

(iv) difficult access to finance and lack of efficient state support at the initial stage of developing a business;

(v) reduced possibilities to insure loans with collateral, combined with high interest rates at commercial banks, and lack of credit guarantee funds;

(vi) lack of informational and consulting support to develop entrepreneurship abilities, especially at the regional level;

(vii) weak qualification of personnel from small enterprises combined with a low level of preparedness of management and a business culture which is less than fully developed.

308. The objectives for the development and support of SMEs are: (i) to increase the contribution of the SMEs to economic growth and (ii) to strengthen the role of SMEs in job creation and poverty reduction. 
309. Since SMEs are characterized by an increased vulnerability in front of barriers to the business framework they will benefit significantly from the envisaged reform of the regulatory framework. This reform includes the simplification of procedures to obtain approvals, authorizations, certificates and licenses, as well as the integration of these activities into one office (OSSO). At the same time well-coordinated actions will promote the development of the SME sector and facilitate the cooperation with organizations that represent the interests of SMEs at the national and local levels.

310. In the medium term the Ministry of Economy will initiate policies that will promote the development of SMEs and will focus on:

i) reviewing and improving the legal and institutional framework of SMEs with a view to facilitating their creation and development, and promotion on the SMEs concept elaborated in line with best international practice;

ii) facilitating the access of SMEs to finance through a number of specific actions including: the further development of microcredit organizations to increase the offer of micro credits with an accessible interest rate; a more efficient use of financial resources provided by or through the state budget, including financial support from international financial institutions and other donors. To facilitate the access of enterprises to long term financing from the existing commercial system, the conditions necessary for the efficient development of risk capital funds will be created.

iii) improving the access of SMEs to information and consultancy services, developing entrepreneurship initiative and promoting the exchange or relevant experience through the creation of a national network of informational-consulting Centers, business-incubators, with the active participation of the local public authorities, and the attraction of technical assistance;

iv) preparing qualified personnel for SMEs and promoting the development of the country's business culture through placing emphasis on economic education of young people.

\subsubsection{The Promotion of External Trade}

311. Trade development is vital for economic growth. Moldova has a liberal trade regime for both exports and imports. Since independence, the trade balance has been characterized by the persistence of a significant deficit. Between 1995-2003, the trade deficit fluctuated between $6.6 \%$ to $31.3 \%$ of the country's GDP. This negative trend coupled with the rapid extension of globalization requires the reform of the strategies in support of the country's trade interests, through the diversification of trade partners and the promotion of exports with a higher value added.

312. The country's accession to the WTO provides the framework for the further development of trade policy in Moldova. Legal commitments regarding the creation of a well-developed economic system, which will ensure the credibility of external economic transactions, and guarantee the fulfillment of the rules and standards provided under the WTO Agreements. Moldova has undertaken clear commitments in relation to the conduct of economic, including fiscal, policies, customs, the protection of intellectual property rights, standardization and technical barriers, and veterinary and phyto-sanitary measures.

313. With the objective of promoting external trade, the following will be undertaken:

(i) a review of the trade regulatory and legal framework for assuring its stability, accessibility and predictability;

(ii) the removal of existing unjustified non-tariff barriers, and the non-introduction of new ones; 
(iii) the rationalization of regulatory procedures aiming at reducing to a minimum "entry/exit" costs for commercial activities and facilitating international commercial transactions;

(iv) a sustained effort to penetrate external markets,

(v) the optimization of customs' administration for trade.

314. In the medium term, the Government will direct its efforts towards:

i) analyzing and evaluating, jointly with the National Bank of Moldova and financial institutions, the factors that can improve the balance of trade and accelerate the growth of Moldova's export industries, while engaging into a process of systematic consultation with the private sector and professional organizations from the business sector;

ii) publicizing international treaties, which Moldova is party to in the field of trade and economic cooperation, in order to promote the national capital interests through the multilateral and bi-lateral trade tools provided by these treaties;

iii) using the potential offered by the preferential commitments provided by the EU and other developed countries, and analyzing and identifying existing or potential areas of comparative advantage;

iv) increasing the efficiency of Moldova's participation at multilateral negotiations within the WTO, negotiating with the EU a preferential commercial arrangement, increasing the active participation of the country in the regional free trade zone with the countries-beneficiaries of the Stability Pact for the South-Eastern Europe, and renegotiating free-trade agreements with Romania and the Russian Federation;

v) developing the legal and institutional framework for the services sector according to the provisions of the appropriate WTO agreement;

vi) collecting, categorizing and disseminating information regarding the conditions for local goods and services that are required for accessing international markets;

vii) developing modern information systems, which would enhance the visibility of export trade opportunities, especially those of SMEs;

viii) using such modern exports promotion tools as:

- partial support through public resources for the participation of local exporters in fairs, exhibitions and international economic missions;

- providing resources for the promotion and the support of Moldovan exports from the special funds created for this purpose;

- simplifying and standardizing the documentation and reducing the costs of customs' formalities, including the accession to international covenants regarding the facilitation of introduction/temporary exits of products with the purpose to participate in fairs, exhibitions, forums, etc (the ATA convention), as tools to foster exports;

- reducing administrative barriers for exporting: enhancing the procedure of VAT refunds and excises on export, refund of customs duties, reviewing the term and procedure for currency repatriation subject to products/sectors;

- implementing programs of specialized training in the export area (marketing, sales development, strategic planning, export financing etc.); 
- creating the Export Credits Insurance and Guarantee Agency in order to lessen commercial and political risks and facilitate commercial operations, and develop export infrastructure;

ix) encouraging SMEs to creating export alliances that will consolidate and facilitate access of domestic exporters to external markets, new technologies and capital;

315. $x$ ) increasing the efficiency of the Embassies and Commercial Representations of the country abroad for promotion domestic products, offering assistance to export companies, and providing comprehensive information to potential importers .Particular attention will be paid to the Customs Service. Due to its special position, the Service is tied to commerce, and to the diversification and the intensification of commercial exchanges. The mission of the Customs Service is to facilitate trade through the promotion of a transparent and rules-based system of customs clearance aiming at reducing the costs of engaging in trade and facilitating the economy's integration into the international trading system. Over the recent years progress has been registered in reforming and modernizing the Customs Service. Further work will be undertaken in this area given the importance of a WTO-consistent Customs Administration in facilitating trade relations in particular and improving the country's investment climate in general.

316. The strategy will consist of:

- reducing the fiscal role of this institution and emphasizing its regulatory functions with a view to facilitating trade flows;

- more efficient application of legislation through the consolidation of institutional capacities;

- a more efficient control system over prohibited, dangerous, and poor-quality goods, with the purpose of protecting society and the environment;

- the rationalization of the import tax collection system, and the strengthening of procedures for preventing and combating fraud in customs transactions;

- a more efficient provision of public services;

- a sustained effort to eliminate corruption.

317. Medium term priority actions will be:

i. revising customs legislation pertaining to economic agents, and developing an open and transparent cooperation with the commercial sector;

ii. identifying and applying appropriate practices, especially in audit and risk assessment, as well as improving relevant procedures;

iii. introducing an irregularities prevention system, especially through quick information checks at customs points;

iv. standardizing customs procedures and controls and developing operational statistics to facilitate commercial exchange;

v. unifying the tariff classification system in cooperation with relevant institutions to improve customs assessment;

vi. developing information and communication systems for ensuring a continuous access of economic agents to customs, and reviewing the possibilities for promoting the creation of the electronic customs environment; 
vii. developing professional training and re-training with a focus on motivations that will lead to eliminating corruption;

viii. establishing a customs administration performance evaluation system.

\subsubsection{Improving the Investment Environment}

318. Investments are vital for the restructuring of the economy and the introduction of new and appropriate technologies that are conducive to a sustained growth in the economy's productivity, profitability, income and employment. The transition period has been characterized by an acute lack of investment, due, to a large extent, to the negative impact of the $90 \mathrm{~s}$ crisis. Despite a slightly improving trend in the amount of investments in fixed capital since 2001, the share of investments in the country's GDP remains at an extremely low level. In addition, investment activity exhibits significant variability across sector. The major share of investments to date has been directed towards the food and wine industries, and to the energy and communications sectors.

319. Over the last two years the inflow of foreign direct investment was reduced significantly, amounting to only $6.8 \%$ of GDP in 2002 , as compared with $10-10.5 \%$ of the GDP in $2000-2001$. The amount of foreign direct investments attracted in 2002 is 2.6 times lower than the amount of money transfers from migrants employed abroad. The total amount of per capita foreign investments in the between 1993-2002, amounts to around USD 198 annually, compared with annual investment inflows into the countries of South East Europe of USD 444, and East and Central European countries of USD 1,958 per capita. It is evident that Moldova does not meet the criteria needed to attract foreign capital, especially in comparison with countries actively engaged in EU integration.

320. The medium term task is to significantly improve the investment climate in order to accelerate the growth in domestic and foreign private sector investment expenditures. The primary state policy objectives in this area are the maintenance of macro-economic stability and the promotion of public sector reforms and reforms in the regulatory framework that will permit an improvement in the investment environment.

321. At the same time medium term policies will be undertaken in order to introduce qualitative improvements by:

(i) improving legislation regarding guarantees and the protection of the rights of investors and creditors, as well as the protection of the industrial and intellectual property rights;

(ii) refraining from creating barriers to investment activities and eliminating existing impediments on a case-by-case basis;

(iii) improving and adjusting the country's fiscal regime towards local and foreign investors.

322. Implementing the new Law on Investment in Entrepreneurship, which is compatible to the European legislative standards, will permit the formation of more favorable conditions and the introduction of stable legal guarantees for investment activities.

323. Priority actions promoted by the Ministry of Economy will include:

i. continuing the privatization of public assets, including adjacent terrains, with the aim to use those assets more efficiently and attracting investors;

ii. modifying fiscal legislation with a view to improving incentives for local and foreign investors; 
iii. developing the regional infrastructure with the purpose of improving investments at the regional level;

iv. supporting the infrastructural and institutional development of the financial market in order to consolidate the role of the financial sector in the mobilization and circulation of investment resources, as well as reduce investment risks;

v. engaging into a permanent dialogue with representatives of the investor community and business, aiming at addressing existing problems and improving the investment climate;

vi. developing instruments and mechanisms for stimulating banks to offer long term loans, and attracting the savings of the population, including the transfers of the people employed abroad to support investment activity;

vii. creating an efficient system for dissemination of information to foreign and local investors about the opportunities for investment in Moldova.

\subsubsection{Building the Real Estate Cadastre}

324. The real estate cadastre facilitates economic development by means of: a) promoting ownership and security of tenure; b) facilitating the operation of the real estate market; c) supporting land privatization, d) supporting urban planning; e) encouraging private sector development and investment; f) implementing new assessment and taxation systems; j) promoting efficient land administration. Real Estate Cadastre is implemented in accordance with the State Program for Building a System of Real Estate Cadastre approved by the Government in October 1998.

325. Promoting land privatization. The implementation of real estate cadastre in administrative and territorial units across the country has facilitated the (i) allocation of land into private ownership and the (ii) delineation of public municipal and state properties. Over the period $1998-$ 2001 the process of farmland allocation into private ownership was completed with approximately 2.8 million landholding titles being issued. Cadastre surveying works are being performed in communities while local public authorities are completing the process of transferring household plots into private ownership. During 1999 - 2003 cadastral surveys were performed in approximately 500 communities (30\% of the total) with about 500000 landholding titles being issued for household plots.

326. Registration of real estate. According to preliminary data, the total number of properties in the country is estimated at 5,7 million, including 3.0 million agricultural parcels, 2.4 million properties within communities (intravillan), and 0.4 million separate premises. The First Cadastre Project (1999 - 2003) identified and registered approximately 4.2 million real properties, including 2.9 million agricultural parcels, 0.9 million properties within localities and gardens, 0.3 million separate premises.

327. Supporting the real estate market. Real estate market development contributes to economic growth by increasing investments in real estate and facilitating allocation of resources in the most cost-efficient manner. During 1999 - 2003 real estate transactions increased by a factor of 6.5 . (with 23.000 transactions registered in 1999 compared to 150.000 in 2003). The number of mortgages secured with real estate has increased by 10 times (from 1000 registered mortgages in 1999 to 10.000 in 2003).

328. Supporting the new system of property assessment and taxation. Taxation assists in improving local government's capacities to generate revenues, which can, in turn, be used to fund 
community projects. The appraisal of real estate for taxation shall be performed in accordance with the Action Program for Implementing the New Evaluation System for Taxation approved by Government Decision in June 2003, and will serve as the groundwork for implementing the new taxation system.

329. Rural development and urban planning. The Cadastre is a unified system for the registration of lands and constructions and provides information for (i) arranging of agricultural parcels (land consolidation, correction of errors in land planning projects), (ii) supporting urban planning and real estate taxation and, thus, enhancing economic growth.

330. Poverty related aspects. The Cadastre has a direct impact on the poor, by protecting property rights through the provision of free land titles and property registration, thus assisting in raising capital by mortgaging real estate and allowing for improved living conditions.

331. Main medium-term objectives in cadastre are:

- To improve the unified national system of real estate registration;

- To complete land privatization in order to facilitate the development of the real estate market;

- To implement the new system of mass appraisal for taxation;

- To ensure the financial and institutional sustainability of national cadastre.

332. Medium term key actions are:

i. final drafting of laws and regulations covering property registration aimed at supporting the real estate market;

ii. completing the transfer of parcels into private ownership;

iii. primary mass registering of properties and assets therein;

iv. completing the appraisal of (a) all apartments and individual residential houses in urban areas and

(b) commercial, industrial and manufacturing properties, for taxation purposes;

v. reorganizing the system of cadastre bodies and creating a specialized cadastre company;

vi. creating an integrated information system of cadastre and making it available to different users.

vii. providing public information and training staff.

\section{Situation Analysis}

\subsection{FINANCE SECTOR}

333. The development of the financial sector is needed to meet the demands of the economy for quality financial services and financial infrastructure, and to ensure the efficient implementation of the state economic and social policies.

334. The most developed segment of the financial infrastructure is the banking sector with its 16 commercial banks. On the whole, the banking sector is developing in a stable way and its role in the economy is growing. In 2000-2003 the rate of growth of bank resources was higher than that of GDP, with the result that the ratio of bank resources to GDP rose from $29.1 \%$ at the end of 2000 to $37.7 \%$ at the end of 2003. The amount of deposits for this period rose 2.8 times, which is indicative of 
growing confidence of depositors in the banking system. At the same time the level of lending to the economy by banks remains relatively small - in 2003 it was $22 \%$ of GDP.

335. The NBM monetary program envisages further continuous growth in economy crediting by commercial banks. It is expected that the rate of crediting growth will continue to be ahead of that of GDP, and that the role of bank crediting in support of economic growth will increase. In this context, there is a need for better coordination of monetary and economic policies between NBM and Government. Not only macroeconomic policy needs coordination, but also actions connected with the improvement of credit terms, the preservation of the banking system's stability, and minimizing bank risks.

\section{Objectives}

336. For the stable development of the banking system and growth of its role in sustained economic growth, the NBM will implement measures which will aim to:

- further consolidation of banks' capital by raising minimum capital requirements;

- improvement of the process of supervision and regulation of banking activity;

- development of internal bank audits system to reduce risks;

- insurance of transparency of information on banking sector activity.

\section{Strategy and Priority Actions}

337. The development of the small business and farming sector requires availability of small credits. Opportunities for borrowing from banks at the moment are very limited due to collateral difficulties, and a lack of interest of banks to work with small borrowers because of the high costs of administration and control of loan repayments, and of legal action in the case of forced debt recovery. In the area of microcredit, about 500 savings and loan associations have been established and are being developed with the logistic and financial support of international organizations. However, loan sizes are small, USD 300 per loan on average, the variety of services being limited.

338. The priorities for sustainable development of citizens' savings and loan associations are:

i) institutional development of associations and their transformation in professional institutions of micro-financing, which offer a large spectrum of services;

ii) a larger attraction of members' saving deposits;

iii) consolidation and strengthening of the financial stability of the associations' system through capitalization, enough to cover undertaken risks;

iv) development of internal control in associations to prevent and control risks;

v) consolidation of the regulatory and supervision capacities of associations' activity and a continuous efficient supervision, in order to protect the interests of depositors and nonadmission of system risks;

vi) establishment of the guarantee fund for deposits in the micro-financing system.

339. There are around 50 companies in the insurance market of Moldova. Though demand for insurance services is growing, this segment of the financial market is rather poorly developed. Insurance premiums account for only $1 \%$ of GDP. Financial potential for insurance companies in terms of coverage of big losses, as well as their investment opportunities, is insufficient.

340. The market for insurance services must be more actively involved in the protection of population and business from potential risks and in the creation of long-term investment resources. The following actions measures must be implemented for this: 
- consolidate the insurance market by increasing the minimal charter capital of insurance organizations;

- rationalize the process of regulation and supervision, in order to comply with liquidity requirements of insurance companies;

- permanent monitoring of the financial state of insurance organizations.

341. The Republic of Moldova's stock market is developing slowly. At the moment there are 109 professional participants in it. The State Securities Register has 3,342 registered joint stock companies, with securities issued by them accounting for $72 \%$ of GDP. At the end of 2002 , capitalization on the stock market exchange was $24 \%$ of GDP, and for the corporate market was $68 \%$. After a sharp decline in activity in 2000 the stock market is gradually recovering. Yet the total number of registered issues and transactions in 2003 was less than in 2000.

342. The main obstacles to the development of the stock market are: low market liquidity, insufficient foreign and domestic investments, a falling number and volume of securities issues, and unsatisfactory corporate management. The above obstacles are caused by the low financial and economic activity of issuers, low level of development of financial instruments, limited financial resources of the population, low return on securities, and absence of the effective system for informing investors and public. Another problem is the activity of investment funds established in the period of patrimony bond privatization (the number of their shareholders at the end 2003 totaled 1.5 million), and trust companies.

343. In the medium term, the role of the stock market in the attraction of investment and efficient capital movement must significantly increase. To attain this, the following tasks should be the main focus:

i) optimizing the mechanisms for the attraction of investment through the stock market;

ii) raising the level of protection of rights and interests of investors and shareholders;

iii) increasing stock market transparency.

344. To address these, priority actions will be to:

i) improve the legal and regulatory framework for the development of new investment institutions;

ii) create conditions for the implementation of new financial instruments;

iii) implement the national informational system on the securities market;

iv) simplify the procedures used in making emissions and market transactions;

v) optimize mechanisms of control and supervision of the activity of participants in the securities market.

\subsection{INDUSTRY}

\section{Situation Analysis}

345. Sustainable economic growth and poverty reduction require restructuring the economy through overcoming its dependency on the agricultural sector, which is characterized by low productivity. The industrial sector has a key-role in ensuring highly productive jobs and increasing the population's incomes. The sustainable development of this sector requires the involvement of qualified staff, which, in turn, is indicative of the need to strengthen their qualifications and improve the quality of human resources in general.

346. Throughout the 90 s the industry remained in a deep crisis, and the volume of industrial production decreased by almost three times. During 2000-2003 high industrial production growth rates were recorded following the recession that took place in 1998-1999. 
347. At present the private sector is dominant in the industrial sector with a share of $92 \%$ in total production, while enterprises with foreign capital enterprises account fro $26 \%$. Despite progress in the reform of sector and the recent high growth rates of, there remain impediments hindering its further development. Presently, the processing industry's share in GDP is of only $15.7 \%$, and the number of employees accounts for only $9.4 \%$ of total employment.

348. The structure of industrial production is not sufficiently diversified. The main part of the sector (accounting for 50\% in 2002) was represented by production of food and drinks, obtained from processing raw agricultural material. Investments in food and drinks enterprises account for the largest share of investments in processing industry, at around $62 \%$ of the total amount in 2002 . At the same time, the weight of other branches remains low. Thus, machinery and equipment producers accounted for less than $6 \%$ of production amount and less than $3 \%$ of investment made in the processing industry in 2002. The chronic lack of necessary investment has generated a considerable degradation of fixed assets in many enterprises (with depreciation in a number of enterprises reaching 80-90\%). Equipment wear-off and obsolete technologies lead to excessive consumption of raw material and other inputs including energy, thus reducing productivity and competitiveness. The largest part of producers is concentrated in the country's capital, which accounts for around $60 \%$ of total industrial production. The economic backwardness of regions is caused to a great extent by the insufficient development of industry in the country's territories, which hampers the economic and social development of Moldova's regions.

349. The transition to a market economy for many enterprises was not associated with changes in organization and management and the introduction of quality corporate management. In some enterprises the processes of restructuring and privatization are not fully completed.

350. Policy co-ordination among public institutions is weak. At present the responsibility for setting policies affecting the development of different industrial sectors (such as branch of food and drinks products, construction materials and other types of products) is divided among three ministries. To enhance competitiveness, attract investments, increase labor productivity, and introduce new technologies it is necessary to efficiently co-ordinate the policy actions of various ministries and departments.

\section{Objectives}

351. The medium term objectives of industry development include:

- the sustainable increase in industrial output and its contribution to economic growth and employment;

- the diversification of industrial production based on the development of branches that are not directly linked with processing raw agricultural material;

- the quality improvement of industrial production activity components (such as management, product competitiveness, and the technology used);

- the accelerated development of industrial production in regions to contribute to the recovery of regional economies and the reduction of poverty in territories.

\section{Long Term Strategy}

352. To successfully address the above-mentioned issues it is necessary to develop a clear and efficient state industrial policy conducive to promoting investment and innovation, and taking into account regional and external trade policies, and the envisaged reform of regulatory framework to 
promote private sector activity. It is also necessary to efficiently co-ordinate the activities of ministries, and local public authorities to establish and promote a comprehensive industrial policy.

\section{Priority Actions 2004-2006}

353. The main measures of industrial policy will include:

i) accelerating the privatization and restructuring processes for industrial enterprises, including bankruptcy procedures of inefficient and insolvent enterprises;

ii) drafting and implementing development programs for certain industrial sectors in order to attract investments and identification and implementation of concrete measures to increase investment attractiveness of sectors and enterprises;

iii) creating the necessary legal base for the creation of industrial parks and the encouragement of technological innovations to support production based on advanced technologies;

iv) providing legislative support to the industrial capital consolidation process, and the formation and development of different forms of associations;

v) developing the infrastructure of industrial production, export promotion, of provision of information and consulting services;

vi) developing the program of implementing integrated systems of quality management, adjusted to international standards requirements;

vii) examine, together with the Ministry of Finance and the Ministry of Economy, possibilities for creating an Industrial Investment Bank with joint private and state capital.

\section{Situation Analysis}

\subsection{RESEARCH AND INNOVATION}

354. The development of innovation is a requirement for the modernization of the economy's technological base and its structure. The technologic discrepancy between the national economy and advanced countries is constantly increasing, as a result of low innovational activity. The share of budget expenditures for science in relation to GDP has decreased from $0.76 \%$ in 1991 to $0.2 \%$ in 2002. This level is not only significantly lower than the level of financing in developed countries (Japan $-3.6 \%$, USA $-2.84 \%$, Germany $-2.29 \%$, France $-2.18 \%$ ), but is also lower in comparison to other formerly command economies (Czech Republic $-1.26 \%$, Hungary $-1.1 \%$, Ukraine $1.1 \%$, Russia $-0.85 \%$, Romania $-0.54 \%$ ).

355. The technical-material base of research institutions is morally and physically outdated. Over the period 2000-2002 the number of research-development institutions decreased from 83 to 76 units, and the number of scientific researchers dropped by $22 \%$. The number of technologicalscientific developments regarding the creation of new types of materials, equipment and test samples is permanently reducing. Only during 2000-2001 the share of designing, building, technology as well as producing experimental articles samples (lots) in the total volume of scientific and research works decreased from $36.6 \%$ to $20.1 \%$.

356. The innovational infrastructure and technological transfer have been largely destroyed. Large enterprises that were realizing the innovational cycle in the 90 s have been liquidated, or have ceased to exist due to insufficiency of finances. Most of economic agents are not interested to make long term investments in research and implementation of innovations, due to the increased level of financial risk. The intellectual potential for research and innovation sphere (researchers, inventors, 
engineers, patenting services employees, and others.) is to a large extent idle, which leads to its fast degradation.

357. Given the importance of developing research and innovation area in ensuring the sustainable growth and competitiveness of the national economy, the country's leadership has adopted a series of legislative acts and strategic documents aimed at improving the created situation. These include those adopted with regard to the Academy of Sciences of Moldova, the state policy in researchdevelopment, the state policy for innovation and technological transfer, the approval of Strategic Priorities of research-development for 2004-2010, and the Strategy for development of the national system of protection and use of intellectual property objects until 2010.

\section{Objectives}

358. The main state policy objectives in the area of research and innovations include:

i) raising the level of research-development;

ii) efficiently using technological-scientific results in the economy;

iii) developing the innovational sector based on selling research-development works and their results;

iv) making use of the existing intellectual potential from the area of research and innovations, as well as further increasing of this potential.

\section{Priority Strategy and Actions}

359. The priority measures of the development policy in research and innovations are the:

i) harmonization of national legislation in the area of intellectual property protection with stipulations of international agreements and conventions, to which Moldova is a signatory, and strengthening the control and responsibility for illegal use of intellectual property objects;

ii) developing legal and organizational measures for transfer of rights over intellectual property, constituted from budgetary means, to organizations that possess this work;

iii) developing the legal and normative base and organizing attestations for state scientific research institutions, reorganizing or liquidating institutions that have lost their scientific potential and do not have sufficient human and technical-material resources;

iv) completing an inventory of state scientific research institutions patrimony, selling unused goods and using the proceeds for the improvement of the research technical-material base;

v) developing and adopting a legal base for regulating the creation and functioning of modern infrastructure of research and innovations, including specialized financial institutions, funds and agencies, innovational parks, and business-incubators;

vi) extending and modernizing the system of statistical record-keeping indices of research and innovational activities and inventory of intellectual property objectives, innovational programs and projects;

vii) implementing mechanisms for reducing the risk associated with the development and implementation of innovations;

viii) improving procedures of amortization and taxation of intellectual property objects and other results of innovational activity, evaluation and inclusion of these objects in the 
statutory capital of legal entities;

ix) developing certain legal and organizational measures for the development of leasing for modern unique equipment and devices for scientific purpose, used to realize scientific research and to implement innovational programs and projects;

$\mathrm{x})$ creating a unique electronic data base that would ensure the registration of innovations, intellectual property objects, as well as the performance of technological expertise and of know-how for patenting purposes;

xi) training and re-training of innovation specialists, by providing support from the state for these activities to higher education institutions;

xii) improving study programs in the area of higher and post-graduate education according to European and international standards of staff training for research and innovations.

360. Special attention will be given to the development of small enterprises that have the necessary flexibility for performing innovational activities and adapting to fast changing market conditions. This will include:

i) the implementation of mechanisms for transmitting, or making available in preferential conditions, public patrimony and/or land for creating small innovational enterprises;

ii) the usage of special crediting regimes for innovational activities performed within small enterprises;

iii) the implementation of a special taxation regime for small innovational enterprises.

\subsection{INFRASTRUCTURE DEVELOPMENT}

\subsubsection{Energy}

\section{Situation Analysis}

361. The current situation in the energy sector reflects the difficulties associated with the process of reform and the application of market principles in the sector. The country's energy sector is developing in a context of an almost complete absence of primary energy resources (98\% of consumed energy resources are imported) and sizable foreign debts to suppliers. The main fuel for the country is natural gas $(80 \%)$.

362. The major problems in the development of the energy sector are associated with the inappropriate technical and financial structures of many energy sector enterprises, as well as with insufficiently effective organization of energy supply and energy consumption. These problems manifest themselves in:

i) high depreciation levels of energy equipment and power lines (up to 70\%); complete degradation of heating systems (only in 17 cities out of 42 have working heating supply systems);

ii) low utilization coefficient of technical-industrial equipment and high voltage electricity network with a trend of falling consumption of power, heat energy and natural gas;

iii) high level of energy losses (the electricity losses amount up to 53\%);

iv) large debts of the population, economic agents and budgetary institutions for consumed energy due to their low paying capacity; 
v) absence of an efficient reporting system for energy resources consumed;

vi) reduced access of population to the main fuel source - natural gas (only $35 \%$ of localities are connected to the gas network).

\section{Objectives}

363. The objectives of the medium-term energy policy are to enhance energy security of the country and to create an environment for efficient and stable development of the sector.

\section{Long Term Strategy}

364. To solve the problems and tasks specific to the energy sector, the following measures will be implemented:

a) in the power engineering sector: i) continuous development of the energy market and promotion of competition; ii) enhancement of reliability of power supplies by connecting internal networks to regional and international networks; iii) combating thefts of power by means of regulatory enforcement and introduction of special measures.

b) in the thermal energy sector: i) providing all consumers with individual meters; ii) promoting actions for energy conservation, reduction of losses during delivery and consumption; iii) implementing the program for modernization and decentralization of heating system of inhabited localities.

c) in the gas supply sector: i) development of the system of gas main and distribution pipelines in accordance with the Republic of Moldova's Gasification Program; ii) introduction of the National Reporting System for imports and transit of natural gas.

365. In order to diversify imports of energy resources and promote the development of international cooperation in the energy field, the following are envisaged:

i) participation in the energy activities and programs/projects of international structures interested in the development and coordination of regional energy policies;

ii) bilateral and multilateral cooperation with the countries of the region with the aim of the creation of the efficient and transparent regional energy market;

iii) elaboration of an Action Plan for the country's participation in the regional energy market of the South-Eastern Europe.

\section{Priority Actions 2004-2006}

366. The priorities for the medium-term development of the energy sector are:

- accelerated gasification of the country;

- diversification of imports of energy resources and liberalization of power, natural gas and heat energy markets;

- implementation of a modern heating systems in 19 cities - raion centers;

- improvement of the market infrastructure and enhancement of commercial discipline in the energy sector (decentralization of apartment blocks' heating systems); 
- increase in the efficiency of the operation of all energy sectors and promotion of energy conservation measures.

367. To implement the above tasks the following measures will be undertaken:

i. adjusting long term energy sector development programs to the provisions of the Republic of Moldova's Energy Development Concept until 2010. The energy programs will be coordinated with the general strategy of the republic's economic and social development;

ii. restructuring the energy sector; attracting private capital, including through privatization;

iii. attracting external financial means, including grants, for the promotion of gasification and renovation of localities heating systems' programs;

iv. improving the regulatory framework for the functioning of the energy sector to ensure conditions for the development of the energy market and creation of a competitive environment;

v. improving the level of payments from households, business and public sector for consumed energy resources, including through the implementation of an efficient policy for social protection of most vulnerable groups of the population;

vi. raising the share of non-traditional sources of energy (such as solar, wind, biogas).

\subsubsection{Roads and Transport}

\section{Situation Analysis}

368. Road and rail transport is an essential component of the economic and social development process, often absorbing a high proportion of national expenditures. Transport promotes the development by facilitating trade, both national and international, and by improving the access of population to workplaces, education, health care and other services. An efficient transport infrastructure facilitates mobility, reduces transport costs and is associated with large positive externalities.

369. The depreciation of Moldova's transportation infrastructure over the transition period with reduced renovation opportunities has reduced significantly the quality of transportation services and has contributed to rising costs due to the increase in operational expenses. The network of public roads is rapidly and continuously deteriorating due to the limited investment undertaken over recent years. In order to maintain the public roads network in their existing technical state, around USD 27 30 million are needed annually. Over the period 1999-2003 only USD 6.9 million, or approximately 0.46 percent of GDP, was spent annually on the repair and maintenance of roads.

370. Out of the full length of 3,325 km of national roads, 2,885 km have passed their economic life span, of which over $900 \mathrm{~km}$ are in a very bad technical condition. The local roads network of $6,137 \mathrm{~km}$ is very heterogeneous. Thus, $2,781 \mathrm{~km}$ are paved roads, $579 \mathrm{~km}$ are unpaved roads, and out of 2,777 km of modern covered roads, 2,253 km have exceeded their economic life (of which 2000 $\mathrm{km}$ are in a bad technical condition).

371. Over 40 localities have weak access to the public transport network, and in adverse weather conditions become isolated, with negative economic and social consequences. At the present time, 26 sections of national roads and 79 sections of local roads, totaling $13.5 \mathrm{~km}$, are affected by landslides. On the public roads network there are 14 damaged bridges, which presents a serious threat to the road traffic. 
372. The estimated Vehicle Operation Costs (VOC) in 2002 in Moldova clearly demonstrate the poor quality of road infrastructure. VOC road users spend at least USD 25-30 million annually, which severely affects the mobility of goods and persons, especially in rural and poor areas. According to international estimates, every dollar spent to improve roads saves road users between USD 3 to 5 every year. At the same time, the maintenance of the road network at its current state requires almost four times more finance than what is currently available.

373. The mainline rail transport of the Republic of Moldova is a natural monopoly owned by the state enterprise "Calea Ferata din Moldova" (CFM - Moldovan Rail Road). CFM is an integrated monopolist managing the sector's capacity, infrastructure and services. On January $1^{\text {st }} 2003$ the Republic of Moldova's railway network accounted for 2,6 km per 10 thousands inhabitants. The total length of rail lines is of $2172 \mathrm{~km}$, of which $1121 \mathrm{~km}$ are currently in use, including $1107 \mathrm{~km}$ with large gauge $(1520 \mathrm{~mm})$. The CFM network has no electrified lines.

374. The rehabilitation of main rail lines is not adequately carried out (capital repairs in 2002 were undertaken for only $43.6 \mathrm{~km}$, while the normative requirement is around $80 \mathrm{~km}$ annually ${ }^{3}$ ). Their modernization to European standards (including the increase in train speed on conventional railways of up to $160 \mathrm{~km} / \mathrm{h}$, the electrification of mainlines, the renewal of the rolling stock fleet, and the upgrading of the informational system) is hampered by lack of finance.

375. At the present time, CFM works profitably within the framework set in the Memorandum Agreement with the Council of Creditors, signed in August 2000. This stipulates a phased payment of historic debts and the restructuring of the enterprise. During 2000-2002 the stabilization of passenger traffic to a level of 355 thousands passengers-km and an increase of merchandise up to 2751.4 net tones-km, was achieved following several years of dramatic decrease. The financial results achieved over the 3 years of CFM's activity under the Memorandum agreement allow for moderate optimism.

\section{Objectives}

376. Main medium term objectives in the transport sector are:

i) To improve access to economic and social services through rehabilitation of roads and rail roads, as well as extend the national and local roads network; ii) To raise the efficiency and quality of transportation services by developing and modernizing the transport infrastructure, by capitalizing on opportunities offered by membership of the Stability Pact for South-Eastern Europe and cross-border cooperation within euro-regions;

iii) To improve security and safety in transport activities and ensure environment protection;

iv) To facilitate international trade and economic activities by integrating arterial roads and railways into the European system and into international transport corridor systems.

\section{Priority Actions 2004-2006}

377. Priority actions for improving the situation in the road sector are:

i. the design and implementation of a program of works for arresting the degradation process of the road network, that, taking into account the available financial means, will provide for an increase in the volume of light periodic maintenance works (bitumen treatment, bitumen singlelayer covers, in "situ" recycling of degraded asphalt cover, etc);

ii. the creation of a sustainable and transparent system of finances accumulation, management and use, in order to ensure continuous maintenance of roads network;

\footnotetext{
${ }^{3}$ According to the calculation of the Tacis project CFM Restructuring, November 2002
} 
iii. the implementation of regional projects, including through contracting external credits and grants to improve access to markets and social services for the rural population;

iv. the implementation of modern systems of road condition technical evaluation and the rationalization of maintenance and repair priorities;

v. the implementation, within the Stability Pact for South-Eastern Europe, of the ChisinauGiurguilesti road rehabilitation project;

vi. the initiation of negotiations with international financial organizations (EBRD, WB, EIB) regarding contracting in advantageous conditions loans for the rehabilitation of national roads (with the priority of pan-European Corridors) and the beginning of rehabilitation works of roads included in the first stage of rehabilitation (covering around $400 \mathrm{~km}$ ).

378. Priority measures for rail transport are:

i. the rehabilitation of the railroad network to the level of projected and safety parameters, through maintaining capital repair cycles of railroad infrastructure depending on wear (covering around $80 \mathrm{~km}$ of railroad annually);

ii. the implementation until 1 August 2005 of the conditions of the Memorandum Agreement between the Council of Creditors and CFM, regarding the enterprise financial situation;

iii. the phased payment of CFM debts towards the rail roads of Russia;

iv. the realization of the existing CFM Restructuring Plan, by separating the management of rail infrastructure from the management of transport services;

v. the divestment of socio-cultural and communal possessions and auxiliary enterprises from the CFM structure;

vi. the introduction of an information system for international train schedules;

vii. the renovation of the passenger rail carriages and diesel trains fleet;

viii. the development necessary investment projects and the attraction of investments for their realization.

\subsubsection{Water Supply and Sewerage}

\section{Situation Analysis}

379. A quality water supply and an efficient system of wastewater treatment affect the quality of life and the population's healthcare. Over the past ten years the water supply and sewerage sectors have increasingly degraded. Currently, over $50 \%$ of the population use drinking water that does not comply with sanitary norms due to water depletion and worsening quality of water resources, the absence or unsatisfactory condition of water treatment systems.

380. Between 1970 and 1980, 1038 central water supply and sewerage systems were built in 1,533 localities. Because of the long period of use, most pipeline networks need replacement and modernization. Losses of drinking water average 30\% (while in some localities are up to $70 \%$ ). The efficiency of the 'well-pump' system is $40-50 \%$, which leads to overspending on power by $15-20 \%$. Water treatment equipment needs renovation and repair in order to reduce power costs which average $34 \%$ of operational expenses. Water treatment technology must also be modernized. 
381. Only $17 \%$ of rural residents have access to centralized water supply. Around $67 \%$ of rural water supply pipelines do not meet hygienic requirements and are in unsatisfactory condition. The rest of the rural population use wells and springs. More than $80 \%$ of wells and $50 \%$ of springs are unfit as drinking water sources. The existing wastewater treatment systems are not operational because they are switched off from power, destroyed or stolen.

382. Tariffs for water supply and sewerage are another issue, which needs to be addressed. The existing tariffs do not cover the financial resources needed to maintain and develop the sector's enterprises. At the same time the low level of population, economic agents and public entities pay capacity and discipline determines the increase of debts and aggravates the financial position of the sector's enterprises.

\section{Objectives}

383. Taking into account the need to facilitate access of the population to safe drinking water and better sewerage as stipulated in the Millennium Development Goals, the objectives for the development of the sector, are:

i) to increase access to drinking water sources and to improve water supply and sewerage service quality;

ii) to improve environmental protection and the protection of water supply from pollution and depletion;

iii) to save water and energy resources;

iv) to rationalize tariffs for water supply and sewerage services.

384. To achieve the $10^{\text {th }}$ goal of the Millennium Development Goals, namely: to reduce by half by 2015 the number of persons without sustainable access to water, the strategy envisages that the ratio of the population with sustainable access to improved water sources will increase from $38.5 \%$ in 2002 to $68.5 \%$ in 2006 . To achieve the $11^{\text {th }}$ goal, namely: to significantly improve by 2020 the living conditions of persons from poor areas, the strategy envisages that the ratio of population with access to improved sewerage will increase from $40.0 \%$ in 2001 to $90.0 \%$ in 2006 .

\section{Strategy and Priority Actions}

385. To improve the quality of services and to increase the number of consumers, it is planned to:

i. develop and modernize water supply and sewerage systems in 156 localities,

ii. rehabilitate of 93,300 rural wells,

iii. develop and introduce pilot projects for ground water treatment with elimination of nitrates and sulphates by biological methods;

iv. introduce a pilot project for mechanical and biological wastewater treatment.

386. In the field of environmental protection and water saving, it is planned to:

i. improve the routine monitoring of the level and quality of ground water, and improve assessment of groundwater usage,

ii. prepare and implement a set of measures for efficient surface water drainage, 
iii. restore and establish new water protection areas, river bank water protection belts and sanitary zones.

387. In the field of tariff policy it is planned to:

i. provide water consumption meters to all consumers;

ii. prepare a uniform methodology of tariff computation and review the possibilities for differentiated tariffs and moving towards real cost recovery;

iii. ensure transparency when resetting tariffs through publicity campaigns;

iv. improve the legal and normative framework of consumer - supplier relations concerning water supply and toughen the requirements vis-à-vis the debtors, and increase the level of payment for consumed water.

388. The improvement of the legislative and regulatory basis for the functioning of the sector's enterprises, includes:

- bringing the existing legislation, standards and regulations on water supply and sewerage in line with the European and international standards;

- improving the legal and regulatory framework to attract private capital to the sector in the form of concessions, rents, trust management, and joint ventures, including privatization of central water supply and sewerage systems;

- implementing services of technical audit of water supply and sewerage systems.

\subsubsection{Telecommunications and Information Technologies}

\section{Situation Analysis}

389. An efficient telecommunication and information technologies sector could have a substantial impact on the pace and quality of economic growth and the population's living standards. The inefficient development and operation of telecommunication and information technologies in Moldova is one of the factors constraining growth of business activity and undermining the development of foreign trade and investment attraction. At present, there are no communities in Moldova, which do not have access to the fixed telecommunication network, nevertheless in 597 localities there are no payphones and in 235 there are no telephones in public places. The level of access to the fixed telephone system in rural areas is only $12.6 \%$. About $10 \%$ of the country's population has no access to the three TV stations with national coverage. Moldova lags well behind the countries of the Central and Southeast Europe in telephone access (including mobile communication), quality and the hardware of telecommunication networks and systems. The average phone coverage of country is of the order of 21.4 fixed phones per hundred residents, and mobile phone coverage has reached 14 phones per 100 residents. The share of optic fiber lines in the total length of long-distance lines is approximately $50 \%$, while the share of digital telephone exchanges in the total capacity of automatic telephone exchanges is about $52 \%$ (this share being lower in rural than in urban areas).

390. A little progress has been made in the use of information technology, which varies considerably across the different sectors of the economy. Access of the population to ICT and the level of development of ICT infrastructure in Moldova is 2 times lower than in Russia and 6 times lower than in Estonia, although the situation was almost the same in the early 1990s. 
391. The main reasons are:

- the monopoly of the state enterprise "MoldTelecom", and its policy of cross-subsidy of tariffs;

- the lack of resources for the development of the sector at the national and local levels;

- the weakness of the legal framework relating to the use of information technologies;

- the incomplete compliance of national telecommunication rules, regulations and procedures with the requirements of the free market.

392. Realizing the importance of developing the telecommunication and information technologies sector, the Government is undertaking a number of measures for their improvement. A National Telecommunications Policy has been prepared and a National Agency on Regulation of Telecommunications and IT Issues has been created. A number of changes have been made in the regulation of the telecommunication market. MoldTelecom has started re-balancing the tariffs for its services. The National Numbering Plan has been introduced.

\section{Objectives}

393. The main objectives for telecommunications and information technologies sector are:

- to improve the quality and access for consumers to information and telecommunication services;

- to liberalize the telecommunications market;

- to create the preconditions for the establishment of the information society;

- to develop international cooperation in the field of telecommunications and information technologies.

\section{Strategy and Priority Actions}

394. To achieve these objectives, the measures will be taken to:

i) harmonize national legislation, special rules, regulations and procedures with the standards of the EU, WTO and the European Conference of Postal and Telecommunications Administrations.

ii) draft and adopt laws on the "protection of personal data", on "circulation of electronic documents and digital signature", and on "electronic commerce and electronic contracts";

iii) develop networks (including optic fiber networks) and upgrade telecommunication systems based on private investment;

iv) increase the transit traffic through national networks;

v) finalize the introduction of the National Numbering Plan;

vi) finalize the re-balancing of MoldTelecom tariffs and facilitate the access of the poor population to its services;

vii) privatize MoldTelecom;

viii) consider the possibilities for introducing of a minimum service package, affordable to all consumer categories, and offering a mechanism for the financial compensations for operators (Universal Service and Universal Service Fund); 
ix) draft the National Strategy "Information society technologies for development";

$\mathrm{x}$ ) develop and introduce a pilot project for the creation of seven collective access points on the basis of post offices, schools, libraries, etc.;

xi) develop a program for introduction of ICT for public authorities to increase the efficiency and transparency of public administration.

395. Priorities areas for the development of international cooperation in the field of telecommunications and information technologies are the participation in the EU programs for the development of an information society, and the cooperation with the countries in the region.

\subsubsection{Housing}

\section{Situation Analysis}

396. According to statistical data, there are 82,000 families listed for receiving a dwelling or housing improvement (of which 81,100 in urban areas and 900 in rural areas). In urban areas more than $30 \%$ of the available housing were built 35-40 years ago. Over the last decade, the housing stock has deteriorated significantly and the living conditions of the majority of the population, especially of the poor, have worsened.

397. There has been a steep decline in the number of new constructions and major repairs. In 2002 the number of new constructions decreased by more than three times, while major repairs decreased by 1.5 times, compared to 1995 . The incidence and quality of minor repairs of buildings and dwellings has also decreased.

398. The main causes of the current situation are: the impossibility to finance housing construction and repairing from state and local budgets, as well as insufficient readiness of the population to maintain their dwelling places in conditions of market economy. These have been accompanied by:

i. a rapid increase in the costs of construction, repairs and building materials;

ii. the termination of state budget financed constructions and the reduction in public financing for capital and current repairs of the public housing fund;

iii. lack of financial resources among the population, in particular among vulnerable groups;

iv. ineffective use of current legislation on condominiums and housing fund;

v. lack of a legal framework on mortgage crediting in housing;

vi. lack of a legal framework for "social housing".

399. The need for additional expenditures to increase the life span of buildings and to ensure safety against dangerous geological impacts complicates the situation in the sector. At present, there are over 130 buildings (especially dwellings) under threat of floods and flooding and over 150 thousand under threat of landslides. The resistance of buildings also deteriorated as a result of seismic activity in $1976-1992$.

400. Given the importance of solving housing problems the Government has recently adopted a number of documents and programs: "National Housing Concept, Strategy of housing space market and other real estate", "On the protection of settlements against dangerous geological processes", "On reconstruction and heating rehabilitation for existing houses", and "On housing benefits and credits". 
A National Housing Agency was created, aiming primarily at developing the market for housing construction and improving financial relations in this area, the main Agency's attributions being to draft normative acts for its activity. Actions are being taken to ensure the effective functioning of the cadastral system to support the housing market and housing construction (see section "Creation of real estate cadastre" of the EGPRSP).

\section{Objectives}

401. In light of the need to address the issues stipulated in the Millennium Development Goals, the main objectives of the development of the housing sector for the medium-term period are the following:

- to improve the access of the population, especially of socially-vulnerable groups, to housing;

- to increase the durability and amenity of existing housing.

\section{Strategy and priority actions for 2004-2006}

402. To achieve the above-mentioned objectives, the following major measures will be taken:

i) develop state "social housing" policy to avoid distortions in the efficient working of the housing property market;

ii) improve the legal and regulatory frameworks and create an infrastructure attracting means in the field of mortgage lending for housing building, reconstruction and purchase;

iii) improve the regulatory framework, and its mechanisms and apply it to condominiums and create owners associations;

iv) approve and implement the state Program for completion of unfinished apartment buildings;

v) develop and implement pilot-projects for upgrading and rehabilitation of existing housing.

\subsection{AGRI-FOOD SECTOR AND RURAL DEVELOPMENT}

\section{Situation analysis}

403. The dominance of agriculture in Moldova's economy derives from its moderate climate and fertile soils. Cernoziom, which are among the most fertile soils in the world, cover $80 \%$ of the land area. Important products include fruits, vegetables, tobacco, grapes, sunflower, winter wheat, corn and animal products. The production of such a variety is due to fertile soils and rich labor resources.

404. These factors and the decline of the non-food industrial sector, has resulted in Moldovan agriculture and food industry accounting together for approximately $33 \%$ of the GDP and for about $65 \%$ of total exports. Moldova has no production capacity for inorganic fertilizers, pesticides, mineral or vitamin nutrition additives, veterinary medicines or fuels, and consequently the country relies on imports of these commodities. Thus the Moldovan economy is necessarily an open one. Because of the importance of trade in the agricultural economy, the relatively faster rise in prices of imported commodities relative to the rise of prices for exported commodities has led to the need for very large adjustments in the sector. 
405. Moldova's agricultural sector has suffered a decline in total volumes of agricultural production and productivity. According to official statistics, agricultural production fell by about $35 \%$ in the first half of the 1990 's and by $20 \%$ in the second half, now being less than half of its 1989 -1991 level.

406. The decline is mainly the result of decreased productivity, as total agricultural area has not changed significantly. Yields depending on crop are 20-60\% lower, than the 1989-1991 levels. Labor productivity has also declined. According to official statistics, value added per person in agriculture is about US $\$ 400$ during last few years.

407. The agricultural production structure also changed during the last decade. Compared to the situation in the early 90's, during past years the areas under low resource crops with assured markets (wheat, corn, sunflower) have increased and areas under intensive crops (tobacco, vegetables) have been reduced.

408. The agricultural-food industry has adjusted better to the changes. During the past years a differentiation has developed in the technical and economic status of agri-processing enterprises. This particularly relates to the enterprises created during the planned economy era. About one third of all these economic units have been successfully restructured - being able to modernize their equipment, management, as well as their raw material supply. However, most enterprises find themselves in deep financial crisis. Some of them have a significant development potential if capital for equipment modernization were available. New technologies, performance methods of management and marketing are of prime importance for most enterprises.

409. The agricultural land privatization process in Moldova covered two phases: the first phase of so-called "small privatization", resulting in a significant increase in the number of household plots (from 180 thousand ha in 1990 to 300 thousand in 1992). The second, the "large privatization" program included the agricultural land cultivated by former collective farms. During the second stage land entitlements ("land shares") were distributed to the rural population for private ownership. In parallel, land plots were physically allocated to individuals or families who left the collective farms.

410. The privatization and restructuring of large-scale state and collective farms is now practically complete, but new enterprises, based on private property, continue to evolve. Recently established farming units display a contrasting picture with about half the land being cultivated by various medium to large enterprises, often with a small number of owners consolidating the land of small owners through various leasing agreements. The second half is owned mainly by small independent farmers.

411. The process has resulted in a very fragmented structure of land ownership. While the initial issues of land privatization have been resolved and the new farming organizations based on private ownership are consistent with the market economy, the consolidation of private ownership and organizational-legal structures will require time and appropriate public policies.

412. The transition toward market economy resulted in a loss of jobs in agriculture. There are no reliable statistical data on rural migration, however, in some villages about $40 \%$ of active population is presumed to have gone abroad or to the urban areas.

413. Food and agricultural products traditionally dominated Moldovan exports. Moldova still remains a net exporter of agriculture and food products mostly to CIS countries, but their contribution in the volume of exports is slightly declining. The agricultural and food sector is always ensuring a positive trade balance in external trade (circa US\$200-400 million), but this surplus has been significantly reduced during past years. It is noticeable the increased imports of agricultural and food products, which causes serious problems on the internal markets for domestic products. At the same time imports of raw materials have contributed to the growth of export of processed products. 
414. Lack of finance is one of the main problems for the majority of agricultural enterprises. It is also a problem for agri-processing enterprises, which would like to modernize and restructure. The credits provided to the agricultural sector in Moldova come from two main sources of rural credits: commercial banks and non-bank financial institutions. A third source is the foreign donor agencies.

415. The major part of the loans/credits provided by banks goes to food processors and input suppliers. Credits provided to the individual sector in Moldova come mostly from non-bank financial institutions supported by the New Lending Initiatives under the World Bank Rural Investment Support Project (RISP). RISP was initiated by the World Bank in late 2000. Within the RISP mechanism, two types of credit lines have been developed for agricultural enterprises as well as individual farmers through commercial banks and the Rural Finance Corporation, Savings and Lending Associations.

416. Foreign donor agencies play a very important role in the national economy. A large number of international financing and donor organizations such as USAID, TACIS, SIDA, DFID, Soros Foundation, from Japan, Poland and the Netherlands have recently become more active in providing support to the agricultural sector, including investment, grants, soft loans and guarantees to banks, and technical assistance.

417. Taking into consideration the objective of European integration in the process of sustainable development of rural localities at regional and local level, EU methods of providing assistance for rural development will be taken into consideration, as it is stipulated in the Recommendation nr.1296/1996 of the Council of Europe Parliamentary Assembly regarding the European Chart of Rural Space. In this context, in order to make full use of the entire potential of the rural space, and first of all - efficient use of human and natural resources, besides agriculture, which is and will be the main activity for the next years, non-economic activities, which are presently underdeveloped will be also deployed,.

418. Agriculture support programs in Moldova are modest when compared to other countries. The state offers support to agriculture through two essential channels:

- subventions from the budget in cash;

- non-monetary support.

419. In recent years, subventions from the budget for agriculture have not exceeded $3 \%$ of the total of budgetary expenditures of the state. Most of such expenditures for agriculture are used for the Agricultural Support Fund and irrigation. Other budgetary expenditures relate to the financing of some limited production activities, for the Unit for the implementation of agricultural projects, research institutions and education, and for state and governmental structures.

420. The main part of non-monetary support for agriculture, in the form of reduction/cancellations of taxes of the economic agents to the state, are intended for the elimination of the results of natural disasters.

421. Moldova under its membership agreement with the WTO has made commitments limiting subsidies. Export subsidies are prohibited. The provisions regarding domestic policy use the concept of the Total Aggregate Measurement of Support (Total AMS). Moldovan commitments limiting subsidization has foreseen a $20 \%$ reduction of subsidies by 2004 . Since Moldova uses now only $8 \%$ of allowed domestic support, the AMS rate will not affect the agricultural sector in the nearest future.

422. The contribution of agriculture to the state budget is lower than the sector's share in GDP. The main components of the existing taxation system are: land tax, Social Fund contributions, income tax, VAT, and excises. Other general taxes and charges for water, real estate, customs tariffs etc. also apply to agricultural producers and processors. 
423. Moldova has signed Free Trade Agreements with 17 countries. However, a number of these agreements have not been ratified or fully implemented. The European Community has granted trade preferences to developing countries since 1971 in order to enhance their access to the EU's market by providing tariff reductions. The Republic of Moldova was granted the "Generalized System of Preferences" in 1993/1994 and its last version was applied from 1 January 2002 to 31 December 2004.

424. Moldova has a liberal import policy. Moldova like other members of the WTO has negotiated tariff rates for most products. These tariff rates are applied to the products of other WTO members. There is a prohibition to use measures, which have not been converted into ordinary customs duties (the so-called tariff policy). This means that Moldova may not use of quantitative import restrictions, variable import levels, minimum import prices, granting discretionary import licensing, non-tariff measures favoring state enterprises, etc.

425. Moldova like many other transition countries has undertaken large market-access commitments. The country thereby contributes to the strengthening of the multilateral trading system. At the same time the Republic of Moldova has relatively limited possibilities for local producers' protection. Tariff levels are lower than in neighboring countries by $30-50 \%$.

\section{Objectives}

426. Enhancing population's welfare in rural areas involve:

- continuing the reform process in the agricultural sector. The goal will be to create agricultural enterprises of optimum scale, advanced productions capacities and connection systems between different components of the agri-food area necessary to enhance higher productivity and international competitiveness of agricultural products, thus moving from volume to quality and value added;

- building a strong commercial and institutional framework according to market economy principles. The focus will be on implementing international standards of quality, efficiency and range of products, and the full spectrum of services required by the market chain from production to selling;

- developing non-agricultural activities in rural areas within rural and regional development strategies;

- ensuring technical and financial support from international donors using effective structures for counterparts interaction.

\section{Long Term Strategy}

427. Moldova will continue to maintain macroeconomic stability as a base for agricultural recovery and poverty reduction. It is recognized that the legal, regulatory, and operating environments in Moldova are not favorable enough to agricultural and overall economic growth. Excessive regulation, inconsistent policies and their implementation have led to an increase in the shadow economy, creating barriers for new enterprise entry and a poor investment climate. The overall legal and regulatory environment will be substantially improved to stimulate investments, trade development and economic growth as set out in the Private Sector Development section of this Strategy.

428. Over the long term, the Government seeks to promote sustainable growth in the agricultural sector through increasing competition and stimulating private initiative. The Government reconfirms its commitment to implement agricultural policies and support agricultural institutions aimed at developing a viable market oriented rural economy. Moldova will promote liberal agricultural 
policies during the years ahead as stated in the Memorandum of Understanding on the Agricultural Sector signed in December 2001 with the World Bank. The Government believes that the foundation laid by the transformation of property rights and markets is in place for developing private agriculture. In the medium term, the efforts will focus on: (a) strengthening land ownership rights; (b) developing land markets; and (c) providing appropriate services to post-privatization agricultural enterprises through creating technological machinery private stations.

429. In doing all the above, the Government will: (i) ensure that creating farming structures and their sizes will be determined by transparent, market based means; (ii) ensure that land transactions can take place freely without administrative interference by Government, local authorities or neighbors; (iii) maintain the institutional and technical capacities of Cadastre offices, which will have trained manager and staff; (iv) continue to seek donor assistance in providing legal aid services including an information campaign on land owners rights, and dispute resolution and problems regarding land transactions; and (v) carry out an information campaign for farmers about different scenarios of, and alternatives to, land leasing and swapping, procedures associated with these types of arrangements: types of contracts, standardized terms and conditions of lease contracts, etc.

430. Land consolidation will be addressed through the further development of the agricultural land market. Land policy will aim to develop economically viable farming units over the next decade. These will be achieved through measures to improve the operation of the land market and promoting land lease. Given that there is no optimum scale of production, appropriate size of production unit depends on the resource intensity of production, and on the relative market prices of land, capital, labor, means of production and agricultural products. For high value, resource intensive products, small and medium scale production may be appropriate. For extensive, mechanized, low value production, larger scale production may be more suitable. The fundamental principle is that producers choose the scale and legal organizational form which best suit their unique configuration of objectives, resources, opportunities and other circumstances. It is recognized that efficient farming is not only about farm size. More important are the skills of people who run farms and the opportunities they have and the constraints they face.

431. The emphasis will be on providing information to land owners about their property rights, alternative forms of organization and resources available in applying their rights for production, income and forms of labor force employment. Different legal-organizational forms consist of peasant farms, joint stock, agricultural production cooperatives, and limited companies as well as various forms of lease arrangement. Considerations of environmental protection and the preservation of areas of special scientific and recreational interest will be part of the overall policy for creating a viable and competitive farming sector.

432. Moldova has limited resources for the subsidization of the agricultural sector. Effective use of limited budgetary resources is crucial in this context. It is necessary that agricultural subsidies are carefully targeted in a way which efficiently promotes the Government's economic growth and poverty reduction objectives. Furthermore policy should encourage restructuring activities in the post privatization phase. Care will be taken to ensure that these policies will be non-discriminatory and, furthermore, not introduce distortions in the efficient functioning of commercial markets.

433. The Government will provide support to peasant farms with the purpose to alleviate poverty in parallel with subsidies to agricultural enterprises. These subsidies, available from the so-called WTO Green Box measures, negotiated during accession to WTO, can be used for extension, advisory, marketing and promotion services, infrastructure, and domestic food security.

434. Taking into consideration the economic growth and poverty reduction objectives set in EGPRSP, the formulation of subsidy policy is a complex area. For this purpose international experience and assistance will be used. 
435. The Rural Investment and Services Project (RISP) plays an important role in improving rural finance in Moldova. It is hoped that the project can be extended into a second phase. After an objective review of the current RISP activities, consideration will be given to continuing the crediting on traditional components, including some possible new components such as:

- risk mitigation,

- agricultural trade,

- irrigation,

- infrastructure development.

436. The fiscal system is based mainly on indirect taxation (VAT, excise duties), which does not reflect the income and profitability situation of individual farms and enterprises. Over the long term, the taxation system should shift to a more direct and progressive system of taxation.

437. The member states of CIS, mainly Russia and Ukraine, continue to be Moldova's major trade partners, despite their decreased shares in exports, and especially imports. The possibilities for Moldova to penetrate other European markets need to be assessed realistically in the light of two ongoing processes: (i) the accession process to the EU both in the present round and beyond, and (ii) the rapidly escalating technical barriers to trade in food products. These arise from the tightening in areas such as phyto-sanitary controls, notably minimum residue levels, and severe requirements on environmentally friendly purchasing, and demands for good agricultural practice (EUROPGAP). From the external suppliers point of view with the accession process, the European market is dividing into three zones:

- the larger countries of Western Europe (notably UK, France, Germany) which are setting the pace in the application of new quality and food safety standards. Accessing these markets is already very difficult.

- the remaining countries of the current EU, which are slower in the application of the technical standards and are at present more accessible for new suppliers, but are likely to progressively apply the new standards in the coming years.

- the accession countries, which are themselves unlikely to apply the new standards in the foreseeable future. However, these countries may well impose these standards on external competitors as a non-tariff barrier to trade.

438. The purpose of trade development policy will be to assist the refocusing of the sector on new market opportunities. All avenues for trade, both domestic and external have to be exploited. Each has differing potential for development in the short, medium and longer terms. The Government will continue conducting bilateral negotiations with official bodies of trade partners responsible for health and sanitary inspections and certifications in order to harmonize the required standards between Moldovan industry and its principal markets.

439. Export markets for unprocessed products provide an area where there is potential in both traditional and new markets. Reviews of international trends for processed food products focus on new market access mechanisms. New access is crucial since Moldova cannot rely entirely on its traditional markets. However, market access relies heavily on total quality management systems, rather than on major investments in marketing. The creation of a quality assured marketing chain would involve processors contracting with producers for the supply of specified volumes using specified inputs and technologies practices. Such integrated producer to consumer models will 
require the attraction and involvement of international commercial partners through the implementation of EGPRSP private sector development strategy.

440. The improvement of the international competitiveness of agriculture and shifting the market focus will inevitably have consequences for many agricultural workers. Their skills or age profiles will no longer match the needs of more specialized agricultural and agri-industrial enterprises. At the same time, the rationalization of agricultural production and processing will create new jobs and new opportunities for commercial and service enterprises. Initiatives for the protection of those affected by the adjustment process, and for the environment will also be required.

441. Therefore, an overall strategy for rural and agricultural development will include:

- private sector development especially for small and medium enterprises;

- a regional approach to development;

- social services and infrastructure provision;

- human resource development;

- focus on other problems related to poverty and social exclusion;

- preservation of the culture and heritage of rural areas and protection of the environment;

- social protection arrangements including pension provisions.

Measures for achieving these are presented in the relevant sections of the EGPRSP, including education, health, social assistance, infrastructure and regional development. A strategy study for rural development will be proposed for international support. A rural development strategy will include various elements, which combined will improve economic and social life in the rural areas.

442. The Ministry of Agriculture and Food Industry will be restructured with a view to adapting its role from executive to facilitator, minimizing regulation. Special attention will be paid to developing its role as a central government body responsible for analysis-based policy development, and the monitoring of the implementation of policy. Regulatory functions will be limited to food safety, and veterinary and phytosanitary controls required by international conventions. Private sector schemes will be encouraged to raise quality standards in agriculture. International donor technical assistance will be needed for preparing a long term strategic plan for restructuring public administration in agriculture including both central and local bodies' level.

443. The Government will promote rationalization and cooperation among the various projects and organizations assisting the development of agriculture. In this context, emphasis will be placed on building on existing structures where possible rather than creating new organizations.

444. With regard to the State Reserves for grain, these in the past played a role that sometimes had an unwanted impact on markets. The purpose of the Reserves is to serve in case of emergency. Government is committed to: (a) limit the Reserves to the maximum level equivalent to one and a half month worth of human grain consumption; (b) maintain the level of grain held by the Reserves in line with the country's fiscal situation, and (c) adhere to the operating principles for the Reserves stipulated in Government's Letter of Development Policy to the World Bank.

445. A number of measures proposed, including the review of subsidy measures, need donors' technical assistance. The implementation practices of international projects should move towards compatibility with technical assistance provided to EU accession countries. 


\section{Priority Actions for 2004-2006}

446. Programs dedicated to the rural poor will be developed jointly with NGO's and international institutions. The framework for rural development requires a public investment and expenditure approach, which should redress the past imbalances in rural areas in the provision of economic and social infrastructure, health education, etc. Attention will be paid to the collaboration between the private and the public sectors in providing information and consultancy for small farmers. The education and vocational training activities will be strengthened and the financing of micro and small enterprises will be developed thought NGO's.

447. Provision of information and advice to rural populations and groups within them will be a medium term priority. There will be a special emphasis on support, skills and capital for new crop, livestock, agro-processing and non-farm enterprise start-ups. Support could come in the form of information and advice about the selection of promising ventures, training, management, legal aspects of activity, access to markets and the technical and commercial feasibility of micro-projects. Support in visiting financing institutions for funding their development activities could also be provided. These activities could largely be contracted out to local organizations, including NGO's having the competence and relevant experience in the area. The actions will be linked to ongoing initiatives to promote and support small and medium scale enterprises (SME).

448. Land consolidation will be pursued through a special study supported by international technical assistance. This will review the evolution of land consolidation in recent years, the efficiency of the functioning of the land market for sale and leasing, cadastre and registration system, the organizational options available to land owners and agricultural producers, the information and advisory needs of land owners and producers in relation to maximizing the income, employment and welfare benefits from available resources. The study would also review a small number of relevant international case studies. On the basis of the study recommendations on concrete actions for addressing the issues of land consolidation over the medium and long term will be developed.

449. Farmers and agricultural entrepreneurs' organizations will be created in order to ensure a more efficient access to information, markets and production opportunities. Creation and development of such organizations is a possible solution to both problems of land consolidation, and grouping in activities of purchasing inputs and selling agricultural production on the market. These associations will provide lower prices in purchasing inputs and reduction of transaction costs. In this context will be practiced the creation of producers' groups, input purchasing associations and cooperatives, producer-owned distribution companies, and bulk purchase agreement.

450. Strategic planning will be promoted in commercial and raw agricultural material processing enterprises. Will be encouraged mergers and rationalization, needed to create "critical masses" capable of competing in international markets, by adjusting the profile of these new enterprises to market requirements.

451. Promoting exports will be carried out through the state Agency MEPO (Moldovan Export Promotion Organization) and providing direct co-funding to enterprises for investment in market development in priority regions and market segments. The promotion of domestic and international investment in the Moldovan agricultural sector will be pursued through the proposals described in EGPRSP regarding the private sector development.

452. In order to realize a sustainable development of rural areas according to EU requirements, technical and financial assistance will be offered in developing programs of rural communities development (on the basis of the participative principle), a study will be undertaken on opportunities for creating the National Agency and National Fund of Rural Development, the provision of assistance will be intensified and incentives will be created to motivate the development of the nonagricultural activities of the rural population. Also a study will be undertaken in order to develop and 
implement the mechanism of industry, trade and services transfer to rural localities, including through the cooperation of rural enterprises with urban and foreign enterprises.

453. Studies relating to the restructuring of the Ministry of Agriculture and Food Industry, the agricultural subsidy policy in the context of economic growth and poverty reduction, and the preparation of a rural development strategy will be undertaken as described in the sub-section "Long Term Strategy". These three studies, and the study of land consolidation, will identify key elements regarding the improvement of the overall framework for the further development of policy formulation, for agricultural reform, and rural transformation.

\subsection{REGIONAL DEVELOPMENT POLICY}

\section{Situation Analysis}

454. During the transition period insufficient attention was paid to the regional aspect of reforms. In most cases policies were essentially macro-economic. No mechanisms were created to promote the institutional and legal frameworks, which were necessary for the development of regional and local self-administration structures.

455. At the same time, the economic crisis had an extremely negative impact on regional economies. Consequently, inter-regional discrepancies in the socio-economic development of regions grew, especially between the country's capital and the rest of Moldova's regions. At present the regional gross domestic product in Chisinau is 3.2 times larger in comparison to other regions, while the volume of investments is higher by 5.9 times. There are, furthermore, fairly large differences amongst regions. Thus, in Taraclia, the regional gross domestic product per inhabitant is 1.3 times larger that the average of regions (with the exception of the municipality of Chisinau), and in Orhei and Lapusna by 1.2 times lower.

456. The considerable differences in the level of regions' economic development are causing substantial territorial differentiation of economic conditions, and the level and quality of population's life. This phenomenon aggravates the problems related to inequality and poverty, because citizens and families' welfare and opportunities are strongly correlated with their place of residence.

457. The political and socio-economic development of the country is affected by the existence of the Transnistrian conflict. Internal reintegration is conditioned by the need to consolidate the statehood based on international norms, to ensure a qualitatively improved economic growth, to increase the population's living standards and reduce poverty, and ensuring democracy in the society. External factors include the Republic of Moldova's European integration process and the internationalization of the Transnistrian problem resolution, through the participation in the regulatory process of guarantee-states and international bodies, in particular the OSCE.

\section{Objectives}

458. The regional development policy will be updated and consolidated, in order to become an efficient component of the EGPRSP. The main objectives of regional policy are the following:

i) balanced and sustainable socio-economic development throughout the country's territory through the reduction of differences in socio-economic development amongst regions, and, especially, between center and periphery; 
ii) augmentation of resources potential for addressing problems that are related to socioeconomic development of regions;

iii) provision of support to local administration bodies in the socio-economic development of territories and coordination with national, sector and territorial development programs;

iv) achievement of significant progress in solving the Transnistrian problem and the country's reintegration, based on respect of the Republic of Moldova's sovereignty and territorial integrity.

\section{Long Term Strategy}

459. To realize the above-mentioned objectives, new principles, tools and mechanisms for regional policies promotion will be implemented, in line with the European practice and experience of EUcandidate countries. Regional development is one of EGPRSP priorities, and is based on the following principles:

- $\quad$ efficiency - efficient use of natural, human, production and financial resources;

- $\quad$ equal access - all citizens, irrespective of their residence, have equal rights of access to economic, social and cultural goods;

- $\quad$ subsidiary - the central authority performs only those measures and actions of regional development support, which cannot be performed more efficiently at lower levels of public administration;

- $\quad$ sustainability - support of regional development is done on a stable base and is ensured with financial resources and necessary tools;

- $\quad$ planning - support of regional development is done based on national and regional development strategies that have well defined objectives, priorities and mechanisms;

- coordination - all regional development support measures are coordinated at national and regional levels;

- $\quad$ partnership - planning, developing and performing regional development support measures is done based on cooperation between central and local public administrations, public and private sectors, as well as civil society institutions;

- $\quad$ transparency - ensuring the transparency of the process of distribution, allocation and usage of resources for implementation of regions' development strategy, programs and projects.

460. The regional development measures and programs will be mainly oriented towards:

i) improvement and development of infrastructure and localities (transport and telecommunications networks, communal services);

ii) development of small business and entrepreneurship in general, increasing its role in the recovery of the regional economy;

iii) development of services and sectors alternative to the agriculture ; 
iv) attraction of local and foreign investments in regions' economies;

v) facilitating production growth and promotion of exports from regions;

vi) development of social assistance systems and social services rendered to regions' inhabitants;

vii) environment protection and maintaining ecological sustainability.

461. For the reintegration of the country the Government's policy will be oriented towards the political regulation of the Transnistrian conflict, the elaboration and implementation of the postconflict development plan and the promotion of democratization and human rights in the region.

\section{Medium Term Priority Actions}

462. To consolidate the legislative base of the updated policy, a Law on regional development support will be passed, which will set objectives, tools and financial resources for undertaking measures to support territories' development. By adopting this law a legal framework will be created for establishing institutions empowered with development, coordination, and control functions, and ensure that regional state policy promotion is provided with necessary resources.

463. In accordance with the Statistical Classifier of Territorial Units used by EU, regions will be identified for development and support, each of which will comprise several existing administrativeterritorial units (with the exception of the municipality of Chisinau).

464. In order to support regional development, a two-level system of coordination and administration will be created. The Coordination Council and National Regional Development Agency will operate at the national level, while, at the local level, a number of administration committees and regional development agencies will operate.

465. Within the Government's country reintegration policy, the following actions will be undertaken:

i) drafting and adopting a new Constitution of the Republic of Moldova;

ii) securing the Moldova-Ukraine border, including its Transnistrian segment;

iii) developing the post-conflict development program.

\subsection{TOURISM}

\section{Situation Analysis}

466. Tourism represents a national economy sector with possibilities of generating socio-economic benefits for the country and its communities. These include the generation of income and employment, as well as increased foreign currency earnings and contributions to the state budget. At the same time, tourism can serve as a catalyst for developing other national economy sectors.

467. There is significant potential for the sustainable development of tourism in Moldova. The country's tourist route combines sites of natural beauty (including natural and sightseeing reserves and interesting elements of flora and fauna) with archeological (monuments and sites, museums, interesting examples of folklore and popular art, etc). 
468. Over the last four years there has been significant growth in the tourism industry of Moldova. Over the period 2000-2003 the total number of visitors involved in organized tourism has increased by $96 \%$, reaching 153 thousands persons in 2003 . The growth in organized international reflects a positive evolution, including for the reception tourism. In 2003 total foreign visitors in the country amounted to 23,598 persons, an increase of around $25 \%$ over their number in 2000.

469. The major problems that hinder the further development of tourism in Moldova are:

i) limited financial resources for the development of tourist infrastructure and attraction of tourists, services facilitation, marketing and promotions;

ii) low quality, or total absence, of road infrastructure in tourist areas;

iii) lack of structures for tourist accommodation, in line with international standards, for the whole country with the exception of the capital;

iv) poor condition of a large number of monuments and tourist sites;

v) insufficient professional training of the personnel employed in this industry;

vi) cumbersome and costly procedures for obtaining visas;

vii) low public awareness with regard to the existing potential for tourism development and the benefits that might be generated for the society as a result of the development of the sector.

\section{Objectives}

470. The main objectives of the development of tourism in Moldova include:

- The international promotion of Moldova's tourism industry;

- The sustainable and balanced development of the country's heritage;

- Improvements in management; and

- an enhanced quality in the services rendered.

\section{Long Term Strategy}

471. The sustainable development of tourism in Moldova will contribute to:

i) increased employment in the country's rural areas;

ii) improved tourism infrastructure;

iii) adjusting and maintaining the quality of rendered tourism services at the international level;

iv) the possibility of fruitful partnerships between the public sector, the private sector and NGOs;

v) increased foreign currency earnings;

vi) increased flows of investment in existing and new tourism enterprises;

vii) quality improvements in the training of personnel, and the diversification of specialty areas, according to requirements of the tourism sector in line with international standards;

viii) maintaining the quality of the environment for both tourists and permanent residents;

ix) the development of actions for the efficient promotion of tourism.

\section{Priority actions for 2004-2006}

472. In the medium term period emphasis will be placed on:

i) Drafting rural tourism development projects (pilots);

ii) Increasing the involvement of local authorities in developing and promoting rural tourism;

iii) Developing environmental tourism by arranging and creating national parks;

iv) Drafting projects for restoring and renovating infrastructure in order to attract domestic and external financing for the necessary quality improvements; 
v) Identifying cultural and historic heritage objects that are likely to be of interest to tourists;

vi) Creating the National Center for Staff Retraining for professional training and upgrade the skills of employees in the sector;

vii) Extension of classification on all types of tourism reception structures;

viii) Offering methodological assistance to economic agents in drafting and promoting investment projects in the sector;

ix) Developing efficient quality control mechanisms for services rendered to tourists;

$\mathrm{x})$ Drafting promotion programs for a number of targeted markets;

xi) Simplifying border-requirements and procedures.

\subsection{ENVIRONMENTAL PROTECTION AND SUSTAINABLE USE OF NATURAL RESOURCES}

\section{Situation Analysis}

473. The state of the environment and the efficient use of natural resources affect economic growth conditions and the level and quality of life of the population. The irrational use of natural resources over the decades, first of all, the intensive exploitation of agricultural lands, the use of ecologically harmful technologies in agriculture and industry, and air and water pollution, have led to significant reduction in productivity of natural potential and a destructive impact on the environment, especially on water resources, air, soils and biodiversity.

474. The water quality of the major rivers of the country varies from "moderately polluted" (Nistru, Prut) to "polluted" (Raut, Bic). The majority of underground water resources do not meet the quality standards and requirements for potable water because of excessive concentrations of undesirable chemical substances (fluorine, iron, hydrogen sulphide, chlorides, sulphates, excessive mineralization). The situation is especially unfavorable in rural areas where the main part of the population uses drinking water from underground water sources (132,000 wells, springs) and only $17 \%$ of families use central supply sources.

475. The main causes of pollution of water resources are: i) disposal of residue water insufficiently cleaned due to the lack of sewerage and treatment systems or their unsatisfactory operation; ii) washout of fertilizers, chemical herbicides and/or pesticides and other polluting substances from warehouses, unequipped or unorganized dumps; iii) agricultural works in water protection areas and belts and lack of equipped conservation zones; iv) storage of animal and household waste in perimeter of settlements and households, v) accidental waste disposal by enterprises, vi) inefficiency of the system of monitoring, evaluation and compensation for damage to water resources.

476. The negative impact of unfavorable water resource conditions is reflected in the increased morbidity of the population caused by poor environmental conditions. Rural areas, where more than $80 \%$ of the population uses substandard water from local (chiefly underground) sources, are especially affected. This impact on population's health generates additional expenditures form the state budget, economic agents and the population. The current situation affects particularly the poor.

477. The condition of soils is the major environmental problem. Soils are the natural resource on which use the main part of the population depends. At present the agricultural soil yield potential is declining. Moldovan soil's natural qualities can serve as a potential basis for the development of a highly productive, export-oriented agriculture and food-processing industry. However, the accelerated degradation of ground resources reduces the opportunities for growth of the agroindustrial sector and of the national economy as a whole. 
478. Soils erosive processes are a serious threat. The area of eroded land increases annually by $0.9 \%$, and 26 million tones of fertile soils are lost from arable lands. The annual damage to the national economy as a result of soil degradation is estimated to circa Lei 3.1 billion including: Lei 1.5 billion of erosion losses; Lei 0.2 billion of landslide and ravine losses; and Lei 1.4 billion - which are the estimated costs of agricultural production losses as a result of decrease of land productivity. Families that practice agriculture for subsistence, being among the poorest, are particularly affected by erosion and fertile soil loss, and lack financial resources to address this problem.

479. The main causes of degradation of soil resources are: i) use of poor cultivation technologies; ii) land allocation taking insufficient account of the need for soil conservation; iii) insufficient crop rotations, iv) lack of financial resources at national and local levels, and at the level of new landowners; v) limited access of the rural population to information on the efficient use of land; vi) unauthorized cutting of agricultural land forestry protection belts; vii) lack of forestry protection curtains.

480. In localities the main problem is air pollution caused by motor transport, thermal power stations and boiler-houses. The average annual concentration of nitrogen oxides in Chisinau, Balti and Tiraspol municipalities exceeds the maximum accepted norm by 1.5 times, sulphur oxides in Bender municipality - by 1.7 times. The main causes of air pollution are: i) excessive use of obsolete vehicles and their emissions; ii) use of low-quality fuel; iii) use of coal and black oil and lack of emissions-clearing facilities; iv) use of obsolete technology for production; and v) insufficient monitoring of emissions, evaluation and compensation of damage to the environment.

481. Air pollution leads to increases in the number of persons affected by serious diseases, such as lung cancer, respiratory diseases, allergies etc. The current situation has a particular negative impact on the poor (primarily, on children and pensioners), who lack financial assets for preventive healthcare and qualitative treatment.

482. A serious problem for the country is the collection and disposal of household and industrial waste. To date, the country has collected 30 million tons of waste, including over 6 million tons industrial waste, derived from processing of building materials, food and drinks. The existing dumpsites (whose total area is about $1000 \mathrm{ha}$ ) cannot ensure ecological safety. Such dumpsites are not present at all in most rural settlements and small towns. Consequently, a considerable part of domestic households and economic agents dump illegally industrial and household waste on unequipped areas (such as roadsides, riverbanks, ravines etc.). Works for neutralization of the collected waste are almost not performed.

483. A major pollution danger is toxic substances and waste, including unusable pesticides. There are 1,712 tons of unsuitable or prohibited pesticides, stored in 340 warehouses, of which $80 \%$ are in unsatisfactory condition. In addition, 23,920 tons of contaminated oils used in power sector, possibly containing BPC are a critical threat to the environment.

484. The main causes in relation to unusable pesticides and environment pollution are: i) lack of waste sorting and processing plants; ii) lack of an effective mechanism for prevention, evaluation and compensation for damage to the environment and natural resources caused by human activity; iii) lack of necessary financial resources at national and local levels; iv) low level of ecological knowledge and culture of the population and economic entities; v) incorrect use and storage of chemical substances and pesticides.

485. Moldova's forest resources are constituted from the resources of forestry fund and forestry vegetation on terrains outside of the fund. According to the Land Cadastre situation on 01.01.2002, the forestry fund covers a surface of 392.4 thousands ha (11.6\% of country's territory), including territory covered with forests - 349.5 thousands ha (forestation level of $10.3 \%$ ). The main function of forestry resources at present and in the long run should be the maintenance of ecological balance. 
However, the share of afforested area (less than 10\% of land area) is insufficient for effective environment protection. This contributes to a high level of soil erosion, landslides, degradation of water resources, and intensifies droughts. Over the last decade the share of forests has decreased due to authorized and unauthorized cuts.

486. The main causes of forest degradation are: i) the increase in illicit cutting caused the increase in prices for wood and fuel; ii) lack of efficient controls on the part of local administration; iii) low levels of ecological knowledge and culture; iv) excessive grazing and lack of adequate management of forest areas; v) long term use of regeneration from scions and non-concordance among some bushes and stational conditions.

487. The areas of natural reserves protected by the state make up only $1.96 \%$ of the country's territory (as compared to $3 \%$ in Ukraine, $7 \%$ in France, $13 \%$ in Germany, $25 \%$ in Austria). This is obviously not enough for the preservation of biodiversity. Moldova has specific conditions of geographical location, climate and geology, territorial relief, and soil structure. Also, Moldova is subject to various extreme acts of nature, including floods, torrential rains, hailstones, strong winds, landslides, severe frosts and droughts, and earthquakes. The vulnerability of national economy and population to the action of nature is aggravated by the prevalence of agro-industrial sector in national economy, the historical specificity of the arrangement of settlements and high population density.

\section{Objectives}

- prevent and reduce the degradation of natural resources and increase efficiency of their use;

- maintain the quality of the environment as a factor that ensures health and quality of life;

- create an effective natural disaster monitoring, prevention and damage compensation system.

488. To solve the tasks set in the Millennium Development Goals "Integration of sustainable development principles in country's policies and programs and reduction of environment resources' losses", the share of terrains covered by forests in Moldova will be increased from $10.3 \%$ in 2002 to $11 \%$ in 2006 , and the weight of natural protected areas for conservation of biodiversity from $1.96 \%$ to $2.1 \%$ respectively.

\section{Long Term Strategy}

489. The priority areas to address the most severe problems and creation of preconditions for achievement of objectives in the field of environment protection and sustainable use of natural resources are:

i) the reduction in the pollution of water resources;

ii) the improvement of waste management and the reduction of toxic substances and waste;

iii) the protection and increase of the forestry fund;

iv) the protection and extension of areas of natural reserves protected by the state;

v) the reduction in the speed of soil degradation;

vi) the improvement of the system of natural disasters monitoring, and the provision of information and education to the population in this area;

vii) the improvement of the administrative, economic and financial mechanisms for environmental protection and sustainable management of natural resources;

viii) the increase in the level of ecological knowledge of the population, the facilitation of access to information on environmental issues, and the participation of the public in decision-making regarding the management of natural resources. 


\section{Priority Actions 2004-2006}

490. Actions will center on:

i) water resources protection:

- preparation of the Action Plan for harmonizing environmental legislation and regulations for water in line with the provisions of the EU legislation on environment;

- preparation of a national strategy on protection and sustainable management of water resources;

- inventory of aquatic potential, quality assessment, and identification of pollution sources;

- preparation and implementation of measures to eliminate pollution sources.

ii) Improvement of waste management, reduction of the impact and quantities of substances and toxic waste, which is based on the implementation and monitoring of the National Program for Household and Industrial Waste Management, approved in 2000, and the implementation of the National Plan of Stockholm Convention, approved in 2004:

- repackaging, centralized storage and destruction of 1,712 tons of pesticides, including from the Persistent Organic Polluters (POP) class;

- inventory of POP and PCB, dismantling and decontamination of oils and equipment used for PCB containing substances;

- conducting a feasibility and cost-efficiency study for upgrading waste disposal sites, the first steps being a change in the separate collection of waste and the building of a new waste processing plant, initially for Chisinau;

- developing and implementing pilot projects for waste processing in rural areas;

- inventory, renovation and re-equipment of Bekkari (animal waste disposal) waste sites;

iii) Forest fund protection and extension, based on the implementation of the Government's Strategy for Sustainable Development of the Forest Sector for the years 2003-2020:

- improvement of forest inventory and development systems;

- increase the number of forest plantations on the surfaces of the Forest Fund and local public administrations;

- development of programs for the rational and sustainable use of wood and non-wood forest's products;

iv) Extending and safeguarding the natural areas protected by the state according to the National Strategy for Biodiversity, approved by the Government:

- conservation of biodiversity in mid-course of river Prut and development of adjacent communal forestry;

- creation of the Ecologic Network;

- creation of the National Park "Lower Nistru";

v) Reducing the pace of soil degradation, on the basis of implementing the Government's Program for Processing New Lands and Increase of Land Fertility for 2003-2010:

- developing and realizing anti-erosion protection measures for soils and rehabilitation of degraded land;

- developing and implementing pilot projects for rational use and irrigation of soils, including protection of moist areas; 
- training of farmers land owners in issues of soil processing and use of mineral fertilizers and pesticides;

- planting forestry belts for agricultural land protection;

- rehabilitating communal pastures, and improving their management.

vi) Improvement of the system of natural disaster monitoring, information and training the population in this area:

- increase the awareness of the population regarding the impact of natural disasters;

- upgrade the equipment and technologies of the disaster monitoring system, for prevention of natural disasters;

vii) Improvement of administrative, economic and financial mechanisms for environmental protection and sustainable management of natural resources:

- review and improvement of the activities and administration capacities of the National Environment Fund;

- preparation and publication of a Guide on environmental impact and its assessment;

viii) Raising the level of public awareness, facilitating access to information regarding the environment, and actions that will be realized with the support of international bodies, NGOs and local authorities:

- developing the legal and institutional framework for implementing the requirements of international environmental Convention that Moldova is a part of;

- consolidating the capacity of central and local public bodies regarding information and participative approaches to environmental protection;

- training on sustainable use of natural resources;

- reviewing and improving the environment monitoring system;

- developing the National Strategy on Environmental Education;

- creating local environmental information and consulting centers;

- developing the methodology for creating and developing the structure of natural resources data base.

\section{B. Social Development}

\subsection{EDUCATION}

\section{Situation Analysis}

491. The quality of education is one of the most important human resource development factors. Education plays a leading role in facilitating economic growth, technologic and intellectual modernization and increasing welfare.

492. The Republic of Moldova has inherited an educational system that placed particular emphasis on providing access to knowledge. One of the factors that is critical for the maintenance of this objective is financing. In 1996-1997 around a quarter of consolidated budget expenditures, which corresponded to approximately $10 \%$ of GDP, were allocated for education. Following the economic crisis in 1998 education expenditures were reduced significantly. In 1999 the share of education expenditures was reduced to $16.4 \%$ of total budget expenditures (corresponding to $4.7 \%$ of GDP). In 2002 , following the economic recovery education expenditures increased to $23.9 \%$ of total budget 
expenditures (corresponding to $5.6 \%$ of GDP). Nevertheless, in comparison to early $90 \mathrm{~s}$, education expenditures were reduced significantly in real terms.

493. The reduction in the financing of educational institutions has resulted in an increased reliance upon charging fees for services rendered. Over the transition a number of private sector institutions were created, with currently around $35 \%$ of universities and $21 \%$ of colleges being private sector establishments. In total around $77 \%$ of higher education students pay for their tuition, with the fee varying from 3000 to 9000 lei.

494. The insufficient public financing, coupled with the increasing reliance upon fees and the reduction of living standards over the transition period have resulted in reduction of access to education for the poor. Currently only around $56 \%$ of children aged 3 to 6 years old are enrolled in pre-school institutions, a factor which is likely to have an adverse effect on their future performance at primary school. The enrollment rate in primary education has dropped from $96 \%$ in 1997 to $93 \%$ in 2002. In 2002 the gross enrollment rate in gymnasiums was $87.9 \%$. Every fifth gymnasium graduate has not continued his studies at the next educational level.

495. The widening social inequality in Moldova has been another factor, which contributed to reduced access to education of vulnerable social groups. In 2002 per capita consumption of poor households on education amounted to only a tenth of the expenditures of non-poor households. The enrolment rate in secondary general education of children from poor households is around $74 \%$, while their enrolment in higher education is only $7 \%$. This compares with $81 \%$ and $24 \%$ for children from non-poor households respectively. There are significant differences regarding access to education of children from rural and urban localities. The share of secondary and higher education graduates from rural localities is $76 \%$ and $6 \%$ respectively. This compares with $81 \%$ and $29 \%$ for graduates from urban localities. It is notable here that there are considerable discrepancies between official statistical information and that based on Household Budget Survey data on children's education due to their reliance on different data sets.

496. In Moldova the institutionalization of orphans and children from vulnerable households was widely used as a means for their social protection. In total 63 special institutions and boarding schools are currently operating in Moldova. Of these 3 are orphanages, with 153 children, 19 are boarding gymnasiums with 5991 children, 13 are special schools for children with physical and sensorial disabilities, cardio-vascular diseases, neuro-psychological diseases, and behavioral deviations, with 1895 children; and 28 are specialized schools for children with mental disorders, with 3377 children. Around $35 \%$ of children in boarding institutions are orphans left without parental care, with the remaining $65 \%$ coming from vulnerable families. Around 5500 institutionalized children have serious health problems, adversely affecting their capacity of learning and their social inclusion following graduation. They require qualified psycho-pedagogical assistance and permanent treatment. These are services that cannot be provided fully under present financing conditions, when the average cost of maintaining a child in these institutions is of the order of 4900-6000 lei per year.

497. Educational institutions are totally non-existent in 250 localities. These correspond to around $16 \%$ of total localities in the country and have a child population of around 10,000 . In another 60 localities there are only primary schools with 1700 pupils, while 500 localities have only gymnasiums. The poor quality of roads, coupled with lack of transportation and finance are additional factors hampering access to education.

498. Over the period 1990-2000 the average duration of studies per person decreased by 3 years. At present, the average duration of secondary general education in Moldova is by 4 years lower than the average for OECD countries. The education enrollment rate of the population aged between 7-24 is around $61 \%$. This is significantly lower than the ratios for Russia $(82 \%)$, Ukraine $(81 \%)$, and Romania (68\%). 
499. Some successes have been achieved with the implementation of education reform. There has been a recent improvement in the results of the national tests of $\mathrm{VI}^{\text {th }}$ grade pupils. Thus in 2002 the average math grade was 44.2 points out of 100, while for Romanian language it was 65 points. These were significantly higher than the results in 1997, which were 32 and 47 respectively). At the same time, the level of preparation of students from rural environment remains insufficient, with a grade gap of around 20 points in comparison with urban pupils. The low level of salaries, amounting to 69 $\%$ of the average salary in the economy in 2003 , adversely affects the quality of education. As a result the sector is not able to retain qualified personnel and, especially, young specialists and is characterized by ageing of the didactic staff.

500. The reduced access of population to education, the poor quality of rendered services, and the outdated equipment in many educational institutions, are not only a result of insufficient financing, but are also exacerbated by the inefficient distribution and use of available means. At present the share of total expenditures channeled to financing pre-school institutions is around $16.2 \%$, the share primary and secondary general education is around $57.2 \%$ (compared to $69 \%$ in OECD countries), while secondary professional education and higher education account for $4.3 \%$ and $10.1 \%$ respectively.

501. The deviation from established normative indicators adversely affects both the quality of offered services and their access. In 2003-2004 the total required teaching staff was 2,305 specialists. Of the 1800 young teachers that were appointed only 1052 took their position covering only $45.6 \%$ of needs. The system is characterized by inefficient use of financial, human and material resources, while education expenditures per pupil vary significantly among institutions, by 2-3 times. The ratio of pupils to teacher is low, while the ratio of students to support staff is very high. Payments for energy account for a quarter of total expenditures. Educational institutions work at around $75 \%$ of their capacity and the envisaged 40\% decrease in number of pupils by 2010 will require the network's optimization. Education management training as well as re-training of teaching staff continues to be weak.

\section{General Objective}

502. Ensuring access to quality education and ensuring the efficient and sustainable functioning of the education system in a way, which facilitates its role in developing human resources and the economy.

\section{Long Term Strategy}

503. The development of the education sector at the beginning of the millennium will be achieved through the following specific objectives:

- increase access to education services, especially for children from vulnerable families;

- systematic improvement in the quality of educational services rendered;

- raising the efficiency of financial, human and material resources management;

- updating the system of social integration of children with special educational needs (SEN) and of vulnerable children.

\section{Priority Directions for 2004-2006}

504. The established specific objective will be achieved through:

i)promoting public and private partnerships for supporting and developing the educational system;

ii)optimizing the network of rural educational institutions;

iii)improving the allocation of resources for the efficient and sustainable development of education; 
iv)motivating the performance of teaching staff and creating of an attractive environment for their activity;

v)providing training to managerial staff.

505. The second Millennium Development Goal on ensuring universal access to primary education has been largely achieved in Moldova. Emphasis will therefore be placed on progress towards the universal access to secondary education. It is envisaged that by 2006 the rate of net enrollment in secondary education will reach $88.9 \%$.

\section{Priority Actions for 2004-2006}

506. The facilitation of access, especially of the poor, to education services requires the redistribution and efficient use of financial resources. These issues will be addressed through:

i) the improvement of legislative and normative acts regarding consolidation and use of community funds for education, especially for the poor;

ii) a re-distribution of resources favoring primary, secondary general and secondary professional education;

iii) the increase in the efficiency of managing resources with emphasis on priority resources allocation for increasing the salaries of staff, and acquiring textbooks, didactical materials and equipment;

iv) drafting and implementing the rural education development program;

v) the creation in the rural environment of "circumscription" schools in parallel with provision of transportation services for pupils;

vi) the implementation of a flexible and equitable system of support to students and pupils from secondary general education by offering scholarships, depending on their successes and the financial situation of their families;

vii) the optimization of pre-school and school institutions, taking into consideration present demographic trends, in order to ensure that all children have access to general mandatory education;

viii) the extension of textbook loan schemes for high schools pupils, and an increase in subventions of textbooks for the poor.

507. The need to essentially improve the quality of education at all levels derives from the priority role of human resources development. Human resources play a key-role in the country's development and poverty reduction efforts. Achieving this objective will be ensured through:

i) developing and implementing state education standards;

ii) developing school and university curricula, including in continuing lifetime education, and implementing new teaching technologies;

iii) the systematic participation in international tests (such as TIMSS, PISA, etc.);

iv) developing and realizing the presidential program "SALT" of implementing information and communication technologies in the educational system;

v) improving the system of continuous training and re-training teaching staff;

vi) reconsidering the place and role of secondary professional education and adjusting it to community requirements, while updating the range of professions offered in consultation with social partners; 
vii) developing and implementing the national system of evaluation of pupils' knowledge and skills and the efficient monitoring of admission in higher educational institutions;

viii) developing mechanisms of implementing the European system of transferable academic credits;

ix) adjusting the catalog of specialties to ISCED 97 and ISCO, and restructuring the curricula in order to organize the higher education in 2 university cycles in accordance with the Bologna Declaration provisions.

508. To improve the integration of children with special educational needs, the following actions will be undertaken:

i) the organization of assistance services for children with special educational requirements in secondary general education institutions, and the development of community services for their assistance and support;

ii) the creation of a database of children with SEN in order to develop efficient programs and measures for their assistance;

iii) the development and implementation of special programs for children with specific educational needs;

iv) the creation and development of a system of services as an alternative to institutionalization;

v) the development and implementation of standards for the care, education, medical assistance, recuperation, and rehabilitation of children with SEN;

vi) the consolidation of didactic and technical-material base for the adequate professional training of special education institutions' graduates in order to facilitate their integration in society.

509. Increasing the efficiency of human, financial and material resources management within the educational system will be ensured through:

i) improving and completing the legislative framework in order to ensure the coherence and continuity of the educational system's development;

ii) creating information systems for education management;

iii) modifying the methodology of financing activities for the training and re-training of teaching and managerial staff of pre-university educational institutions;

iv) improving the methodology of budget financing of the educational system (program, unitbased financing, etc.);

v) upgrading the technical-material base of education institutions and implementing energy conservation measures;

vi) improving the system of teaching and management staff attestation;

vii) establishing the responsibilities and competences of central and local public authorities and social partners, in order to create conditions for the efficient functioning of educational institutions.

\subsection{HEALTHCARE}

\section{Situation Analysis}

510. The transition period has had an unfavorable impact on the state of health of the population and Moldova's healthcare system. The existing situation hampers the achievement of one of the most important medium-term objectives, namely human resources development. Furthermore, the increasing inequality in access to medical services is worsening the health of the poor, while, 
restricting their ability to take part in the country's economic development and benefit from the increases in welfare.

511. The worsening health of the population is reflected by the evolution of health indicators. The death rate increased from 9.7 per 1,000 in 1990 to 11.6 in 2002, and the birth rate fell from 13.0 per 1,000 to 9.9 respectively. Falling birth rates were registered among both the urban and rural population.

512. The most frequent causes of death are blood circulatory diseases, malignant tumors, digestive diseases, traumas, poisonings, and respiratory diseases. The death rate is high among the working-age population, with $26.4 \%$ of all deaths in 2002 being people belonging to the working-age, and, especially, among men (were it accounted for $37.7 \%$ of the total for 2002). These data indicate the low health level of the population of Moldova.

513. Moldova faces a double problem in disease incidence, involving both diseases typical for developing countries (such as infectious and parasitic diseases), as well as high level of diseases specific to developed countries (such as cardiovascular diseases and cancer).

514. According to official data, there has been a recent growth registered in endocrine diseases, metabolic diseases, blood related diseases, pregnancy and birth complications. At the same time the overall incidence of registered sicknesses has been falling. In 1995 the total number of cases of morbidity was $1,736,5$ people (400.0 cases per 1000 people). In 2002 the number had fallen to $1,276,3$ thousand people ( 352.3 cases per 1000 people). The falling number of visits to medical institutions is caused by reduced access to healthcare services and medicines, as well as by labor migration abroad.

515. Moldova has considerable variations in illness incidence in different parts of the country particularly in relation to chronic hepatitis, cirrhosis, anemia, and others. This can be explained by discrepancies in the ecological situation in different regions of the country.

516. Socially preconditioned illnesses, such as TB, HIV/AIDS and addictions - pose a serious threat. The number of people diagnosed for the first time with active TB was 54.5 per 100,000 people in 1995, and grew to 83.6 in 2002. The number of patients with AIDS rose from 0.05 per 100,000 people in 1995 to 0.5 in 2002, while the number of HIV carriers rose from 0.2 per 100,000 people to 4.5. The number of people diagnosed for the first time with drug addiction and drug abuse rose from 7.1 per 100,000 people in 1995 to 33.9 in 2002. The Millennium Development Goals seek to reverse the incidence of HIV/AIDS and other serious illnesses by 2015. Due to a rise in incidence of these diseases in Moldova, major efforts must be made in order to successfully reverse these trends.

517. Falling child mortality rates show some recent positive trends. The infant mortality rate (under 1 year old) felt from 21.2 per 1000 of births in 1995, to 14.7 in 2002. The epidemiological situation with regard to some viral infections, including diphtheria, polio, viral hepatitis B and others, has recently stabilized thanks to international aid in purchasing vaccines.

518. Cuts in the state financing of healthcare have led to an increase in the number of medical services provided against fees as a result of the introduction of official payments in public institutions, emerging private healthcare sector, and unofficial payments. According to the Household Budget Survey, only $44.1 \%$ of the population has adequate access to medical services, with $40.0 \%$ having limited access, and $15.1 \%$ having no access whatsoever. There is considerable inequality in the access of different population groups to healthcare services. Poor families spend only $2.1 \%$ of disposable income on medical services, and extremely poor $1.8 \%$. Households with a decent level of living spend $4.4 \%$ of their budget on healthcare. Per capita cash expenditures of poor households for health are 5 times less than those of the non-poor. Only $27.0 \%$ of the poor have financial access to medical services. The access to healthcare services of rural residents, elderly and large families is under the national average. 
519. The negative consequences of the 1990s economic crisis have manifested themselves not only in diminished access to medical services, but also in the significant reduction in the budget financing of public medical institutions. The total budget expenditures on healthcare fell from $6.7 \%$ of GDP in 1996 to $3.6 \%$ in 2002. The largest share of budget resources has been allocated to finance the current expenses of the institutions, resulting in their material and technical base deterioration. At the same time, salaries and wages in healthcare remained among the lowest in the economy. Underfunding of healthcare has long hampered the improvement in the quality of medical services. To improve the situation measures have been taken to restructure the sector in accordance with the Republic of Moldova's Healthcare Development Concept for the period 1997-2003 which has been approved by the government. As a result of these measures a number of medical institutions were consolidated, the total number of the institutions and beds in hospitals was cut, and the number of medical personnel was reduced, with the focus placed on primary medical care and urgent medical assistance.

520. Moldova achieved significant progress in reforming the healthcare system in terms of decreasing expenditures for auxiliary services and modifying the financing structure by redistributing resources from the hospital level to the primary and emergency medical care sectors.

521. The Government proceeded with the countrywide introduction of the mandatory health insurance on January 1, 2004. The Government's program, which is based on the 1998 Mandatory Health Insurance Law, foresees that the entire population will be covered by the mandatory health insurance. A Pilot program implemented in the Hincesti raion from July 1, 2003 to December 31, 2003, tested regulatory acts, procedures, and instruments that were designed for the entire country. The National Health Insurance Company (NHIC) has signed medical assistance provision contracts with a number of public medical-sanitary institutions rendering medical services in order to provide the basic package of health services. The latter comprise primary healthcare services at sector level, drugs for children under 5 years, pre-hospital emergency care, ambulatory care and hospital care.

522. The entire population is covered for all primary medical sector and emergency services at the pre-hospital stage, irrespective of the person's insurance status. With the exception of emergency cases, access to hospital services is granted to the insured following the referral of a family doctor. Mandatory health insurance is being funded from three sources: (i) mandatory health insurance premiums amounting to $4 \%$ of the salary for the employed, which equally shared by employees and employers; (ii) own contributions by entrepreneurs, and other persons that are insuring themselves individually, and (iii) government budget contributions on behalf of those that are ensured by the Government by law. Budget contributions are expected to cover around 70 percent of projected expenditures. Local governments are also expected to support materially the public medical-sanitary institutions and participate in the co-financing of National health programs.

\section{Objectives}

523. The main objectives of the healthcare sector reform program are the following:

- to increase access of the population, and, especially, of the poor, to basic health services through the development of primary medical care;

- to improve the quality and standards of heath care, by upgrading clinical procedure, skills of the medical personnel, primary health care equipment, extending the process of re-accreditation of medical institutions, and implementing efficient monitoring and evaluation mechanisms;

- to improve measures for the prevention and treatment of socially conditioned diseases; 
- to increase service efficiency in the use of financial, human and material healthcare resources by continued rationalization of the hospital sector and the implementation of the mandatory health insurance to improve financial stability.

Good progress towards the achievement of the Millennium Development Goals for Moldova presupposes the improvement in a number of relevant indicators by 2006. It is envisaged to:

- reduce the under 5 child mortality rate from 18,2 (per 1000 children) in 2002 to 15,0 in 2006, and the infant mortality rate from 14,7 (per 1000 new-born) to 12,1 respectively;

- ensure the vaccination of children under the age of 2 to $98 \%$ against measles;

- reduce the maternal mortality rate from 28,0 (per 100.000 births) in 2002 to 23,0 in 2006, and ensure that qualified medical personnel attend all births;

- reduce the TBC associated mortality from 15,8 (per 100.000 persons) to 14,0 in 2006.

- reduce the incidence of HIV/AIDS from 4,66 (per 100.000 persons) in 2002 to 4,00 in 2006.

\section{Long Term Strategy}

524. The development of the mandatory healthcare insurance is one of main instruments to address the above-mentioned problems and improve healthcare. Introduction of market principles, and development of the competition on the healthcare market will contribute to the enhancement of the quality of medical services, and an improved healthcare management and efficient use of resources. The insurance by the state of specific groups will guarantee their access to healthcare services.

525. During the process of implementing the mandatory health care insurance system, special attention will be paid to the mobilization of sufficient financial resources to support the increased access of the poor to medical services. It is envisaged that the introduction of medical insurance will contribute to the partial solution of healthcare financing problems, by providing increased financing to improve the quality of medical services, and to increase the access of worse-off people to medical services.

526. In practice the introduction of mandatory health care insurance system is associated with certain risks. These include: the partial and untimely collection of the envisaged mandatory health care insurance contributions; the instability in attendance rates at medical institutions which can cause instability in the financing of these institutions; the poor management of finance and information flows; and the persistently low accessibility of services to the poor due to the obligation to pay for the services not included in the Uniform Program of mandatory health care insurance services. A permanent monitoring of the mandatory heath care insurance implementation process and its results and necessary measures will be undertaken in order to improve the overall efficiency of the system.

\section{Priority Actions 2004-2006}

527. To ensure the efficient development of the healthcare system, a number of measures must be implemented with the aim of improving conditions and outcomes of its activity, the most important of which are:

i) improvement of the regulatory and legal framework governing the relationships between the participants in the system and defining their rights and obligations,

ii) strengthening institutional capacity for collection, pooling and transfer of funds including accounting, administrative and IT capacities,

iii) ensuring transparent management of the NHIC's operations to maintain credibility with the contributors, 
iv) continuing accreditation of medical institutions,

v) development and implementation of an integrated medical information system in the public health care system;

vi) development and implementation of a system for monitoring and assessments of results;

vii) implementation of mechanisms for regulation and supervision of financial flows and quality of services;

viii) strengthening the capacity of national and regional staff in working with the new system.

ix) consolidating and strengthening the technical-material basis of the health care system through equipping medical-sanitary institutions with modern medical equipment and technologies.

528. Within the healthcare reform, the process of consolidation of medical institutions will continue. This will allow the focusing of resources on the development of advanced specialized medical centers in the Chisinau municipality in accordance with the hospital services restructuring program. Emphasis will be placed on increasing allowances for scientific research and information.

529. A major role in the improvement of the health of the population will be played by national programs financed from the state budget aimed at preventing and combating serious diseases. Among the most important programs which will be reviewed and improved are:

i) The National immunization program for 2001-2005,

ii) The National program for TB control for 2001-2005,

iii) The program for strengthening the material and technical resource base of the Blood Service,

iv) The National program for the prevention and treatment of diabetes - MoldDiab program for 20022005 ,

v) The program of quality perinatal services,

vi) The National Program for fighting viral hepatitis,

vii) The National Program for the prevention and treatment HIV/AIDS and sexually transmitted diseases for 2001-2005,

viii) The National Program for prevention and fighting cancer,

ix) Measures for fighting mental diseases, drug addiction and alcoholism.

530. Several programs are aimed at the improvement of mother and child care, including:

i) programs of medical assistance for pregnant women and sick children;

ii) the provision of compensated in ambulatory conditions drugs to babies and pregnant women. 


\subsection{SOCIAL INSURANCE}

\section{Situation Analysis}

531. The social insurance system is the main tool of social protection and is based on compulsory contributions. The contributions are accumulated and the following payments are made to the insured persons:

- retirement pension;

- disability pension;

- survivor pension;

- temporary disability indemnity;

- unemployment indemnity;

- sickness prevention indemnity and work rehabilitation indemnity;

- maternity indemnity;

- child raising indemnity;

- sick child care indemnity;

- death grant to cover burial costs in the case of death.

532. For some categories of citizens, particularly for the poorest, social insurance payments from the mandatory social insurance system are the main source of income. For this reason, poverty dynamics, incidence, gap and severity will depend on the efficiency of this system.

533. The development of the social insurance system was greatly restricted by a number of factors connected with the 1990s crisis and reforms in the country. Major changes in the level and structure of employment had a negative impact on the state social insurance budget. A cut in the number of employees in the economy caused a decrease in the number of insured persons and constrained the growth of social insurance contributions. The majority of Republic of Moldova's residents from abroad found themselves outside the mandatory social insurance system, for them being available only the voluntary insurance.

534. Meanwhile, the pensions system continues to be fragmented. The existence of numerous pension allowances violates the principle of "social equity". Besides this, a critical situation appeared in the area of pension insurance for workers in agriculture who contribute only $14 \%$ to the state social insurance budget (SSIB) but receive $52 \%$ of its incomes. Means gathered from contributions provide less than one third of expenditures needed for social insurance payments.

535. Until 2003, the real value of pensions was to be maintained through indexation with an increase of at least 5\% annually. But the accumulation of pension arrears made impossible the implementation of this mechanism and pensions were increased only through their recalculation. Starting with 2003 a new pension indexation procedure has been applied on an annual basis, taking into consideration not only the average inflation rate, as previously stipulated by law, by also the country's average wage increase.

536. The social insurance system accumulated a number of problems that need to be solved in the course of further reform of the system. The key problems are:

i. financial instability of the system;

ii. fragmented and non-uniform pension legislation; 
iii. significant and, in many cases, unfair redistribution of resources among different categories of insured persons;

iv. relatively small size of pensions and indemnities.

\section{Objectives}

537. The objectives aiming at eliminating the weaknesses of the current system are:

- To consolidate the financial stability of the social insurance system;

- To ensure consistency between insurance contributions, benefits and risks;

- To improve the methodology for calculating and reviewing the amount of payments.

\section{Long Term Strategy}

538. The main reason for the insufficient financial stability of the social insurance system is the decrease in the number of working people, the decline in social insurance funding, and low social insurance coverage. As the economy grows and the number of working people and incomes from working activity increase, the negative impact of the above will diminish. At the same time there are possibilities to increase the medium-term financial stability of the system by:

i) completing the work of keeping individual records of the insured and corresponding social insurance contributions which will encourage growth in the number of insured people;

ii) defining more clearly social risks against which each category of citizens is insured, which will increase the transparency of the system;

iii) introducing medium-term forecasts of revenues and expenditures of the mandatory state social insurance budget, taking into account macroeconomic, demographic and budget forecasts, which will help improve the management of funds;

iv) raising the efficiency of social insurance system administration by computerizing the procedures of individual record-keeping of insured persons and record-keeping of social insurance beneficiaries.

To implement these actions it is necessary to:

- develop and implement the computerized information system of individual tracking of insured persons and social insurance beneficiaries, of presenting reports in electronic format to the National Social Insurance House and self-service of contributors and social insurance beneficiaries through the web site www.CNAS.md;

- develop the concept, mechanism and components of the computerized informational system of servicing insured persons, state public and local bodies with information of social insurance;

- improve the mechanism of interaction with social insurance informational systems of economic agents, central and local public bodies;

- popularize the social insurance legislation and educate taxpayers on the voluntary payment of social insurance obligations.

539. In the area of pensions provision, the main tasks will be to:

i) further unify and harmonize the pension legislative framework and its practical application, as well as creation of single pension conditions for all pension categories;

ii) reform the pension system for those persons that work in agriculture; 
iii) apply the principle of dependence of the amount of pension on the size of contributions for each insured person;

iv) increase the amount of social insurance delivery through indexation.

540. In the medium term, the priority will be to improve the efficiency of the social insurance system. It will be necessary to revise the procedures and conditions for benefits paid to certain beneficiaries, to establish a clearer linkage between insurable risks and benefits payable when an insured event happens. The indemnity for raising a child from 3 to 16 years will continue to be offered through the insurance system. However, during the next years there will be developed a new mechanism for its delivery. Given the fact that these are granted based on obtained income, a new type of indemnity granted for families with children through the social assistance will be developed in the future.

\section{Priority Actions 2004-2006}

541. Priority actions will be directed to achieving the strategy's objectives. The improvement of the system will be pursued in the first place by analyzing the previous studies done in this area and the respective proposals for the reform of the system. This analysis will be carried out by the Ministry of Labor and Social Protection in 2004 and 2005.

542. Other priority actions will be to:

i. continue keeping individual records of the insured and a computerized informational system of corresponding social insurance contributions;

ii. develop a more accurate assessment of social risks;

iii. implement the medium-term forecasts of revenues and expenditures of the mandatory social insurance budget, taking into account macroeconomic, demographic and budget forecasts, which will allow improving the management of finances;

iv. reform the pension system for those in agriculture;

v. improve contributions' calculation methods;

vi. increase the amount of social insurance benefits.

543. Over the medium term, the priority will be to increase the quantum pensions and benefits paid from the social insurance system, because there is still a big gap between the size of these payments and the average monthly wage. At the same time additional financial resources from the budget will be necessary to diminish the disparity between pensions and wages, and to increase social insurance benefits. It is expected that improved transparency and efficiency in the social insurance system, combined with further economic growth will contribute to increasing the financial stability of the system, and growth of its resources. 


\section{Situation Analysis}

\subsection{SOCIAL ASSISTANCE}

544. The social assistance system is an important instrument in the redistribution of results of the economic development in favor of poor citizens. The achievement of poverty and inequality reduction goals is directly dependent on enhancing the efficiency of this system. The social assistance is a component of the social protection system and comprises a set of programs, measures and specialized services, targeted at the protection of persons, families, groups in difficult situations, which have no possibility to access on their own a decent life, due to economic, sociocultural, biological or psychological circumstances.

545. The current social assistance system includes two forms that can be used separately or in combination to meet the needs of people at risk: social benefits and social services.

546. Despite considerable changes, the social assistance system in terms of benefits and services in recent years, the overall performance of the system remains inefficient. The main problem is poor targeting of resources. In 2002 the poorest $20 \%$ (lowest quintile) of the population accounted for only $6.6 \%$ of the total amount of a social benefits (except pensions), whereas another $20 \%$ (upper quintile) of wealthiest citizens accounted for $46.0 \%$. That means that a considerable portion of the poor fall outside the monetary support system, and existing resources require a reorientation towards them.

547. The main shortcomings in the existing social benefits system are:

- $\quad$ social benefits are based on the category approach (except for two types of benefits granted on the basis of means testing: monthly indemnities for children aged 1.5-16, and cash benefits provided by the Social Support Fund);

- $\quad$ there is no well-grounded methodology for determining the sizes of different benefits, conditions and procedure for adjusting their quantum;

- $\quad$ there is no uniform record keeping of recipients of social benefits and as a result some people get payments within different programs, whereas a number of those in need fail to receive any social benefits;

- $\quad$ there is no system for monitoring and assessing the results of social benefit programs, and their impact on the welfare of recipients and poverty dynamics;

- $\quad$ there is no distinct mechanism for allocation and use of budgetary means for social assistance. Resources from the state budget are allocated to the mandatory social insurance budget and are managed within its budget by NSIH;

the legal and regulatory framework for social assistance is not consistent. Different benefits and allowances are regulated by numerous Government laws and regulations of, which are insufficiently connected with each other.

548. In some cases, intervention is much more efficient if a person benefits from a number of social services, beside social benefits. This is particularly relevant to disabled people. The system of social services is poorly developed and remains centralized. This system is developed at the central level and then dispatched for execution in the field. This does not allow for the assessment of real community needs and their specific problems.

549. Social services are targeted at only limited number of groups of people. Home-based services are rendered only to the elderly and disabled people living alone. These services are not extended to 
other groups such as disabled children or adults, and families in need of home-based support to their members.

550. At the same time, even the existing services do not meet the demand. The number of applicants is almost twice the number of actual beneficiaries. The lack of financial resources to maintain the network of workers and employ new ones is one of the causes of failure to meet the demand.

551. The fact that at present institutional based care forms are widely used can be explained by the underdevelopment of social services. From the cost-quality ratio perspective, this is not the most efficient form, neither for children nor for adults and the elderly.

\section{Objectives}

552. The main objectives of social assistance are to:

- improve the efficiency of the social benefit system by targeting them at the poorest, and focusing on the social groups at risk;

- develop the system of social services by diversifying and improving their quality and facilitating a more active involvement of civil society;

- develop and implement some specific programs, such as: protection of family and child and the protection of people with disabilities.

\section{Long Term Strategy}

553. To continue the social benefits systems reform, it will be necessary to address existing weaknesses relating to the financing procedures, organization and administration of this system.

554. Adjusting the mechanism of social benefits delivery is to be achieved through the following measures aimed at the improvement of targeting and increasing efficiency of the system:

i. impact monitoring of programs to improve social benefits eligibility criteria, to rationalize the types, forms and duration of benefits provision;

ii. provision of social benefits to the poor, consistent with the objectives of the social assistance system, which will require the development and approval of poverty criteria, a household welfare evaluation model and other necessary tools;

iii. creation of a separate social assistance budget, establishment of clear procedures for its formation, management and planning within the medium-term planning of budget expenditures;

iv. development and implementation of a unified data base of social assistance recipients, needed for the more efficient use of funds and their better targeting to the most needy citizens and families;

v. revision, consolidation and improvement of the legal framework regulating provision of monetary social assistance;

vi. improvement of coordination of measures and actions in the field of social assistance, provided at the central and local level by non-government organizations and foreign donors.

555. The system of social services will be developed in two directions: 
i) diversification of forms and types of social services;

ii) improving the quality of services rendered by social institutions and developing alternative protection forms adjusted to minimum quality standards.

556. In order to deinstitutionalize children, the disabled and the elderly, community-based social services will be developed, which will allow the maintenance of groups of persons at risk in their own family or community, through:

i. (re)integration into the community with the support from existing social services and social workers;

ii. (re)integration into their own families, extended families or placement at parental assistants (persons/families ensuring through their home-based activity the care and education needed for the harmonious development of children with a view to ensuring (re)integration into their own biological family, establishing guardianship, placement in family-type orphanages or adoption).

557. Development of new forms of social services requires the active participation of public authorities and local communities, improvement of social services locally and encouraging local civil initiatives. Thus, it is necessary to extend the spectrum of social services provided to the population. In the process of development and diversification of social services the role of local public authorities and civil society must be considerably increased. Passing from the development of universal centralized social policies to community forms would lead to a massive increase in civil society's participation in social life. In perspective, the community-based solution of social problems will be extended considerably.

\section{Priority Actions for 2004-2006}

558. Medium term actions will support the stipulations of the long-term strategy.

559. The impact monitoring of social assistance programs will be carried out under the general monitoring arrangements for EGPRSP implementation.

560. The current social benefit system (primarily of targeted benefits) will be improved through the gradual implementation of the beneficiary means-testing principle.

561. The process of developing and determining the mechanism for providing poverty social benefits will be gradually developed. The development of the necessary legislative framework, the identification of responsibilities and institutional arrangements have been planned for 2004. The terms of reference for the specification of poverty criterion, a household means testing model, and other necessary tools will be designed with external assistance.

562. In 2005-2006 the social assistance budget will be separated from the social insurance budget, while an efficient mechanism will be created and implemented providing clear procedures of planning and management of financial means for medium term social assistance.

563. The implementation of the single database of social assistance beneficiaries is also envisaged.

564. Over 2005-2006 a primary network of diversified social services under the Law on Social Assistance and the National Strategy on protection of child and family will be created. Minimum quality standards for social services provided by resident institutions and community centers will be developed, approved and implemented. A system for accreditation and monitoring of social 
services and evaluation of their quality will be set up within the Ministry of Labor and Social Protection in 2005.

\subsection{LABOR MARKET}

\section{Situation Analysis}

565. The economic crisis has led to a considerable fall in the number of jobs, sizable unemployment and labor force migration abroad. In 1994-1999 the number of employed in the economy fell by 193,000 people, or by $11.4 \%$. The most massive reductions in those in work occurred in 1998-1999 (151,000 employees, or 9.2\%), as a result of the Russian economic-financial crisis.

566. The recent economic growth has not had a significant positive impact on formal employment. In 2000-2002 the number of the employed rose by only 10,000 (0.7\%). In general, a visible mismatch persists between the supply of and the demand for jobs. According to the methodology of the International Labor Organization based on the labor force survey, the unemployment rate declined from $11.1 \%$ in 1999 to $6.8 \%$ in 2002. But this decrease in this "statistical" unemployment rate was due to a massive outflow of labor abroad, rather than to an increase in the number of jobs and rising employment in the national economy.

567. A decrease in the number of jobs inevitably resulted in a falling employment rate, a rising dependency burden on the active population, and a diminishing role of labor income in the formation of incomes of the population. In 2000-2002 incomes generated by hired labor and selfemployed activity in the non-agricultural sector accounted for only around $40 \%$ of the total disposable income of the population. At the same time some unfavorable changes took place in the employment structure. The share of those employed in the low-productivity agrarian sector increased (49.6\% in 2002) and the proportion of the employed in the budget-financed sectors $(17.3 \%$ in 2002), where salaries and wages are constrained by budget possibilities, also remained relatively high.

568. The number and share of hired employees has decreased. The economic crisis, the considerable cost of social insurance covered by employers, and the growing self-employment have exacerbated this trend. It is notable that in 2002 social insurance deductions accounted for $26.5 \%$ of direct expenses of employers for salaries and wages.

569. The official labor market is characterized by a low level of registration of the unemployed. In 2002 , only 24,000 people were registered as unemployed, whereas the number of the unemployed according to the ILO methodology amounted to 110,000 . The small number of those who go to employment agencies can be explained by weak capacities of these services to assist in resolving employment issues and rendering material aid. In 2002 only $38 \%$ of those who had applied to these agencies were employed, and only $6 \%$ of them got unemployment indemnities.

570. A shortage of work places, the low employment rate in the economy, the high proportion of those who get relatively low income from their work, and weak motivation for employers to create jobs and increase wages are the most crucial factors that determine the high level of poverty in Moldova.

571. Prevention and reduction of unemployment among young people is one of the priorities for both labor market policy and youth policy. Regardless of the recent onset of growth the unemployment problem among young people remains acute. In 2002 the unemployment rate among the youngsters aged 15-19 was $15.3 \%$, and for those aged $20-24$ was $15.1 \%$, which is more than twice the country's average unemployment rate. This issue is of international concern, which is why a need for its consequent solution is stated in the Millennium Development Goals. 
572. With regard to their employment prospects are concerned the second most vulnerable group following youth are socially vulnerable persons. There is a need to pay a special attention to the following categories of population: persons with disabilities (physical and mental), persons released from detention places and social rehabilitation institutions, drug addicts, etc. In the Republic of Moldova the number of disabled persons (according to the legislation - invalids) that benefit from social aid account for circa 111 thousands persons. The social inclusion policy is being promoted by the Ministry of Labor and Social Protection and by certain invalids associations, but this activity is a limited one. Through the system of the National Agency for Labor Force Employment in 2002 only 139 invalids have been employed, while the number of requests has been far larger. At the same time, there is a need to establish specialized institutions for offering integration services on the labor market for these categories of persons.

\section{Long Term Strategy}

573. In perspective, further economic growth must be accompanied by higher levels of participation of the labor force in production and services provision, by increasing employment and a growing importance of wage income in poverty reduction. Unemployment is partly caused by labor market regulation rigidities, which raise the transaction costs of adjusting the numbers of employees in an organization, as well as redistribution of employees' functions within organizations of enterprises. As with the policy for private sector development, deregulation to reduce bureaucratic barriers to job creation is considered to have the main impact.

574. Equally important for improving employment, incomes and wages is the implementation of an environment for private investment, the support of small and medium scale business and the development of the private sector as a whole. In the long and medium term perspective investment and small business promotion are the best solutions to unemployment

575. An important element of the Strategy will be to evaluate the outcomes of employment policies, to improve their content and impact. These polices will be adjusted on the basis of monitoring and review of their effectiveness. The results of evaluation will be used to improve the selection of policy measures, their content and objectives.

\section{Medium Term Measures}

576. The medium term perspective of addressing labor market constraints will be accomplished in two ways: the regulatory framework improvement, and offering administrative support for the market's more efficient operation.

577. The regulatory framework will be reviewed to ensure higher flexibility of the labor market and provide incentives for hiring.

578. The other priority area will be to improve the services and training of unemployed, especially of socially vulnerable groups' representatives. The main policies will aim at:

i) diversifying and improving the quality of employment services;

ii) assisting the disabled in finding employment;

iii) preventing unemployment of youth and assisting the young people in finding employment.

579. To improve the diversity and quality of services of employment, the following measures are planned: i) improvement of the technical equipment of employment agencies; ii) establishment of a labor market information system to keep the population informed on employment and retraining possibilities, as well as of the situation in the labor market in general; iii) update and diversify labor mediation services, iv) the development and optimization of the retraining and professional 
education system for the unemployed, according to the labor market situation; v) the improvement of the social protection system for the unemployed, vi) the implementation of marketing research and forecast on the labor market.

580. Providing employment assistance to the disabled is one of the elements of social protection for this category of the population. To facilitate access of disabled persons to jobs, three special training Centers will be established. A mechanism for the encouragement of flexible employment arrangements for the disabled will be developed and implemented, based on a thorough study of needs, as well as barriers of this group of population in integration on the labor market.

581. The main task is to reduce unemployment risks among young people, due to lack of job experience and the necessary professional training. Employers are not interested in employing young people who have to be trained and adapted to specific jobs, because this requires additional costs. In 2002 expenses for the professional training of staff accounted for only $0.4 \%$ of all employers' expenses on labor force. Thus, professional orientation, information, consultations, employment assistance to the young, especially to those who are looking for a job for the first time, will be provided by appropriate state administration bodies. It is planned to establish a network of centers for information, professionally orient and integrate young people under primarias (municipalities), education institutions, and territorial employment agencies. These Centers will also provide advice to young people on how to set up their own businesses, which will simultaneously facilitate the development of small business.

\section{Situation Analysis}

\subsection{YOUTH POLICY}

582. The social and economic situation in the country has affected all social categories, but the main victims of transition are the children and youth. The youth constitute $25.7 \%$ of the total population i.e. each fourth person is aged between 15 and 29 years. Recent opinion polls have established that, regardless of place of living, the most acute problems of young people are linked to low levels of income, unemployment and healthcare, limited access and low quality of education, and high levels of insecurity and criminality. During the transition period, youth became one of the most vulnerable social layers.

583. Opportunities for employment are limited, and that is why many young people see no economic future in Moldova. Furthermore, the few economic opportunities that exist are not equally accessible to youth from different regions. Youth from villages and towns are affected by unemployment, but most hardly hit are young persons with disabilities. The lack of professional and economic opportunities compels many young people to leave the country. As a consequence, human trafficking and the number of youth involved in criminal activities are alarming.

584. Many young people abandon school, and few get adequate professional training, especially because of limited access possibilities, and resources to benefit from good quality and competitive education. Education methods are inadequate to develop a critical and independent capacity to think, necessary in modern society. When starting to work, many young people realize that they lack the skills and competences necessary to start an independent life. This is especially important in the education and professional training, areas that require special attention.

585. The vulnerability of youth is maintained because of the continuous transition that the country is going through. Young persons are susceptible to a range of economic, physical and psychological risks. The effects of this phenomenon can be seen in our society, for example, in the existence of a large group of excluded or marginalized young people, growth of drug abuse, youth violence, spread of sexually transmitted diseases and HIV/AIDS, and dark perceptions of the future combined with the general feeling of incapacity and uncertainty. All these represent major dangers 
that undermine the reproductive and sexual health of youth. In general, the extended poverty has a dramatically impact on the health of youth.

586. Despite the chances and opportunities developing under the country's new pluralist system of democracy, the participation of youth in public and political life continues to be limited. In our society, young people are most of the time excluded from decision-making processes. Their participation in the electoral process continues to be insignificant. This does not mean that they are not interested in the problems affecting them or are not ready to look for solutions for these problems. Because of the absence of youth in the decision making process, the problems they face are unknown.

\section{Objectives}

587. The main objectives in this area are to:

i) improve employment and self-employment prospects for young people;

ii) increase the accessibility to educational and health services, as well as to those regarding healthy living and personal development;

iii) develop human and institutional capacities in working with the youth;

iv) stimulate the involvement of young people in the decision-making process in the areas of social, economic, cultural and political development of the country, by creating local youth councils and other forms of participation;

v) facilitate access to information, to services and quality leisure time.

588. Government actions in the field of youth will be guided by four key principles: (i) guaranteeing non-discrimination - every young person has equal rights regardless of race, color, sex, age, religion, ethnic origin, social origin, political orientation, family, place of living or any other characteristic; (ii) ensuring equal opportunities - every young person, regardless of his/her background, will be offered the chance to develop his/her potential as an individual, as well as a citizen; (iii) respecting the youth as citizens - young persons are full citizens, with the same rights and obligations as any other group in society, including the right of expression, opinion and meeting; (iv) encouraging youth participation - young people are to be encouraged to exercise their rights in order to be able to fully participate in the life of society.

589. Young people will be offered the opportunity to express freely their opinion on the problems they face and to be listened by administrative institutions, directly or with the help of a representative body, as well as to participate in formulating youth policies. The Government will implement this by: (i) consolidating the social partnership with civil society, especially youth associations; (ii) encouraging dialogue and the inter-ministerial cooperation on youth problems; (iii) consolidating European and international cooperation in youth problems and related areas; (iv) creating an adequate legal framework on the basis of European practices.

590. To ensure the access to information and services, the following measures will be accomplished: (i) undertaking studies regarding the youth situation and, based on such studies, revising youth policy; (ii) ensuring the access of the young to information regarding the rights and opportunities in all spheres of activity (education, healthcare, social protection, leisure time etc.) by creating a national network of youth service Centers; (iii) the development of a promotion program through the mass-media (TV, radio, written and electronic press) of social messages pertaining to healthy life style and youth development; (iv) ensuring quality services for the youth within the framework of healthcare, educational and social assistance institutions; (v) the development of policies for supporting young families, searching for possibilities to ensure them with dwelling premises, child care facilities, consultations for young mothers, etc.; (vi) the promotion of special 
programs for groups of disadvantaged youth and youth at risk, in order to prevent and fight against their social exclusion.

591. In order to reduce unemployment amongst young people, there will be a series of measures, including: (i) vocational training of unemployed youth, review and modernization of the youth vocational training system, youth support in rural areas through the development of private financing of agricultural and non-agricultural activities; (ii) contribution to the reduction of the youth emigration and stimulation of the reverse flow of the young people studying and working abroad, by creating work opportunities in the country; (iii) conclusion of bilateral agreements with other countries regarding the legalization of the work of the young abroad.

592. One of the basic principles of state policy will be the active participation of the youth in the life of the community. To achieve this, the Government will promote young people as equal and dynamic partners in the political, economic and social life of the country, will create a mechanism for permanent inter-sector consultations (education, healthcare, social protection, police, army, local public authorities) with the participation of civil society and foreign donors for the accomplishment of the strategy and action plans in the field of youth. The Government will create conditions for cooperation of youth and youth associations with governmental bodies and local public authorities, will promote voluntary services as a form of youth participation and social integration, will support development of youth networks and associations throughout the country.

593. Favorable conditions for organizations and persons working with and for the youth will be created. The education of youth specialists will be facilitated and voluntary youth leaders training will be offered. The Department of Youth and Sports will integrate the national, regional and local youth administrations and programs and will create a link between them and the activities of nongovernmental organizations. The youth situation will be permanently monitored and evaluated on the basis of a National Youth Research Center.

594. To utilize the leisure time of the young, local authorities and civil society organizations (mayoralties, schools, the church) will be encouraged to use existing resources to meet the interests and needs of the young, will stimulate the private sector to offer support and consolidate the technical-material basis for organizing leisure time activities at the local level, will ensure proper conditions for the development of international contacts between young people and will support talented young people in various areas of human activities. 


\section{EXPECTED OUTCOMES AND RISKS IN STRATEGY IMPLEMENTATION}

595. Over the last four years, a modest economic growth has taken place in Moldova. The macroeconomic situation stabilized, and income levels increased. At the same time, the achieved economic growth is more perceived as a statistical trend with no significant impact on the lives of ordinary people. This contradiction is due to the fact that economic growth is based on traditional factors, and its results are not efficiently and equitably distributed. As a result, there is little new potential for economic development, which could provide sustainable development of the country in the long-term and ensure higher living standards and better quality of life for the people.

596. The main objective of the EGPRSP consists in laying a foundation for changing the quality and nature of economic development, and humanizing the principles and process of the distribution of its outcomes. To this end, it is necessary to focus efforts on overcoming the constraints and imbalances, which impede long-term sustainable economic and human development. These constraints and imbalances can only be eliminated by the successive solution of problems in the field of investment and business activity, which, in turn, require qualitative changes in the entire economic management system. The substantial growth in investments, exports and employment are the basic conditions for Moldova's transition onto a socially focused development trajectory.

597. The strategy covers a range of issues and actions, which are not over-ambitious in them. Nevertheless, the successful fulfillment of tasks will lead to ambitious results. For the first time a single document covers issues related to the overall direction of the macroeconomic policy, and, furthermore, describes the tasks and priorities of the development for almost all sectors and fields of activity in the national economy.

598. The integrated and systemic character of policies for the medium term is considered by the Government as a precondition for success. For more than ten years experience has been gained in implementing economic and social reforms under market economy conditions. The critical assessment of this experience and constructive learning from the experience will help in addressing problems in qualitatively new ways.

599. The Government anticipates the support of civil society in the attainment of the objectives and priorities of the strategy. This rationale is based on the high expectations of citizens concerning the positive changes in the economy and their personal well-being. The country's authorities consider the openness of the document and its policies, and the dialogue with civil society, as major success factors in the strategy's implementation.

600. There are also risks, which might prevent the achievement of objectives or reduce predicted outcomes. These include the limited experience to date in carrying out well-targeted policies that require professionalism, special instruments and mechanisms for their efficient implementation and monitoring, as well as limited skills in co-coordinating activities to effectively address priority issues. Therefore, the implementation of the strategy can only succeed through a radical change in the management system and its components.

601. It is possible that upgrading the country's management system will be the most difficult issue, which needs to be addressed. The inadequate development of market economy institutions and infrastructure may be an additional weakness hampering the process of achieving planned objectives. Emphasis is placed in the strategy on the development of the private sector, and this requires accelerated development and introduction of new mechanisms, tools and infrastructure. An issue, which needs to be addressed, is the uneven regional development of market infrastructures, which, in turn, gives rise to an uneven regional development of the private sector in the country. 
602. Finally, external debt and lack of external support may impede the flow of investments into the economy. Inadequate investment will not allow Moldova to achieve the priorities set forth in the strategy, including in the social sector. Attempting to upgrade the economy under conditions of investments shortages will prevent the successful resolution of problems related to poverty and distribution. The Government recognizes that the successful implementation of the strategy depends on the endeavors and actions of the country's management, the support of the business community and citizens, and, crucially, on the provision of external support.

\section{EGPRSP IMPLEMENTATION, MONITORING AND EVALUATION}

\subsection{Implementation}

603. Following the approval of the EGPRSP, the economic and social development programs will be adjusted according to the sectoral priorities and policies provided by the strategy. The new programs and projects at the national, local and sectoral level will be harmonized with and promote the realization of the medium and long-term objectives stipulated in the EGPRSP.

604. The EGPRSP implementation process will be developed at national and local levels. At the national level, line ministries and departments will be responsible for the implementation of the strategy's components. The local public administration bodies will lead the EGPRSP's implementation at the local level. The Ministry of Economy will have a coordinating role in this process.

605. Both line ministries and local administrations will cooperate with civil society and private sector organizations. The implementation of a series of envisaged activities could be even outsourced to relevant NGOs.

606. A critical role in the implementation of the EGPRSP will be played by the civil society, which should:

- act as a "social watch" and actively participate in the monitoring and evaluation processes, including through the generation and dissemination of independent data;

- engage in a policy dialogue with the government and provide feedback on the effectiveness of the chosen strategies and policies;

- advocate more effective policy options;

- assume responsibility for the implementation of specific initiatives.

607. The participation and consultation processes, initiated during the elaboration of EGPRSP, will continue throughout implementation, to support monitoring, evaluation and adjustment of the strategy. The EGPRSP will be adjusted according to the experience gathered in the implementation phase. The organizational forms will evolve as well, in order to ensure the interaction of all parties interested in the successful implementation of the strategy.

608. The oversight and coordination role of EGPRSP implementation, monitoring, evaluation and annual update will be performed by the EGPRSP National Council, headed by the President of the Republic of Moldova. The tasks and functions of the EGPRSP National Council are: (i) coordinating activities for implementation, monitoring and annual update of EGPRSP; (ii) approving annual plans for EGPRSP implementation; (iii) hearing and approving the annual report on EGPRSP and MDG implementation; (iv) facilitating the interaction between the executive, legislative and local public administration bodies in the EGPRSP implementation process, as well as of the civil society. 


\subsection{Monitoring and Evaluation}

609. Within the EGPRSP implementation a continuous monitoring and evaluation process will be developed at national and local levels. It will include:

i) monitoring the implementation of sectoral policies and of the overall EGPRSP;

ii) monitoring and evaluation of achieved results;

iii) evaluation of the impact of implemented policies on the poverty reduction and economic growth objectives.

610. The final indicators of impact will be widely used not only during the evaluation, but will also serve for measuring the level of the achievement of fundamental goals. Intermediate indicators used during monitoring, measure contributions, actions and factors, whose combined effect assists the attainment of final objectives. During EGPRSP implementation, the indicators will be reviewed and improved for a better measurement of progress achieved.

The EGPRSP monitoring and evaluation envisages the use of final and intermediate indicators. The list of final and intermediate indicators is provided in Annex 5.

611. Special groups (Monitoring Units - MU) made up from personnel of respective divisions from ministries and departments will monitor the implementation of sectoral policies, and of the final and intermediate progress of policies and actions implementation.

612. The MUs will be responsible for:

- monitoring the implementation of sectoral action plans;

- monitoring and recording results of ongoing activities;

- reporting on progress towards established targets, based on defined sectoral indicators;

- monitoring sectoral trends;

- analyzing impact of the specific policies on the situation in the sector;

- developing recommendations for alternative policies and sectoral interventions and revising sectoral action plans accordingly;

- ensuring cooperation and coordination between relevant entities for the implementation of cross-sectoral initiatives;

- ensuring proper information sharing.

613. The coordination of the monitoring and evaluation process at local levels will be performed by the economic directorates/sections of the municipal and raion councils. The involvement of local communities will be ensured through representatives of public authorities, community organizations, nongovernmental organizations networks etc.

614. The MUs will provide local communities with necessary support, thus ensuring the information flow from national to local level through dissemination of relevant materials, publications, reports, etc.

615. Regional forums will be organized annually to discuss progress and plans, and evaluate EGPRSP impact in every region. Annual reports will be published in each region, based on monitoring data, collected evaluations and results of the national forum.

616. The Ministry of Economy will:

i) coordinate the monitoring and evaluation process at interdepartmental and regional levels;

ii) perform the synthesis analysis of impact of policies promoted to achieve the EGPRSP objectives at the national level. 
617. To achieve these goals the EGPRSP Implementation Monitoring Unit (EIMU) will be formed. This unit will comprise three subdivisions:

- A division for monitoring and synthetically evaluating the EGPRSP's implementation;

- A division for monitoring poverty and the impact of poverty reduction policies;

- A division facilitating information, communication and participation.

Box 4

EIMU will perform the following main functions:

Work planning:

- Development, in cooperation with line ministries, of the EGPRSP Annual Implementation Work plans and follow up on their implementation;

- Setting specific final and intermediate targets and performance indicators, to be used in monitoring and evaluation, including by the implementing partners (line ministries); making recommendations on measurement methodologies and tools;

Monitoring:

- Regular monitoring of various intermediate and final indicators; aggregating national data;

- Rating progress towards the agreed objectives and providing relevant comments to implementing partners;

- Ensuring the consistency, quality and coherence of data and monitoring mechanisms used by implementing partners;

- Providing capacity building support to implementing partners;

- Monitoring the progress of the Republic of Moldova in achieving medium and long term goals;

Analysis and evaluation of Policies and Reporting:

- Reviewing and analyzing current situation in the country, including regular poverty analysis;

- Assessing the impact of policies set forth in the EGPRSP;

- Analyzing links between various sectoral policies;

- Providing policy recommendations to both the National Council and implementing partners (line ministries);

- Facilitating more consistent data application for evidence-based policy development and advocacy;

- Preparing annual reports for EGPRSP implementation and MDG reports;

Information, Communication, Participation

- Coordinating various information flows and disseminating relevant data/reports to interested parties, especially the National Council, line ministries, general public, through structures and networks existing at national and local levels;

- Facilitating, in cooperation with the Participation Council, the involvement of various stakeholders in the policy analysis and monitoring and evaluation process;

- Providing support in organization of the mandatory evaluation;

- Providing assistance in organization of the activity of the Participation Council.

618. The EIMU will be maintaining an integrated database of strategic economic and social development indicators (MDG, EGPRSP, EU, etc.) and will act as a main point of contact ("one-stop shop") for the development of data. This web-based database will be open for public access to foster ownership and participation. 
619. The Participation Council will play an active role as facilitator of participation of all stakeholders - at the national and local levels, within and outside government. It will ensure that participation is carried out effectively and will have the responsibility for: (i) ensuring transparency of EGPRSP implementation; (ii) mobilizing and facilitating the involvement of different partners into the implementation of specific activities; (iii) serving as a discussion forum for various stakeholder groups aimed at the identification of innovative solutions to problems and challenges; (iv) fostering a meaningful policy dialogue between the civil society and the government; (v) facilitating participatory monitoring and independent evaluation of the results achieved; (vi) ensuring, in cooperation with EIMU, the development and implementation of a sound communication strategy, including wide and timely dissemination of the relevant information to partners.

620. The Participation Council will comprise representatives of different constituent groups, in particular of central authorities (Parliament, Government and Presidency), local public administration, NGOs, private sector, trade unions and donors. The PC will be formed to a great extent by representatives of the civil society. Members of the Council will be delegated by representative organizations/coalitions/unions. The terms of reference of the PC and the meetings schedule will be set during its first sessions.

621. The Participation Council will initiate the creation of Working Groups to address specific sectoral or cross-sectoral issues. The Working Groups will facilitate discussions with participation of representatives from ministries/departments and civil society.

622. The EGPRSP will be updated annually based on information collected from a number of sources and discussions first at the local, and then at the national level. National level debates will provide a series of documents, which will be discussed with all stakeholders from the Government, civil society and donors. As a result of these meetings, the progress achieved over the year will be assessed and opinions to improve the policies and plans for the next year will be shared.

623. The report "Policy on Poverty Reduction Impact in Moldova" will be annually developed and submitted. It will be presented to public for discussions and suggestions on how to improve the strategy. The National Council will be responsible for the examination and approval of the report. 


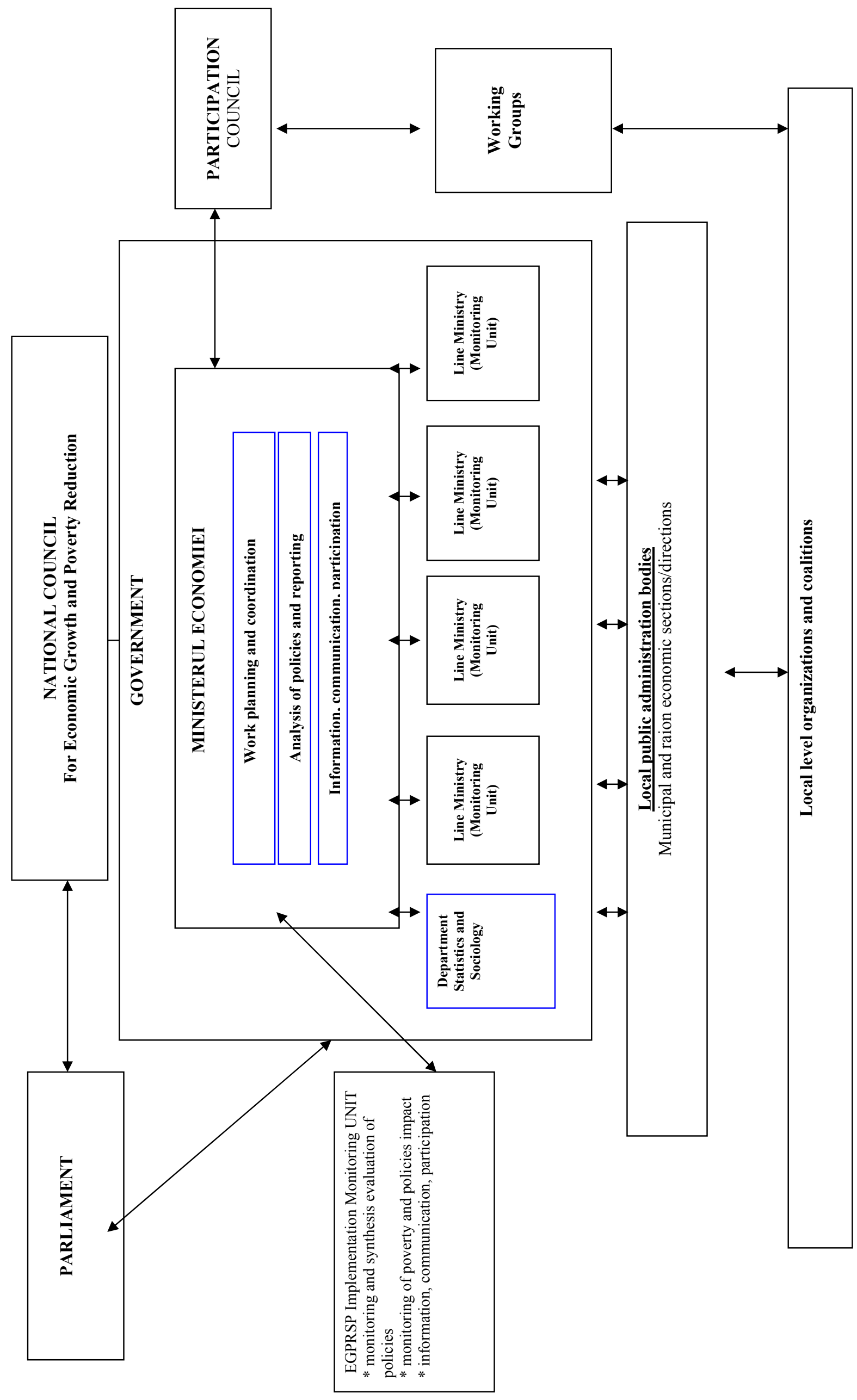




\subsection{Sources of information for monitoring and evaluation}

624. For monitoring and evaluation of the results of EGPRSP implementation, a series of statistical and administrative data will be used. These data will be compiled and submitted by the Department Statistics and Sociology, National Bank of Moldova, other central and local public administration bodies.

625. It will be necessary to improve the informational and methodological base for monitoring and evaluation, through:

i) Undertaking the population's census, which will generate more reliable information on demographic situation, and lead to improvements in the sampling framework for conducting the Household Budget Survey, Labor Force Survey, and other statistical researches;

ii) Developing with the support of donors new social researches on health status, living conditions, access to studies etc., including participatory poverty evaluation and qualitative surveys, and using the views of poor as an important performance indicator;

iii) Officially approving the methodology for measuring the poverty line;

iv) Developing a poverty map for the detailed monitoring and the development of more efficient poverty reduction policies at the local level;

v) Specifying the list of poverty indicators, to be published by the Department of Statistics and Sociology.

626. To improve the quality of information used by ministries and departments in monitoring and impact evaluation, the interaction of these bodies with the Department of Statistics and Sociology will be improved. The later will concentrate on defining and improving indicators to ensure the correspondence between indicators with final and intermediate impact of the strategy.

627. The dis-aggregation of information will be important to ensure that different stakeholders will be able to analyze the impact of strategies over a variety of groups. Whether possible, data will be structured by sex, age, ethnicity, socio-economic status and geographic location.

628. Information and methodologies used in assessing progress will be published to ensure transparency. This will allow external bodies, such as NGO coalitions, to access the information and to provide an independent evaluation of the efficiency of public policies.

\subsection{Development of statistics}

629. The new law on statistics will improve the legal framework on statistical activity and ensure its correspondence with the guidelines approved by the Statistics Division of the United Nations in April 1994.

630. Improvements will be made in compiling statistical indices and revising methodologies for data collection and processing in line with international standards, and, especially, those of the European Union. A priority will be the development of reliable information on the sustainable economic, social, and environmental development of the country and, especially, of the data necessary to monitor the implementation of EGPRSP objectives, progress towards the attainment of the Millennium Development Goals and the indicators included in the IMF General System and Special System of Data Dissemination. To this end statistical work will efficiently combine surveys and administrative data. 
631. Of special importance is the Population's Census, envisaged to be undertaken in 2004, and the General Agricultural Census, scheduled to be undertaken in 2006, that will ensure the gathering of important statistical data on the demographic situation and the state of agricultural sector, as well as generate valuable information for further statistical work.

632. In the area of economic statistics emphasis will be placed on establishing an integral system of enterprises' statistics, comprised of a coherent set of annual, monthly and quarterly observations in accordance with international standards. The core of this system will comprise the National Register of Statistical Units (NRSU) that will be continuously updated, as well as complimentary statistical research.

633. In the field of social statistics studies on the labor force and the living standards of the population, they will be improved by creating a network of universal "Master" survey that will include various new modules. This will contribute to the improvement in the efficiency and coverage of statistical data, which are indispensable for the multidimensional monitoring of the populations' welfare.

634. Measures will be undertaken to develop technical capacities by: i) equipping IT hardware with licensed software products; ii) fundamentally modifying the process of information gathering, storing and dissemination; iii) creating centralized databases, to be used for statistical purposes by authorized users in order to protect data confidentiality; iv) maximizing the capacities to satisfy the increasing informational requirements of users regarding diverse statistical data; v) ensuring a better compatibility with other information systems in order to create an integrated national informational system.

635. The system of statistical classifications will be elaborated and developed further in a number of economic, social, and demographic areas harmonized with European Union classifications (NACE, CPA, PRODCOM). From 2004, statistical data will be developed only on the basis of the new national statistical classifications of economic activities (CEAM), of products (CP). From 2005 the inclusion of industrial products and services (PRODMOLD), will allow the modernization of the cycle of statistical data collection, processing, storing and disseminating, in order to use more efficiently the resources, improve the quality, reduce the costs of developing and disseminating statistical information.

636. Emphasis will be placed on human resources development, by i) improving the qualifications of staff; ii) providing training to personnel both abroad and within the country, involving foreign expects; iii) motivating employees in order to increase the efficiency of their activity; vi) creating better working conditions in order to increase the attractiveness of statistical work and develop the professional competences of staff.

637. An increased attention will be paid to international cooperation in the field of statistics by: i) compiling data in accordance with international standards in order to ensure their comparability and the continuous improvement of statistical methods and IT; ii) presenting the information to international bodies in accordance with the responsibilities assumed by the state. 


\section{ACTIONS, COSTS, AND LINKAGE TO MTEF}

638. A comprehensive package of priority actions to support the EGPRSP strategies is presented in the Policy and Action Plan Matrix in Annex 6. The Matrix also indicates the lead-implementing agency, additional funding requirements, and timing of actions.

639. There are priority actions for 17 sectors and these are distributed over a larger number (about 30) of programs. Approximately 50\% of the actions have "nil" or "low" additional funding implications. "Nil" refers to actions to be carried out from existing budgets and includes legal and regulatory drafting, internal studies and policy and strategy reviews. "Low" is where limited funding is needed, e.g. for studies requiring local consultants, small group training, local information systems etc.

640. Actions have been ranked in order of priority by sector, and, in some cases, by sub sector. Guidelines to assist with the prioritizing of actions were issued to line ministries towards the end of the EGPRSP preparation. Ministries were requested to focus on the following criteria in preparing their prioritization decisions:

- activities and expenditures which contribute, directly or indirectly, to the reduction of poverty and/or the facilitation of economic growth. The numbers, type, and location of beneficiaries, and the extent of the benefits should ideally be identifiable;

- activities and expenditures which can affordably be extended to all within a relevant target population rather than to a few;

- expenditures which favor vulnerable and disadvantaged groups;

- expenditures that involve making savings e.g. the closure of underutilized facilities, and replacement services provided more cheaply or with better quality;

- expenditures for which activities are well-planned with realistic and modest costs.

641. At this stage, it has not been possible to apply prioritization criteria rigorously. The applications of the poverty criteria have been limited by their introduction at a relatively late stage, and by relatively weak policy analysis capacities in the Ministries. In addition, policy traditionally has had a solely growth oriented direction, with little regard for the socio-economic benefits or impact on poverty. Training and mentoring will focus on this aspect in the next round of EGPRSP to strengthen the conception and application of pro-poor sectoral strategies and actions.

642. Indicative costing figures for actions are provided in Annex 7. The table shows actions (as identified by line ministries) which will be covered under the Ministry of Finance Medium Term Expenditure Framework (MTEF) sectoral envelops, and the remaining actions for which funding is not secured. Costs are estimated on a preliminary basis. A contingency item has been included for activities for which costing are not available. Technical Assistance (TA) requirements, defined as non-project investment support, are indicated but not estimated. The table below shows the figures for aggregate funding needs for 2004-2006.

Table: EGPRSP Total Costs 2004-2006 (million Lei) and Percentages of Total

\begin{tabular}{|l|l|l|l|}
\hline & \multicolumn{1}{|c|}{2004} & \multicolumn{1}{|c|}{2005} & \multicolumn{1}{c|}{2006} \\
\hline Activities under MTEF & 948,3 & 1154,0 & 1114,1 \\
\hline $\begin{array}{l}\text { Activities with unsecured } \\
\text { funding }\end{array}$ & 1195,8 & 2152,2 & 2664,8 \\
\hline
\end{tabular}




\begin{tabular}{|l|l|l|l|}
\hline Total & 2144,1 & 3306,2 & 3778,9 \\
\hline
\end{tabular}

643. The estimated total costs increase from Lei 2144.1 million in 2004 to Lei 3778.9 million in 2006. The figures show that the MTEF will be able to finance approximately $44.2 \%, 34.9 \%$ and $29.5 \%$ (proportions) in 2004, 2005 and 2006 respectively. The activities with unsecured financing are candidates for consideration by development partners.

644. Ministry of Finance assessments (supported by the main donors) suggest that it is unrealistic to expect the EGPRSP to generate large flows of new, additional resources during the EGPRSP period 2004-2006. The domestic resource position will continue to be extremely tight during the next three years. There is no realistic basis for expecting additional domestic resource flows above those already included in the MTEF ceilings.

645. Recent trends of external project financing (recorded by the Ministry of Finance) show that donor commitments between 2000 and 2003 averaged $\$ 30$ million, about 90\% of which was in the form of credits, the remainder being provided as grants. Projected commitments for 2004 are for US\$33 million in new credits and US $\$ 2.3$ million in grants.

646. Because of the long lead times involved with external financing, most external donor flows for 2004-2006 are already committed and are in the pipeline. Analysis carried out by the Ministry of Finance suggests that an optimistic scenario for new commitments of external grants and financing (for both budget support and projects) would be around \$60 million in 2005 and US\$67 in 2006. Disbursements of new financing, however, would be significantly below this level at around US\$16 million in 2005, and US\$37.5 million in 2006. Of this disbursement figure, a substantial share of the budget support financing (US\$11 million in 2005 and US\$18 million in 2006) is already taken into account in MTEF ceilings. This leaves only US\$5 million in 2005 and US\$19.5 million in 2006 for spending on the new activities proposed under the EGPRSP.

647. The Government recognizes that an increase in current levels of assistance is dependent on building and maintaining confidence by the preparation and effective implementation of a sound, reform oriented and realistic EGPRSP, and is committed to this end. The Government hopes that the EGRPSP will be able to provide a basis for additional development partner flows.

648. It is also recognized that new activities to support the EGPRSP will need to be financed in part from within existing resources, by restructuring existing budgets, reducing costs and using the savings on new priorities. The three main spending sector Ministries (Education, Health and Social Protection) have been involved in robust policy and expenditure analysis under the MTEF. This is leading to significant improvements in spending policies in those ministries. The expansion of the MTEF methodology in other sectors will provide a general strengthening of capacity in the area of public expenditures. 
ANNEX I. POVERTY PROFILE

Table 1.1. HOUSEHOLD MEMBERS, THEIR rate and structure OF POVERTY according to the selected characteristics, 2002 (percent)

\begin{tabular}{|c|c|c|c|c|c|}
\hline & $\begin{array}{l}\text { All household } \\
\text { members }\end{array}$ & & & Extrem & or \\
\hline & & & & & \\
\hline Urban & 36.8 & 32.2 & 29.9 & 19.4 & 27.5 \\
\hline Rural & 63.2 & 45.1 & 70.1 & 30.2 & 72.5 \\
\hline Total & 100.0 & 40.4 & 100.0 & 26.2 & 100.0 \\
\hline 2. Household size & & & & & \\
\hline 1 person & 10.4 & 34.6 & 9.1 & 19.6 & 8.0 \\
\hline 2 persons & 22.6 & 32.9 & 18.4 & 18.7 & 16.0 \\
\hline 3 persons & 22.8 & 35.4 & 20.2 & 20.4 & 18.0 \\
\hline 4 persons & 25.2 & 43.4 & 26.8 & 30.6 & 28.9 \\
\hline 5 persons & 12.4 & 49.8 & 15.2 & 36.6 & 17.3 \\
\hline 6 and more persons & 6.7 & 63.0 & 10.3 & 46.4 & 11.8 \\
\hline Total & 100.0 & 40.4 & 100.0 & 26.2 & 100.0 \\
\hline 3. Household type & & & & & \\
\hline One-member Household & 10.4 & 34.6 & 9.1 & 19.6 & 8.0 \\
\hline Couple without children & 16.3 & 32.5 & 13.1 & 17.4 & 10.8 \\
\hline Couple with under-18 children & 30.9 & 42.0 & 32.2 & 28.3 & 33.1 \\
\hline Lone parent with under-18 children & 6.9 & 34.4 & 5.9 & 22.4 & 5.9 \\
\hline Other households with under-18 children & 22.7 & 48.0 & 26.9 & 34.6 & 30.1 \\
\hline Other households without children & 12.7 & 40.9 & 12.8 & 25.2 & 12.1 \\
\hline Total & 100.0 & 40.4 & 100.0 & 26.2 & 100.0 \\
\hline 4. Household composition & & & & & \\
\hline Household with 1 child & 26.8 & 36.1 & 24.4 & 23.9 & 24.6 \\
\hline Household with 2 children & 23.8 & 45.4 & 26.4 & 31.9 & 28.7 \\
\hline Household with 3 children & 7.4 & 53.4 & 9.7 & 38.5 & 10.9 \\
\hline Household with 4 and more children & 2.7 & 69.5 & 4.5 & 48.6 & 4.9 \\
\hline Household without children & 39.3 & 35.8 & 35.0 & 20.5 & 30.9 \\
\hline Total & 100.0 & 40.4 & 100.0 & 26.2 & 100.0 \\
\hline 5. Social-economic groups & & & & & \\
\hline Farmers & 20.8 & 47.3 & 24.0 & 32.7 & 25.8 \\
\hline Agricultural employees & 14.7 & 56.0 & 20.1 & 39.5 & 22.4 \\
\hline Non-agricultural employees & 34.1 & 28.0 & 24.1 & 17.0 & 21.9 \\
\hline Entrepreneurs & 2.3 & 18.8 & 1.0 & 6.1 & 0.5 \\
\hline Pensioners & 26.1 & 45.5 & 29.1 & 28.4 & 27.9 \\
\hline Others & 2.1 & 32.6 & 1.7 & 19.9 & 1.6 \\
\hline Total & 100.0 & 40.4 & 100.0 & 26.2 & 100.0 \\
\hline 6. Main source of income & & & & & \\
\hline Remunerated activity & 31.7 & 29.3 & 23.4 & 18.2 & 22.0 \\
\hline Individual agricultural activity & 41.8 & 46.8 & 48.0 & 31.5 & 49.9 \\
\hline Individual non-agricultural activity & 2.2 & 22.6 & 1.2 & 11.7 & 0.9 \\
\hline Social allowances & 12.6 & 59.1 & 18.1 & 39.1 & 18.5 \\
\hline Other sources & 11.7 & 32.3 & 9.3 & 19.1 & 8.6 \\
\hline Total & 100.0 & 40.4 & 100.0 & 26.2 & 100.0 \\
\hline 7. Number of employees & & & & & \\
\hline 1 person households & & & & & \\
\hline Without an employee & 7.2 & 42.3 & 7.6 & 23.3 & 6.5 \\
\hline 1 employee & 3.2 & 18.5 & 1.5 & 11.7 & 1.5 \\
\hline Households with 2 and more employed & & & & & \\
\hline Neither person works & 12.5 & 44.3 & 13.3 & 26.1 & 12.0 \\
\hline 1 employee & 21.6 & 35.1 & 19.1 & 22.1 & 18.2 \\
\hline Two employees & 42.0 & 39.7 & 41.5 & 26.2 & 42.4 \\
\hline Three and more employees & 13.5 & 51.8 & 17.0 & 38.2 & 19.5 \\
\hline Total & 100.0 & 40.4 & 100.0 & 26.2 & 100.0 \\
\hline 8. Educational level of the HH head & & & & & \\
\hline Higher and incomplete higher education & 11.5 & 13.3 & 3.9 & 6.3 & 2.7 \\
\hline Secondary and vocational studies & 58.0 & 40.8 & 58.5 & 26.3 & 58.2 \\
\hline Incomplete secondary and primary education & 27.2 & 49.4 & 33.0 & 34.0 & 34.9 \\
\hline No primary education or illiterate & 3.2 & 59.2 & 4.7 & 34.5 & 4.2 \\
\hline Total & 100.0 & 40.4 & 100.0 & 26.2 & 100.0 \\
\hline
\end{tabular}

Source: PPMU based on HBS data. 
Diagram 1.1. Evolution of the absolute, extreme and relative poverty rate in $1998 \mathbf{- 2 0 0 2}$

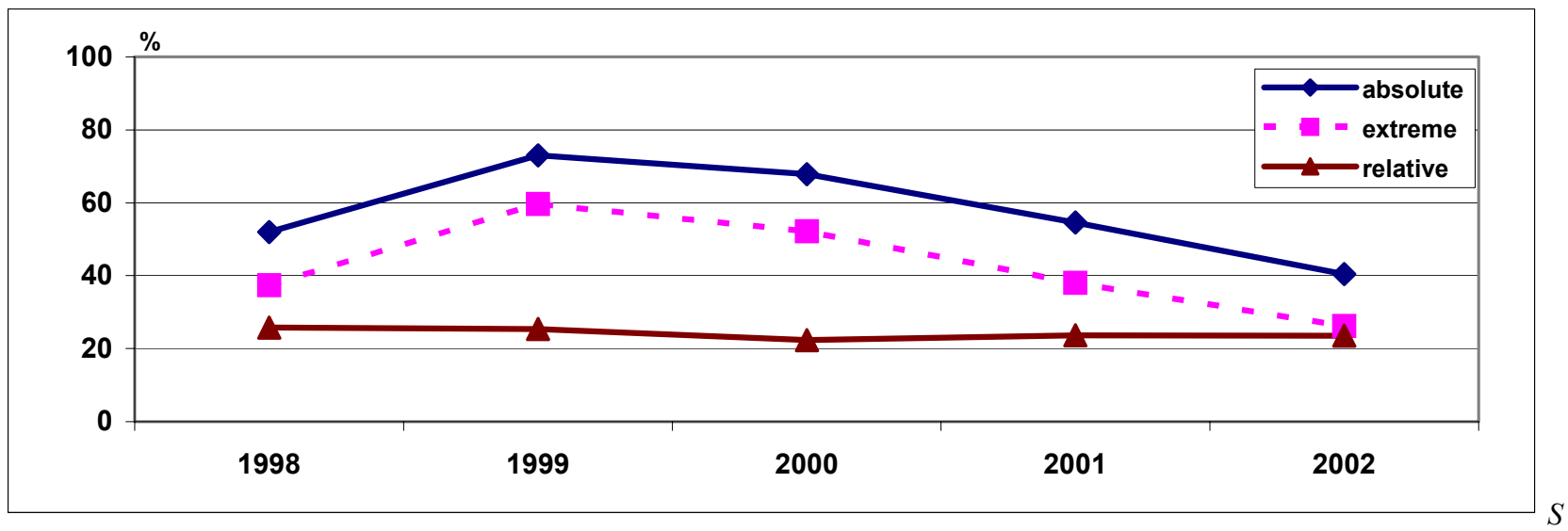

ource: PPMU based on HBS data.

Diagram 1.2. The structure of population in poverty and extreme poverty (2002)
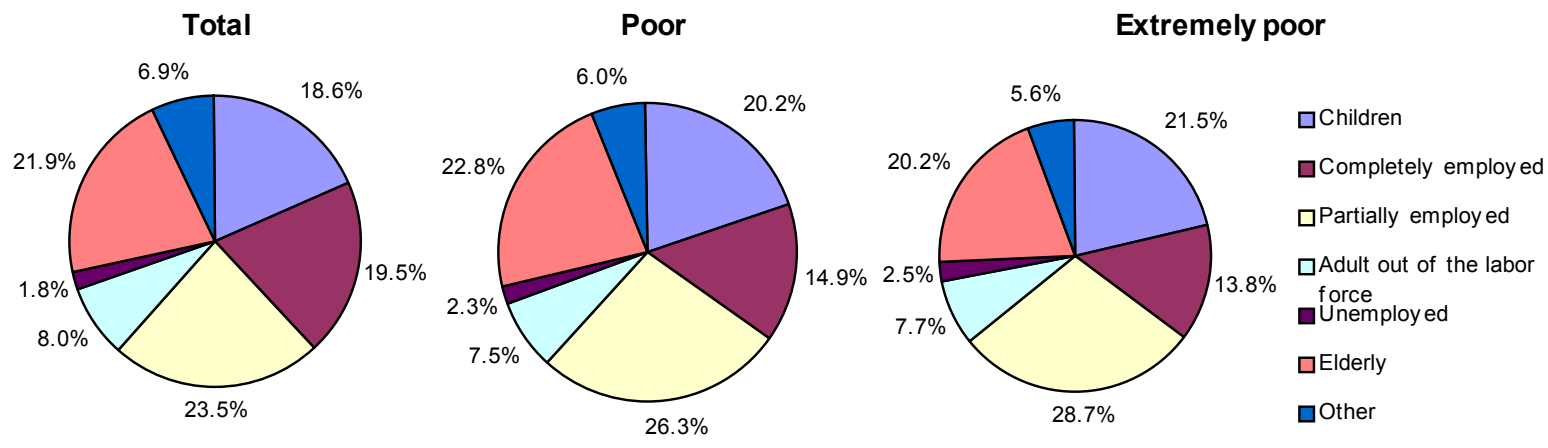

Source: PPMU based on HBS data.

Table 1.2. Child poverty rate in Moldova, 2002 (percent)

\begin{tabular}{|c|c|c|c|c|c|c|}
\hline & \multicolumn{2}{|c|}{ All } & \multicolumn{2}{c|}{ Urban } & \multicolumn{2}{c|}{ Rural } \\
\hline & Poor & Extremely poor & Poor & Extremely poor & Poor & Extremely poor \\
\hline CHILDREN - TOTAL & $\mathbf{4 5 . 2}$ & $\mathbf{3 1 . 2}$ & $\mathbf{3 5 . 7}$ & $\mathbf{2 1 . 6}$ & $\mathbf{5 0 . 0}$ & $\mathbf{3 6 . 1}$ \\
\hline under 5 years & 48.0 & 34.5 & 32.5 & 21.1 & 55.3 & 40.8 \\
\hline MALE & $\mathbf{4 4 . 2}$ & $\mathbf{3 0 . 3}$ & $\mathbf{3 4 . 3}$ & $\mathbf{1 9 . 9}$ & $\mathbf{4 9 . 4}$ & $\mathbf{3 5 . 7}$ \\
\hline Under 5 years & 46.9 & 33.1 & 31.2 & 18.4 & 54.4 & 40.2 \\
\hline FEMALE & $\mathbf{4 6 . 2}$ & $\mathbf{3 2 . 1}$ & $\mathbf{3 7 . 2}$ & $\mathbf{2 3 . 4}$ & $\mathbf{5 0 . 7}$ & $\mathbf{3 6 . 5}$ \\
\hline Under 5 years & 49.2 & 36.1 & 34.0 & 24.3 & 56.3 & 41.5 \\
\hline
\end{tabular}

Source: PPMU based on HBS data.

Table 1.3. Structure of poor and extremely poor economically active* population by their employment status, 2002 (percent)

\begin{tabular}{|c|c|c|c|}
\hline & Total & Poor & Extremely poor \\
\hline $\begin{array}{c}\text { Total economically active population: } \\
\text { Employed }\end{array}$ & $\begin{array}{c}\mathbf{1 0 0 . 0} \\
\mathbf{1 0 0 . 0} \\
\text { of which: }\end{array}$ & $\begin{array}{c}\mathbf{1 0 0 . 0} \\
97.8\end{array}$ & 97.1 \\
\hline$\quad$ fully employed & 68.4 & & \\
\hline $\begin{array}{c}\text { - partially, casually employed } \\
\text { or in administrative leave) }\end{array}$ & & & \\
\hline & 29.4 & 3.5 & \\
\hline Unemployed & 2.2 & 2.9 & 37.6 \\
\hline
\end{tabular}

*) The economically active population is the total population of 14-62 years old men and 14-57 years old women who are employed, partially employed or unemployed.

Source: PPMU, based on HBS data. 
Table 1.4. Temporal aspects of poverty, $1999-2002$

\begin{tabular}{|l|c|c|}
\hline & Number of HHs & Percentage \\
\hline Total & $\mathbf{9 3 0}$ & $\mathbf{1 0 0 . 0}$ \\
\hline One-off poverty (1 out of 4 years) & 212 & 22.8 \\
Repeated Extreme Poverty (2, 3, 4 out of 4 years) & 617 & 52.7 \\
$\quad$ including: & & 207 \\
$\quad$ 2 out of 4 years & 198 & 22.3 \\
3 out of 4 years & 85 & 9.1 \\
4 out of 4 years & 228 & 24.5 \\
Non-poor (0 out of 4 years) & & 21.3 \\
\hline
\end{tabular}

Source: PPMU based on HBS data.

Diagram 1.3. Distribution of the poor by type of residence areas, 2002
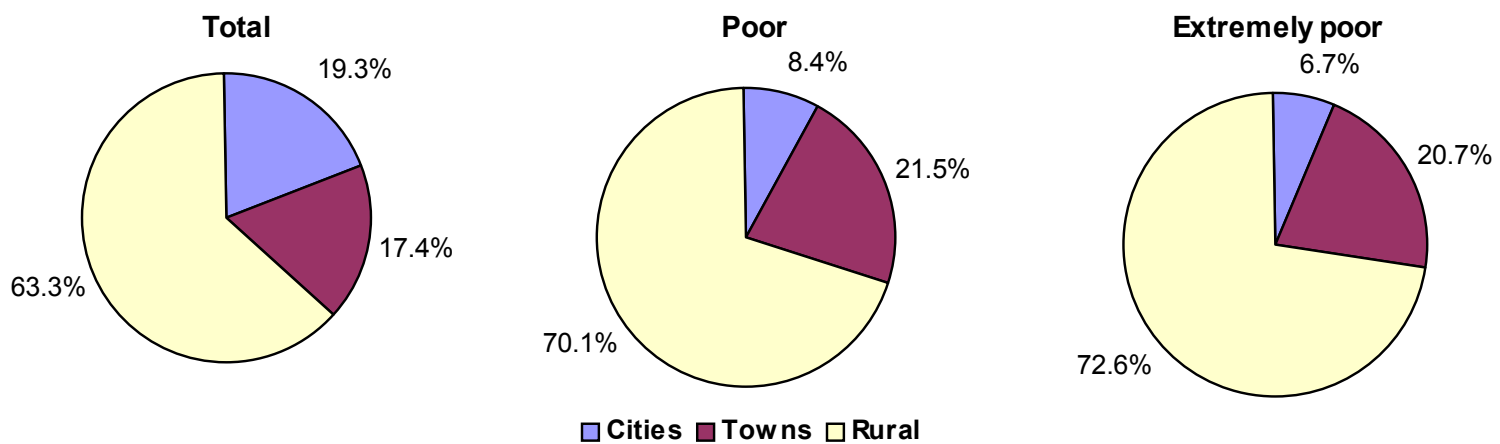

Source: PPMU based on HBS data.

Table 1.5. Poverty indicators by residence areas, 2002 (percent)

\begin{tabular}{|c|c|c|c|c|c|c|}
\hline \multirow{2}{*}{} & \multicolumn{2}{|c|}{ Rate $-\mathbf{P}_{\mathbf{0}}$} & \multicolumn{2}{c|}{ Gap - $\mathbf{P}_{\mathbf{1}}$} & \multicolumn{2}{c|}{ Severity - $\mathbf{P}_{\mathbf{2}}$} \\
\cline { 2 - 7 } & Poverty & Extreme poverty & Poverty & Extreme poverty & Poverty & Extreme poverty \\
\hline Total & $\mathbf{4 0 . 4}$ & $\mathbf{2 6 . 2}$ & $\mathbf{1 2 . 4}$ & $\mathbf{6 . 6}$ & $\mathbf{5 . 2}$ & $\mathbf{2 . 4}$ \\
\hline Urban: & 32.2 & 19.4 & 9.7 & 5.1 & 4.1 & 2.0 \\
\hline cities & 16.5 & 8.5 & 4.2 & 1.8 & 1.5 & 0.6 \\
\hline towns & 53.2 & 33.9 & 17.1 & 9.5 & 7.5 & 3.8 \\
\hline
\end{tabular}

Source: PPMU based on HBS data.

Table 1.6. Structure of the poor by socio-economic groups in rural areas, 2002 (percent)

\begin{tabular}{|l|c|c|c|}
\hline & Total & Poor & Extremely poor \\
\hline Total & $\mathbf{1 0 0 . 0}$ & $\mathbf{1 0 0 . 0}$ & $\mathbf{1 0 0 . 0}$ \\
\hline Farmers & 32.0 & 33.1 & 34.5 \\
\hline Agricultural employees & 22.3 & 27.8 & 30.3 \\
\hline Non-agricultural employees & 14.3 & 9.0 & 8.1 \\
\hline Entrepreneurs (non-farm self-employed) & 1.2 & 0.5 & 0.1 \\
\hline Pensioners & 29.6 & 29.3 & 26.8 \\
\hline Others & 0.5 & 0.2 & 0.1 \\
\hline
\end{tabular}

Source: PPMU based on HBS data. 
Table 1.7. Structure of the poor by socio-economic groups in urban areas, 2002 (percent)

\begin{tabular}{|l|c|c|c|}
\hline & Total & Poor & Extremely poor \\
\hline Total & $\mathbf{1 0 0 . 0}$ & $\mathbf{1 0 0 . 0}$ & $\mathbf{1 0 0 . 0}$ \\
\hline Farmers & 1.5 & 2.6 & 2.6 \\
\hline Agricultural employees & 1.5 & 2.0 & 1.5 \\
\hline Non-agricultural employees & 68.1 & 59.5 & 58.2 \\
\hline Entrepreneurs & 4.0 & 2.1 & 1.5 \\
\hline Pensioners & 20.0 & 28.6 & 30.7 \\
\hline Others & 4.8 & 5.2 & 5.5 \\
\hline
\end{tabular}

Source: PPMU based on HBS data.

Table 1.8. Poverty rate by Gender, 2002 (percent)

\begin{tabular}{|c|c|c|}
\hline & Poor & Extremely Poor \\
\hline Household members - total & 41.5 & 26.9 \\
\hline Men & 41.4 & 26.9 \\
\hline Women & 41.6 & 27.0 \\
\hline Household heads - total & 38.6 & 23.8 \\
\hline HH Head - men & 38.9 & 23.8 \\
\hline HH Head - women & 38.3 & 23.7 \\
\hline
\end{tabular}

Source: PPMU based on HBS data.

Diagram 1.4. Structure of population's disposable income by quintiles, 1999 and 2002

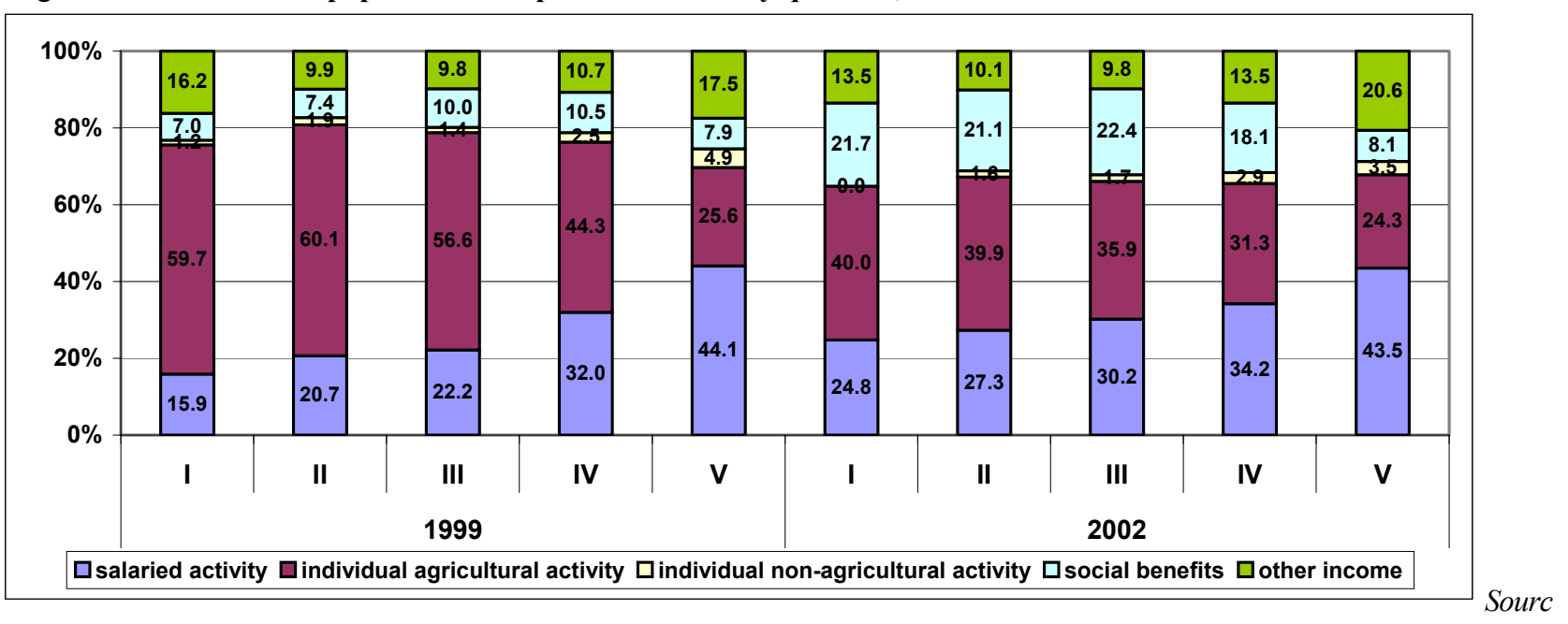

e: PPMU based on HBS data.

Table 1.9. Structure of disposable income of the extremely poor by activity in urban and rural areas, 2002 (percent)

\begin{tabular}{|l|c|c|}
\hline & Urban & Rural \\
\hline Total & $\mathbf{1 0 0 . 0}$ & $\mathbf{1 0 0 . 0}$ \\
\hline salaried activity & 52.3 & 14.0 \\
\hline individual agricultural activity & 8.0 & 52.0 \\
\hline individual non-agricultural activity & 2.4 & 0.6 \\
\hline social benefits & 27.1 & 22.6 \\
\hline other income & 10.2 & 10.8 \\
\hline
\end{tabular}

Source: PPMU based on HBS data.

Table 1.10. Structure of disposable income by type of sources, 2002 (percent)

\begin{tabular}{|l|c|c|c|}
\hline & total income & income in cash & income in kind \\
\hline rural poor & 100.0 & 44.9 & 55.1 \\
\hline rural population & 100.0 & 49.5 & 50.5 \\
\hline urban poor & 100.0 & 87.7 & 12.3 \\
\hline urban population & 100.0 & 89.8 & 10.2 \\
\hline total poor & 100.0 & 57.6 & 42.4 \\
\hline
\end{tabular}


total population

100.0

67.5

32.5

Source: PPMU based on HBS data.

Table 1.11. Poverty rate in households by gender and age of the head, 2002 (percent)

\begin{tabular}{|l|c|c|c|c|c|c|}
\hline \multirow{2}{*}{ Age of the HH head } & \multicolumn{2}{|c|}{ Total HH } & \multicolumn{4}{c|}{ Gender of HH head } \\
\cline { 2 - 7 } & Poor & $\begin{array}{c}\text { Extremely } \\
\text { poor }\end{array}$ & & \multicolumn{2}{c|}{ Men } & \multicolumn{2}{c|}{ Women } \\
\cline { 4 - 7 } & & Poor & Extremely poor & Poor & Extremely poor \\
\hline Total & $\mathbf{3 8 . 6}$ & $\mathbf{2 3 . 8}$ & $\mathbf{3 8 . 9}$ & $\mathbf{2 3 . 8}$ & $\mathbf{3 8 . 3}$ & $\mathbf{2 3 . 7}$ \\
\hline Below 30 & 23.7 & 14.2 & 31.9 & 19.0 & 15.8 & 9.5 \\
\hline $30-39$ years old & 38.1 & 24.0 & 40.7 & 26.1 & 32.5 & 19.5 \\
\hline $40-49$ years old & 38.1 & 25.9 & 40.2 & 27.8 & 33.6 & 21.8 \\
\hline $50-59$ years old & 36.2 & 21.9 & 35.8 & 20.8 & 36.9 & 23.7 \\
\hline $60-69$ years old & 39.5 & 23.1 & 37.4 & 20.9 & 42.2 & 25.9 \\
\hline $70-75$ years old & 46.2 & 24.3 & 44.8 & 23.3 & 47.6 & 25.3 \\
\hline Over 75 years old & 51.6 & 32.7 & 41.8 & 24.2 & 57.3 & 37.6 \\
\hline
\end{tabular}

Source: PPMU based on HBS data.

Table 1.12. Poverty rate by type of household, 2002 (percent)

\begin{tabular}{|c|c|c|}
\hline & Poor & Extremely poor \\
\hline Total & 38.6 & 23.8 \\
\hline HH with one member & 36.2 & 20.6 \\
\hline Family couple without children & 33.5 & 17.9 \\
\hline Family couple with children & 41.6 & 27.2 \\
\hline One adult with children & 32.9 & 21.4 \\
\hline Other $\mathrm{HH}$ with children & 47.6 & 34.4 \\
\hline Other HH without children & 41.6 & 25.1 \\
\hline
\end{tabular}

Source: PPMU based on HBS data.

Table 1.13. Poverty rate in HHs headed by pensioners, 2002 (percent)

\begin{tabular}{|l|c|c|c|c|c|c|}
\hline \multirow{2}{*}{} & \multicolumn{2}{|c|}{ Total } & \multicolumn{2}{c|}{ Urban } & \multicolumn{2}{c|}{ Rural } \\
\cline { 2 - 7 } & Poor & $\begin{array}{c}\text { Extremely } \\
\text { Poor }\end{array}$ & Poor & $\begin{array}{c}\text { Extremely } \\
\text { Poor }\end{array}$ & $\begin{array}{c}\text { Poor } \\
\text { Extremely } \\
\text { Poor }\end{array}$ \\
\hline Total households & $\mathbf{3 8 . 6}$ & $\mathbf{2 3 . 8}$ & $\mathbf{3 2 . 7}$ & $\mathbf{1 9 . 3}$ & $\mathbf{4 2 . 6}$ & $\mathbf{2 6 . 7}$ \\
\hline HH headed by pensioners - total & 45.0 & 26.2 & 48.0 & 29.6 & 43.6 & 24.5 \\
\hline HH headed by pensioners - men & 41.6 & 23.0 & 47.2 & 29.0 & 39.8 & 21.2 \\
\hline HH headed by pensioners - women & 48.0 & 28.9 & 48.4 & 29.9 & 47.8 & 28.2 \\
\hline
\end{tabular}

Source: PPMU based on HBS data

Table 1.14. Poverty rate by presence of disabled persons in households, 2002 (percent)

\begin{tabular}{|l|c|c|c|c|c|c|}
\hline \multirow{2}{*}{} & \multicolumn{3}{|c|}{ Poor } & \multicolumn{3}{c|}{ Extremely Poor } \\
\cline { 2 - 8 } & Total & Urban & Rural & Total & Urban & Rural \\
\hline Total & $\mathbf{3 8 . 6}$ & $\mathbf{3 2 . 7}$ & $\mathbf{4 2 . 6}$ & $\mathbf{2 3 . 8}$ & $\mathbf{1 9 . 3}$ & $\mathbf{2 6 . 7}$ \\
\hline Without Disabled & 38.7 & 32.3 & 42.9 & 23.9 & 18.9 & 27.3 \\
\hline With Disabled & 38.3 & 35.3 & 40.3 & 22.6 & 22.4 & 22.7 \\
\hline
\end{tabular}

Source: PPMU based on HBS data.

Table 1.15. Access to the social infrastructure / public institutions, 2002

\begin{tabular}{|c|c|c|c|c|c|c|c|c|c|}
\hline \multirow{2}{*}{ Institution: } & \multicolumn{3}{|c|}{ Total } & \multicolumn{3}{c|}{ Urban } & \multicolumn{3}{c|}{ Rural } \\
\cline { 2 - 7 } & $\begin{array}{c}\text { Extremely } \\
\text { poor }\end{array}$ & Poor & $\begin{array}{c}\text { Non- } \\
\text { poor }\end{array}$ & $\begin{array}{c}\text { Extremely } \\
\text { poor }\end{array}$ & Poor & $\begin{array}{c}\text { Non- } \\
\text { poor }\end{array}$ & $\begin{array}{c}\text { Extremely } \\
\text { poor }\end{array}$ & Poor & Non-poor \\
\hline
\end{tabular}




\begin{tabular}{|l|c|c|c|c|c|c|c|c|c|}
\hline $\begin{array}{l}\text { Clinic, medical } \\
\text { station: number of } \\
\text { visits per month }\end{array}$ & 0.24 & 0.25 & 0.58 & 0.31 & 0.35 & 0.79 & 0.21 & 0.21 & 0.43 \\
\hline $\begin{array}{l}\text { Hospital: number of } \\
\text { visits per month }\end{array}$ & 0.02 & 0.03 & 0.23 & 0.01 & 0.03 & 0.24 & 0.03 & 0.03 & 0.22 \\
\hline $\begin{array}{l}\text { Post-office: : number } \\
\text { of visits per month }\end{array}$ & 0.85 & 0.90 & 1.01 & 0.67 & 0.70 & 0.85 & 0.94 & 1.00 & 1.12 \\
\hline $\begin{array}{l}\text { Public administration } \\
\text { offices: number of } \\
\text { visits per month }\end{array}$ & 0.20 & 0.21 & 0.24 & 0.04 & 0.04 & 0.07 & 0.28 & 0.29 & 0.37 \\
\hline
\end{tabular}

Source: PPMU based on HBS data.

Table 1. 16. Structure of the poor and non-poor by educational attainments and residence area, 2002 (percent)

\begin{tabular}{|l|c|c|c|c|c|c|}
\hline \multirow{2}{*}{ Total } & \multicolumn{3}{|c|}{ Poor } & \multicolumn{3}{|c|}{ Non-poor } \\
\cline { 2 - 7 } & Total & Urban & Rural & Total & Urban & Rural \\
\hline Higher and incomplete higher & $\mathbf{1 0 0 . 0}$ & $\mathbf{1 0 0 . 0}$ & $\mathbf{1 0 0 . 0}$ & $\mathbf{1 0 0 . 0}$ & $\mathbf{1 0 0 . 0}$ & $\mathbf{1 0 0 . 0}$ \\
\hline Secondary and vocational & 4.1 & 8.6 & 2.0 & 15.4 & 27.8 & 6.2 \\
\hline Incomplete secondary and primary & 47.8 & 61.4 & 41.6 & 51.5 & 56.6 & 47.6 \\
\hline No primary education and illiterate & 42.6 & 26.4 & 49.9 & 30.2 & 14.9 & 41.5 \\
\hline
\end{tabular}

Source: PPMU based on HBS data.

Table 1.17. Poverty rate by educational attainments, in rural and urban areas, 2002 (percent)

\begin{tabular}{|l|c|c|c|c|c|c|}
\hline \multirow{2}{*}{} & \multicolumn{3}{|c|}{ Poor } & \multicolumn{3}{c|}{ Extremely poor } \\
\cline { 2 - 7 } & Total & Urban & Rural & Total & Urban & Rural \\
\hline Total & $\mathbf{4 0 . 6}$ & $\mathbf{3 3 . 4}$ & $\mathbf{4 5 . 0}$ & $\mathbf{2 5 . 9}$ & $\mathbf{2 0 . 0}$ & $\mathbf{2 9 . 5}$ \\
\hline Higher and incomplete higher & 15.3 & 13.4 & 21.0 & 7.4 & 5.9 & 11.7 \\
\hline Secondary and vocational & 38.9 & 35.2 & 41.7 & 24.4 & 21.4 & 26.8 \\
\hline Incomplete secondary and primary & 49.1 & 47.0 & 49.6 & 32.6 & 29.7 & 33.4 \\
\hline No primary education and illiterate & 56.2 & 73.1 & 53.1 & 35.2 & 42.3 & 33.9 \\
\hline
\end{tabular}

Source: PPMU based on HBS data.

Table 1.18. Rate of enrollment in the educational system by poverty status and residential area, 2002

\begin{tabular}{|c|c|c|c|c|c|c|c|c|c|c|c|c|}
\hline & \multicolumn{3}{|c|}{ All HH members } & \multicolumn{3}{|c|}{ Poor } & \multicolumn{3}{|c|}{ Extremely poor } & \multicolumn{3}{|c|}{ Non-poor } \\
\hline & Total & Urban & Rural & Total & Urban & Rural & Total & Urban & Rural & Total & Urban & Rural \\
\hline \multicolumn{13}{|c|}{ Gross Enrollment Rates } \\
\hline $\begin{array}{l}\text { Primary } \\
\text { Education }\end{array}$ & 1.02 & 1.03 & 1.01 & 1.01 & 1.00 & 1.01 & 1.01 & 1.02 & 1.01 & 1.03 & 1.04 & 1.02 \\
\hline $\begin{array}{l}\text { Secondary } \\
\text { Education }\end{array}$ & 0.79 & 0.82 & 0.77 & 0.75 & 0.79 & 0.73 & 0.74 & 0.77 & 0.73 & 0.82 & 0.84 & 0.81 \\
\hline Higher Education & 0.27 & 0.44 & 0.10 & 0.11 & 0.27 & 0.04 & 0.09 & 0.23 & 0.03 & 0.36 & 0.50 & 0.16 \\
\hline \multicolumn{13}{|c|}{ Net Enrollment Rates } \\
\hline $\begin{array}{l}\text { Primary } \\
\text { Education }\end{array}$ & 0.93 & 0.94 & 0.93 & 0.92 & 0.92 & 0.92 & 0.92 & 0.92 & 0.92 & 0.94 & 0.95 & 0.94 \\
\hline $\begin{array}{l}\text { Secondary } \\
\text { Education }\end{array}$ & 0.78 & 0.81 & 0.76 & 0.74 & 0.78 & 0.72 & 0.73 & 0.77 & 0.71 & 0.81 & 0.83 & 0.80 \\
\hline Higher Education & 0.17 & 0.29 & 0.06 & 0.07 & 0.17 & 0.01 & 0.05 & 0.15 & 0.01 & 0.24 & 0.33 & 0.10 \\
\hline
\end{tabular}

Source: PPMU based on HBS data 
Table 1.19. Inequality of the household disposable income 'before' and 'after' social transfers

\begin{tabular}{|c|c|c|}
\hline \multirow{2}{*}{ Years } & \multicolumn{2}{|c|}{ Gini } \\
\cline { 2 - 3 } & Before social transfers & After social transfers \\
\hline $\mathbf{1 9 9 8}$ & 0.4448 & 0.4435 \\
\hline $\mathbf{1 9 9 9}$ & 0.4351 & 0.4342 \\
\hline $\mathbf{2 0 0 0}$ & 0.4172 & 0.4165 \\
\hline $\mathbf{2 0 0 1}$ & 0.4308 & 0.4279 \\
\hline $\mathbf{2 0 0 2}$ & 0.4241 & 0.4214 \\
\hline
\end{tabular}

Source: PPMU based on HBS data.

Table 1.20. Incidence of social transfers, 2002 (percent)

\begin{tabular}{|l|c|c|c|c|}
\hline & Total & Poor & Non-poor & Poverty rate \\
\hline Total & $\mathbf{1 0 0 . 0}$ & $\mathbf{1 0 0 . 0}$ & $\mathbf{1 0 0 . 0}$ & $\mathbf{2 3 . 8}$ \\
\hline Households: & & & & 24.2 \\
\hline - without beneficiaries & 85.3 & 86.9 & 84.7 & 21.1 \\
\hline - with beneficiaries & 14.7 & 13.1 & 15.3 & \\
\hline
\end{tabular}

Source: PPMU based on HBS data. 


\title{
ANNEX 2. METHODOLOGICAL PRINCIPLES FOR THE EVALUATION OF THE ABSOLUTE POVERTY LINE
}

\author{
(Excerpt from the document awaiting approval by \\ the Ministry of Economy and the Department of Statistics and Sociology \\ of the Republic of Moldova)
}

1. Background: The proposed methodology for calculation of the absolute poverty line was developed in conformity with the Decision of the Government of the Republic of Moldova no. 619 of 16 May 2002 „On approval of the Plan of actions designed to build the capacity for poverty monitoring and evaluation for the period 1 June 2002 - 31 May 2005".

The absolute poverty line shall be used for the purpose of poverty analysis and evaluation of anti-poverty impact of the Government policies, and will be conducted on a regular basis over the long period of time. The methodology deals with three fundamental issues in the measurement of poverty: measuring welfare of the population comparing households of different size and composition (equivalence scale) - designing the poverty line.

\section{Conceptual and methodological principles.}

The basic unit of the poverty measurement and analysis is household (as defined in the Household Budget Survey). The basic measure of population's welfare is household's consumption expenditures (considered a more reliable and accurate measure of welfare than widely underreported in statistical surveys income). They include expenditures for food consumption (including imputed market value of items taken from household's production), for non-food items and payment for services. Population's consumption expenditures per capita (divided by the number of persons in the sampled households) and 'equivalized' consumption expenditures (divided by adultequivalent number of household members) are (to be) used for measuring the household welfare level.

- To ensure comparability between households surveyed in different months, the consumption expenditures will be deflated using the monthly Consumer Price Index (CPI), the prices as of January of the year of study will be taken for the base.

- To ensure compatibility between households of different size and composition the OECD equivalence scale will be used (according to which value of 1.0 is assigned to the first adult at a household; 0.7 to each other adult; and 0.5 to each child aged under 15). This is a temporary solution, as it is expected that a country-specific equivalence scale be developed.

\section{The method of calculation of the absolute poverty line.}

According to its ,absolute" nature -- being rendered in the concept of the minimum standard of living -- this method focuses on estimating the amount of money necessary to guarantee meeting the basic needs defined in terms of food and non-food requirements (necessities). At its core is the food-energy-intake method of assessing the value of food consumption level meeting the energy requirement for health and normal activity, defined in terms of minimum of daily calories intake equal to $2282 \mathrm{Kcal}$ per person per day. Subsequently, minimal requirement of non-food items (including services) is also assessed and added to the food component resulting in absolute poverty threshold, as below.

- Determining the absolute extreme poverty line (or the food line): The population in $2^{\text {nd }}$ to $4^{\text {th }}$ deciles of the distribution of the total consumption expenditure is selected (the population in the $1^{\text {st }}$ decile is not included because the consumption structure of this group differs significantly from the rest of the population). The food basket for this group consists of 46 products. The food-energy-intake of each product is calculated (according to the Alimentation Institute of the Academy of Science USSR, 1989) and its percentage share in total consumption expressed in calories is established. The caloric input of each consumed product is adjusted to the value of $2282 \mathrm{kcal} /$ day, the required food consumption per person in the Republic of Moldova stipulated in the Decision of the Government of the Republic of Moldova „Regulations relating to the procedure of calculation of the existence minimum" no. 902 of 28 August 2000). The resulting amount of money represents the value of the food line or extreme poverty line.

- Establishment of the absolute poverty line is based on the assumption that the population whose consumption expenditures are equal to the food line spend for non-food consumption only a required minimum. Thus, the amount spent by this population for non-food and services is added to the food line (absolute extreme poverty line), as follows: 
Select the population, whose consumption expenditures $\left(\mathrm{C}_{\mathrm{T}}\right)$ match the food line $\left(\mathrm{S}_{\mathrm{ex}}\right) \pm$ the standard deviation $(\sigma)$ of this value: $\mathrm{C}_{\mathrm{T}}=\mathrm{S}_{\mathrm{ex}} \pm \sigma$. Establish the actual structure of the monthly consumption expenditures for this population group and consumption structure is calculated on the basis of structure of the monthly consumption expenditures (which represent the share of food and non-food consumption in the total amount of consumption). To obtain the absolute poverty line, the value of the food line $\left(\mathrm{S}_{\mathrm{ex}}\right)$ line is added to the food line quantum multiplied by the established coefficient of non-food component $\left(\mathrm{S}_{\mathrm{ex}} \mathrm{x}\right.$ the share of non-food products and services): $\mathrm{S}=\mathrm{S}_{\mathrm{ex}}+\left(\mathrm{S}_{\mathrm{ex}}\right.$ $\mathrm{x}$ the share of non-food products and services). 
ANNEX 3. MAIN SOCIO-ECONOMIC INDICATORS IN 2000-2003

\begin{tabular}{|c|c|c|c|c|c|}
\hline & Meas. Unit & 2000 & 2001 & 2002 & 2003 \\
\hline Nominal Gross Domestic Product (GDP) & mln. MDL & 16020 & 19052 & 22556 & 27297 \\
\hline vs. previous year, in comparable prices & $\%$ & 102,1 & 106,1 & 107,8 & 106,3 \\
\hline $\begin{array}{l}\text { Consumer Price Index, annual average } \\
\text { vs. previous year }\end{array}$ & $\%$ & 131 & 109,6 & 105,2 & 111,6 \\
\hline $\begin{array}{l}\text { Inflation rate: } \\
\text { monthly average } \\
\text { end-year }\end{array}$ & $\begin{array}{l}\% \\
\%\end{array}$ & $\begin{array}{r}1,4 \\
18,4\end{array}$ & $\begin{array}{l}0,5 \\
6,3\end{array}$ & $\begin{array}{l}0,4 \\
4,4\end{array}$ & $\begin{array}{r}1,2 \\
15,7\end{array}$ \\
\hline Gross monetary reserve of the NBM (end-year) & mln. USD & 204 & 228,5 & 268,9 & 302,3 \\
\hline $\begin{array}{l}\text { Commercial bank loans to the economy (end- } \\
\text { year) }\end{array}$ & mln. MDL & 2291,2 & 3101,3 & 4165,8 & 5999,7 \\
\hline \multicolumn{6}{|l|}{ Monetization: } \\
\hline Cash in circulation vs. GDP (M0) & $\%$ & 9,2 & 9,6 & 10,1 & 10,0 \\
\hline Monetary mass vs. GDP (M2) & $\%$ & 15,7 & 18,2 & 20,0 & 20,6 \\
\hline Monetary mass vs. GDP (M3) & $\%$ & 21,9 & 25,1 & 28,9 & 31,2 \\
\hline Monetary multiplier (M3) & & 1,80 & 1,92 & 2,00 & 2,23 \\
\hline Dollarization of deposits & $\%$ & 48,8 & 44,8 & 47,2 & 50,1 \\
\hline \multicolumn{6}{|l|}{ Exchange rate of the national currency: } \\
\hline $\begin{array}{l}\text { average } \\
\text { end-year }\end{array}$ & $\begin{array}{l}\text { MDL/USD } \\
\mathrm{MDL} / \mathrm{USD}\end{array}$ & $\begin{array}{l}12,43 \\
12,38\end{array}$ & $\begin{array}{l}12,87 \\
13,09\end{array}$ & $\begin{array}{l}13,57 \\
13,82\end{array}$ & $\begin{array}{l}13,94 \\
13,22\end{array}$ \\
\hline \multicolumn{6}{|l|}{ Foreign trade } \\
\hline Export (F.O.B.) & mln. USD & $\begin{array}{l}471,5 \\
1017\end{array}$ & $\begin{array}{l}568,1 \\
1205\end{array}$ & 643,9 & $\begin{array}{l}790,3 \\
1227\end{array}$ \\
\hline Import (C.I.F.) & mln. USD & 776,4 & 892,7 & 1038,5 & 1402,7 \\
\hline Trade balance - total & mln. USD & $-304,9$ & $-324,6$ & $-394,6$ & $-612,4$ \\
\hline$\%$, vs. GDP & $\%$ & $-23,7$ & $-21,9$ & $-23,7$ & $-21,3$ \\
\hline Import coverage by export & $\%$ & 60,7 & 63,6 & 62,0 & 56,3 \\
\hline Current account of balance of payments & mln. USD & $-125,7$ & $-91,7$ & $-98,2$ & -212 \\
\hline$\%$, vs. GDP & $\%$ & $-9,8$ & $-6,2$ & $-5,9$ & $-10,8$ \\
\hline \multicolumn{6}{|l|}{ Consolidated budget } \\
\hline Revenues & mln. MDL & 4102,4 & 4324,9 & 5084,4 & 6620,1 \\
\hline Expenditures & mln. MDL & 4268,8 & 4325,9 & 5194,1 & 6179,3 \\
\hline Deficit $(-)$, surplus $(+)$ & mln. MDL & $-166,4$ & -1 & $-109,7$ & 440,8 \\
\hline$\%$, vs. GDP & $\%$ & $-1,0$ & $-0,0$ & $-0,5$ & 1,6 \\
\hline $\begin{array}{l}\text { State domestic debt (end-year) } \\
\quad \% \text {, vs. GDP }\end{array}$ & $\begin{array}{l}\operatorname{mln} . \mathrm{MDL} \\
\%\end{array}$ & $\begin{array}{r}2022,2 \\
12,6\end{array}$ & $\begin{array}{r}2400,5 \\
12,6\end{array}$ & $\begin{array}{r}2821,4 \\
12,5\end{array}$ & $\begin{array}{r}2920,4 \\
10,7\end{array}$ \\
\hline
\end{tabular}




\begin{tabular}{|c|c|c|c|c|c|}
\hline & Meas. Unit & 2000 & 2001 & 2002 & 2003 \\
\hline Foreign debt - total (end-year) & mln. USD & 1254,8 & 1255,0 & 1361,3 & 1436,9 \\
\hline \%, vs. GDP & $\%$ & 97,4 & 84,8 & 81,9 & 73,4 \\
\hline Foreign debt - public (end-year) & mln. USD & 1022,0 & 954,9 & 987,0 & 1008,2 \\
\hline$\%$, vs. GDP & $\%$ & 79,3 & 64,5 & 59,4 & 51,5 \\
\hline State foreign debt, direct and guaranteed by the & & & & & \\
\hline $\begin{array}{l}\text { Govt. (end-year) } \\
\% \text {, vs. GDP }\end{array}$ & $\begin{array}{l}\operatorname{mln} . \text { USD } \\
\%\end{array}$ & $\begin{array}{r}867,8 \\
67,3\end{array}$ & $\begin{array}{r}809,0 \\
54,7\end{array}$ & $\begin{array}{r}835,6 \\
50,3\end{array}$ & $\begin{array}{r}866,1 \\
44,2\end{array}$ \\
\hline Industrial production & & & & & \\
\hline vs. previous year, in comparable prices & $\%$ & 107,7 & 113,7 & 110,8 & 113,6 \\
\hline $\begin{array}{l}\text { Agricultural production } \\
\text { vs. previous vear, in comparable prices }\end{array}$ & $\%$ & 967 & 1064 & 1034 & 859 \\
\hline & & & & & \\
\hline $\begin{array}{l}\text { Fixed capital investments } \\
\text { vs. previous year, in comparable prices }\end{array}$ & $\%$ & 85 & 111 & 111 & 116 \\
\hline $\begin{array}{l}\text { Commodities transported by specialized } \\
\text { transport enterprises }\end{array}$ & mln. tons & 11,1 & 13,5 & 16,4 & 18,6 \\
\hline $\begin{array}{l}\text { Amount of retail sales } \\
\text { vs. previous year, in comparable prices }\end{array}$ & $\%$ & 104 & 114,8 & 134,2 & 118,2 \\
\hline $\begin{array}{l}\text { Amount of paid services to population } \\
\text { vs. previous year, in comparable prices }\end{array}$ & $\%$ & 100,1 & 121,2 & 111,8 & 112,5 \\
\hline $\begin{array}{l}\text { Nominal wage of economy workers (monthly } \\
\text { average) }\end{array}$ & MDL & 407,9 & 543,7 & 691,5 & 892 \\
\hline $\begin{array}{l}\text { vs. previous year: } \\
\text { nominal }\end{array}$ & $\%$ & 134 & 133 & 127 & 129 \\
\hline real & $\%$ & 102 & $\frac{122}{122}$ & 121 & 116 \\
\hline Amount of established pension (end-year) & MDL & 85,1 & 135,8 & 161,0 & 210,5 \\
\hline $\begin{array}{l}\text { vs. previous year: } \\
\text { nominal }\end{array}$ & $\%$ & 103 & 160 & 119 & 131 \\
\hline real & $\%$ & $\frac{78}{78}$ & $\overline{146}$ & 113 & 117 \\
\hline $\begin{array}{l}\text { Number of unemployed (at the end of period): } \\
\text { according to ILO }\end{array}$ & $\begin{array}{l}\text { thou. } \\
\text { persons }\end{array}$ & 140 & 118 & 110 & 117 \\
\hline unemployment rate, according to ILO & $\%$ & 8,5 & 7,3 & 6,8 & 7,9 \\
\hline
\end{tabular}




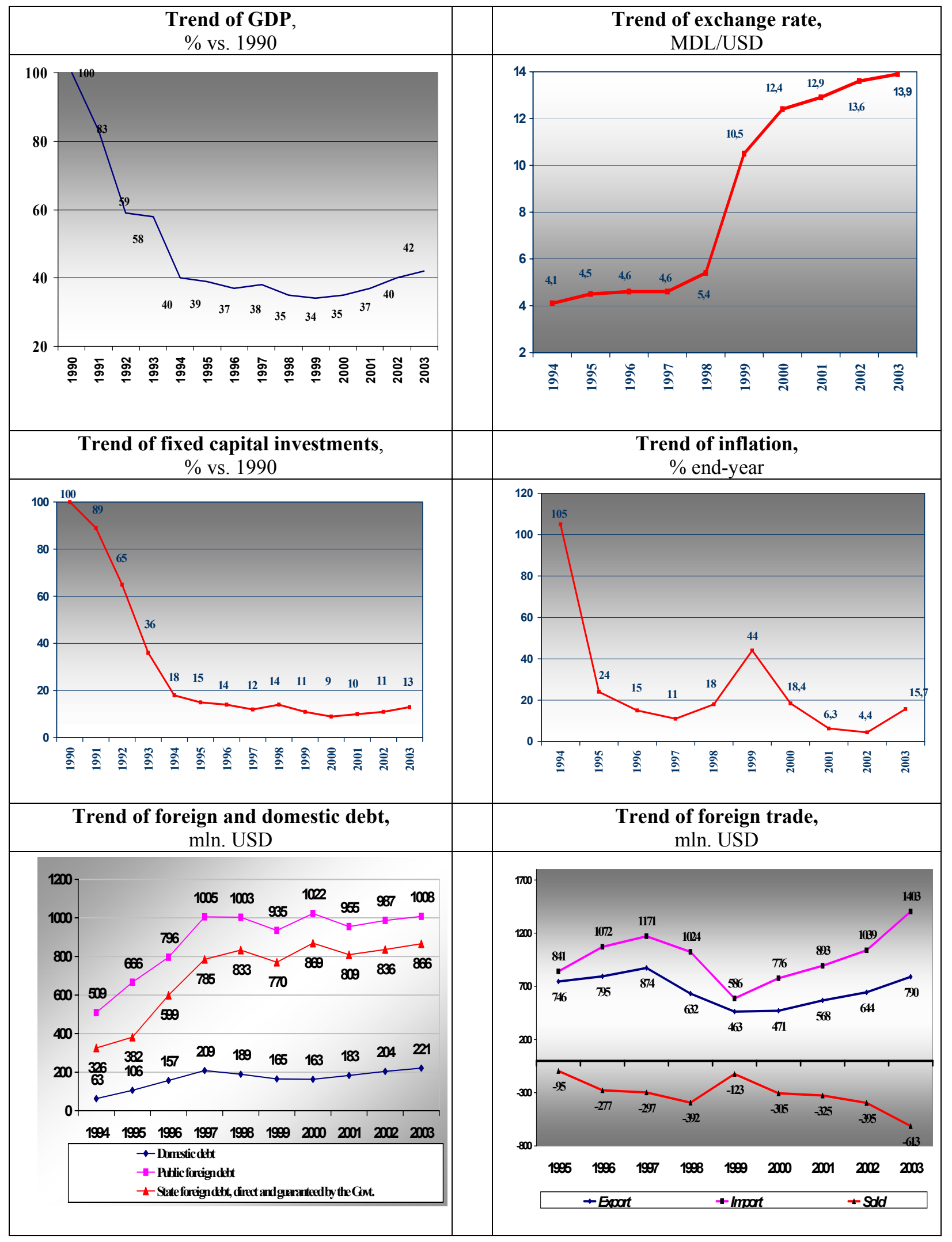




\section{ANNEX 4. THE FORECAST OF MACROECONOMIC INDICATORS FOR 2004-2006}

Moderate (basic) scenario

\begin{tabular}{|c|c|c|c|c|c|c|c|c|}
\hline \multirow{2}{*}{ Indicators } & \multirow[b]{2}{*}{ Meas. Unit } & 2000 & 2001 & 2002 & 2003 & \multirow{2}{*}{$\begin{array}{c}2004 \\
\text { Updated } \\
\text { estimates }\end{array}$} & 2005 & 2006 \\
\hline & & \multicolumn{4}{|c|}{ De facto } & & \multicolumn{2}{|c|}{ forecast } \\
\hline $\begin{array}{l}\text { Nominal GDP } \\
\text { Vs. previous year, } \\
\text { in comparable prices }\end{array}$ & $\begin{array}{c}\text { billion } \\
\text { MDL } \\
\% \\
\end{array}$ & $\begin{array}{l}16,02 \\
102,1 \\
\end{array}$ & $\begin{array}{l}19,05 \\
106,1 \\
\end{array}$ & $\begin{array}{l}22,56 \\
107,8 \\
\end{array}$ & $\begin{array}{r}27,3 \\
106,3 \\
\end{array}$ & $\begin{array}{l}30,6 \\
106 \\
\end{array}$ & $\begin{array}{l}34,9 \\
105 \\
\end{array}$ & $\begin{array}{l}38,8 \\
105 \\
\end{array}$ \\
\hline GDP Structure & & & & & & & & \\
\hline $\begin{array}{l}\text { Gross Value Added } \\
\text { agriculture } \\
\text { industry } \\
\text { services }\end{array}$ & $\begin{array}{l}\% \\
\% \\
\% \\
\%\end{array}$ & $\begin{array}{l}87,5 \\
25,4 \\
16,3 \\
48,2\end{array}$ & $\begin{array}{l}88,0 \\
22,4 \\
18,7 \\
49,2\end{array}$ & $\begin{array}{l}87,3 \\
21,0 \\
17,3 \\
51,0\end{array}$ & $\begin{array}{l}85,6 \\
19,3 \\
17,8 \\
50,8\end{array}$ & $\begin{array}{l}85,0 \\
17,1 \\
18,2 \\
52,2\end{array}$ & $\begin{array}{l}84,9 \\
16,2 \\
18,8 \\
52,5\end{array}$ & $\begin{array}{l}85,2 \\
15,0 \\
19,6 \\
53,3\end{array}$ \\
\hline $\begin{array}{l}\text { financial intermediation } \\
\text { services indirectly measured } \\
\text { Net taxes on products and }\end{array}$ & $\begin{array}{l}\% \\
\%\end{array}$ & $\begin{array}{l}-2,4 \\
12,5\end{array}$ & $\begin{array}{l}-2,3 \\
12,0\end{array}$ & $\begin{array}{l}-2,1 \\
12,7\end{array}$ & $\begin{array}{l}-2,3 \\
14,4\end{array}$ & $\begin{array}{l}-2,5 \\
15,0\end{array}$ & $\begin{array}{l}-2,6 \\
15,1\end{array}$ & $\begin{array}{l}-2,7 \\
14,8\end{array}$ \\
\hline $\begin{array}{l}\text { Final consumption } \\
\text { by households } \\
\text { by public and private }\end{array}$ & $\begin{array}{l}\% \\
\%\end{array}$ & $\begin{array}{c}103,0 \\
87,6\end{array}$ & $\begin{array}{l}101,1 \\
86,0\end{array}$ & $\begin{array}{c}103,2 \\
82,0\end{array}$ & $\begin{array}{l}108,8 \\
89,5\end{array}$ & $\begin{array}{c}108,3 \\
89,5\end{array}$ & $\begin{array}{c}106,3 \\
88,0\end{array}$ & $\begin{array}{c}104,3 \\
86,4\end{array}$ \\
\hline administration & $\%$ & 15,4 & 15,1 & 21,3 & 19,4 & 18,8 & 18,3 & 17,9 \\
\hline Gross capital formation & $\%$ & 23,9 & 23,3 & 21,7 & 21,7 & 22,1 & 22,6 & 23,0 \\
\hline gross fixed capital & $\%$ & 15,4 & 16,7 & 16,3 & 17,1 & 17,9 & 18,7 & 19,3 \\
\hline stocks variation & $\%$ & 8,5 & 6,5 & 5,3 & 4,6 & 4,2 & 3,9 & 3,7 \\
\hline Net export & $\%$ & $-27,0$ & $-24,4$ & $-24,9$ & $-30,5$ & $-30,4$ & $-28,9$ & $-27,3$ \\
\hline Consumer Price Index & & & & & & & & \\
\hline annual average & $\%$ & 131,1 & 109,6 & 105,2 & 111,6 & 110,0 & 108,9 & 106,9 \\
\hline end-year & $\%$ & 118,4 & 106,3 & 104,4 & 115,7 & 109,0 & 108,0 & 106,0 \\
\hline $\begin{array}{l}\text { MDL exchange rate } \\
\text { annual average } \\
\text { end-year }\end{array}$ & $\begin{array}{l}\text { MDL/USD } \\
\text { MDL/USD }\end{array}$ & $\begin{array}{l}12,4 \\
12,4\end{array}$ & $\begin{array}{l}12,9 \\
13,1\end{array}$ & $\begin{array}{l}13,6 \\
13,8 \\
\end{array}$ & $\begin{array}{l}13,9 \\
13,2\end{array}$ & $\begin{array}{l}13,5 \\
14,1\end{array}$ & $\begin{array}{l}14,4 \\
14,9\end{array}$ & $\begin{array}{l}15,0 \\
15,4\end{array}$ \\
\hline Export & mln. USD & 471 & 568 & 644 & 790 & 900 & 1020 & 1140 \\
\hline Vs. previous year & $\%$ & 101,7 & 120,5 & 113,3 & 122,7 & 114 & 113 & 112 \\
\hline Import & mln. USD & 776 & 893 & 1039 & 1403 & 1525 & 1632 & 1730 \\
\hline Vs. previous year & $\%$ & 132,4 & 115,0 & 116,3 & 135,1 & 109 & 107 & 106 \\
\hline Trade balance - total & mln. USD & -305 & -325 & -395 & -613 & -625 & -612 & -590 \\
\hline $\begin{array}{l}\text { Current account of balance of } \\
\text { payments }\end{array}$ & mln. USD & $-125,7$ & $-91,7$ & $-98,2$ & -212 & -175 & -141 & -117 \\
\hline
\end{tabular}




\begin{tabular}{|c|c|c|c|c|c|c|c|c|}
\hline \multirow[b]{2}{*}{ Indicators } & \multirow[b]{2}{*}{ Meas. Unit } & 2000 & 2001 & 2002 & 2003 & \multirow{2}{*}{$\begin{array}{c}2004 \\
\text { Updated } \\
\text { estimates }\end{array}$} & 2005 & 2006 \\
\hline & & \multicolumn{4}{|c|}{ De facto } & & \multicolumn{2}{|c|}{ forecast } \\
\hline$\%$, vs. GDP & $\%$ & $-9,8$ & $-6,2$ & $-5,9$ & $-10,8$ & $-7,7$ & $-5,8$ & $-4,5$ \\
\hline $\begin{array}{l}\text { Consolidated budget } \\
\text { Revenues } \\
\text { Expenditures } \\
\text { Deficit (-), surplus (+) } \\
\text { \%, vs. GDP } \\
\end{array}$ & $\begin{array}{l}\text { mln. MDL } \\
\text { mln. MDL } \\
\text { mln. MDL } \\
\%\end{array}$ & $\begin{array}{c}4102,4 \\
4268,8 \\
-166,4 \\
-1,0 \\
\end{array}$ & $\begin{array}{c}4324,9 \\
4325,9 \\
-1 \\
-0,0 \\
\end{array}$ & $\begin{array}{c}5084,4 \\
5194,1 \\
-109,7 \\
-0,5 \\
\end{array}$ & $\begin{array}{c}6620,1 \\
6179,3 \\
440,8 \\
1,6 \\
\end{array}$ & $\begin{array}{c}7109,2 \\
6769,2 \\
340 \\
1,1 \\
\end{array}$ & $\begin{array}{c}8206,9 \\
8007,4 \\
199,5 \\
0,6 \\
\end{array}$ & $\begin{array}{c}8904,1 \\
8608,6 \\
295,5 \\
0,8 \\
\end{array}$ \\
\hline $\begin{array}{l}\text { Monetization (monetary mass } \\
\text { (M3) vs. GDP) }\end{array}$ & $\%$ & 21,9 & 25,1 & 28,9 & 31,2 & 36,0 & 39,4 & 43,9 \\
\hline $\begin{array}{l}\text { Industrial production } \\
\text { in current prices } \\
\text { Vs. previous year, } \\
\text { in comparable prices }\end{array}$ & $\begin{array}{l}\text { billion } \\
\text { MDL } \\
\%\end{array}$ & $\begin{array}{c}8,2 \\
107,7\end{array}$ & $\begin{array}{l}10,4 \\
113,7 \\
\end{array}$ & $\begin{array}{l}12,6 \\
110,8 \\
\end{array}$ & $\begin{array}{r}16,2 \\
113,6 \\
\end{array}$ & $\begin{array}{l}18,8 \\
112 \\
\end{array}$ & $\begin{array}{l}22,5 \\
111 \\
\end{array}$ & $\begin{array}{l}26,3 \\
110,5 \\
\end{array}$ \\
\hline $\begin{array}{l}\text { Agricultural production in } \\
\text { current prices, in all households } \\
\text { Vs. previous year, } \\
\text { in comparable prices }\end{array}$ & $\begin{array}{l}\text { billion } \\
\text { MDL } \\
\%\end{array}$ & $\begin{array}{l}8,3 \\
96,7\end{array}$ & $\begin{array}{c}8,6 \\
106,4\end{array}$ & $\begin{array}{c}9,5 \\
103,4\end{array}$ & $\begin{array}{l}10,3 \\
85,9\end{array}$ & $\begin{array}{c}10,5 \\
107,5\end{array}$ & $\begin{array}{l}11,7 \\
104\end{array}$ & $\begin{array}{l}12,3 \\
103\end{array}$ \\
\hline $\begin{array}{l}\text { Fixed Capital Investments } \\
\text { Vs. previous year, } \\
\text { in comparable prices }\end{array}$ & $\begin{array}{l}\text { billion } \\
\text { MDL }\end{array}$ & 1,8 & $\begin{array}{l}2,3 \\
111 \\
\end{array}$ & 2,8 & $3,7 *$ & 4,4 & $\begin{array}{l}5,3 \\
110 \\
\end{array}$ & 6,1 \\
\hline
\end{tabular}

* Estimated by the Ministry of Economy 


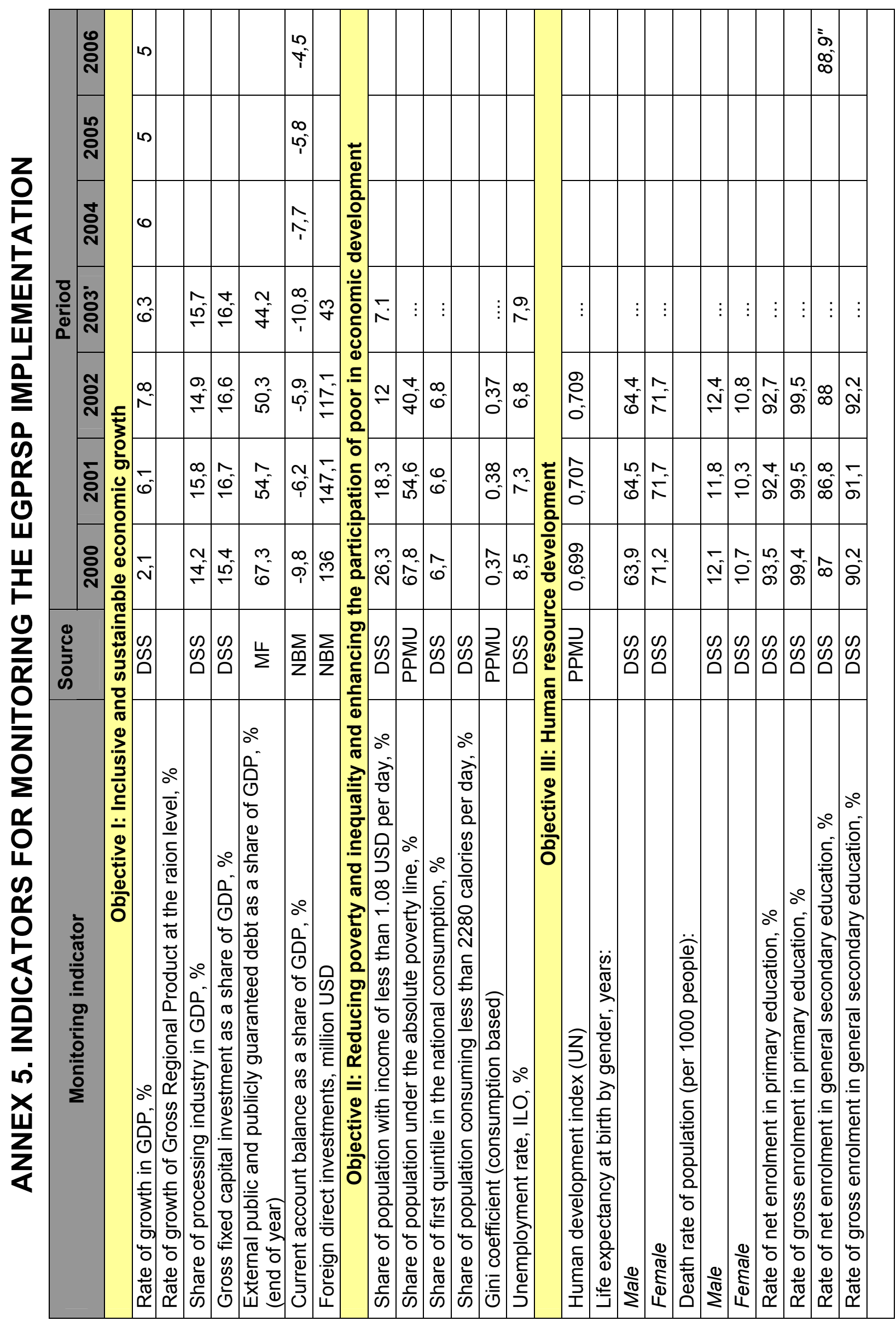




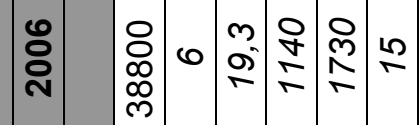

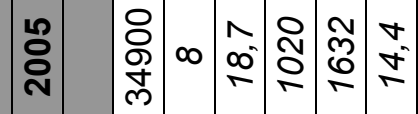

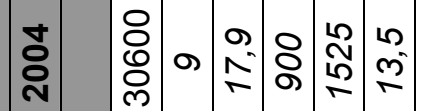

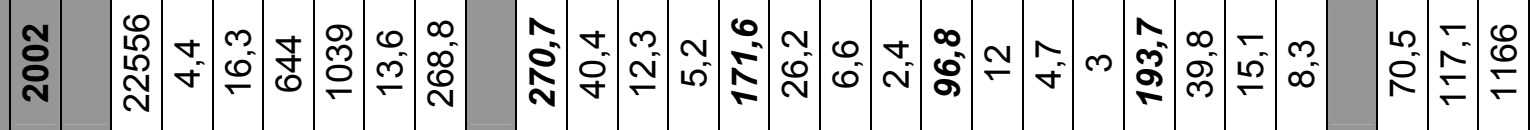

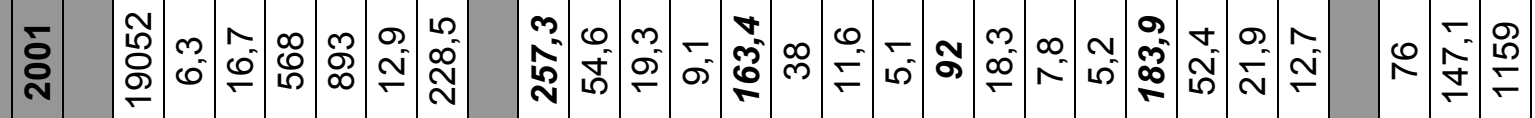

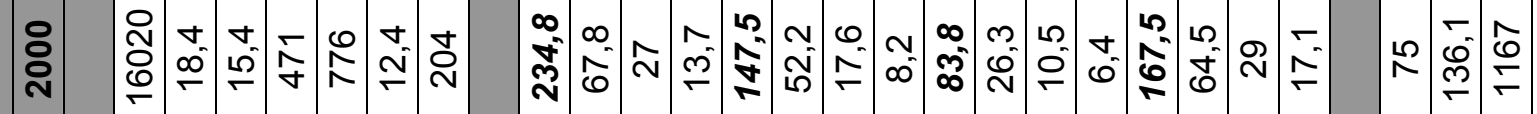

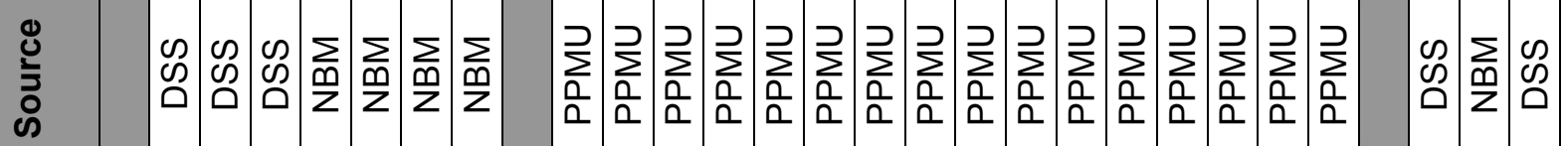

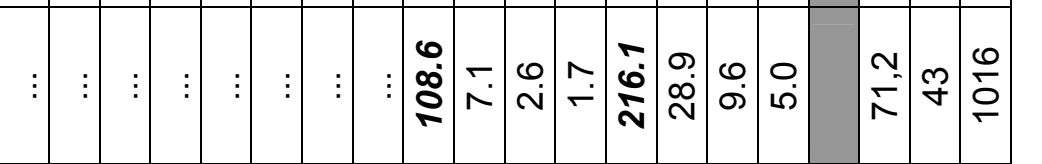

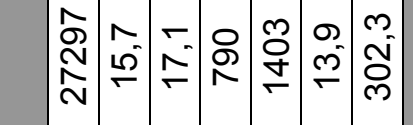




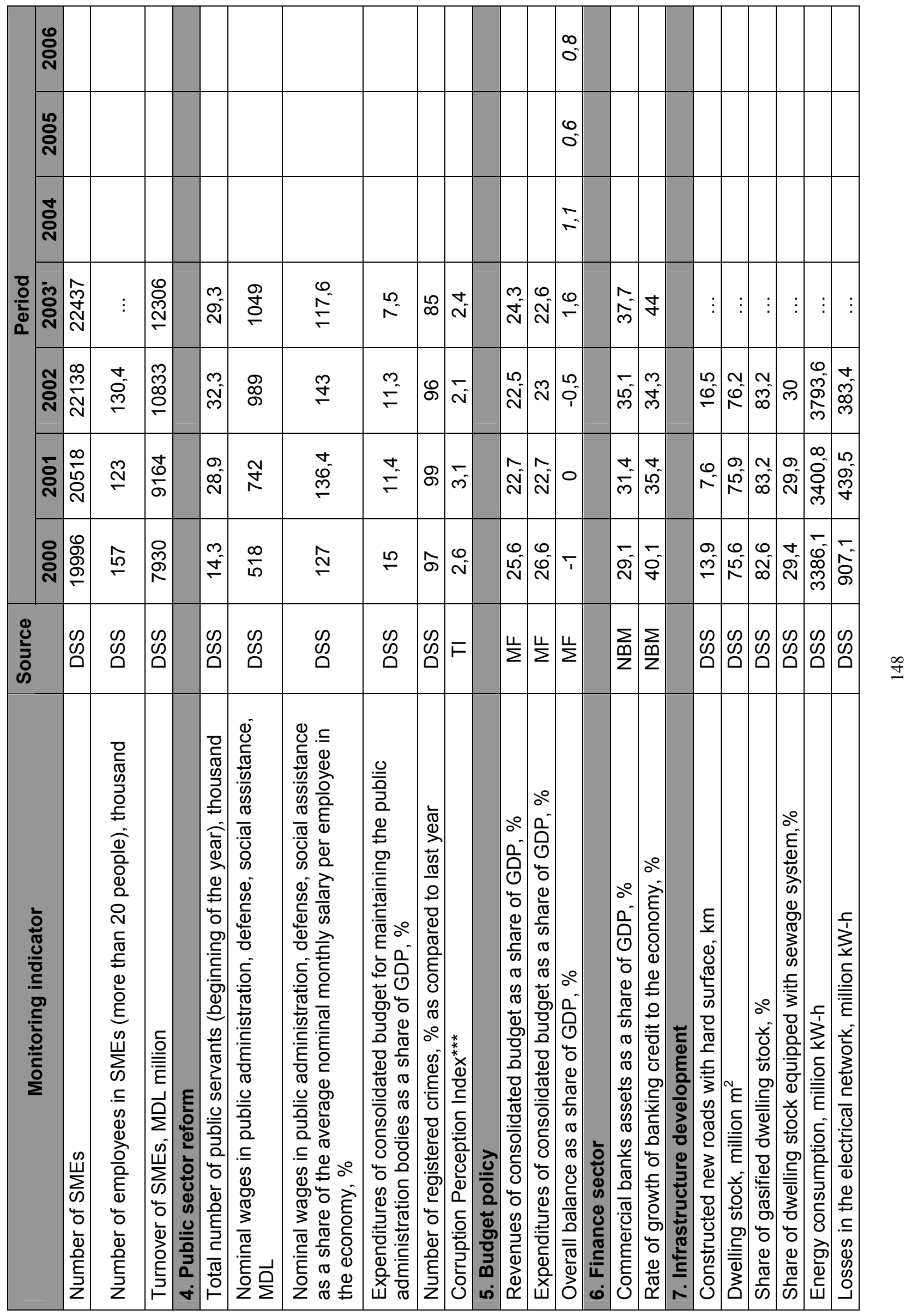




\begin{tabular}{|c|c|c|c|c|c|c|c|c|c|c|c|c|c|c|c|c|c|c|c|c|c|c|}
\hline ) & & & & & & & & & & & & & $\begin{array}{l}0 \\
0 \\
0\end{array}$ & & & & & & & & & $m$ \\
\hline 용 & & & & & & & & & & & & & $\pi$ & & & & & & & & & $\nabla$ \\
\hline ষ্ㅇ & & & & & & & & & & & & & $\stackrel{N}{\sim}$ & & & & & & & & & م \\
\hline 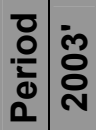 & 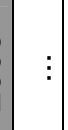 & $\vdots$ & $\vdots$ & $\vdots$ & $\vdots$ & $\vdots$ & $\vdots$ & & $\vdots$ & $\vdots$ & $\vdots$ & $\vdots$ & $\begin{array}{l}\omega \\
\tilde{n}\end{array}$ & & $\vdots$ & $\vdots$ & $\vdots$ & & $\vdots$ & $\vdots$ & $\begin{array}{l}\infty \\
\text { ñ } \\
\text { N }\end{array}$ & $\frac{5}{+}$ \\
\hline 용 & $\frac{a}{\bar{m}}$ & $\begin{array}{l}\infty \\
\infty \\
\infty\end{array}$ & $\tilde{\tilde{N}}$ & $\stackrel{m}{\sim}$ & $\stackrel{\sim}{\sim}$ & $\tilde{\sigma}$ & $\stackrel{m}{m}$ & & $\stackrel{\Sigma}{\approx}$ & $\underset{\sigma}{\check{\sigma}}$ & $\stackrel{N}{\mp}$ & $\begin{array}{l}0 \\
\infty \\
\infty\end{array}$ & $\begin{array}{l}\infty \\
0 \\
0\end{array}$ & & $\stackrel{0}{N}$ & $\begin{array}{l}0 \\
0\end{array}$ & \begin{tabular}{l}
0 \\
\multirow{J}{+}{} \\
-
\end{tabular} & & 守 & ڤా & 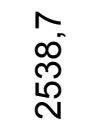 & $\stackrel{\nabla}{\dot{m}}$ \\
\hline 훙 & $\mid \begin{array}{l}0 \\
0 \\
0\end{array}$ & क) & $\frac{m}{m_{1}^{\prime}}$ & $\begin{array}{l}0 \\
\sim \\
\sim\end{array}$ & $\stackrel{-}{\stackrel{\infty}{\sim}}$ & $\bar{\infty}$ & $\dot{\sigma}$ & & $\stackrel{\iota}{\varrho}$ & $\mp$ & $\stackrel{9}{\check{2}}$ & $\stackrel{\infty}{\infty}$ & $\vec{m}$ & & 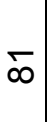 & $\begin{array}{l}0 \\
N\end{array}$ & $\stackrel{\infty}{\infty}$ & & ষ্ঠ & ז & 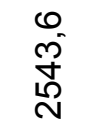 & \begin{tabular}{l}
+ \\
\multirow{0}{*}{}
\end{tabular} \\
\hline 용 & $\begin{array}{l}0 \\
\pm \\
\pm\end{array}$ & $\widetilde{\sim}$ & $\begin{array}{l}\infty \\
0^{-} \\
\frac{-}{1}\end{array}$ & $\stackrel{9}{\stackrel{n}{\sigma}}$ & 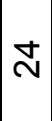 & $\left|\begin{array}{l}\infty \\
0^{-}\end{array}\right|$ & ஸ) & & $\ddot{\sigma}$ & $\stackrel{0}{\circ}$ & $\underset{\leftarrow}{\mp}$ & $\stackrel{m}{\sigma}$ & $\hat{N}$ & & 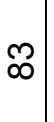 & $\begin{array}{l}\sim \\
\infty\end{array}$ & $\stackrel{n}{m}$ & & @્ & $\begin{array}{l}0 \\
0 \\
0\end{array}$ & $\begin{array}{l}m \\
\stackrel{n}{n} \\
\stackrel{n}{N}\end{array}$ & $m^{m}$ \\
\hline 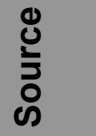 & $\begin{array}{l}\mathcal{\omega} \\
\mathcal{D}\end{array}$ & $\begin{array}{l}\infty \\
\mathcal{D} \\
0\end{array}$ & ભ & $\begin{array}{l}\mathscr{\omega} \\
\text { ஸ }\end{array}$ & & & $\stackrel{\mathscr{D}}{\mathscr{D}}$ & & ल & $\stackrel{\mathscr{\Omega}}{\mathscr{D}}$ & 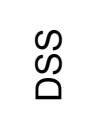 & $\begin{array}{l}\infty \\
\mathscr{D}\end{array}$ & $\begin{array}{l}\mathscr{\omega} \\
\mathscr{\omega}\end{array}$ & & $\begin{array}{l}\text { ஸુ } \\
\text { ஸे }\end{array}$ & $\begin{array}{l}\mathscr{\omega} \\
\mathscr{D}\end{array}$ & ص & & $\begin{array}{l}\mathscr{\Omega} \\
\end{array}$ & $\stackrel{\mathscr{D}}{\mathscr{D}}$ & 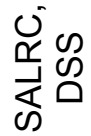 & ڤ \\
\hline 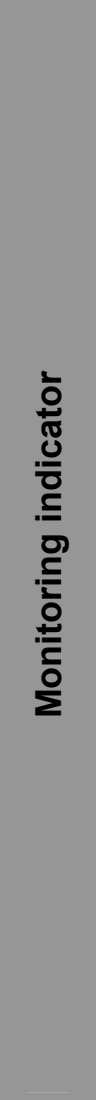 & 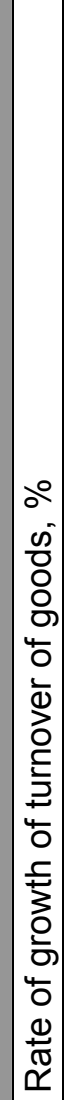 & 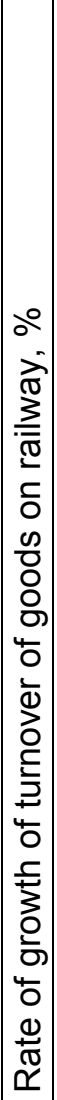 & 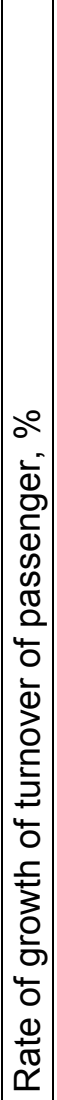 & 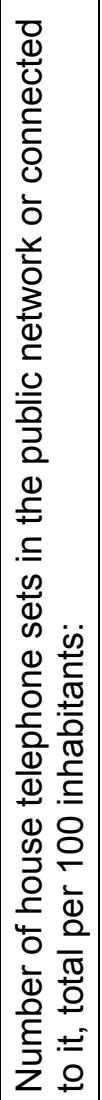 & 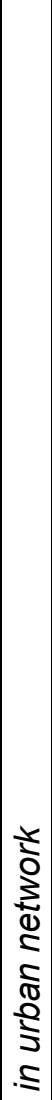 & 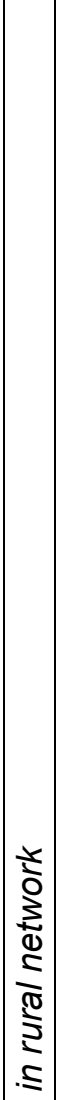 & 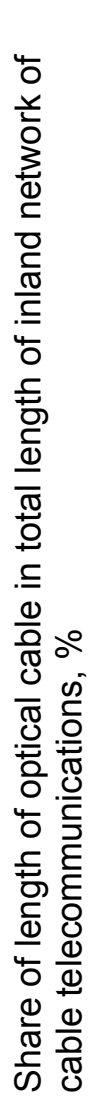 & $\begin{array}{l} \\
\geq \frac{5}{5} \\
\underline{0} \\
\underline{0} \\
\underline{\underline{0}} \\
\infty\end{array}$ & 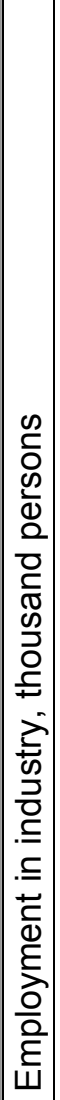 & 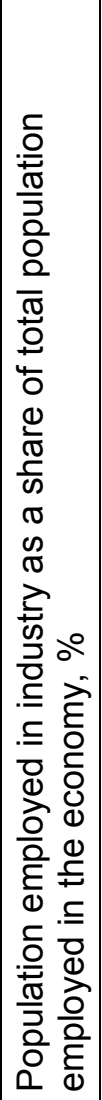 & 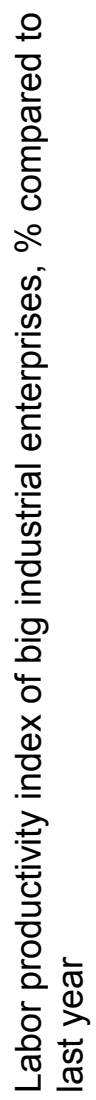 & 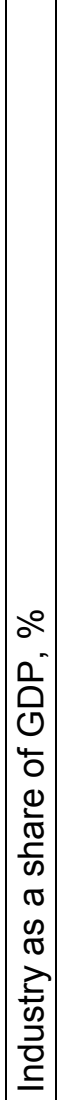 & 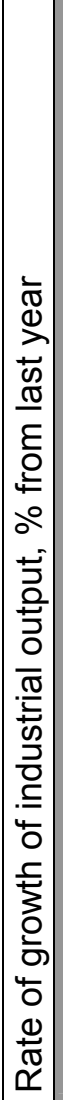 & 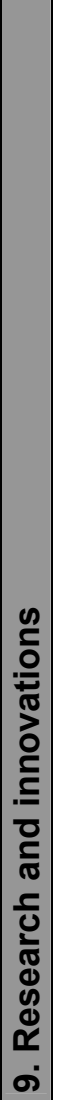 & 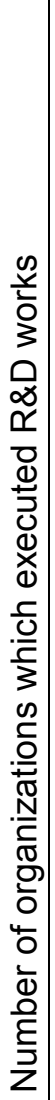 & 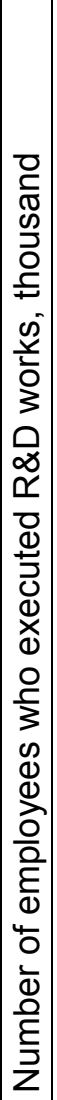 & 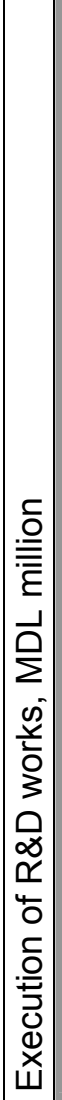 & 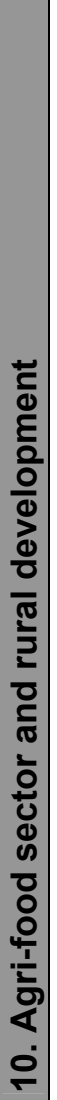 & 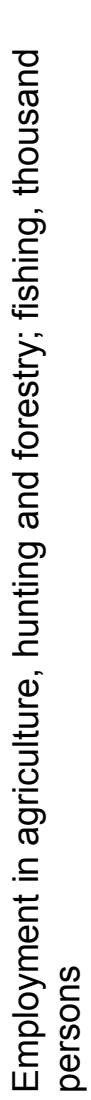 & 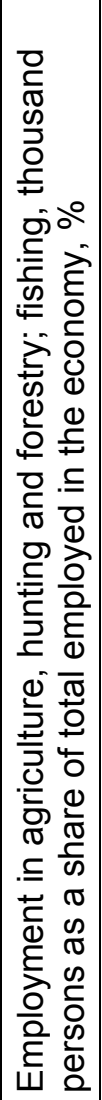 & 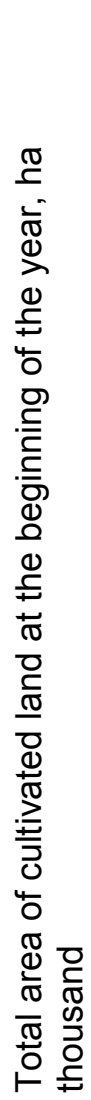 & 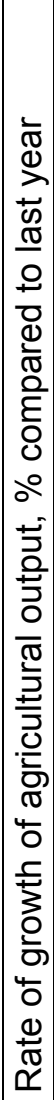 \\
\hline
\end{tabular}




\begin{tabular}{|c|c|c|c|c|c|c|c|c|c|c|c|c|c|c|c|c|c|c|c|c|c|c|c|c|}
\hline 융 & & & & & & & & & & & & $\frac{1}{10}$ & & $\frac{\hat{N}}{\hat{\gamma}}$ & 60 & $\begin{array}{l}\bar{i} \\
\bar{v}\end{array}$ & & & & & & & & $\begin{array}{l}0 \\
\infty^{\circ} \\
\infty\end{array}$ \\
\hline 융 & & & & & & & & & & & & & & & & & & & & & & & & \\
\hline ర్ & & & & & & & & & & & & & & & & & & & & & & & & \\
\hline \begin{tabular}{l|l}
$\overline{0}$ \\
\hdashline \\
\hdashline
\end{tabular} & $\underset{\sim}{\infty}$ & & & & & & $\begin{array}{l}0 \\
\stackrel{N}{N}\end{array}$ & $\begin{array}{l}m \\
0 \\
0\end{array}$ & 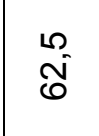 & & $\begin{array}{l}m \\
\infty \\
\infty \\
\infty\end{array}$ & & & & $\vdots$ & & $\stackrel{m}{\forall}$ & & & & & & & \\
\hline ণิ & $\stackrel{\check{N}}{\sim}$ & & & & שֶ & & $\tilde{i}$ & $\left|\begin{array}{l}0 \\
-1 \\
50\end{array}\right|$ & $\bar{f}$ & & $\begin{array}{l}N \\
\mathscr{L}^{-} \\
\stackrel{n}{n}\end{array}$ & 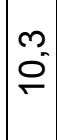 & $\stackrel{\check{N}}{\sim}$ & $\begin{array}{l}\tilde{D} \\
\infty^{\infty} \\
m^{\circ}\end{array}$ & & ब్ & $\stackrel{\sim}{ }$ & $\begin{array}{l}\stackrel{\rho}{\circ} \\
\stackrel{\infty}{\leftarrow}\end{array}$ & 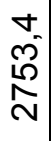 & 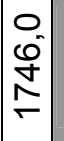 & & $\begin{array}{l}\hat{N} \\
\tilde{\sigma}\end{array}$ & $\begin{array}{l}\infty \\
\delta \\
\Omega \\
\Omega\end{array}$ & $\begin{array}{l}\Omega \\
\stackrel{\infty}{\infty}\end{array}$ \\
\hline 흉 & ָ̊ & $\begin{array}{l}\infty \\
\stackrel{\infty}{m} \\
\leftarrow\end{array}$ & & & 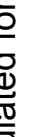 & & $\stackrel{r}{\omega^{\circ}}$ & $\begin{array}{l}m \\
0 \\
0 \\
\end{array}$ & $\begin{array}{l}0 \\
\tilde{m}^{\circ}\end{array}$ & & 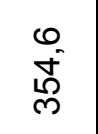 & $\begin{array}{l}0 \\
\sigma\end{array}$ & 음 & $\bar{\infty}$ & \& & 吕 & $\stackrel{\curvearrowright}{\sim}$ & $\stackrel{\stackrel{\Xi}{N}}{\underset{N}{ }}$ & $\mid$ & $\begin{array}{l}0 \\
0 \\
\infty \\
\infty\end{array}$ & & 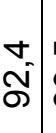 & $\begin{array}{l}\mathbf{0} \\
\text { S) }\end{array}$ & $\begin{array}{l}\infty \\
\infty^{-} \\
\infty\end{array}$ \\
\hline ঃ্ & ণ్లి & $\begin{array}{l}0 \\
0 \\
8\end{array}$ & & & $\frac{d}{\omega}$ & & $\stackrel{9}{\square}$ & $\begin{array}{l}10 \\
\tilde{N} \\
\tilde{n}\end{array}$ & $\hat{\hat{N}^{-}}$ & & 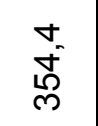 & $\begin{array}{l}0 \\
\sigma\end{array}$ & 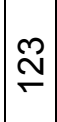 & 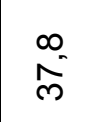 & & $\begin{array}{l}\hat{\sigma} \\
-\end{array}$ & $\stackrel{\sim}{\sim}$ & $\begin{array}{l}\infty \\
\infty \\
\stackrel{-}{\leftarrow}\end{array}$ & \begin{tabular}{l}
$\dot{v}$ \\
$\stackrel{0}{ }$ \\
\multirow{N}{N}{}
\end{tabular} & 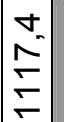 & & 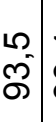 & $\begin{array}{l}\stackrel{+}{\Delta} \\
\dot{\Omega}\end{array}$ & $\hat{\infty}$ \\
\hline 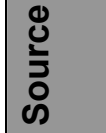 & $\begin{array}{l}0 \\
\frac{\alpha}{\alpha} \\
\frac{1}{4} \\
\omega\end{array}$ & מ & & & & & 心 & $\begin{array}{l}\mathscr{\omega} \\
\mathscr{D}\end{array}$ & ஸ) & & 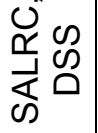 & $\stackrel{\frac{\alpha}{z}}{\underset{\Sigma}{\Sigma}}$ & D & $\underset{⿱ ㇒ ⿲ 丶 丶 ㇒}{\underline{\Sigma}}$ & $\stackrel{\frac{\alpha}{z}}{\underset{\Sigma}{\Sigma}}$ & 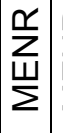 & 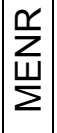 & $\begin{array}{l}\stackrel{\underline{z}}{\Sigma} \\
\underset{\Sigma}{\rightleftarrows}\end{array}$ & $\begin{array}{l}\mathscr{\infty} \\
\mathscr{D}\end{array}$ & $\begin{array}{l}\infty \\
\infty\end{array}$ & & 心 & ભ & ભ \\
\hline 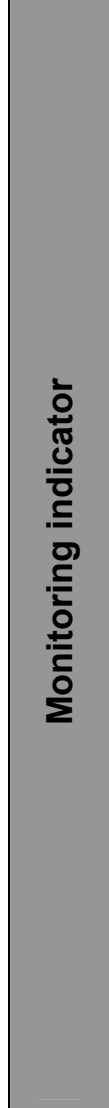 & 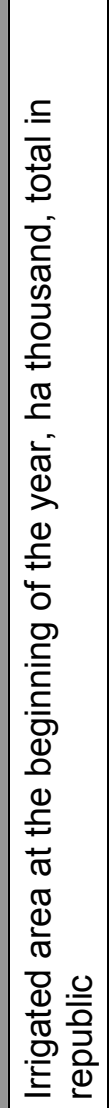 & 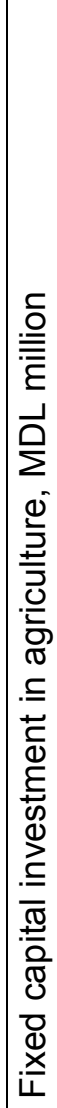 & 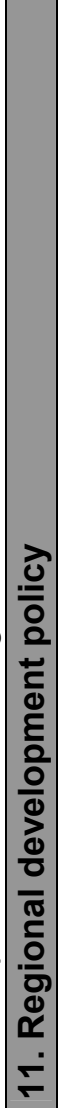 & 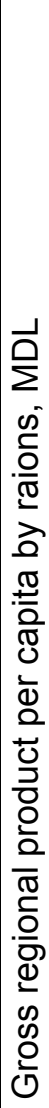 & 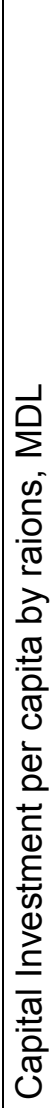 & 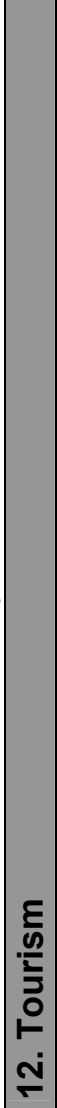 & 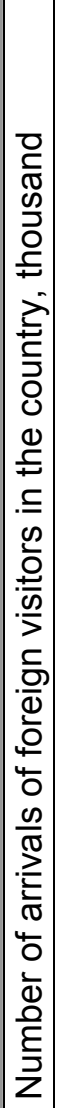 & 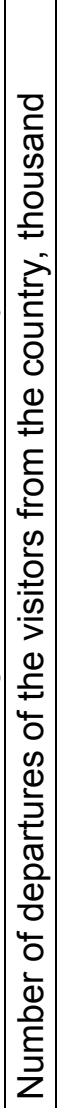 & 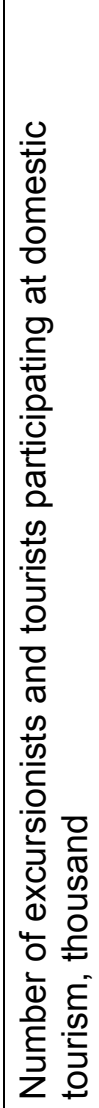 & 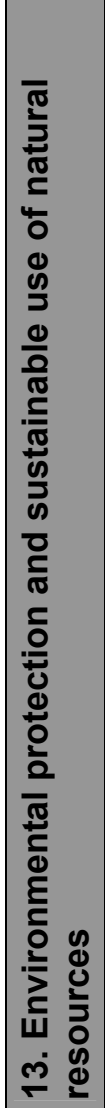 & 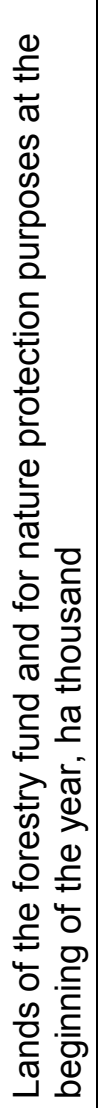 & 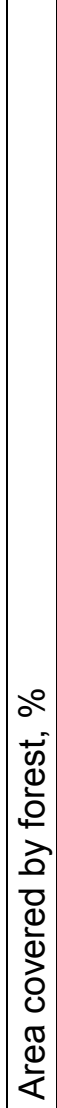 & 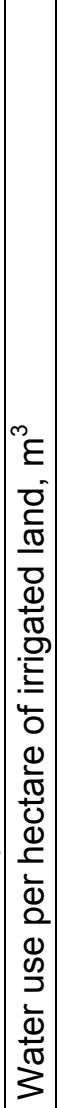 & 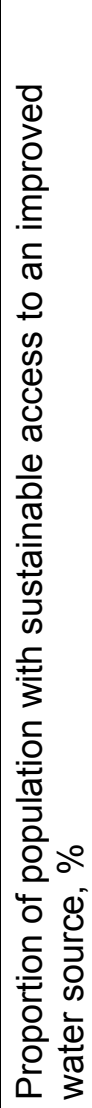 & 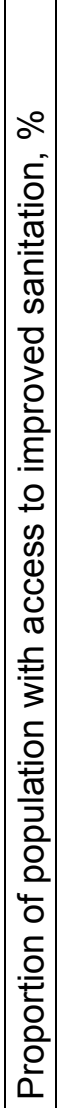 & 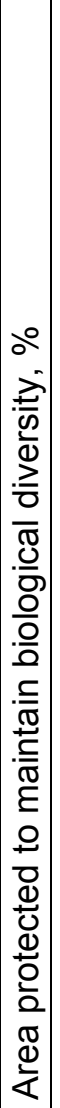 & 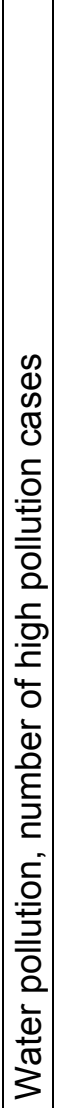 & 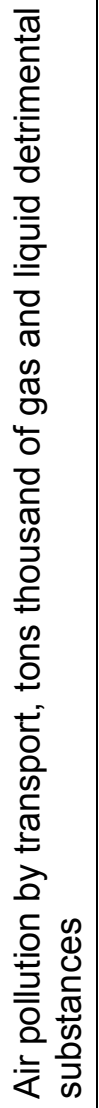 & 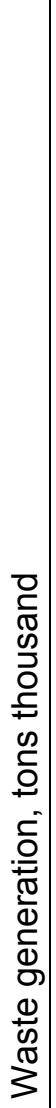 & 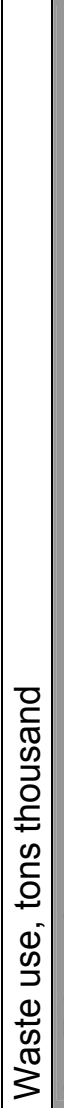 & 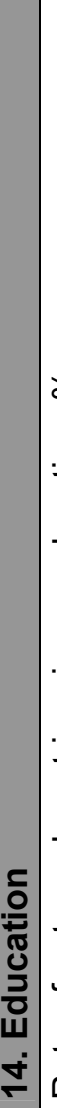 & 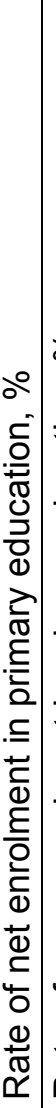 & 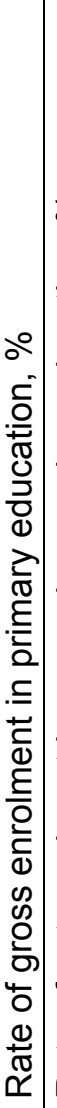 & 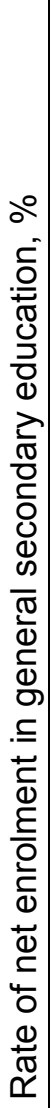 \\
\hline
\end{tabular}




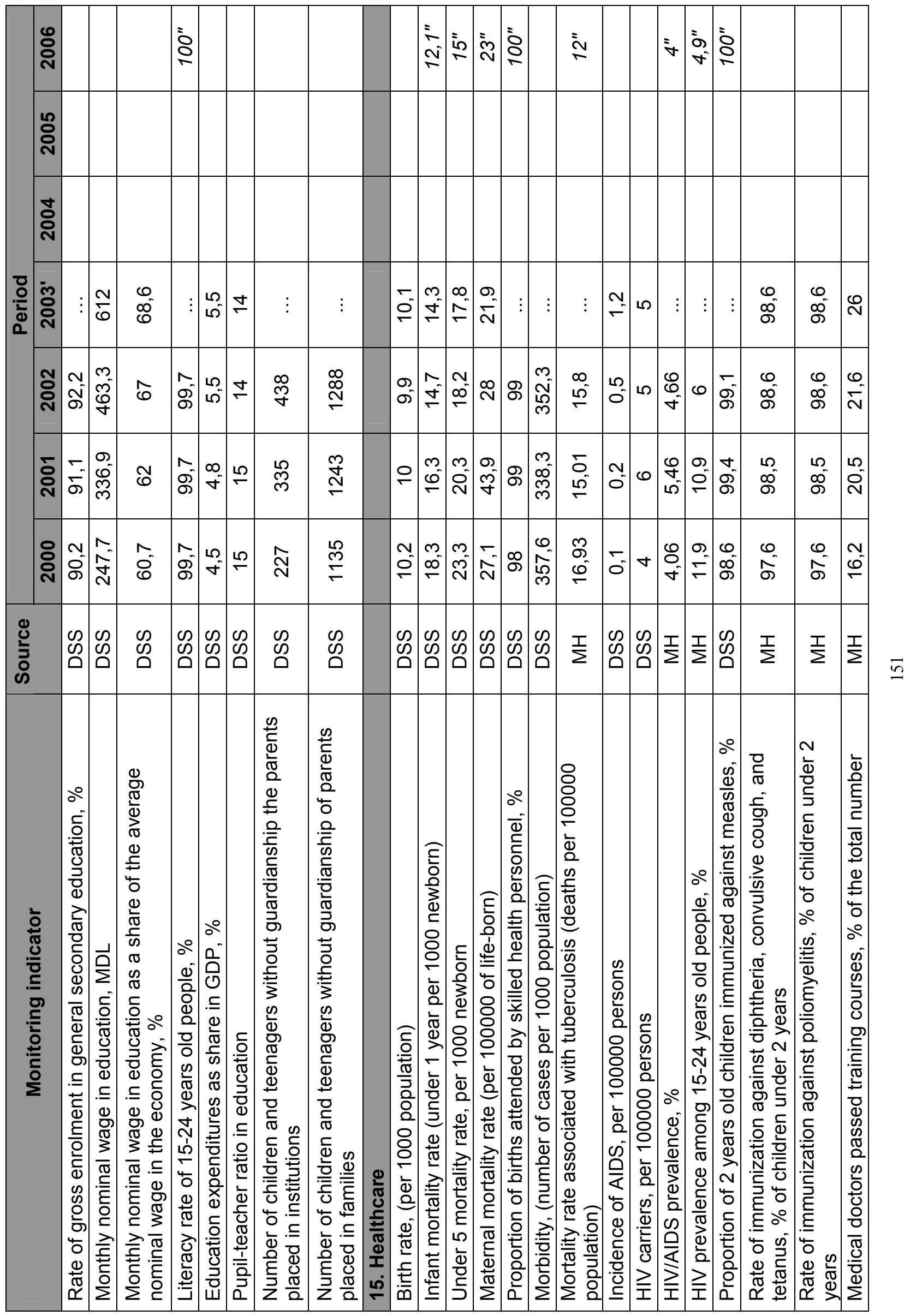




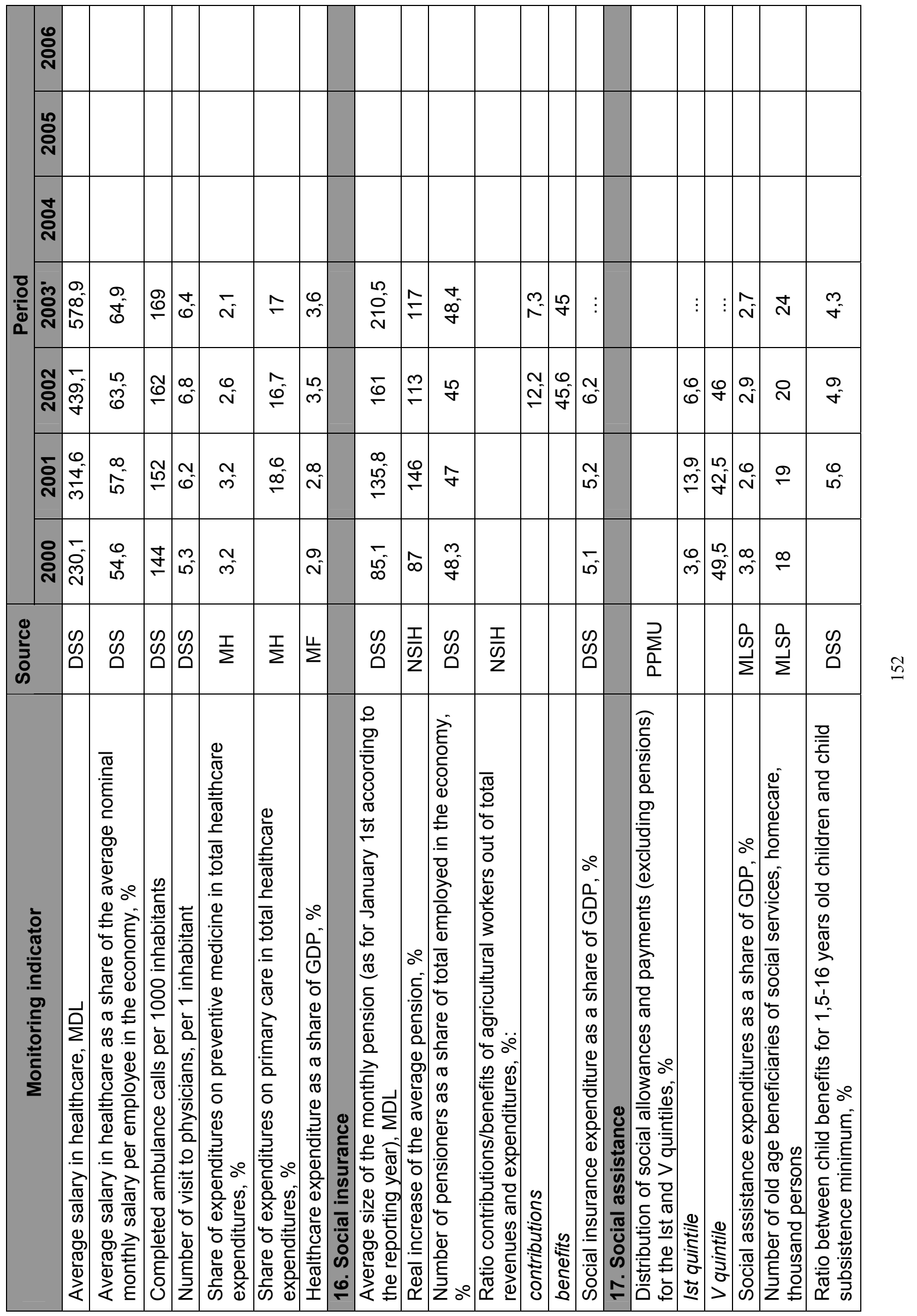






ธุำ

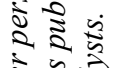
ذँ ₹

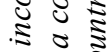

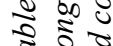
है ह : क. ปี 咅 เ 5 จ

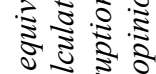
दू 8 ह ₹

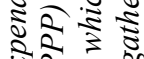
कर 2 ह ₹ $\frac{2}{3}$ है हे ड़ इ खे है ป 8 is o : है हิ है

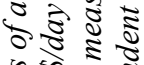
ऊुके है ป

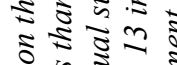
ช

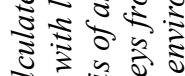

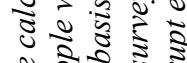
है ₹ ํำ ชูำ

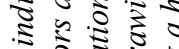

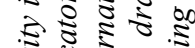
ปั ते 3 ० के के है क्षे

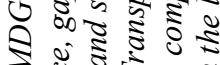
रु०

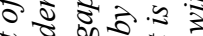
उ.

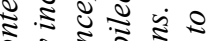

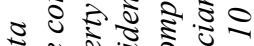

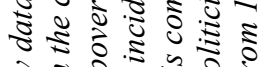

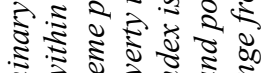

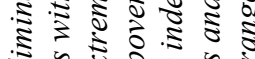
ปั

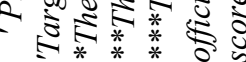




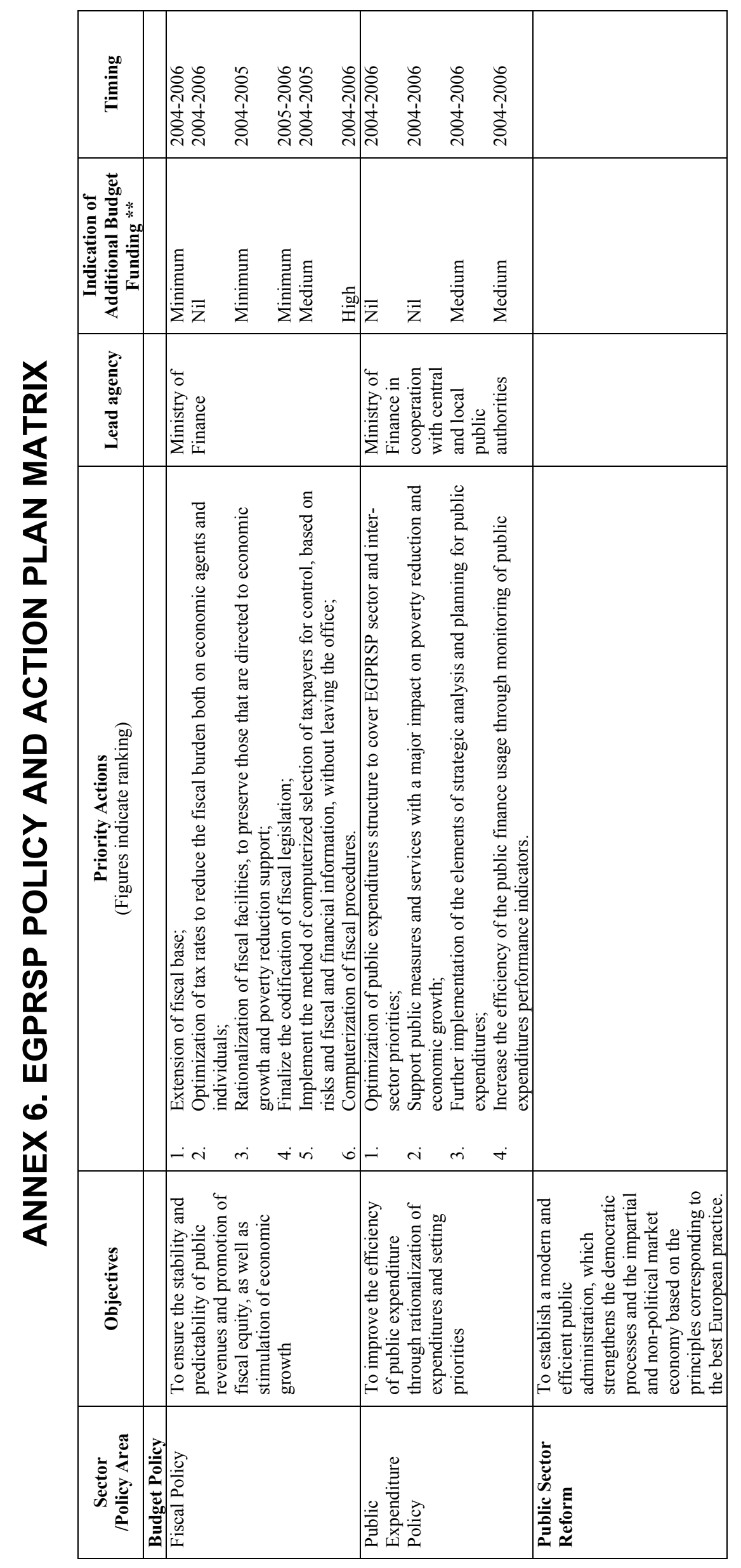




\begin{tabular}{|c|c|c|c|c|c|c|c|}
\hline$\stackrel{90}{\stackrel{\Xi}{\Xi}}$ & \multicolumn{7}{|l|}{ 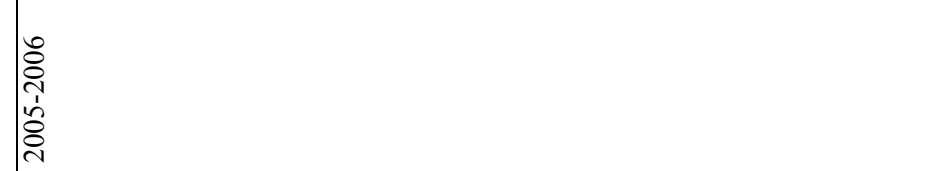 } \\
\hline 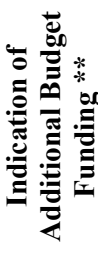 & \multicolumn{7}{|c|}{ 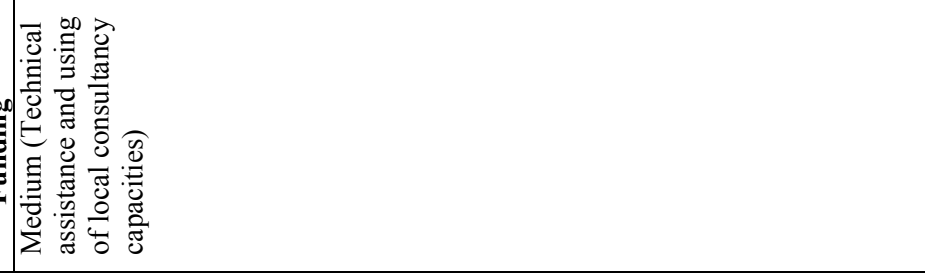 } \\
\hline 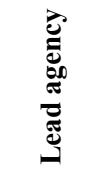 & \multicolumn{7}{|c|}{ 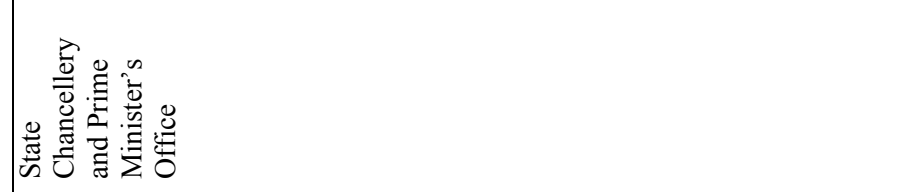 } \\
\hline 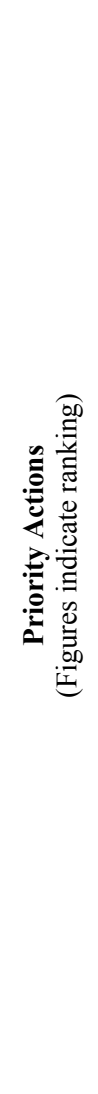 & 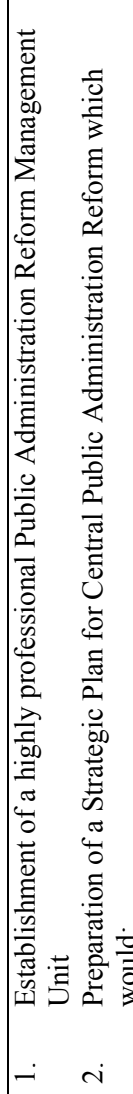 & 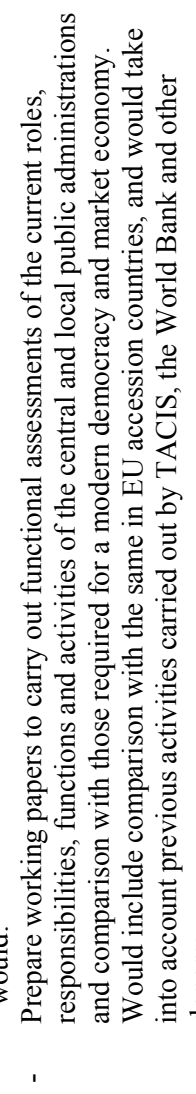 & 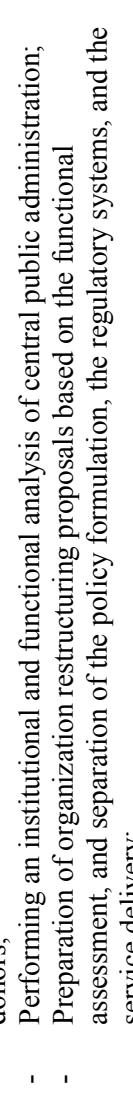 & 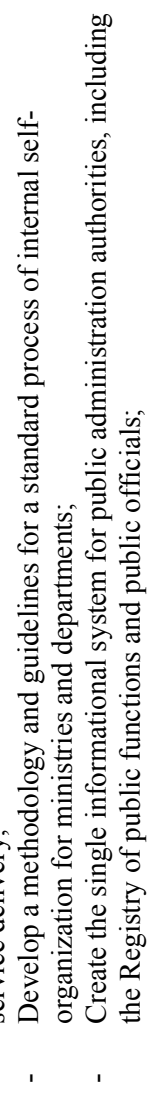 & 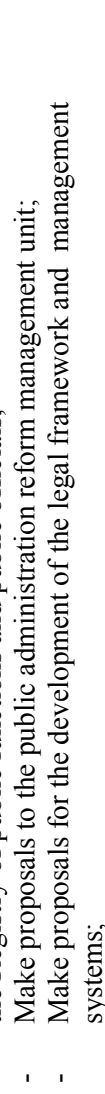 & 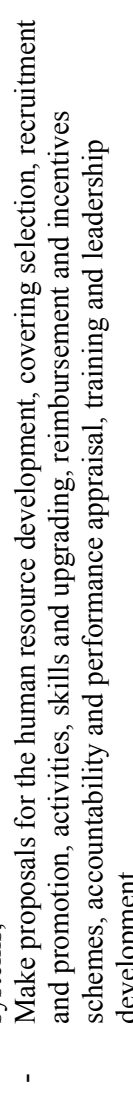 & 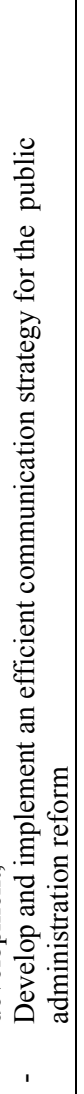 \\
\hline 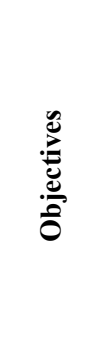 & 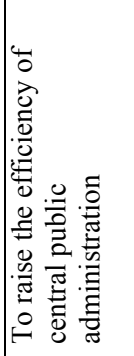 & 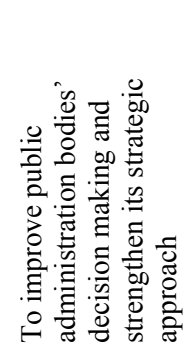 & 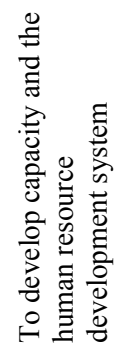 & 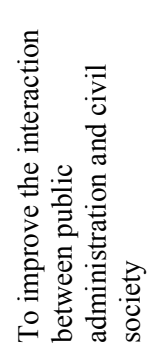 & & & \\
\hline 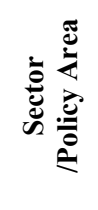 & 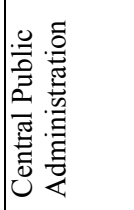 & & & & & & \\
\hline
\end{tabular}




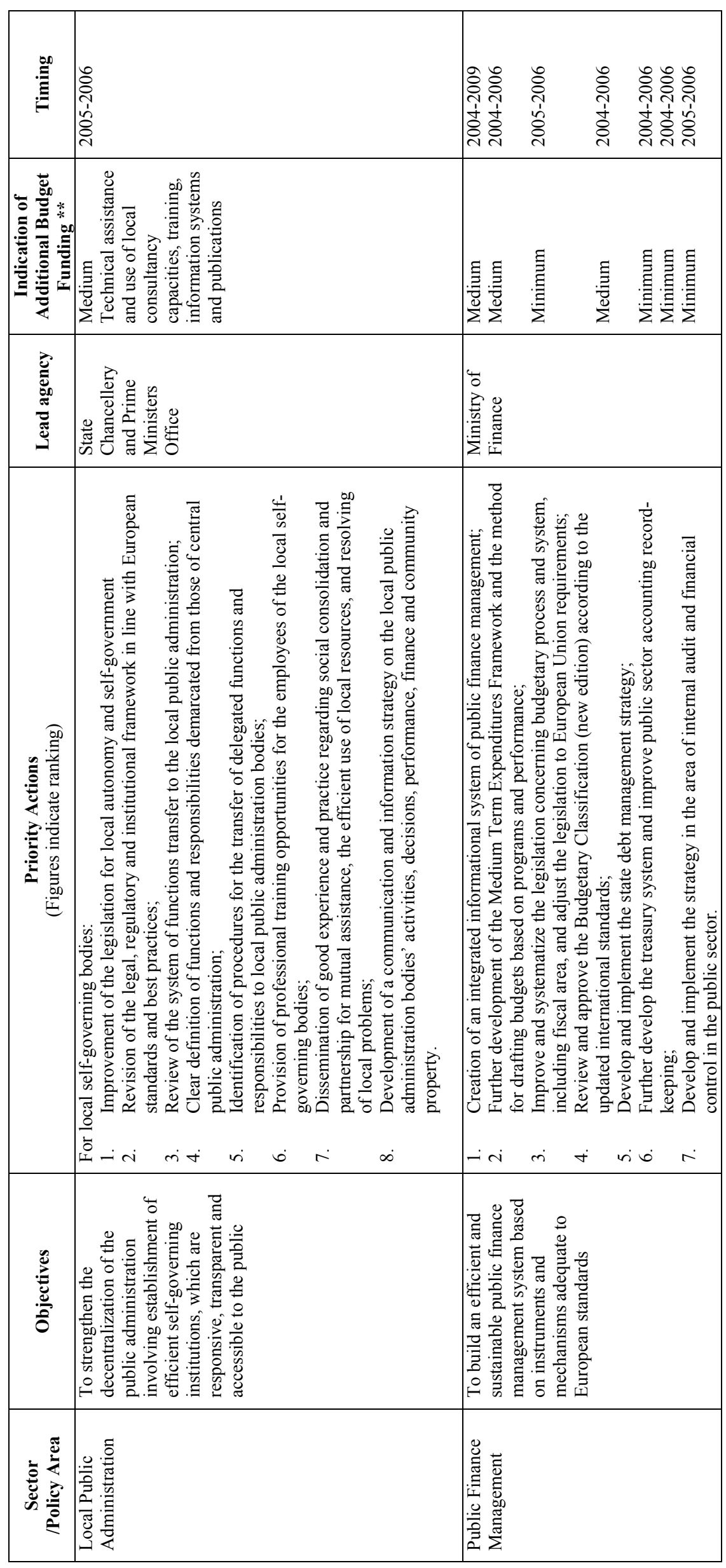




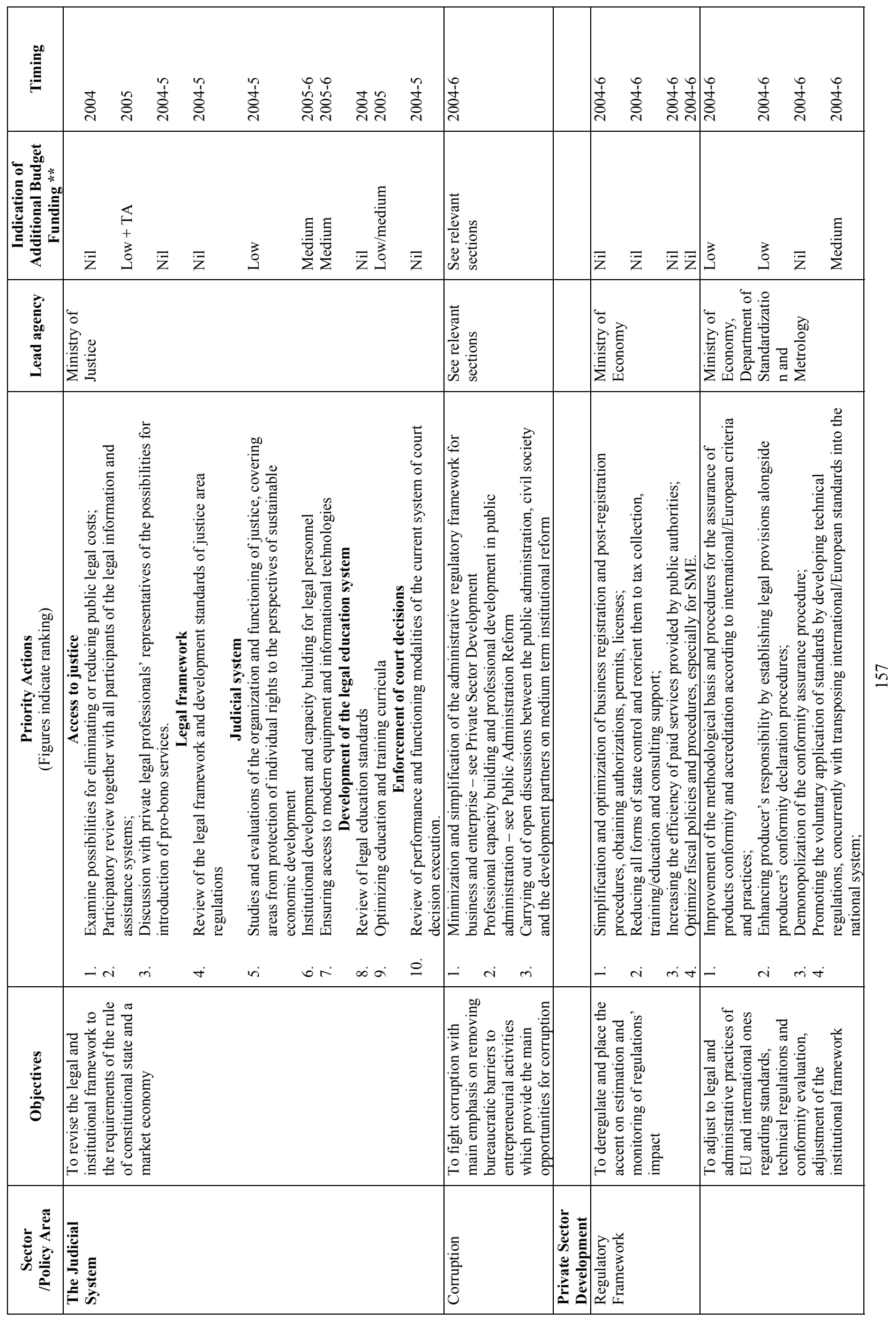




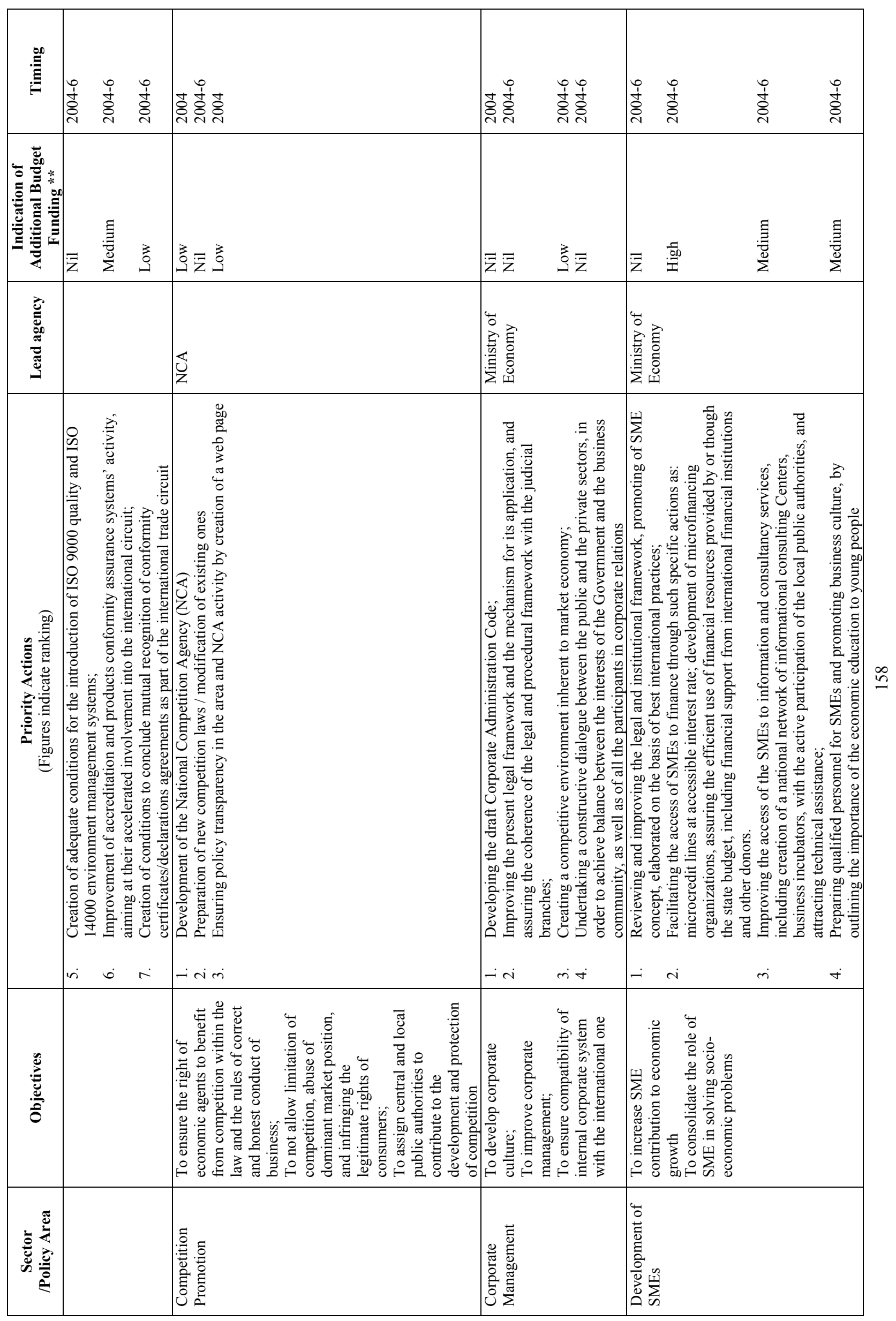




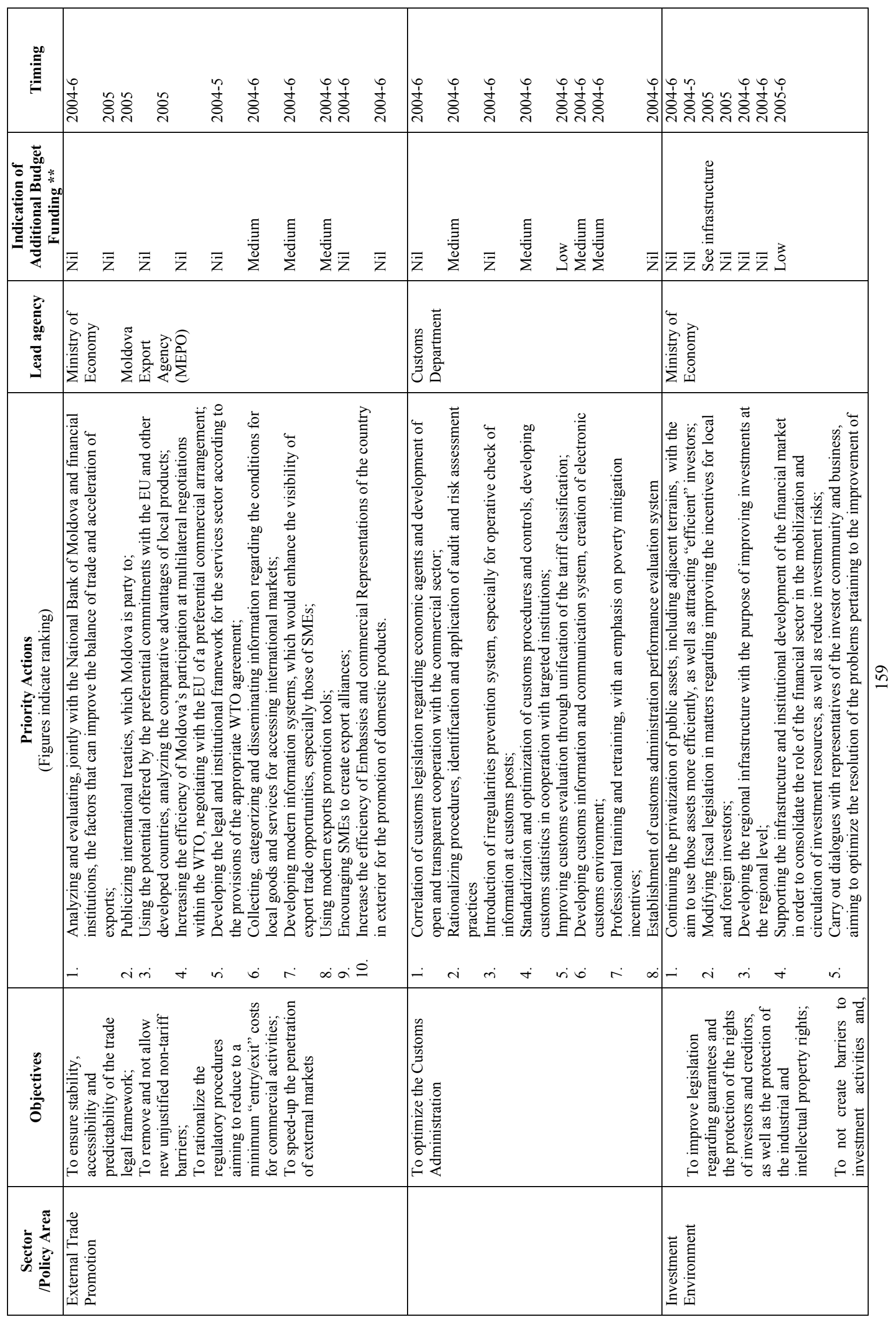




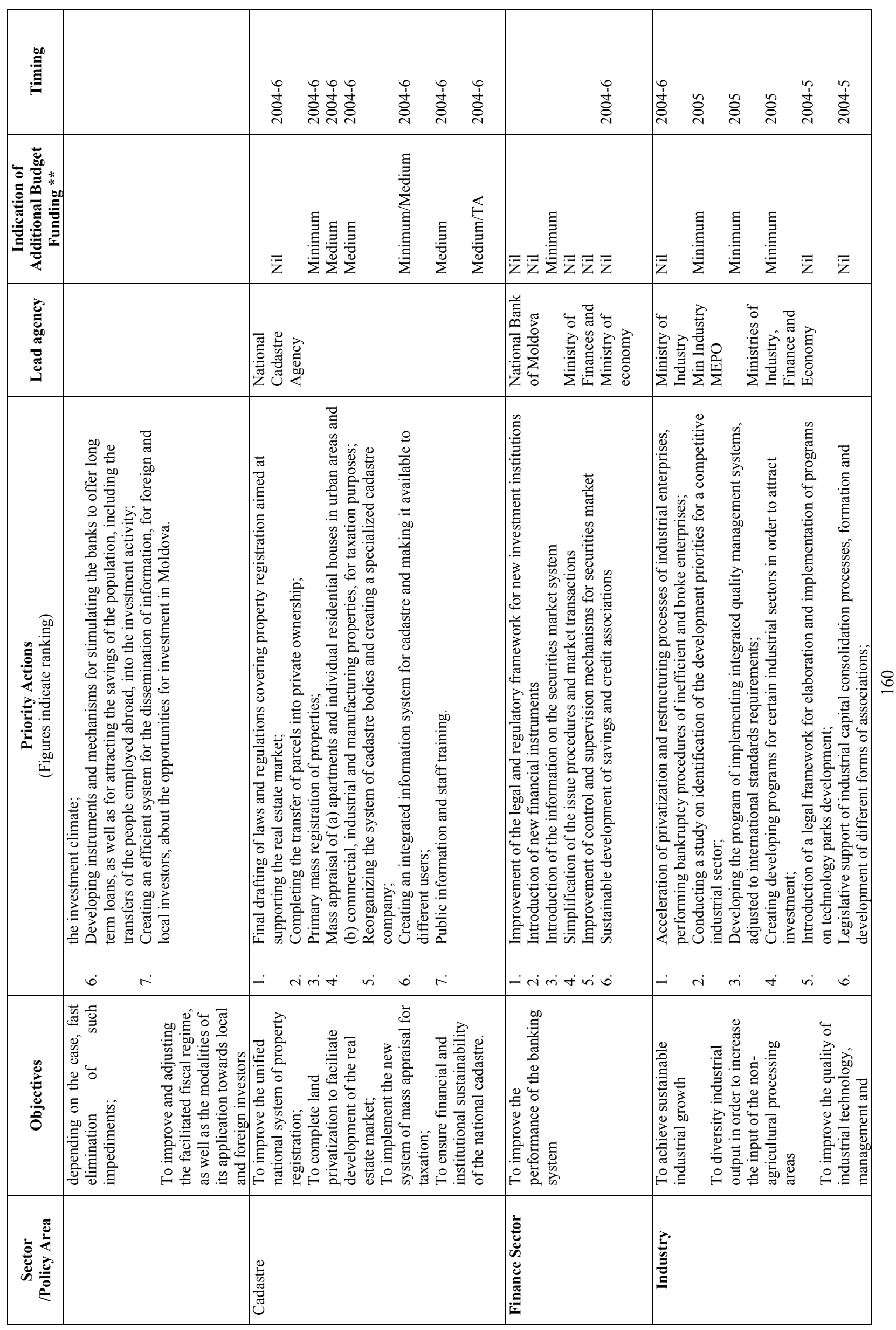




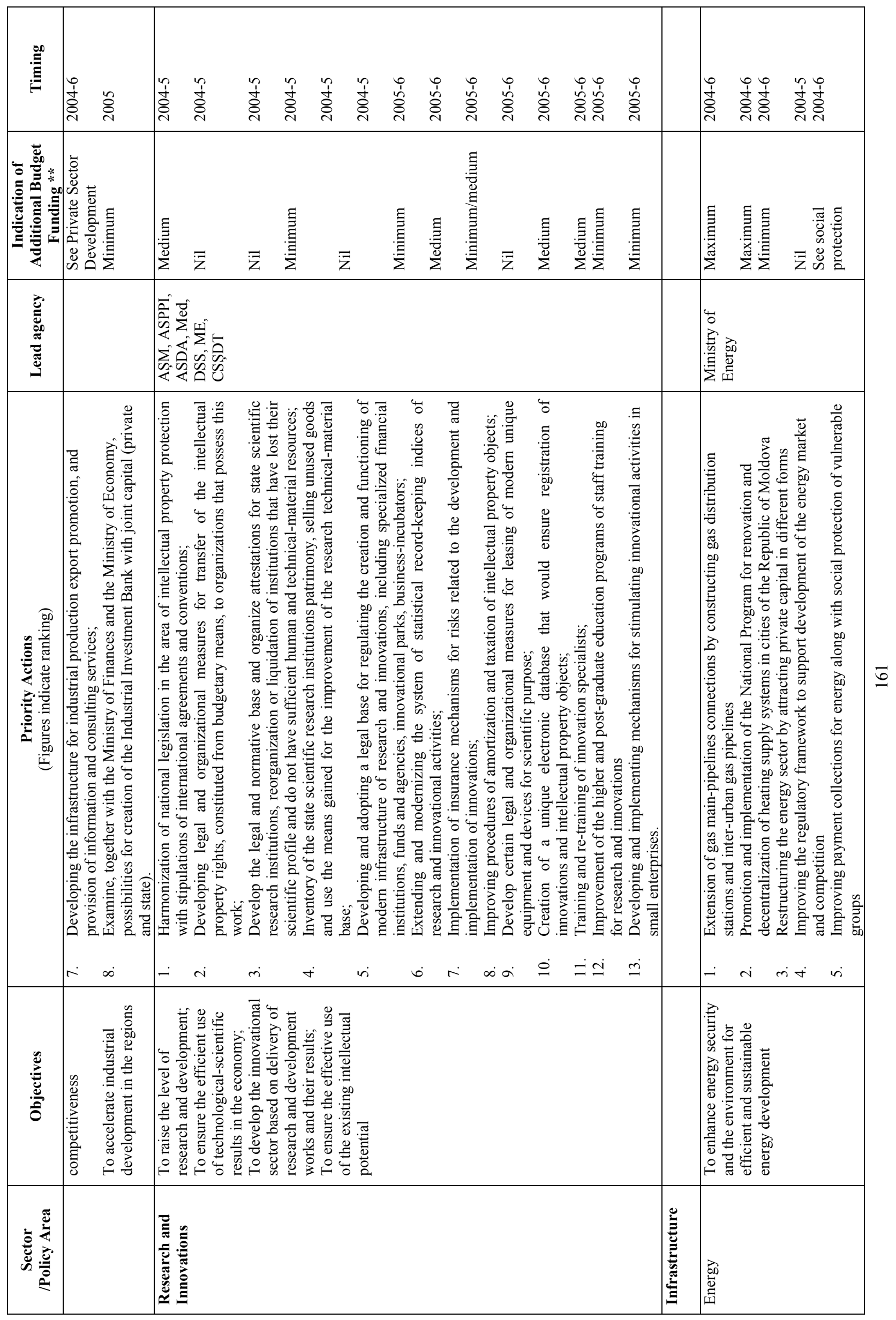




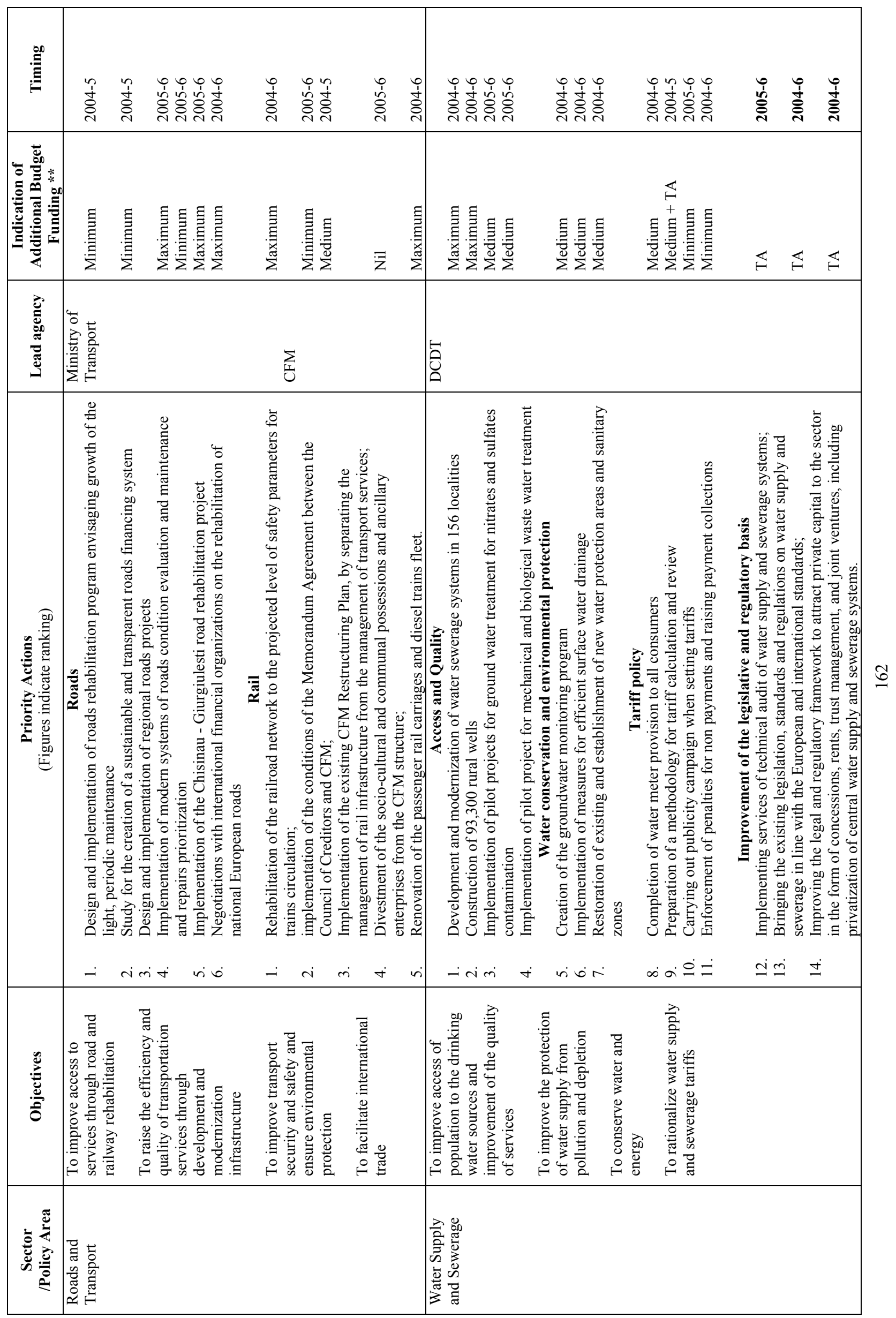




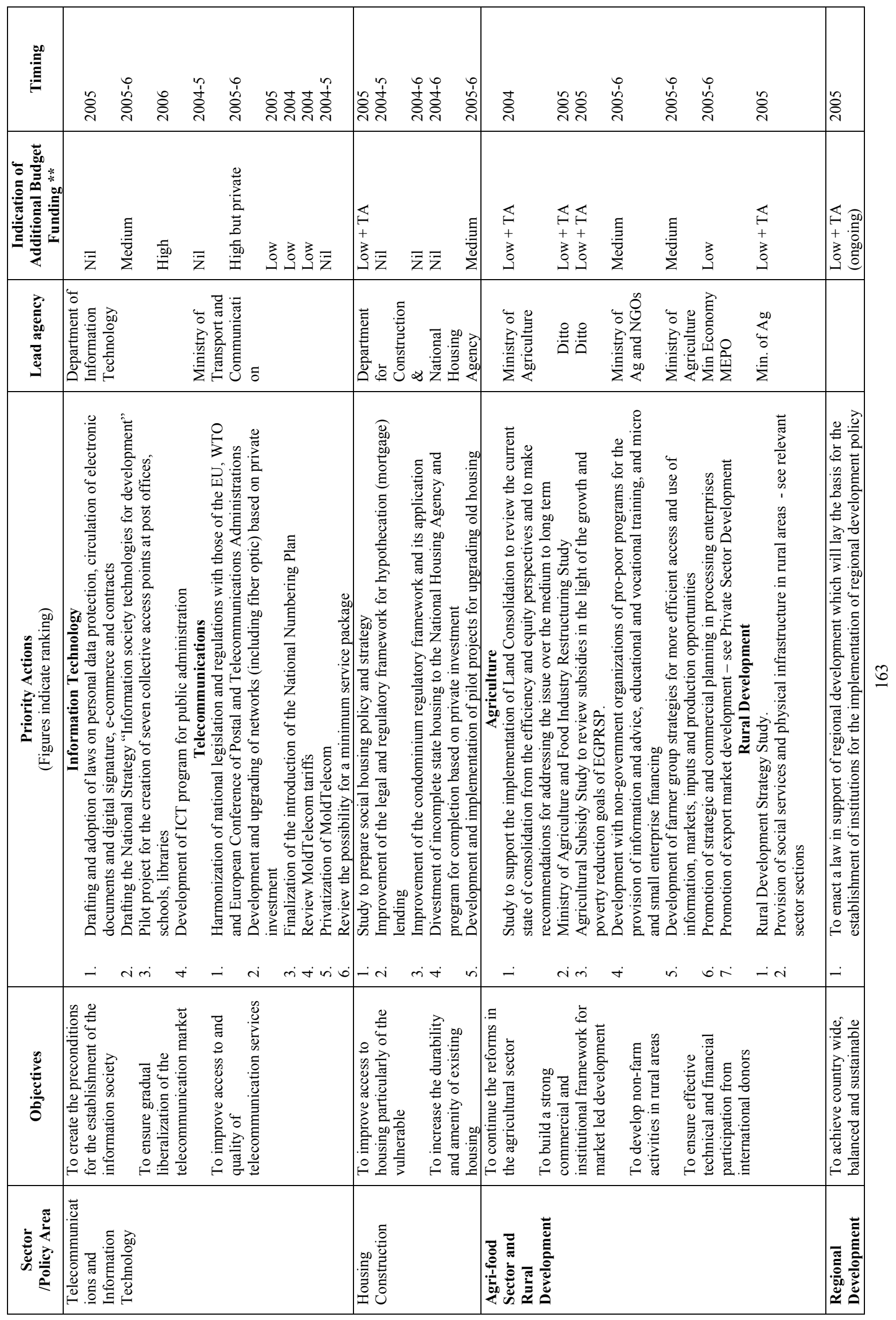




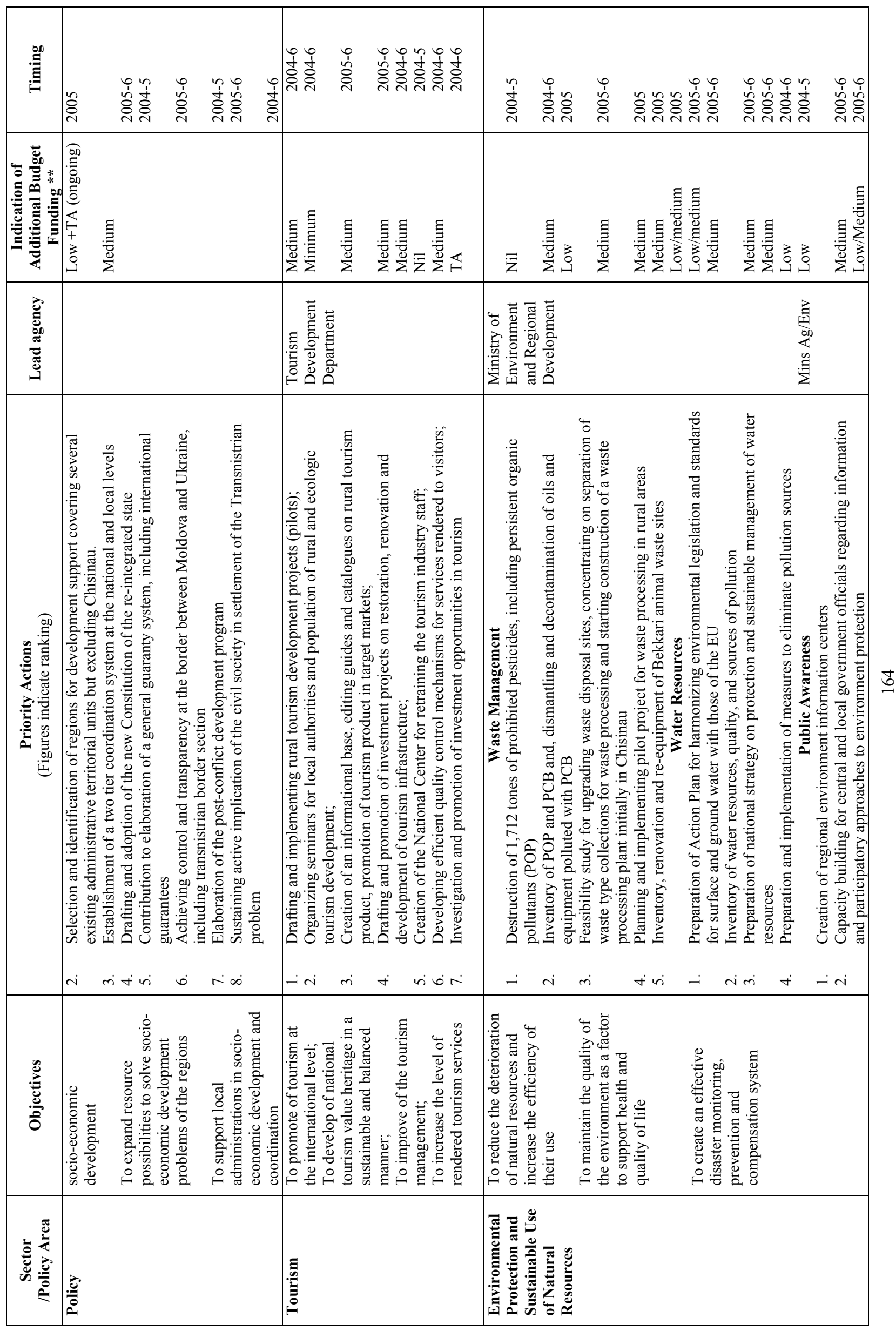




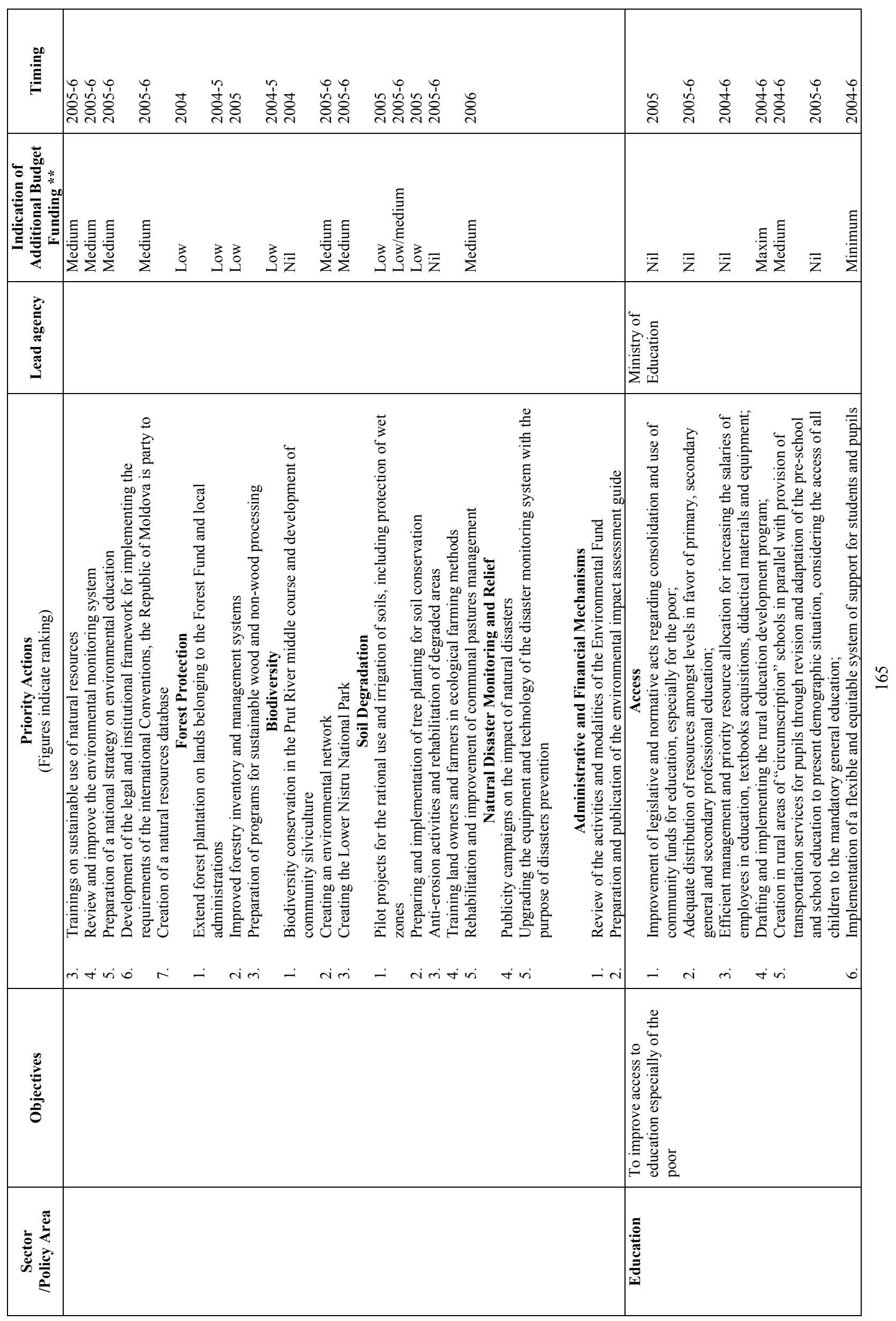




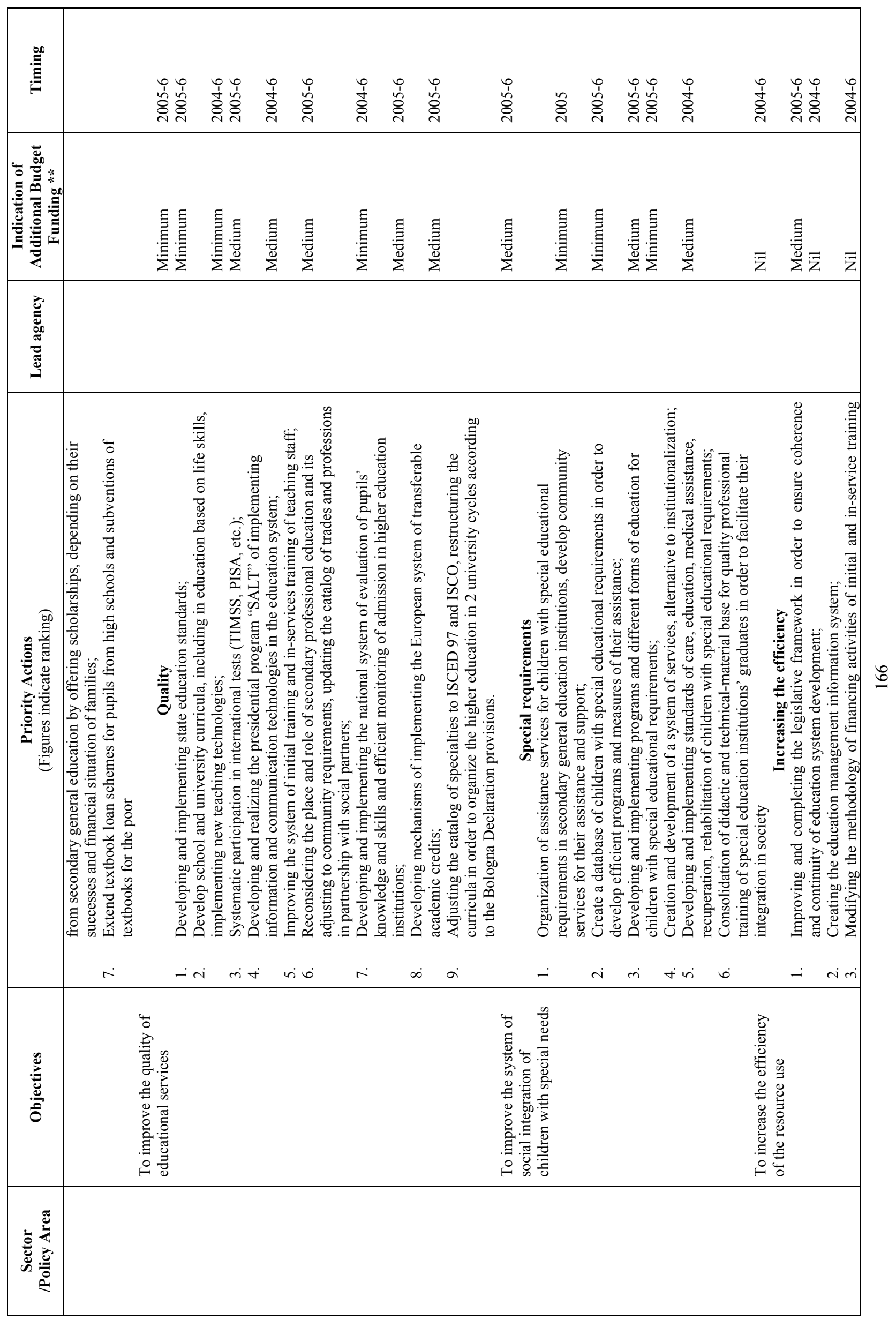




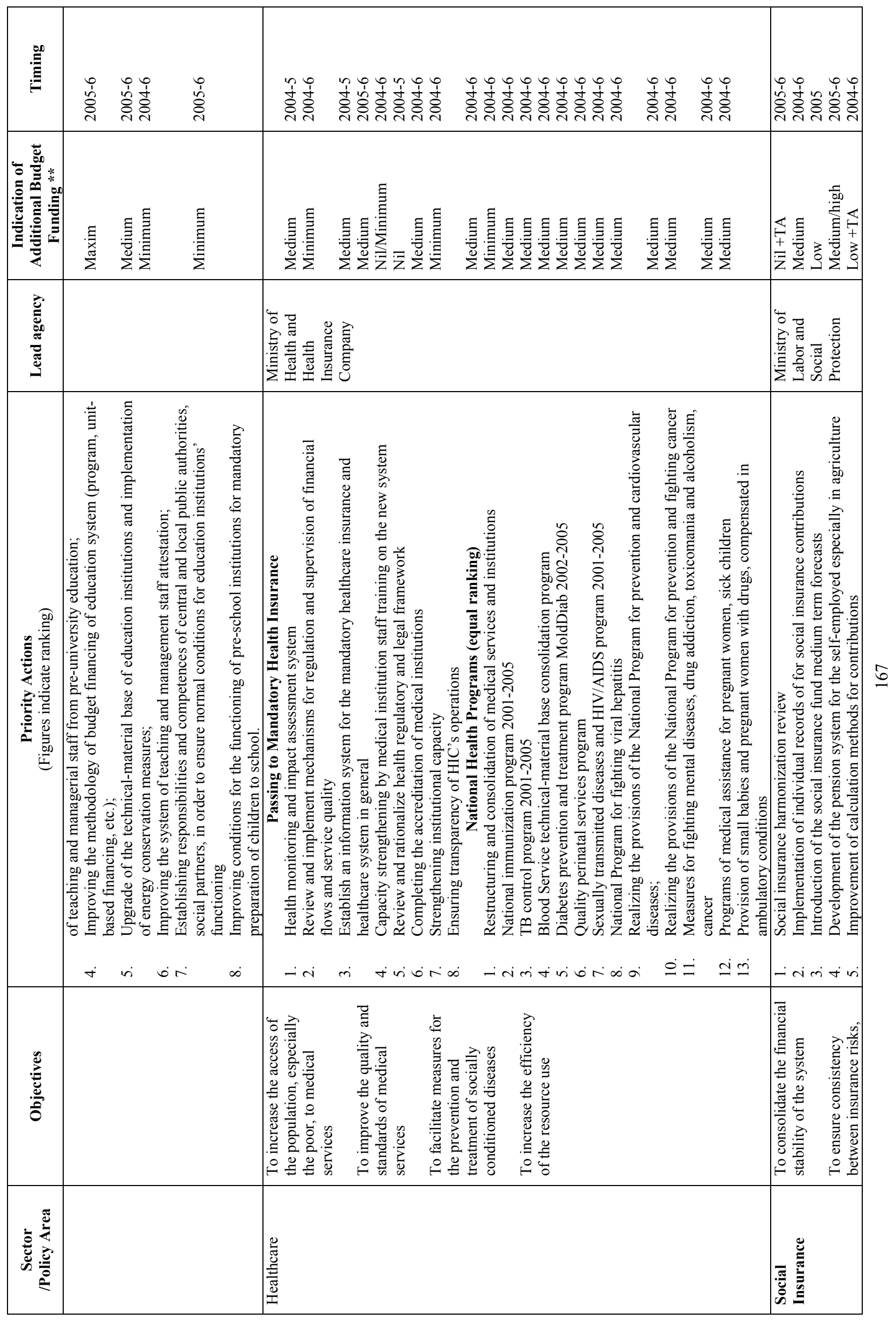




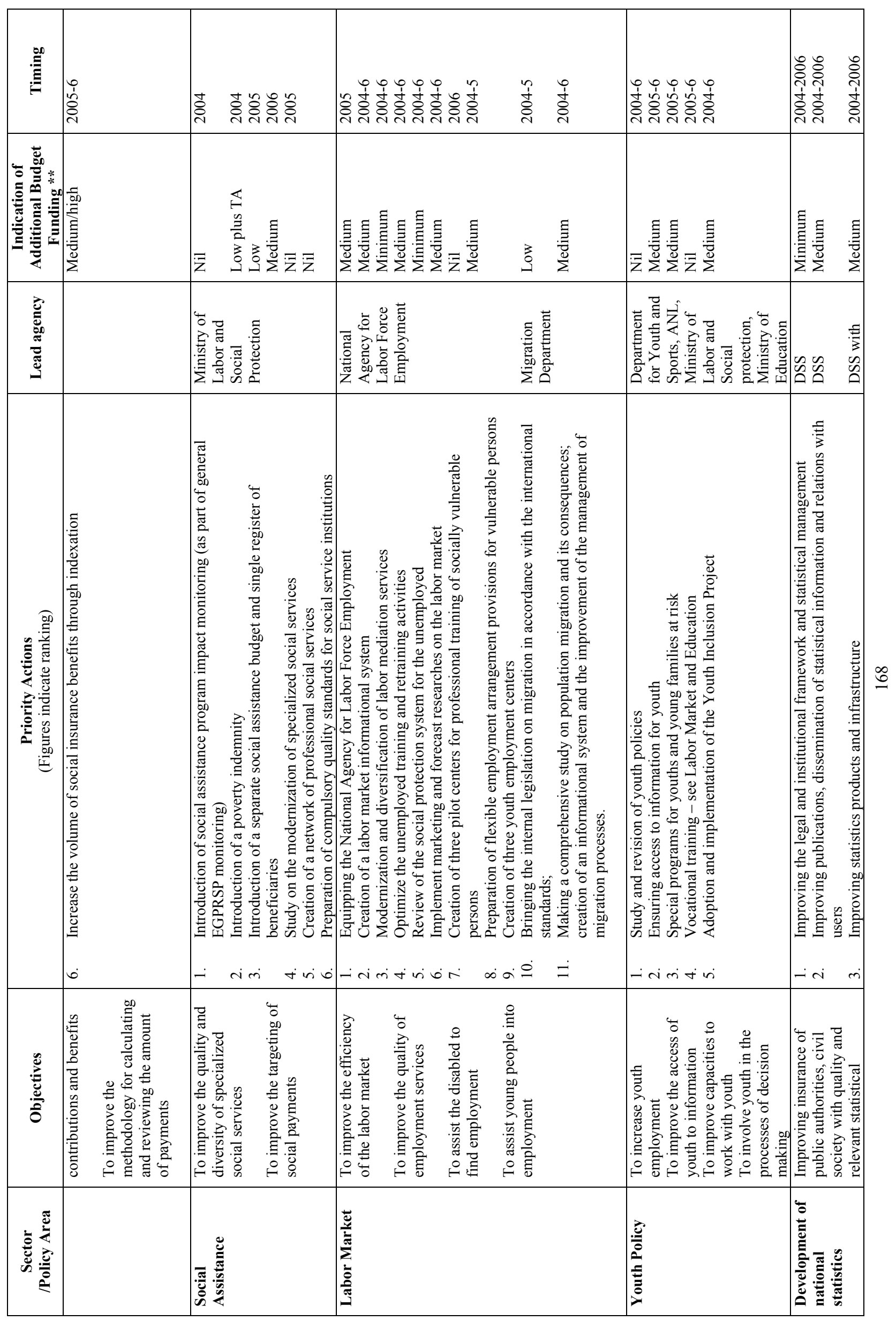




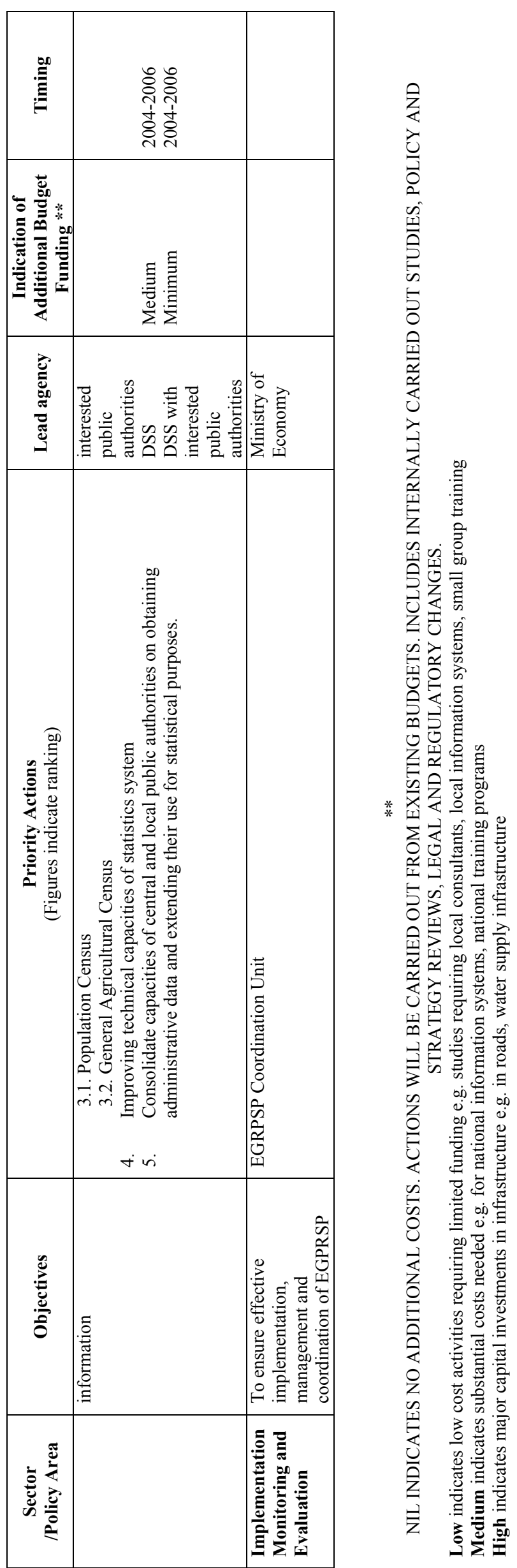




\section{ANNEX 7. EGPRSP PRIORITY ACTIONS INDICATIVE COSTS}

\begin{tabular}{|c|c|c|c|c|c|c|c|}
\hline \multirow{3}{*}{ No } & \multirow{3}{*}{ Priority Actions } & \multicolumn{6}{|c|}{ (Thousand lei) } \\
\hline & & \multicolumn{3}{|c|}{ MTEF costs envelope } & \multicolumn{3}{|c|}{ Unsecured additional costs } \\
\hline & & 2004 & 2005 & 2006 & 2004 & 2005 & 2006 \\
\hline & 1. PRIVATE SECTOR DEVELOPMENT & 156726 & 83832 & 68397 & 17416 & 41230 & 44650 \\
\hline & & & & & & & \\
\hline & 1.1 Regulatory framework & 0 & 0 & 0 & 3250 & 3550 & 3800 \\
\hline 1 & $\begin{array}{l}\text { Simplification and optimization of business } \\
\text { registration and post-registration procedures, } \\
\text { obtaining authorizations, permits, licenses } \\
\text { ("one window" approach) }\end{array}$ & & & & & & \\
\hline 2 & $\begin{array}{l}\text { Development and application of the law on } \\
\text { state control and supervision systems and } \\
\text { modification of relevant legislation }\end{array}$ & & & & & & \\
\hline 3 & $\begin{array}{l}\text { Optimization of state control and } \\
\text { supervision bodies, under institutional and } \\
\text { procedural aspect }\end{array}$ & & & & & & \\
\hline 4 & $\begin{array}{l}\text { Creation of a database on state supervision } \\
\text { and control bodies and economic agents } \\
\text { passable of control }\end{array}$ & & & & & & \\
\hline 5 & $\begin{array}{l}\text { Creation and implementation of an } \\
\text { informational system of state control and } \\
\text { monitoring of supervision activities }\end{array}$ & & & & & & \\
\hline 6 & $\begin{array}{l}\text { Increase of the efficiency of paid services } \\
\text { provided by public authorities }\end{array}$ & & & & & & \\
\hline 7 & $\begin{array}{l}\text { Optimization of fiscal policies and } \\
\text { procedures }\end{array}$ & & & & & & \\
\hline 8 & $\begin{array}{l}\text { Implementation of systems of conformity } \\
\text { evaluation of products by the module } \\
\text { principle (global approach and modular of } \\
\text { the European Union) }\end{array}$ & & & & 100 & 100 & 100 \\
\hline 9 & $\begin{array}{l}\text { Development of the practice of declaring the } \\
\text { product conformity by the producer }\end{array}$ & & & & 50 & 150 & 100 \\
\hline 10 & $\begin{array}{l}\text { Creation of adequate conditions for the } \\
\text { introduction of ISO } 9000 \text { quality and ISO } \\
14000 \text { environment management systems }\end{array}$ & & & & & & \\
\hline 11 & $\begin{array}{l}\text { Creation of adequate conditions for the } \\
\text { introduction of food products quality } \\
\text { management systems, based on the system } \\
\text { for food security and hygiene HACCP (risks } \\
\text { analysis and control of critical points), as } \\
\text { well as implementation of Codex Stan } \\
\text { standards in developing national standards } \\
\text { for food products }\end{array}$ & & & & & & \\
\hline 12 & $\begin{array}{l}\text { Accession and accreditation of the } \\
\text { Accreditation Body in the area of products' } \\
\text { conformity evaluation at the European } \\
\text { Organization of Accreditation }\end{array}$ & & & & 1000 & 1000 & 1000 \\
\hline 13 & $\begin{array}{l}\text { Update of the Law on standardization and } \\
\text { Law on technical barriers to trade }\end{array}$ & & & & & & \\
\hline 14 & $\begin{array}{l}\text { Execution of the program of technical } \\
\text { regulations development }\end{array}$ & & & & 2000 & 2200 & 2500 \\
\hline 15 & $\begin{array}{l}\text { Harmonization of the national } \\
\text { standardization system with the provisions } \\
\text { of European and international }\end{array}$ & & & & & & \\
\hline
\end{tabular}




\begin{tabular}{|c|c|c|c|c|c|c|c|}
\hline \multirow{2}{*}{ No } & \multirow{2}{*}{ Priority Actions } & \multicolumn{3}{|c|}{ MTEF costs envelope } & \multicolumn{3}{|c|}{ Unsecured additional costs } \\
\hline & & 2004 & 2005 & 2006 & 2004 & 2005 & 2006 \\
\hline & standardization organizations & & & & & & \\
\hline 16 & $\begin{array}{l}\text { Update of the Law on metrology and } \\
\text { fulfillment of the Program for National } \\
\text { Etalon System Development }\end{array}$ & & & & & & \\
\hline 17 & $\begin{array}{l}\text { Accession to the international organization } \\
\text { "Meter Convention" }\end{array}$ & & & & & & \\
\hline 18 & $\begin{array}{l}\text { Creation of adequate internal conditions for } \\
\text { signing agreements of mutual recognition of } \\
\text { conformity certificates/declarations }\end{array}$ & & & & 100 & 100 & 100 \\
\hline 19 & $\begin{array}{l}\text { Development and implementation of } \\
\text { methodology for systemic analysis of } \\
\text { regulations' impact on the national economy } \\
\text { and monitoring of execution and efficiency } \\
\text { of adopted decisions }\end{array}$ & & & & & & \\
\hline 20 & $\begin{array}{l}\text { Deployment of regular consultation with } \\
\text { representatives of the private sector }\end{array}$ & & & & & & \\
\hline 21 & $\begin{array}{l}\text { Participation in the initiative "Regulatory } \\
\text { governance" within the Investments Chart, } \\
\text { Stability Pact for South-Eastern Europe }\end{array}$ & & & & & & \\
\hline & & & & & & & \\
\hline & 1.2 Competition Development \& Promotion & 0 & 0 & 0 & 0 & 0 & 0 \\
\hline 1 & $\begin{array}{l}\text { Creation of the National Competition } \\
\text { Agency (NCA) }\end{array}$ & & & & & & \\
\hline 2 & $\begin{array}{l}\text { Development/modification of legislation on } \\
\text { competition protection and revision of the } \\
\text { relevant legal and normative framework }\end{array}$ & & & & & & \\
\hline 3 & $\begin{array}{l}\text { Maintenance of the registry of monopolistic } \\
\text { enterprises }\end{array}$ & & & & & & \\
\hline 4 & $\begin{array}{l}\text { Development and fulfillment of the program } \\
\text { for de-monopolization of certain } \\
\text { commodities and services' markets }\end{array}$ & & & & & & \\
\hline 5 & $\begin{array}{l}\text { Promotion of the NCA activity on } \\
\text { international level, concluding relevant } \\
\text { arrangements }\end{array}$ & & & & & & \\
\hline 6 & $\begin{array}{l}\text { Dissemination of information for ensuring } \\
\text { the transparency of the policy and activities, } \\
\text { through: NCA web page, editing collection } \\
\text { of normative acts, information and studies, } \\
\text { publishing annual reports }\end{array}$ & & & & & & \\
\hline & & & & & & & \\
\hline & 1.3 Corporate management & 0 & 0 & 0 & 0 & 0 & 0 \\
\hline 1 & $\begin{array}{l}\text { Development of the draft Corporate } \\
\text { Administration Code }\end{array}$ & & & & & & \\
\hline 2 & $\begin{array}{l}\text { Improvement of the present legal framework } \\
\text { and application mechanisms }\end{array}$ & & & & & & \\
\hline 3 & $\begin{array}{l}\text { Creation of a competitive environment } \\
\text { inherent to market economy }\end{array}$ & & & & & & \\
\hline 4 & $\begin{array}{l}\text { Introduction of the mechanism of regular } \\
\text { consultations between public and private } \\
\text { sectors }\end{array}$ & & & & & & \\
\hline 5 & $\begin{array}{l}\text { Participation in the initiative "Corporative } \\
\text { governance" within the Investments Chart, } \\
\text { Stability Pact for South-Eastern Europe }\end{array}$ & & & & & & \\
\hline & 1.4 Development of SMEs & 0 & 0 & 0 & 0 & 20160 & 21000 \\
\hline
\end{tabular}




\begin{tabular}{|c|c|c|c|c|c|c|c|}
\hline \multirow{2}{*}{ No } & \multirow{2}{*}{ Priority Actions } & \multicolumn{3}{|c|}{ MTEF costs envelope } & \multicolumn{3}{|c|}{ Unsecured additional costs } \\
\hline & & 2004 & 2005 & 2006 & 2004 & 2005 & 2006 \\
\hline 1 & $\begin{array}{l}\text { Revision and improvement of the legal } \\
\text { framework with a set of relevant laws and } \\
\text { adaptation of existing legislation }\end{array}$ & & & & & & \\
\hline 2 & $\begin{array}{l}\text { Development and execution of the state } \\
\text { medium term strategy and program for SME } \\
\text { development and support }\end{array}$ & & & & & & \\
\hline 3 & $\begin{array}{l}\text { Facilitation of SME access to low interest } \\
\text { finance and loan guarantees }\end{array}$ & & & & & 14400 & 15000 \\
\hline 4 & $\begin{array}{l}\text { Optimization of efficient use of finances } \\
\text { allocated from or through state budget, } \\
\text { including financial support from } \\
\text { international financial institutions and other } \\
\text { donors }\end{array}$ & & & & & & \\
\hline 5 & $\begin{array}{l}\text { Optimization of fiscal policies and } \\
\text { procedures for SME }\end{array}$ & & & & & & \\
\hline 6 & $\begin{array}{l}\text { Creation of a national network of } \\
\text { informational-consulting centers and } \\
\text { business-incubators with the participation of } \\
\text { local public authorities }\end{array}$ & & & & & 2880 & 3000 \\
\hline 7 & $\begin{array}{l}\text { Adaptation of curricula to the needs of SME, } \\
\text { including by supporting partnership relations } \\
\text { between education institutions and } \\
\text { representatives of SME }\end{array}$ & & & & & 2880 & 3000 \\
\hline 8 & $\begin{array}{l}\text { Active participation in the European Chart } \\
\text { for Small Enterprises }\end{array}$ & & & & & & \\
\hline & 1.5 External trade promotion & 83800 & 6800 & 3000 & 9150 & 8880 & 10850 \\
\hline 1 & $\begin{array}{l}\text { Analysis and evaluation, jointly with the } \\
\text { National Bank of Moldova and financial } \\
\text { institutions, of the factors that can improve } \\
\text { the balance of trade, increase exports }\end{array}$ & & & & & & \\
\hline 2 & $\begin{array}{l}\text { Analysis of comparative advantages of } \\
\text { domestic products in using the potential of } \\
\text { the System of generalized Preferences } \\
\text { offered by EU and other developed countries }\end{array}$ & & & & & & \\
\hline 3 & $\begin{array}{l}\text { Fulfillment of conditions to obtain the } \\
\text { preferential trade regime for exporting } \\
\text { products from Moldova to EU market }\end{array}$ & & & & & & \\
\hline 4 & $\begin{array}{l}\text { Execution of recommendations of the } \\
\text { European Commission on setting adequate } \\
\text { internal conditions for creating a free trade } \\
\text { zone Moldova-EU }\end{array}$ & & & & & & \\
\hline 5 & $\begin{array}{l}\text { Use of the opportunities offered by the } \\
\text { regional free trade zone within the Stability } \\
\text { Pact for South-Eastern Europe }\end{array}$ & & & & & & \\
\hline 6 & $\begin{array}{l}\text { Development of the legislative and } \\
\text { institutional framework for the service } \\
\text { sector according to provisions of the } \\
\text { corresponding WTO agreement }\end{array}$ & & & & & & \\
\hline 7 & $\begin{array}{l}\text { Collection, categorization and dissemination } \\
\text { of information regarding the conditions for } \\
\text { local goods and services for accessing } \\
\text { international markets }\end{array}$ & & & & 500 & 500 & 500 \\
\hline 8 & $\begin{array}{l}\text { Use of modern exports promotion tools, } \\
\text { especially informational capacities }\end{array}$ & $\underline{2000}$ & $\underline{3000}$ & $\underline{3000}$ & $\underline{5500}$ & $\underline{5000}$ & $\underline{4500}$ \\
\hline 9 & $\begin{array}{l}\text { Encouragement of SMEs to create export } \\
\text { alliances }\end{array}$ & & & & & & \\
\hline
\end{tabular}




\begin{tabular}{|c|c|c|c|c|c|c|c|}
\hline \multirow{2}{*}{ No } & \multirow{2}{*}{ Priority Actions } & \multicolumn{3}{|c|}{ MTEF costs envelope } & \multicolumn{3}{|c|}{ Unsecured additional costs } \\
\hline & & 2004 & 2005 & 2006 & 2004 & 2005 & 2006 \\
\hline 10 & $\begin{array}{l}\text { Increase of the efficiency of Embassies and } \\
\text { commercial Representations of the country } \\
\text { abroad for promotion of domestic products }\end{array}$ & & & & & & \\
\hline 11 & $\begin{array}{l}\text { Improvement of customs legislation } \\
\text { regarding trade }\end{array}$ & & & & & & \\
\hline 12 & $\begin{array}{l}\text { Identification and application of audit and } \\
\text { risk assessment practices }\end{array}$ & & & & 250 & 300 & 300 \\
\hline 13 & $\begin{array}{l}\text { Introduction of the system for irregularities } \\
\text { prevention, especially for operative check of } \\
\text { information at customs posts }\end{array}$ & & & & & & \\
\hline 14 & $\begin{array}{l}\text { Standardization and optimization of customs } \\
\text { procedures and controls }\end{array}$ & 2700 & 2000 & & & & 2300 \\
\hline 15 & Unification of tariff classification & & & & 200 & 200 & 250 \\
\hline 16 & $\begin{array}{l}\text { Development of customs information and } \\
\text { communication system, creation of } \\
\text { electronic customs environment }\end{array}$ & 69000 & & & 1350 & 1440 & 1500 \\
\hline 17 & $\begin{array}{l}\text { Professional training and retraining, with an } \\
\text { emphasis on motivations contributing to the } \\
\text { corruption eradication and open and } \\
\text { transparent cooperation with economic } \\
\text { agents }\end{array}$ & 10100 & 1800 & & 1350 & 1440 & 1500 \\
\hline \multirow[t]{3}{*}{18} & $\begin{array}{l}\text { Establishment of a system for customs } \\
\text { administration performance assessment }\end{array}$ & & & & & & \\
\hline & & & & & & & \\
\hline & 1.6 Investment environment & 0 & 0 & 0 & 0 & 0 & 0 \\
\hline 1 & $\begin{array}{l}\text { Continuation of the privatization of public } \\
\text { assets, including adjacent terrains }\end{array}$ & & & & & & \\
\hline 2 & $\begin{array}{l}\text { Revision of fiscal legislation, to stimulate } \\
\text { local and foreign investors }\end{array}$ & & & & & & \\
\hline 3 & $\begin{array}{l}\text { Development of regional infrastructure, to } \\
\text { improve the investment activity at regional } \\
\text { level }\end{array}$ & & & & & & \\
\hline 4 & $\begin{array}{l}\text { Development of financial market } \\
\text { infrastructure reduction of investment risks }\end{array}$ & & & & & & \\
\hline 5 & $\begin{array}{l}\text { Cooperation with the banking sector to } \\
\text { stimulate long term crediting }\end{array}$ & & & & & & \\
\hline 6 & $\begin{array}{l}\text { Identification of mechanisms and } \\
\text { instruments for attraction of population's } \\
\text { savings, including transfers of employees } \\
\text { from abroad, in the investment activity }\end{array}$ & & & & & & \\
\hline 7 & $\begin{array}{l}\text { Development of practices of consulting with } \\
\text { investors community and businessmen in } \\
\text { identification of problems and solutions that } \\
\text { are related to improvement of investment } \\
\text { climate }\end{array}$ & & & & & & \\
\hline 8 & $\begin{array}{l}\text { Increase of the efficiency of information } \\
\text { dissemination on investment opportunities in } \\
\text { Moldova }\end{array}$ & & & & & & \\
\hline \multirow[t]{2}{*}{9} & $\begin{array}{l}\text { Participation in the initiative Investments } \\
\text { Chart, Stability Pact for South-Eastern } \\
\text { Europe }\end{array}$ & & & & & & \\
\hline & $\begin{array}{l}1.7 \text { Creation of the cadastre of immovable } \\
\text { property }\end{array}$ & 72926 & 77032 & 65397 & 5016 & 8640 & 9000 \\
\hline
\end{tabular}




\begin{tabular}{|c|c|c|c|c|c|c|c|}
\hline \multirow{2}{*}{ No } & \multirow{2}{*}{ Priority Actions } & \multicolumn{3}{|c|}{ MTEF costs envelope } & \multicolumn{3}{|c|}{ Unsecured additional costs } \\
\hline & & 2004 & 2005 & 2006 & 2004 & 2005 & 2006 \\
\hline 1 & $\begin{array}{l}\text { Final drafting of laws and regulations } \\
\text { covering property registration aimed at } \\
\text { supporting the real estate market }\end{array}$ & 5221 & 9168 & 5928 & & & \\
\hline 2 & $\begin{array}{l}\text { Reorganization of the system of cadastre } \\
\text { bodies and creation of a specialized cadastre } \\
\text { company }\end{array}$ & 1130 & & 2880 & & & \\
\hline 3 & $\begin{array}{l}\text { Creation of an integrated information system } \\
\text { for cadastre and making it available to } \\
\text { different users }\end{array}$ & 5251 & 1072 & 6714 & & & \\
\hline 4 & $\begin{array}{l}\text { Provision of public information and staff } \\
\text { training }\end{array}$ & 3043 & 2315 & 1995 & 5016 & 8640 & 9000 \\
\hline 5 & $\begin{array}{l}\text { Completion of the transfer of land parcels } \\
\text { into private ownership }\end{array}$ & 44111 & 44599 & 33750 & & & \\
\hline 6 & Primary mass registration of properties & 14171 & 14174 & 9600 & & & \\
\hline 7 & $\begin{array}{l}\text { Mass appraisal of (a) apartments and } \\
\text { individual residential houses in urban areas } \\
\text { and (b) commercial, industrial and } \\
\text { manufacturing properties, for taxation } \\
\text { purposes }\end{array}$ & & 5704 & 4529 & & & \\
\hline & $\begin{array}{l}\text { 2. PUBLIC ADMINISTRATION } \\
\text { REFORM }\end{array}$ & 20175 & 26314 & 25955 & $\mathbf{0}$ & 3206 & 5585 \\
\hline & 2.1 Central Public Administration & 0 & 0 & 0 & & TA & TA \\
\hline 1 & $\begin{array}{l}\text { Establishment of a high level Public } \\
\text { Administration Reform Management Unit }\end{array}$ & & & & & & \\
\hline 2 & $\begin{array}{l}\text { Preparation of a Strategic Plan for Central } \\
\text { Public Administration Reform }\end{array}$ & & & & & & \\
\hline & 2.2 Local self-government & 0 & 0 & 0 & & $\mathrm{TA}$ & TA \\
\hline 1 & $\begin{array}{l}\text { Improvement of legislation for local } \\
\text { autonomy and self-government }\end{array}$ & & & & & & \\
\hline 2 & $\begin{array}{l}\text { Revision of the legal, regulatory and } \\
\text { institutional framework in line with } \\
\text { European standards and good practices }\end{array}$ & & & & & & \\
\hline 3 & $\begin{array}{l}\text { Revision of the state of transfer of functions } \\
\text { to local government }\end{array}$ & & & & & & \\
\hline 4 & $\begin{array}{l}\text { Clear definition of functions and } \\
\text { responsibilities demarcated from those of } \\
\text { central administration }\end{array}$ & & & & & & \\
\hline 5 & $\begin{array}{l}\text { Identification of procedures for the transfer } \\
\text { of delegated functions and responsibilities to } \\
\text { local government }\end{array}$ & & & & & & \\
\hline 6 & $\begin{array}{l}\text { Provision of opportunities for the } \\
\text { professional training and development of } \\
\text { local self-government employees }\end{array}$ & & & & & & \\
\hline 7 & $\begin{array}{l}\text { Dissemination of good experience and } \\
\text { practice in social mobilization and } \\
\text { partnership for mutual assistance, the } \\
\text { efficient use of local resources, and } \\
\text { resolution of local problems }\end{array}$ & & & & & & \\
\hline 8 & $\begin{array}{l}\text { Development of a communication and } \\
\text { information strategy on local government } \\
\text { activities, decisions, performance, finance } \\
\text { and property }\end{array}$ & & & & & & \\
\hline & 2.3 Public finance management & 20175 & 26314 & 25955 & 0 & 2806 & 5385 \\
\hline
\end{tabular}




\begin{tabular}{|c|c|c|c|c|c|c|c|}
\hline \multirow{2}{*}{ No } & \multirow{2}{*}{ Priority Actions } & \multicolumn{3}{|c|}{ MTEF costs envelope } & \multicolumn{3}{|c|}{ Unsecured additional costs } \\
\hline & & 2004 & 2005 & 2006 & 2004 & 2005 & 2006 \\
\hline 1 & $\begin{array}{l}\text { Creation of an integrated informational } \\
\text { system of public finances management }\end{array}$ & 14500 & 21024 & 22185 & & & \\
\hline 2 & $\begin{array}{l}\text { Further development of the Medium Term } \\
\text { Expenditures Framework and the method for } \\
\text { drafting budgets based on programs and } \\
\text { performance }\end{array}$ & 2150 & 2210 & 2300 & & & \\
\hline 3 & $\begin{array}{l}\text { Improvement and systematization of the } \\
\text { legislation concerning budgetary process } \\
\text { and system, as well as in fiscal area and } \\
\text { harmonization of the legislation to European } \\
\text { Union requirements }\end{array}$ & 250 & 250 & & & 605 & 605 \\
\hline 4 & $\begin{array}{l}\text { Revision and approval of the Budgetary } \\
\text { Classification (new version) according to } \\
\text { updated international standards }\end{array}$ & 250 & 200 & & & 630 & 630 \\
\hline 5 & $\begin{array}{l}\text { Development and implementation of the } \\
\text { state debt management strategy }\end{array}$ & 2900 & 2060 & 1100 & & 543 & \\
\hline 6 & $\begin{array}{l}\text { Development of the treasury system and } \\
\text { improvement of public sector accounting }\end{array}$ & 125 & 300 & & & 578 & 3600 \\
\hline 7 & $\begin{array}{l}\text { Development and implementation of the } \\
\text { strategy in the area of internal audit and } \\
\text { financial control in the public sector }\end{array}$ & & 270 & 370 & & 450 & 550 \\
\hline & 2.4 The Judicial system & 0 & 0 & 0 & 0 & 400 & 200 \\
\hline & Access to justice & & & & & & \\
\hline 1 & Revision of public legal costs & & & & & & \\
\hline 2 & $\begin{array}{l}\text { Participatory revision of public legal } \\
\text { information and assistance systems }\end{array}$ & & & & & & \\
\hline 3 & $\begin{array}{l}\text { Discussion with private legal profession } \\
\text { regarding the possibilities for introducing } \\
\text { pro-bono services for the poor }\end{array}$ & & & & & & \\
\hline & The legal framework & & & & & & \\
\hline 4 & $\begin{array}{l}\text { Revision of the legal framework and } \\
\text { standards }\end{array}$ & & & & & & \\
\hline & The judicial system & & & & & & \\
\hline 5 & $\begin{array}{l}\text { Study and evaluation of the organization and } \\
\text { functioning of justice, from protection of } \\
\text { property and individual rights to the } \\
\text { perspective of sustainable economic } \\
\text { development }\end{array}$ & & & & & 200 & \\
\hline 6 & $\begin{array}{l}\text { Institutional development and capacity } \\
\text { building for legal personnel }\end{array}$ & & & & & 200 & 200 \\
\hline 7 & Ensuring public access to legal information & & & & & $\mathrm{TA}$ & $\mathrm{TA}$ \\
\hline & The legal education system & & & & & & \\
\hline 8 & Revision of legal education standards & & & & & & \\
\hline 9 & Upgrade of education and training curricula & & & & & & \\
\hline & Enforcement of court decisions & & & & & & \\
\hline 10 & $\begin{array}{l}\text { Revision of performance and modalities of } \\
\text { current system activity }\end{array}$ & & & & & & \\
\hline & 2.5 Corruption & 0 & 0 & 0 & 0 & 0 & 0 \\
\hline 1 & $\begin{array}{l}\text { Minimization and simplification of the } \\
\text { administrative regulatory framework for } \\
\text { business and enterprise - see Private Sector } \\
\text { Development }\end{array}$ & & & & & & \\
\hline
\end{tabular}




\begin{tabular}{|c|c|c|c|c|c|c|c|}
\hline \multirow{2}{*}{ No } & \multirow{2}{*}{ Priority Actions } & \multicolumn{3}{|c|}{ MTEF costs envelope } & \multicolumn{3}{|c|}{ Unsecured additional costs } \\
\hline & & 2004 & 2005 & 2006 & 2004 & 2005 & 2006 \\
\hline 2 & $\begin{array}{l}\text { Professional capacity building and } \\
\text { professional development in government - } \\
\text { see Public Administration Reform }\end{array}$ & & & & & & \\
\hline 3 & $\begin{array}{l}\text { Promotion of an open discussion between } \\
\text { the public administration, civil society and } \\
\text { the development partners on medium term } \\
\text { institutional reform }\end{array}$ & & & & & & \\
\hline & 3. BUDGET-FISCAL POLICY & 1610 & 4060 & 6500 & 14700 & 27960 & 14680 \\
\hline & 3.1 Fiscal policy and administration & 1560 & 4000 & 6400 & 14700 & 25300 & 12100 \\
\hline 1 & $\begin{array}{l}\text { Broadening of the tax basis and } \\
\text { improvement of tax structure to reduce fiscal } \\
\text { burden }\end{array}$ & & & & & & \\
\hline 2 & $\begin{array}{l}\text { Improvement of tax preferences system to } \\
\text { support economic growth and poverty } \\
\text { reduction }\end{array}$ & & & & & & \\
\hline 3 & $\begin{array}{l}\text { Finalization of the Tax Code and } \\
\text { streamlining with EU requirements }\end{array}$ & & 300 & 100 & & 300 & 100 \\
\hline 4 & $\begin{array}{l}\text { Development of fiscal information system } \\
\text { (the immovable property evaluation for tax } \\
\text { purposes, computer-aided tracking system of } \\
\text { alcohol and oil products) and } \\
\text { computerization of fiscal procedures. }\end{array}$ & 1560 & 3700 & 6300 & 14700 & 25000 & 12000 \\
\hline & 3.2 Public Expenditure Policy & 50 & 60 & 100 & 0 & 2660 & 2580 \\
\hline 1 & $\begin{array}{l}\text { Improvement of procedures for sectoral and } \\
\text { inter-sectoral resource allocation under } \\
\text { EGPRSP }\end{array}$ & & & & & & \\
\hline 2 & $\begin{array}{l}\text { Development of support measures and } \\
\text { public services to support economic growth } \\
\text { and poverty reduction }\end{array}$ & & & & & & \\
\hline 3 & $\begin{array}{l}\text { Continuous implementation of public } \\
\text { expenditures review and strategic planning } \\
\text { elements }\end{array}$ & 50 & 50 & 50 & & 2160 & 2250 \\
\hline 4 & $\begin{array}{l}\text { Improvement of public spending through the } \\
\text { use of performance indicators for } \\
\text { monitoring public expenditure }\end{array}$ & & & & & & \\
\hline 5 & $\begin{array}{l}\text { Improvement of state and local budget } \\
\text { allocation mechanisms }\end{array}$ & & 10 & 50 & & 500 & 330 \\
\hline & 4. FINANCE SECTOR & $\mathbf{0}$ & $\mathbf{0}$ & $\mathbf{0}$ & $\mathbf{0}$ & $\mathbf{0}$ & $\mathbf{0}$ \\
\hline 1 & $\begin{array}{l}\text { Improvement of the legal and regulatory } \\
\text { frameworks for new investment institutions }\end{array}$ & & & & & & \\
\hline 2 & Introduction of new financial instruments & & & & & & \\
\hline 3 & $\begin{array}{l}\text { Establishment of an informational system on } \\
\text { the securities market }\end{array}$ & & & & & & \\
\hline 4 & $\begin{array}{l}\text { Simplification of the issues procedures and } \\
\text { market transactions }\end{array}$ & & & & & & \\
\hline 5 & $\begin{array}{l}\text { Improvement of control and supervision } \\
\text { mechanisms for securities market }\end{array}$ & & & & & & \\
\hline 6 & $\begin{array}{l}\text { Sustainable development of savings and } \\
\text { loans associations }\end{array}$ & & & & & & \\
\hline & 5. RESEARCH AND INNOVATION & $\mathbf{0}$ & $\mathbf{0}$ & $\mathbf{0}$ & 3200 & 10150 & 7500 \\
\hline 1 & $\begin{array}{l}\text { Harmonization of national legislation in the } \\
\text { area of intellectual property protection with } \\
\text { stipulations of international agreements and }\end{array}$ & & & & 2000 & 1250 & \\
\hline
\end{tabular}




\begin{tabular}{|c|c|c|c|c|c|c|c|}
\hline \multirow{2}{*}{ No } & \multirow{2}{*}{ Priority Actions } & \multicolumn{3}{|c|}{ MTEF costs envelope } & \multicolumn{3}{|c|}{ Unsecured additional costs } \\
\hline & & 2004 & 2005 & 2006 & 2004 & 2005 & 2006 \\
\hline & conventions & & & & & & \\
\hline 2 & $\begin{array}{l}\text { Development of legal and organizational } \\
\text { measures for transfer of intellectual property } \\
\text { rights, constituted from budgetary means, to } \\
\text { organizations that possess this work }\end{array}$ & & & & & & \\
\hline 3 & $\begin{array}{l}\text { Creation of the framework for } \\
\text { reorganization and accreditation of state } \\
\text { research institutions }\end{array}$ & & & & 200 & 300 & \\
\hline 4 & $\begin{array}{l}\text { Inventory of state scientific research } \\
\text { institutions patrimony, trade of unused } \\
\text { goods and use of released means for } \\
\text { improvement of the research technical- } \\
\text { material base }\end{array}$ & & & & 500 & 500 & \\
\hline 5 & $\begin{array}{l}\text { Development of a legal base for regulating } \\
\text { the creation of modern infrastructure of } \\
\text { research and innovations }\end{array}$ & & & & 500 & 500 & \\
\hline 6 & $\begin{array}{l}\text { Extension and modernization of the system } \\
\text { of statistical record-keeping indices of } \\
\text { research and innovational activities }\end{array}$ & & & & & 100 & \\
\hline 7 & $\begin{array}{l}\text { Implementation of insurance mechanisms } \\
\text { for risk connected with development and } \\
\text { implementation of innovations }\end{array}$ & & & & & & \\
\hline 8 & $\begin{array}{l}\text { Improvement of procedures of amortization } \\
\text { and taxation of intellectual property objects }\end{array}$ & & & & & & \\
\hline 9 & $\begin{array}{l}\text { Development of organizational and legal } \\
\text { measures for development of science- } \\
\text { intensive equipment lease }\end{array}$ & & & & & & \\
\hline 10 & $\begin{array}{l}\text { Creation of a single electronic database that } \\
\text { would ensure registration of innovations, } \\
\text { intellectual property objects }\end{array}$ & & & & & 5000 & 5000 \\
\hline 11 & $\begin{array}{l}\text { Training and re-training of innovation } \\
\text { specialists }\end{array}$ & & & & & 2500 & 2500 \\
\hline 12 & $\begin{array}{l}\text { Improvement of study programs in the area } \\
\text { of higher and post-graduate education of } \\
\text { staff training for research and innovations }\end{array}$ & & & & & & \\
\hline 13 & $\begin{array}{l}\text { Development and implementation of } \\
\text { mechanisms for stimulating innovational } \\
\text { activities in small enterprises }\end{array}$ & & & & & & \\
\hline & 6. INFRASTRUCTURE & 261713 & 462539 & 395680 & 436705 & 597930 & 754121 \\
\hline & 6.1 Energy & 5740 & 5740 & 5740 & 15540 & 15540 & 15540 \\
\hline 1 & $\begin{array}{l}\text { Extension of main gas pipelines connections } \\
\text { by constructing gas distribution stations and } \\
\text { inter-urban gas-lines }\end{array}$ & & & & 82255 & 88348 & 91410 \\
\hline 2 & $\begin{array}{l}\text { Promotion and realization of the National } \\
\text { Program for renovation and decentralization } \\
\text { of heating supply systems in cities of the } \\
\text { Republic of Moldova }\end{array}$ & & & & 41460 & 44530 & 46080 \\
\hline 3 & $\begin{array}{l}\text { Restructuring the energy sector by attracting } \\
\text { private capital through different forms }\end{array}$ & 5740 & 5740 & 5740 & 5740 & 5740 & 5740 \\
\hline 4 & $\begin{array}{l}\text { Improvement of the regulatory framework to } \\
\text { support development of the energy market } \\
\text { and competition }\end{array}$ & & & & 9800 & 9800 & 9800 \\
\hline 5 & $\begin{array}{l}\text { Improvement of payment recovery for } \\
\text { energy in association with social protection } \\
\text { of vulnerable groups }\end{array}$ & & & & & & \\
\hline
\end{tabular}




\begin{tabular}{|c|c|c|c|c|c|c|c|}
\hline \multirow{2}{*}{ No } & \multirow{2}{*}{ Priority Actions } & \multicolumn{3}{|c|}{ MTEF costs envelope } & \multicolumn{3}{|c|}{ Unsecured additional costs } \\
\hline & & 2004 & 2005 & 2006 & 2004 & 2005 & 2006 \\
\hline & 6.2 Roads and Transport & 174300 & 333740 & 321600 & & 128000 & 217000 \\
\hline & Road transport & & & & & & \\
\hline 1 & $\begin{array}{l}\text { Design and implementation of roads } \\
\text { rehabilitation program with an accent on } \\
\text { growth of light, periodic maintenance }\end{array}$ & 171200 & 291600 & 321600 & & & \\
\hline 2 & $\begin{array}{l}\text { Creation of a sustainable and transparent } \\
\text { roads financing system for continuous } \\
\text { maintenance of road network }\end{array}$ & & & & & & \\
\hline 3 & $\begin{array}{l}\text { Design and implementation of regional } \\
\text { projects }\end{array}$ & & & & & 123000 & 187000 \\
\hline 4 & $\begin{array}{l}\text { Implementation of modern systems of roads } \\
\text { condition evaluation and maintenance and } \\
\text { repairs prioritization }\end{array}$ & & & & & & \\
\hline 5 & Recovery of the bridge over Prut, Lipcani & 3100 & 42140 & & & & \\
\hline 6 & $\begin{array}{l}\text { Implementation of the Chisinau-Giurguilesti } \\
\text { road rehabilitation project }\end{array}$ & & & & & 5000 & 30000 \\
\hline 7 & $\begin{array}{l}\text { Negotiation with international financial } \\
\text { institutions on the rehabilitation of national } \\
\text { European roads }\end{array}$ & & & & & & \\
\hline & $\underline{\text { Rail }}$ & & & & & & \\
\hline 1 & $\begin{array}{l}\text { Rehabilitation of the railroad network to the } \\
\text { level of projected and safety parameters for } \\
\text { trains circulation }\end{array}$ & & & & & & \\
\hline 2 & $\begin{array}{l}\text { Implementation of the conditions of the } \\
\text { Memorandum Agreement between the } \\
\text { Council of Creditors and CFM }\end{array}$ & & & & & & \\
\hline 3 & $\begin{array}{l}\text { Realization of the existing CFM } \\
\text { Restructuring Plan, by separating the } \\
\text { management of rail infrastructure from the } \\
\text { management of transport services }\end{array}$ & & & & & & \\
\hline 4 & $\begin{array}{l}\text { Divestment of socio-cultural and communal } \\
\text { possessions and ancillary enterprises from } \\
\text { the CFM structure }\end{array}$ & & & & & & \\
\hline 5 & $\begin{array}{l}\text { Renovation of the passenger rail carriages } \\
\text { and diesel trains fleet }\end{array}$ & & & & & & \\
\hline & 6.3 Water Supply and Sewerage & 81270 & 88877 & 68250 & 295405 & 310002 & 369731 \\
\hline & Access and quality & & & & & & \\
\hline 1 & $\begin{array}{l}\text { Development and modernization of water } \\
\text { supply and sewerage systems in } 156 \\
\text { localities }\end{array}$ & 80770 & 88477 & 67750 & 270305 & 273602 & 328681 \\
\hline 2 & Development of 93,300 rural wells & 500 & 400 & 500 & 14500 & 19600 & 24500 \\
\hline 3 & $\begin{array}{l}\text { Implementation of pilot project for } \\
\text { mechanical and biological ground water } \\
\text { treatment for nitrates and sulphates } \\
\text { contamination }\end{array}$ & & & & & 1800 & 1800 \\
\hline 4 & $\begin{array}{l}\text { Implementation of pilot projects for } \\
\text { mechanical and biological waste water } \\
\text { treatment }\end{array}$ & & & & & 1900 & 1900 \\
\hline & $\begin{array}{l}\text { Water conservation and environmental } \\
\text { protection }\end{array}$ & & & & & & \\
\hline
\end{tabular}




\begin{tabular}{|c|c|c|c|c|c|c|c|}
\hline \multirow{2}{*}{ No } & \multirow{2}{*}{ Priority Actions } & \multicolumn{3}{|c|}{ MTEF costs envelope } & \multicolumn{3}{|c|}{ Unsecured additional costs } \\
\hline & & 2004 & 2005 & 2006 & 2004 & 2005 & 2006 \\
\hline 5 & $\begin{array}{l}\text { Introduction of the groundwater monitoring } \\
\text { program }\end{array}$ & & & & 1000 & 1000 & 1000 \\
\hline 6 & $\begin{array}{l}\text { Implementation of measures for efficient } \\
\text { surface water drainage }\end{array}$ & & & & 5000 & 5500 & 6000 \\
\hline 7 & $\begin{array}{l}\text { Restoration of existing and establishment of } \\
\text { new water protection areas and sanitary } \\
\text { zones }\end{array}$ & & & & 3000 & 4000 & 5000 \\
\hline & Tariff policy & & & & & & \\
\hline 8 & $\begin{array}{l}\text { Completion of water meter provision to all } \\
\text { consumers }\end{array}$ & & & & 1000 & 1500 & 500 \\
\hline 9 & $\begin{array}{l}\text { Preparation of a single methodology for } \\
\text { tariff calculation and review }\end{array}$ & & & & 400 & 500 & \\
\hline 10 & $\begin{array}{l}\text { Promotion of transparency when setting } \\
\text { tariffs }\end{array}$ & & & & & 300 & 200 \\
\hline 11 & $\begin{array}{l}\text { Improvement of legal and normative } \\
\text { framework in relations with consumers and } \\
\text { suppliers regarding water supply and raising } \\
\text { penalties for non payments and substantial } \\
\text { raise of payment collections for } \\
\text { consumption }\end{array}$ & & & & 200 & 300 & 150 \\
\hline & $\begin{array}{l}\text { Improvement of the legislative and } \\
\text { regulatory framework }\end{array}$ & & & & & & \\
\hline 12 & $\begin{array}{l}\text { Implementation of services of technical } \\
\text { audit of water supply and sewerage systems }\end{array}$ & & & & & TA & TA \\
\hline 13 & $\begin{array}{l}\text { Adjustment of the existing legislation, } \\
\text { standards and regulations on water supply } \\
\text { and sewerage in line with the European and } \\
\text { international standards }\end{array}$ & & & & TA & TA & TA \\
\hline 14 & $\begin{array}{l}\text { Improvement of the legal and regulatory } \\
\text { framework to attract private capital to the } \\
\text { sector in the form of concessions, rents, trust } \\
\text { management, and joint ventures, including } \\
\text { privatization of central water supply and } \\
\text { sewerage systems }\end{array}$ & & & & TA & TA & TA \\
\hline & $\begin{array}{l}\text { 6.4 Telecommunications and Information } \\
\text { Technologies }\end{array}$ & 403 & 34182 & 90 & 725 & 360 & 360 \\
\hline & Information Technology & & & & & & \\
\hline 1 & $\begin{array}{l}\text { Elaboration and adoption of laws on } \\
\text { personal data protection, circulation of } \\
\text { electronic documents and digital signature, } \\
\text { and e-commerce and contracts }\end{array}$ & & 92 & & & & \\
\hline 2 & $\begin{array}{l}\text { Elaboration of the National Strategy } \\
\text { "Information society technologies for } \\
\text { development" }\end{array}$ & & & & & & \\
\hline 3 & $\begin{array}{l}\text { Pilot project for the creation of seven } \\
\text { collective access points at post offices, } \\
\text { schools, libraries }\end{array}$ & 48 & 50 & 50 & 200 & 150 & 150 \\
\hline 4 & $\begin{array}{l}\text { Development of ICT program for public } \\
\text { administration }\end{array}$ & 355 & 34040 & 40 & 525 & 210 & 210 \\
\hline & Telecommunication & & & & & & \\
\hline 5 & $\begin{array}{l}\text { Harmonization of national legislation and } \\
\text { regulations with those of the EU, WTO and } \\
\text { European Conference of Postal and } \\
\text { Telecommunications Administrations }\end{array}$ & & & & & TA & TA \\
\hline
\end{tabular}




\begin{tabular}{|c|c|c|c|c|c|c|c|}
\hline \multirow{2}{*}{ No } & \multirow{2}{*}{ Priority Actions } & \multicolumn{3}{|c|}{ MTEF costs envelope } & \multicolumn{3}{|c|}{ Unsecured additional costs } \\
\hline & & 2004 & 2005 & 2006 & 2004 & 2005 & 2006 \\
\hline 6 & $\begin{array}{l}\text { Development and upgrading of networks } \\
\text { (including optical cable) based on private } \\
\text { investment }\end{array}$ & & & & & & \\
\hline 7 & $\begin{array}{l}\text { Finalization of the introduction of the } \\
\text { National Numbering Plan }\end{array}$ & & & & & & \\
\hline 8 & Rebalance of MoldTelecom tariffs & & & & & & \\
\hline 9 & Privatization of MoldTelecom & & & & & & \\
\hline \multirow[t]{2}{*}{10} & $\begin{array}{l}\text { Creation and introduction of a minimum } \\
\text { service package }\end{array}$ & & & & & & \\
\hline & 6.5 Housing Construction & & & & 1320 & 11150 & 14000 \\
\hline 1 & $\begin{array}{l}\text { Study to prepare social housing policy and } \\
\text { strategy }\end{array}$ & & & & & TA & \\
\hline 2 & $\begin{array}{l}\text { Creation and improvement of the legal and } \\
\text { regulatory framework for mortgage lending }\end{array}$ & & & & & & \\
\hline 3 & $\begin{array}{l}\text { Improvement of the condominium } \\
\text { regulatory framework and its application }\end{array}$ & & & & & & \\
\hline 4 & $\begin{array}{l}\text { Approval of the State Program on } \\
\text { incomplete housing completion }\end{array}$ & & & & & & \\
\hline \multirow[t]{2}{*}{5} & $\begin{array}{l}\text { Development and implementation of pilot } \\
\text { projects for upgrading and rehabilitation of } \\
\text { existing housing }\end{array}$ & & & & 1320 & 11150 & 14000 \\
\hline & 7. INDUSTRY & $\mathbf{0}$ & $\mathbf{0}$ & $\mathbf{0}$ & $\mathbf{0}$ & 8200 & $\mathbf{0}$ \\
\hline 1 & $\begin{array}{l}\text { Continuation of privatization and } \\
\text { restructuring of industrial enterprises, and } \\
\text { bankruptcy for insolvent and inefficient } \\
\text { enterprises }\end{array}$ & & & & & & \\
\hline 2 & $\begin{array}{l}\text { Study to identify competitive industry } \\
\text { development priorities adjusted to } \\
\text { globalization and EU integration trends }\end{array}$ & & & & & 4000 & \\
\hline 3 & $\begin{array}{l}\text { Promotion of a Program of adjusting } \\
\text { production process to international standards } \\
\text { by implementing integrated quality } \\
\text { management systems }\end{array}$ & & & & & 1200 & \\
\hline 4 & $\begin{array}{l}\text { Preparation of investment programs for } \\
\text { certain industrial sectors }\end{array}$ & & & & & 3000 & \\
\hline 5 & $\begin{array}{l}\text { Establishment of a legal base for programs } \\
\text { for technology parks }\end{array}$ & & & & & & \\
\hline 6 & $\begin{array}{l}\text { Creation of the legal framework for capital } \\
\text { formation, consolidation and merger }\end{array}$ & & & & & & \\
\hline 7 & $\begin{array}{l}\text { Export promotion and the provision of } \\
\text { information and consulting services }\end{array}$ & & & & & & \\
\hline \multirow[t]{3}{*}{8} & $\begin{array}{l}\text { Revision of the possibilities to create a } \\
\text { mixed capital Industrial Investment Bank }\end{array}$ & & & & & & \\
\hline & $\begin{array}{l}\text { 8. AGRICULTURE AND RURAL } \\
\text { DEVELOPMENT }\end{array}$ & 186154 & 148120 & 141930 & 99455 & 141400 & 159000 \\
\hline & 8.1 Agriculture & 168304 & 135220 & 139330 & 94455 & 128100 & 135300 \\
\hline 1 & $\begin{array}{l}\text { Study to support the implementation of Land } \\
\text { Consolidation to review the current state of } \\
\text { consolidation from the efficiency and equity } \\
\text { perspectives and to make recommendations } \\
\text { for addressing the issue over the medium to } \\
\text { long term }\end{array}$ & & & & TA & & \\
\hline 2 & $\begin{array}{l}\text { Ministry of Agriculture and Food Industry } \\
\text { Restructuring Study }\end{array}$ & & & & & TA & \\
\hline
\end{tabular}




\begin{tabular}{|c|c|c|c|c|c|c|c|}
\hline \multirow{2}{*}{ No } & \multirow{2}{*}{ Priority Actions } & \multicolumn{3}{|c|}{ MTEF costs envelope } & \multicolumn{3}{|c|}{ Unsecured additional costs } \\
\hline & & 2004 & 2005 & 2006 & 2004 & 2005 & 2006 \\
\hline 3 & $\begin{array}{l}\text { Agricultural Subsidy Study to review } \\
\text { subsidies in the light of the growth and } \\
\text { poverty reduction goals of EGPRSP }\end{array}$ & & & & & TA & \\
\hline 4 & $\begin{array}{l}\text { Development with non-government } \\
\text { organizations of pro-poor programs for the } \\
\text { provision of information and advice, } \\
\text { educational and vocational training, and } \\
\text { micro and small enterprise financing }\end{array}$ & 7304 & 4820 & 3130 & 955 & 2600 & 2800 \\
\hline 5 & $\begin{array}{l}\text { Development of farmer group strategies for } \\
\text { more efficient access and use of } \\
\text { information, markets, inputs and production } \\
\text { opportunities }\end{array}$ & & & & & & \\
\hline 6 & $\begin{array}{l}\text { Development of a market based trade and } \\
\text { institutional framework (harmonization of } \\
\text { legislative acts regarding standardization, } \\
\text { facilitation of the accreditation process for } \\
\text { enterprises and laboratories in line with } \\
\text { international standards) }\end{array}$ & 7000 & & & 13500 & 25500 & 27500 \\
\hline 7 & $\begin{array}{l}\text { Development of lending schemes in rural } \\
\text { areas and promoting loan guarantees } \\
\text { preferences }\end{array}$ & 70300 & 90600 & 96400 & & 20000 & 25000 \\
\hline 8 & Support to farm machinery services start-ups & 83700 & 39800 & 39800 & 80000 & 80000 & 80000 \\
\hline 9 & $\begin{array}{l}\text { Promotion of export market development - } \\
\text { see Private Sector Development }\end{array}$ & & & & & & \\
\hline & 8.2 Rural development & 17850 & 12900 & 2600 & 5000 & 13300 & 23700 \\
\hline 1 & Rural Development Strategy Study & & & & & 300 & 300 \\
\hline 2 & $\begin{array}{l}\text { Development of institutional network in } \\
\text { rural sector: business promotion centers, } \\
\text { consulting and information agencies, } \\
\text { business-incubators }\end{array}$ & 17850 & 12900 & 2600 & & & 3400 \\
\hline 3 & $\begin{array}{l}\text { Development of non-agricultural activities } \\
\text { in rural areas }\end{array}$ & & & & 5000 & 13000 & 20000 \\
\hline & 9. REGIONAL DEVELOPMENT & $\mathbf{0}$ & $\mathbf{0}$ & $\mathbf{0}$ & $\mathbf{0}$ & $\mathbf{0}$ & $\mathbf{0}$ \\
\hline 1 & $\begin{array}{l}\text { Implementation of a law in support of } \\
\text { regional development which will lay the } \\
\text { basis for the establishment of institutions for } \\
\text { the implementation of regional development } \\
\text { policy }\end{array}$ & & & & & TA & \\
\hline 2 & $\begin{array}{l}\text { Selection and identification of regions for } \\
\text { development support covering several } \\
\text { existing administrative territorial units but } \\
\text { excluding Chisinau }\end{array}$ & & & & & TA & \\
\hline 3 & $\begin{array}{l}\text { Establishment of a two tier coordination } \\
\text { system at the national and local levels }\end{array}$ & & & & & & \\
\hline & Country Re-integration & & & & & & \\
\hline 4 & $\begin{array}{l}\text { Drafting and adoption of the new } \\
\text { Constitution of Moldova }\end{array}$ & & & & & & \\
\hline 5 & $\begin{array}{l}\text { Contribution to elaboration a general } \\
\text { guaranty system, including international } \\
\text { guarantees }\end{array}$ & & & & & & \\
\hline 6 & $\begin{array}{l}\text { Achievement of control and transparency at } \\
\text { the border between Moldova and Ukraine, } \\
\text { including Transnistrian border section }\end{array}$ & & & & & & \\
\hline
\end{tabular}




\begin{tabular}{|c|c|c|c|c|c|c|c|}
\hline \multirow{2}{*}{ No } & \multirow{2}{*}{ Priority Actions } & \multicolumn{3}{|c|}{ MTEF costs envelope } & \multicolumn{3}{|c|}{ Unsecured additional costs } \\
\hline & & 2004 & 2005 & 2006 & 2004 & 2005 & 2006 \\
\hline 7 & $\begin{array}{l}\text { Elaboration of the post-conflict development } \\
\text { program }\end{array}$ & & & & & & \\
\hline \multirow[t]{2}{*}{8} & $\begin{array}{l}\text { Promotion of active implication of the civil } \\
\text { society in settlement of the Transnistrian } \\
\text { problem }\end{array}$ & & & & & & \\
\hline & 10. TOURISM & 1437 & & & & 24249 & 25068 \\
\hline 1 & $\begin{array}{l}\text { Drafting and implementation of rural } \\
\text { tourism development projects (pilots) }\end{array}$ & 1000 & & & & 4800 & 4800 \\
\hline 2 & $\begin{array}{l}\text { Organization of seminars for local } \\
\text { authorities and population of rural and } \\
\text { ecologic tourism development }\end{array}$ & 47 & & & & 508 & 508 \\
\hline 3 & $\begin{array}{l}\text { Support in creating the tourism reception } \\
\text { infrastructure alongside major objects }\end{array}$ & & & & & 10400 & 10400 \\
\hline 4 & $\begin{array}{l}\text { Creation of the National Center for } \\
\text { retraining the tourism industry staff }\end{array}$ & 390 & & & & 2925 & 2340 \\
\hline 5 & $\begin{array}{l}\text { Creation of an informational base, editing } \\
\text { guides and catalogues on rural tourism } \\
\text { product, promotion of tourism product in } \\
\text { target markets }\end{array}$ & & & & & 5616 & 7020 \\
\hline 6 & $\begin{array}{l}\text { Investigation and promotion of opportunities } \\
\text { for investment in tourism }\end{array}$ & & & & & TA & \\
\hline \multirow[t]{3}{*}{7} & $\begin{array}{l}\text { Developing efficient quality control } \\
\text { mechanisms of services rendered to visitors }\end{array}$ & & & & & & \\
\hline & 11. ENVIRONMENT & $\mathbf{5 1 7 4 7}$ & 108527 & 111977 & 97687 & 161862 & 368712 \\
\hline & $\begin{array}{l}\text { 11.1 Waste Management, reduction of the } \\
\text { impact and quantities of toxic substances } \\
\text { and wastes }\end{array}$ & 32100 & 84150 & 91400 & 22900 & 82650 & 231800 \\
\hline 1 & $\begin{array}{l}\text { Destruction of } 1,712 \text { tones of prohibited } \\
\text { pesticides }\end{array}$ & 32100 & 28150 & 17200 & 2900 & 1850 & 1800 \\
\hline 2 & $\begin{array}{l}\text { Inventory and dismantling and } \\
\text { decontamination of PCB equipment }\end{array}$ & & 56000 & 74200 & & & \\
\hline 3 & $\begin{array}{l}\text { Feasibility study for upgrading waste } \\
\text { disposal sites initially in Chisinau }\end{array}$ & & & & & 50000 & 150000 \\
\hline 4 & $\begin{array}{l}\text { Planning and implementation of pilot project } \\
\text { for waste processing in rural areas }\end{array}$ & & & & & 800 & 60000 \\
\hline 5 & $\begin{array}{l}\text { Inventory, renovation and re-equipment of } \\
\text { Bekkari animal waste sites }\end{array}$ & & & & 20000 & 30000 & 20000 \\
\hline & 11.2 Water Resources & 260 & 260 & 260 & 390 & 9015 & 9015 \\
\hline 1 & $\begin{array}{l}\text { Preparation of Action Plan for harmonizing } \\
\text { environmental legislation and standards for } \\
\text { surface and ground water with those of the } \\
\text { EU }\end{array}$ & & & & & 8500 & 8500 \\
\hline 2 & $\begin{array}{l}\text { Inventory of water resources, quality, and } \\
\text { sources of pollution }\end{array}$ & 60 & 60 & 60 & 190 & 315 & 315 \\
\hline 3 & $\begin{array}{l}\text { Preparation of national strategy on } \\
\text { protection and sustainable management of } \\
\text { water resources }\end{array}$ & & & & & & \\
\hline 4 & $\begin{array}{l}\text { Preparation and implementation of measures } \\
\text { to eliminate pollution sources }\end{array}$ & 200 & 200 & 200 & 200 & 200 & 200 \\
\hline
\end{tabular}




\begin{tabular}{|c|c|c|c|c|c|c|c|}
\hline \multirow{2}{*}{ No } & \multirow{2}{*}{ Priority Actions } & \multicolumn{3}{|c|}{ MTEF costs envelope } & \multicolumn{3}{|c|}{ Unsecured additional costs } \\
\hline & & 2004 & 2005 & 2006 & 2004 & 2005 & 2006 \\
\hline & 11.3 Public Awareness & 0 & 0 & 0 & 2000 & 2000 & 2000 \\
\hline 1 & $\begin{array}{l}\text { Creation of regional environment } \\
\text { information centers }\end{array}$ & & & & & & \\
\hline 2 & $\begin{array}{l}\text { Capacity development of government } \\
\text { central and local officials regarding } \\
\text { information and participatory approaches to } \\
\text { environment protection }\end{array}$ & & & & & & \\
\hline 3 & $\begin{array}{l}\text { Trainings on sustainable use of for natural } \\
\text { resources }\end{array}$ & & & & & & \\
\hline 4 & $\begin{array}{l}\text { Revision and improvement of the } \\
\text { environmental monitoring system }\end{array}$ & & & & & & \\
\hline 5 & $\begin{array}{l}\text { Preparation of a national strategy on } \\
\text { environmental education }\end{array}$ & & & & & & \\
\hline 6 & $\begin{array}{l}\text { Development of the legal and institutional } \\
\text { framework for implementing the } \\
\text { requirements of the Arhus Convention }\end{array}$ & & & & 2000 & 2000 & 2000 \\
\hline \multirow[t]{2}{*}{7} & Creation of a natural resources database & & & & & & \\
\hline & 11.4 Forest Protection & 11087 & 11087 & 11087 & 18877 & 18877 & 18877 \\
\hline 1 & $\begin{array}{l}\text { Extension of forest plantation on lands of } \\
\text { Forest Fund and local administrations }\end{array}$ & 11002 & 11002 & 11002 & 18512 & 18512 & 18512 \\
\hline 2 & $\begin{array}{l}\text { Improved forestry inventory and } \\
\text { management systems }\end{array}$ & 60 & 60 & 60 & 140 & 140 & 140 \\
\hline \multirow[t]{2}{*}{3} & $\begin{array}{l}\text { Preparation of programs for sustainable } \\
\text { wood and non-wood processing }\end{array}$ & 25 & 25 & 25 & 225 & 225 & 225 \\
\hline & 11.5 Biodiversity & 6000 & 5000 & 3000 & 6000 & 2000 & 1000 \\
\hline 1 & $\begin{array}{l}\text { Biodiversity conservation in the Prut River } \\
\text { middle course and development of } \\
\text { community silviculture }\end{array}$ & 6000 & 5000 & 3000 & 4000 & 2000 & 1000 \\
\hline 2 & Creation of an environmental network & & & & 2000 & & \\
\hline \multirow[t]{2}{*}{3} & Creation of the Lower Nistru National Park & & & & & & \\
\hline & 11.6 Soil Protection & 0 & 6230 & 6230 & 44720 & 46520 & 105720 \\
\hline 1 & $\begin{array}{l}\text { Pilot projects for the rational use and } \\
\text { irrigation of soils }\end{array}$ & & & & & 800 & 60000 \\
\hline 2 & $\begin{array}{l}\text { Preparation and implementation of tree } \\
\text { planting for soil conservation }\end{array}$ & & & & 43720 & 43720 & 43720 \\
\hline 3 & $\begin{array}{l}\text { Anti-erosion activities and rehabilitation of } \\
\text { degraded areas }\end{array}$ & & & & & & \\
\hline 4 & $\begin{array}{l}\text { Training land owners and farmers in } \\
\text { ecological farming methods }\end{array}$ & & & & 1000 & 2000 & 2000 \\
\hline \multirow[t]{2}{*}{5} & $\begin{array}{l}\text { Rehabilitation, improvement of communal } \\
\text { pastures management }\end{array}$ & & 6230 & 6230 & & & \\
\hline & 11.7 Natural Disasters & 2000 & 1800 & 0 & 700 & 800 & 300 \\
\hline 1 & Publicity campaigns & & & & & & \\
\hline \multirow[t]{2}{*}{2} & $\begin{array}{l}\text { Upgrade of the equipment and technology of } \\
\text { the disaster monitoring system }\end{array}$ & 2000 & 1800 & 0 & 700 & 800 & 300 \\
\hline & $\begin{array}{l}\text { 11.8 Administrative and Financial } \\
\text { Mechanisms }\end{array}$ & 300 & 0 & 0 & 2100 & 0 & 0 \\
\hline 1 & $\begin{array}{l}\text { Revision of the activities and modalities of } \\
\text { the National Environmental Fund }\end{array}$ & & & & 2100 & & \\
\hline
\end{tabular}




\begin{tabular}{|c|c|c|c|c|c|c|c|}
\hline \multirow{2}{*}{ No } & \multirow{2}{*}{ Priority Actions } & \multicolumn{3}{|c|}{ MTEF costs envelope } & \multicolumn{3}{|c|}{ Unsecured additional costs } \\
\hline & & 2004 & 2005 & 2006 & 2004 & 2005 & 2006 \\
\hline \multirow[t]{3}{*}{2} & $\begin{array}{l}\text { Preparation and publication of the } \\
\text { environmental impact assessment guide }\end{array}$ & 300 & & & & & \\
\hline & 12. EDUCATION & 14790 & 111520 & 162420 & 50500 & 130805 & 152400 \\
\hline & $\underline{\text { Access }}$ & & & & & & \\
\hline 1 & $\begin{array}{l}\text { Creation of the legal framework for the use } \\
\text { of community funds for schooling, } \\
\text { especially for the poor }\end{array}$ & & & & & & \\
\hline 2 & $\begin{array}{l}\text { Reallocation resources between sectors to } \\
\text { favor primary and gymnasium education }\end{array}$ & & 28300 & 59700 & & & \\
\hline 3 & $\begin{array}{l}\text { Efficient management and priority resources } \\
\text { allocation for increasing the salaries of } \\
\text { employees in education, textbooks } \\
\text { acquisitions, didactical materials and } \\
\text { equipment }\end{array}$ & & & & & & \\
\hline 4 & $\begin{array}{l}\text { Drafting and implementation of the rural } \\
\text { education development program }\end{array}$ & & & & 39000 & 39000 & 45000 \\
\hline 5 & $\begin{array}{l}\text { Creation in the rural environment of } \\
\text { "circumscription" schools in parallel with } \\
\text { provision of transportation services for } \\
\text { pupils }\end{array}$ & & & & \multicolumn{3}{|c|}{$\begin{array}{l}\text { Available budget resources } \\
\text { reallocation within the sector }\end{array}$} \\
\hline 6 & $\begin{array}{l}\text { Implementation of a flexible and equitable } \\
\text { system of support for students and pupils } \\
\text { from secondary general education by } \\
\text { offering scholarships, depending on their } \\
\text { successes and financial situation of families }\end{array}$ & & 12000 & 12000 & & & \\
\hline 7 & $\begin{array}{l}\text { Extension of textbook loan schemes for } \\
\text { pupils from high schools and subventions of } \\
\text { textbooks for the poor }\end{array}$ & 2500 & 2500 & 2500 & 1500 & 6000 & 5600 \\
\hline & Quality & & & & & & \\
\hline 1 & $\begin{array}{l}\text { Preparation and introduction of state } \\
\text { standards for education }\end{array}$ & 2800 & 2800 & 2800 & & 6700 & 6700 \\
\hline 2 & $\begin{array}{l}\text { Development of school and university } \\
\text { curricula, including in education based on } \\
\text { life skills, implementing new teaching } \\
\text { technologies }\end{array}$ & \multicolumn{6}{|c|}{$\begin{array}{l}\text { The program started, costs for implementation are } 1900 \text { thousands } \\
\text { USD and are covered from the grant }\end{array}$} \\
\hline 3 & $\begin{array}{l}\text { Systematic participation in international } \\
\text { tests (TIMSS, PISA, etc.) }\end{array}$ & & & & & & \\
\hline 4 & $\begin{array}{l}\text { Development and implementation of the } \\
\text { presidential program "SALT" of } \\
\text { implementing information and } \\
\text { communication technologies in the } \\
\text { education system }\end{array}$ & & & & & & \\
\hline 5 & $\begin{array}{l}\text { Improvement of the system of initial training } \\
\text { and in-services training of teaching staff }\end{array}$ & & & & & 2500 & 2500 \\
\hline 6 & $\begin{array}{l}\text { Reconsideration of the place and role of } \\
\text { secondary professional education and its } \\
\text { adjusting to community requirements, } \\
\text { updating the catalog of trades and } \\
\text { professions in partnership with social } \\
\text { partners }\end{array}$ & & & & & & \\
\hline 7 & $\begin{array}{l}\text { Development of and implementing the } \\
\text { national system of evaluation of pupils' } \\
\text { knowledge and skills and efficient } \\
\text { monitoring of admission in higher education } \\
\text { institutions }\end{array}$ & 3800 & 3800 & 3800 & & & \\
\hline
\end{tabular}




\begin{tabular}{|c|c|c|c|c|c|c|c|}
\hline \multirow{2}{*}{ No } & \multirow{2}{*}{ Priority Actions } & \multicolumn{3}{|c|}{ MTEF costs envelope } & \multicolumn{3}{|c|}{ Unsecured additional costs } \\
\hline & & 2004 & 2005 & 2006 & 2004 & 2005 & 2006 \\
\hline 8 & $\begin{array}{l}\text { Development of mechanisms of } \\
\text { implementing the European system of } \\
\text { transferable academic credits }\end{array}$ & & & & & & \\
\hline 9 & $\begin{array}{l}\text { Adjustment of the catalog of specialties to } \\
\text { ISCED } 97 \text { and ISCO, restructuring the } \\
\text { curricula in order to organize the higher } \\
\text { education in } 2 \text { university cycles according to } \\
\text { the Bologna Declaration provisions }\end{array}$ & & & & & 7200 & 13900 \\
\hline & Special Requirements & & & & & & \\
\hline 1 & $\begin{array}{l}\text { Organization of assistance services for } \\
\text { children with special educational } \\
\text { requirements in secondary general education } \\
\text { institutions, develop community services for } \\
\text { their assistance and support }\end{array}$ & & & & & 4000 & 4000 \\
\hline 2 & $\begin{array}{l}\text { Creation of a database of children with } \\
\text { special educational requirements in order to } \\
\text { develop efficient programs and measures of } \\
\text { their assistance }\end{array}$ & & & & & 105 & \\
\hline 3 & $\begin{array}{l}\text { Development and implementation of } \\
\text { programs and different forms of education } \\
\text { for children with special educational } \\
\text { requirements }\end{array}$ & & & & & 10300 & 13000 \\
\hline 4 & $\begin{array}{l}\text { Creation and development of a system of } \\
\text { services, alternative to institutionalization } \\
\text { (family type institutions, etc.) }\end{array}$ & 790 & 820 & 820 & & & \\
\hline 5 & $\begin{array}{l}\text { Development and implementation of } \\
\text { standards of care, education, medical } \\
\text { assistance, recuperation, rehabilitation of } \\
\text { children with special educational } \\
\text { requirements }\end{array}$ & & & & & 10300 & 2700 \\
\hline 6 & $\begin{array}{l}\text { Consolidation of didactic and technical- } \\
\text { material base for quality professional } \\
\text { training of special education institutions' } \\
\text { graduates in order to facilitate their } \\
\text { integration in society }\end{array}$ & 4900 & 4100 & 4100 & 10000 & 12000 & 15000 \\
\hline & Management Efficiency & & & & & & \\
\hline 1 & $\begin{array}{l}\text { Improvement and completion of the } \\
\text { legislative framework in order to ensure } \\
\text { coherence and continuity of education } \\
\text { system development }\end{array}$ & & & & & & \\
\hline 2 & $\begin{array}{l}\text { Creation of the education management } \\
\text { information system }\end{array}$ & & & 11900 & & 15000 & 17000 \\
\hline 3 & $\begin{array}{l}\text { Modification of the methodology of } \\
\text { financing activities of initial and in-service } \\
\text { training of teaching and managerial staff } \\
\text { from pre-university education }\end{array}$ & & & & & & \\
\hline 4 & $\begin{array}{l}\text { Improvement of the methodology of budget } \\
\text { financing of education system (program, } \\
\text { unit-based financing, etc.) }\end{array}$ & & & & & & \\
\hline 5 & $\begin{array}{l}\text { Upgrade of the technical-material base of } \\
\text { education institutions and implementation of } \\
\text { energy conservation measures }\end{array}$ & & 18100 & 24800 & & 25000 & 27000 \\
\hline 6 & $\begin{array}{l}\text { Improvement of the system of teaching and } \\
\text { management staff attestation }\end{array}$ & & & & & & \\
\hline 7 & $\begin{array}{l}\text { Establishment of responsibilities and } \\
\text { competences of central and local public } \\
\text { authorities, social partners, in order to }\end{array}$ & & & & & & \\
\hline
\end{tabular}




\begin{tabular}{|c|c|c|c|c|c|c|c|}
\hline \multirow{2}{*}{ No } & \multirow{2}{*}{ Priority Actions } & \multicolumn{3}{|c|}{ MTEF costs envelope } & \multicolumn{3}{|c|}{ Unsecured additional costs } \\
\hline & & 2004 & 2005 & 2006 & 2004 & 2005 & 2006 \\
\hline & $\begin{array}{l}\text { ensure normal conditions for education } \\
\text { institutions' functioning }\end{array}$ & & & & & & \\
\hline \multirow[t]{3}{*}{8} & $\begin{array}{l}\text { Improvement of conditions for the } \\
\text { functioning of pre-school institutions for } \\
\text { mandatory preparation of children to school }\end{array}$ & & 39100 & 40000 & & & \\
\hline & 13. HEALTHCARE & 182840 & 144650 & 132880 & 287712 & 689137 & 789702 \\
\hline & $\begin{array}{l}\text { 13.1 Implementation and Support of } \\
\text { Mandatory Health Insurance System }\end{array}$ & 52400 & 67250 & 60900 & 157886 & 506436 & 608386 \\
\hline 1 & $\begin{array}{l}\text { Establishment of an information system for } \\
\text { mandatory medical insurance }\end{array}$ & & & & 65000 & 65000 & 65000 \\
\hline 2 & $\begin{array}{l}\text { Capacity consolidation by medical } \\
\text { institution staff training on the new system }\end{array}$ & & & & 2886 & 2886 & 2886 \\
\hline 3 & $\begin{array}{l}\text { Completion of accreditation of medical } \\
\text { institutions }\end{array}$ & 1100 & 1200 & 1300 & & & \\
\hline 4 & Consolidation of institutional capacity & 51300 & 66050 & 59600 & 90000 & 424550 & 526500 \\
\hline \multirow[t]{2}{*}{5} & $\begin{array}{l}\text { Modernization of the Republican College of } \\
\text { Medicine }\end{array}$ & & & & & 14000 & 14000 \\
\hline & 12.2 National Health Programs & 130440 & 77400 & 71980 & 129826 & 182701 & 181316 \\
\hline 1 & $\begin{array}{l}\text { Restructuring and consolidation of medical } \\
\text { services and institutions }\end{array}$ & & & & & & \\
\hline 2 & $\begin{array}{l}\text { Implementation of National immunization } \\
\text { program }\end{array}$ & 10400 & 6700 & 7000 & 3370 & 1070 & 770 \\
\hline 3 & $\begin{array}{l}\text { Implementation of National TB control } \\
\text { program }\end{array}$ & 26000 & 5900 & 3500 & 6500 & 6300 & 6100 \\
\hline 4 & $\begin{array}{l}\text { Implementation of Blood Service technical- } \\
\text { material base consolidation program }\end{array}$ & 5830 & 6180 & 6680 & 12198 & 33848 & 33348 \\
\hline 5 & $\begin{array}{l}\text { Implementation of Diabetes prevention and } \\
\text { treatment program MoldDiab }\end{array}$ & 8610 & 11300 & 11800 & 52243 & 49553 & 49053 \\
\hline 6 & $\begin{array}{l}\text { Implementation of HIV/AIDS prevention } \\
\text { and treatment program }\end{array}$ & 57500 & 20920 & 16400 & 2180 & 1980 & 1880 \\
\hline 7 & $\begin{array}{l}\text { Implementation of quality prenatal services } \\
\text { program }\end{array}$ & & & & & 40600 & 40600 \\
\hline 8 & $\begin{array}{l}\text { Implementation of measures for fighting } \\
\text { mental diseases, drug addiction, toxicomany } \\
\text { and alcoholism }\end{array}$ & 2400 & 5000 & 5100 & 7400 & 5000 & 5200 \\
\hline 9 & $\begin{array}{l}\text { Implementation of the National Program for } \\
\text { fighting viral hepatitis }\end{array}$ & & & & 2030 & 2145 & 2260 \\
\hline 10 & $\begin{array}{l}\text { Implementation of the Program for } \\
\text { prevention and fighting cancer }\end{array}$ & 2700 & 4400 & 4500 & 12905 & 11205 & 11105 \\
\hline 11 & $\begin{array}{l}\text { Implementation of the Programs of medical } \\
\text { assistance for pregnant women, sick children }\end{array}$ & & & & 8000 & 8000 & 8000 \\
\hline 12 & $\begin{array}{l}\text { Provision of small babies and pregnant } \\
\text { women with drugs, compensated in } \\
\text { ambulatory conditions }\end{array}$ & 17000 & 17000 & 17000 & 23000 & 23000 & 23000 \\
\hline & 14. SOCIAL PROTECTION & 4180 & 16168 & 16180 & 28988 & 30443 & 29019 \\
\hline & 14.1 Social Insurance & 3240 & 15212 & 15212 & 0 & 1440 & 0 \\
\hline 1 & Social insurance harmonization review & & & & & TA & TA \\
\hline 2 & $\begin{array}{l}\text { Implementation of individual records of } \\
\text { social insurance contributions }\end{array}$ & 3240 & 5000 & 5000 & & & \\
\hline 3 & $\begin{array}{l}\text { Introduction of social insurance fund } \\
\text { medium term forecasts }\end{array}$ & & & & & 1440 & \\
\hline 4 & $\begin{array}{l}\text { Development of pension system for the self- } \\
\text { employed especially in agriculture }\end{array}$ & & & & & & \\
\hline
\end{tabular}




\begin{tabular}{|c|c|c|c|c|c|c|c|}
\hline \multirow{2}{*}{ No } & \multirow{2}{*}{ Priority Actions } & \multicolumn{3}{|c|}{ MTEF costs envelope } & \multicolumn{3}{|c|}{ Unsecured additional costs } \\
\hline & & 2004 & 2005 & 2006 & 2004 & 2005 & 2006 \\
\hline 5 & $\begin{array}{l}\text { Improvement of calculation methods for } \\
\text { contributions }\end{array}$ & & & & & & \\
\hline 6 & $\begin{array}{l}\text { Unification and harmonization of the system } \\
\text { and pension legislation, and the application } \\
\text { of general pension norms to judges and } \\
\text { prosecutors }\end{array}$ & & 10212 & 10212 & & & \\
\hline & 14.2 Social Assistance & 940 & 956 & 968 & 28988 & 29003 & 29019 \\
\hline 1 & $\begin{array}{l}\text { Introduction of social assistance program } \\
\text { impact monitoring }\end{array}$ & & & & & & \\
\hline 2 & Introduction of poverty benefits system & & & & TA & TA & \\
\hline 3 & $\begin{array}{l}\text { Introduction of separate social assistance } \\
\text { budget and register }\end{array}$ & & & & & & \\
\hline 4 & $\begin{array}{l}\text { Study on the modernization of specialized } \\
\text { social services }\end{array}$ & & & & & & \\
\hline 5 & $\begin{array}{l}\text { Development of professional network for } \\
\text { social services }\end{array}$ & 940 & 956 & 968 & 988 & 1003 & 1019 \\
\hline 6 & $\begin{array}{l}\text { Preparation of quality standards for social } \\
\text { service institutions }\end{array}$ & & & & & & \\
\hline 7 & $\begin{array}{l}\text { Support of most vulnerable population's } \\
\text { layers to cope with growth of energy tariffs }\end{array}$ & & & & 28000 & 28000 & 28000 \\
\hline & 15. LABOR MARKET & 32595 & 41808 & 48659 & 4500 & $\mathbf{5 7 2 0}$ & 2760 \\
\hline 1 & $\begin{array}{l}\text { Equipping the National Agency for Labor } \\
\text { Force Employment }\end{array}$ & & & & & & \\
\hline 2 & $\begin{array}{l}\text { Creation of a labor market informational } \\
\text { system }\end{array}$ & 1100 & 761 & 597 & 2000 & 1500 & 500 \\
\hline 3 & $\begin{array}{l}\text { Modernization and diversification of labor } \\
\text { mediation services }\end{array}$ & 85 & 175 & 262 & & & \\
\hline 4 & $\begin{array}{l}\text { Optimization of the unemployed training } \\
\text { and retraining activities }\end{array}$ & 5700 & 10246 & 10724 & & 1500 & 760 \\
\hline 5 & $\begin{array}{l}\text { Revision of the social protection system for } \\
\text { the unemployed }\end{array}$ & 25700 & 30526 & 36080 & & & \\
\hline 6 & $\begin{array}{l}\text { Implementation marketing and forecast } \\
\text { researches on the labor market }\end{array}$ & 10 & 100 & 100 & 500 & 500 & 500 \\
\hline 7 & $\begin{array}{l}\text { Creation of three pilot centers for work } \\
\text { preparation of socially vulnerable persons }\end{array}$ & & & & 1000 & 1220 & 1000 \\
\hline 8 & $\begin{array}{l}\text { Preparation of flexible employment } \\
\text { arrangement provisions for vulnerable } \\
\text { persons }\end{array}$ & & & 896 & & & \\
\hline 9 & $\begin{array}{l}\text { Creation of three centers of youth } \\
\text { employment centers }\end{array}$ & & & & 1000 & 1000 & \\
\hline 10. & $\begin{array}{l}\text { Bringing the internal legislation regarding } \\
\text { the migration and asylum in accordance } \\
\text { with the international standards; }\end{array}$ & & & & TA & TA & \\
\hline 11 , & $\begin{array}{l}\text { Making a complex study on the migration } \\
\text { of the population and its consequences; } \\
\text { creation of an informational system and } \\
\text { improvement of the management of } \\
\text { migration processes. }\end{array}$ & & & & TA & TA & TA \\
\hline & 16. YOUTH POLICY & 200 & 770 & 780 & 10200 & 11410 & 11300 \\
\hline 1. & $\begin{array}{l}\text { Conduct of studies on Youth situation and } \\
\text { modification based on that of youth policies } \\
\text { and legal framework }\end{array}$ & & & & & & \\
\hline 2. & $\begin{array}{l}\text { Fulfillment of actions of forming new } \\
\text { technology skills and other life skills of } \\
\text { unemployed youth, according to the Youth }\end{array}$ & 50 & 50 & 50 & 750 & 850 & 750 \\
\hline
\end{tabular}




\begin{tabular}{|c|c|c|c|c|c|c|c|}
\hline \multirow{2}{*}{ No } & \multirow{2}{*}{ Priority Actions } & \multicolumn{3}{|c|}{ MTEF costs envelope } & \multicolumn{3}{|c|}{ Unsecured additional costs } \\
\hline & & 2004 & 2005 & 2006 & 2004 & 2005 & 2006 \\
\hline & Inclusion Project (YIP) & & & & & & \\
\hline 3. & $\begin{array}{l}\text { Implementation of actions for youth that } \\
\text { graduated secondary studies and are not } \\
\text { employed and/or studying - at regional level } \\
\text { (YIP) }\end{array}$ & & & & 700 & 1100 & 1000 \\
\hline 4. & $\begin{array}{l}\text { Professional orientation actions with } \\
\text { internships and employment in selected } \\
\text { enterprises from Republic's raions (YIP) }\end{array}$ & & & & 1600 & 2000 & 2000 \\
\hline & $\begin{array}{l}\text { Increase access to services and information } \\
\text { sources }\end{array}$ & & & & & & \\
\hline 5. & $\begin{array}{l}\text { Creation of a support fund for gifted youth } \\
\text { in science and technique, education and } \\
\text { culture by offering stipends and other } \\
\text { supports }\end{array}$ & & & & 1500 & & \\
\hline 6. & $\begin{array}{l}\text { Implementation of actions for preventing of } \\
\text { risky behavior by promoting cognitive, } \\
\text { cultural and sport opportunities, and access } \\
\text { to new IT (YIP) }\end{array}$ & 50 & 100 & 100 & 450 & 900 & 900 \\
\hline 7. & $\begin{array}{l}\text { Realization of cultural, cognitive and sport } \\
\text { radio and TV projects and programs for } \\
\text { youth }\end{array}$ & & 70 & 80 & & 130 & 220 \\
\hline & $\begin{array}{l}\text { Development of human and institutional } \\
\text { capacities in working with the youth }\end{array}$ & & & & & & \\
\hline 8. & $\begin{array}{l}\text { Creation of a Youth National Research and } \\
\text { Investigations Center and a network of } \\
\text { Youth Centers in rural areas (YIP) }\end{array}$ & & & & 2000 & 2000 & 2000 \\
\hline 9. & $\begin{array}{l}\text { Creation of Youth Resources Centers } \\
\text { (Chişinău - } 2 \text { centers, in Soroca, Bălți, } \\
\text { Cahul, Ungheni, Orhei - each one center) }\end{array}$ & & & & 3000 & 3680 & 3680 \\
\hline 10. & $\begin{array}{l}\text { Realization of the National Program for } \\
\text { training and re-training of youth } \\
\text { professional workers }\end{array}$ & 100 & 200 & 100 & 200 & 400 & 300 \\
\hline & $\begin{array}{l}\text { Stimulation of youth participation in } \\
\text { decision-making process }\end{array}$ & & & & & & \\
\hline 11. & $\begin{array}{l}\text { Promotion of youth representation in } \\
\text { collegial and consulting structures of local } \\
\text { and central bodies }\end{array}$ & & & & & & \\
\hline 12. & $\begin{array}{l}\text { Promotion of financial (through project } \\
\text { contests) and technical support (youth } \\
\text { resource centers) to the youth associative } \\
\text { sector (YIP) }\end{array}$ & & 350 & 450 & & 350 & 450 \\
\hline & $\begin{array}{l}\text { 17. DEVELOPMENT OF NATIONAL } \\
\text { STATISTICS }\end{array}$ & 34122 & 5679 & 2770 & 29205 & 58466 & 43089 \\
\hline 1 & $\begin{array}{l}\text { Improvement of the legal and institutional } \\
\text { framework and statistical management }\end{array}$ & & 463 & 463 & 1489 & 3123 & 1134 \\
\hline 2 & $\begin{array}{l}\text { Improvement of publications, dissemination } \\
\text { of statistical information and relations with } \\
\text { users }\end{array}$ & & & & 644 & 639 & 471 \\
\hline 3 & $\begin{array}{l}\text { Improvement of statistics products and } \\
\text { infrastructure, including Population Census } \\
\text { and General Agricultural Census }\end{array}$ & 34122 & 5216 & 2307 & 9603 & 18234 & 38397 \\
\hline 4 & $\begin{array}{l}\text { Improvement of technical capacities of } \\
\text { statistics system }\end{array}$ & & & & 17469 & 36470 & 3087 \\
\hline 5 & $\begin{array}{l}\text { Consolidation of capacities of central and } \\
\text { local public authorities on obtaining } \\
\text { administrative data and extending their use } \\
\text { for statistical purposes. }\end{array}$ & & & & & & \\
\hline
\end{tabular}




\begin{tabular}{|c|c|c|c|c|c|c|c|}
\hline \multirow{2}{*}{ No } & \multirow{2}{*}{ Priority Actions } & \multicolumn{3}{|c|}{ MTEF costs envelope } & \multicolumn{3}{|c|}{ Unsecured additional costs } \\
\hline & & 2004 & 2005 & 2006 & 2004 & 2005 & 2006 \\
\hline & $\begin{array}{l}\text { 18. CAPACITIES DEVELOPMENT } \\
\text { EGPRSP Implementation Monitoring } \\
\text { Unit }\end{array}$ & & & & 6800 & 14400 & 15000 \\
\hline & TOTAL & 948289 & $\begin{array}{l}115398 \\
7\end{array}$ & $\begin{array}{l}111412 \\
8\end{array}$ & $\begin{array}{l}108706 \\
8\end{array}$ & $\begin{array}{l}195656 \\
8 \\
\end{array}$ & 2422586 \\
\hline & $\begin{array}{l}\text { Costs of inestimable actions }(10 \% \text { of } \\
\text { TOTAL) }\end{array}$ & $\mathrm{x}$ & $\mathrm{X}$ & $\mathrm{X}$ & 108707 & 195657 & 242259 \\
\hline & GENERAL TOTAL & 948289 & $\begin{array}{l}115398 \\
7\end{array}$ & $\begin{array}{l}111412 \\
8\end{array}$ & $\begin{array}{l}119577 \\
5\end{array}$ & $\begin{array}{l}215222 \\
5\end{array}$ & 2664845 \\
\hline
\end{tabular}




\section{ANNEX 8. STRUCTURE OF PUBLIC REACTIONS IN THE DEBATES PROCESS ON EGPRSP, JANUARY-MARCH 2004}

\section{Identified types of public reactions}

During public discussions on EGPRSP and sector strategies there has been both general criticism and substantial proposals. Reactions were on:

- $\quad$ Methodological aspects and structure of papers under discussion;

- $\quad$ Content (text);

- $\quad$ Conceptual aspects of documents;

- $\quad$ Action plans.

Some reactions refer to EGPRSP in general; others are limited to sector components. Below is a structural analysis of public reactions.

\section{$\underline{\text { Reactions to integrated EGPRSP }}$}

\section{Reactions on structure and methodology}

It was proposed to include a chapter on endogenous and exogenous risks that might compromise the Strategy implementation in the following three years. It was suggested that the Government should conduct more thorough quality studies on the nature of poverty, as well as establish a clear procedure of consultation with the poor. The choice of a scientifically grounded methodology for the calculation of an official poverty line was another recommendation meant to contribute to a better "targeting" of social assistance policies.

\section{Reactions to the text}

The EGPRSP variant, which was the start of public debate in January 2004, was considered to contain too many findings with a political character meant at polarizing rather than brining the society together around the EGPRSP idea. There were proposals to extend social actors involved in the EGPRSP process. Trade unions, local communities associations and opposition political forces are the main nominees.

Economic experts argue for the reduction of the number of priority areas of EGPRSP. The opinions of most experts converge on the fact that a social policy needs to be selected (healthcare, education, or social insurance), to develop the private sector as a driving force of the economic growth and towards the improvement of governance.

There were proposals like, the intensification of sector strategy "Environment protection and sustainable use of natural resources" presence in EGPRSP and give a more "ecological" character to the EGPRSP in general.

The participants in debates suggested to the EGPRSP team to include a sub-component referred to science, and as result the chapter 6.5 "Development of the science sector" has been introduced. This chapter should clearly stipulate one of the main necessary preconditions, that in the future the academic community could bring a plenary contribution to the development of papers like EGPRSP and namely, to the research sector and its integration within higher education of Republic of Moldova (following the European model of scientific research and education). Also, it should provide for some institutional and fiscal conditions to create incentives for more confident domestic and foreign investment into the research and development sector, to integrate the financial and scientific capitals and to create, at the intersection of economy, science and higher education, of a true scientific-economic sector "economy of intellectual products". But 
for this chapter to preserve the EGPRSP "identity" it should clearly state, what is going to be the link between the consolidation of the research and development sector and poverty reduction until 2006.

Another issue brought up during the consultations was the non-uniform development of territories. In this context it was suggested to add another general objective "Regional development" or to formulate a sector strategy that would comprise regional development, with a clear stipulation of implementation and monitoring indicators, of responsible institutions (Regional Development Agency and Ministry of Economy).

\section{Reactions to the action plan}

It was deemed necessary to more clearly identify public agencies responsible for the implementation of actions. It was also suggested to eliminate some actions with a purely formal character or with no impact upon poverty and economic growth, as well as some actions and measures, which apriori are not achievable within a three-year time frame, envisaged for EGPRSP implementation.

Have been identified some problems related to the fact that EGPRSP will be implemented during 20042006. In fact, EGPRSP will be approved only in June-July of 2004. Therefore it reasonable to change the implementation term to 2005-2007.

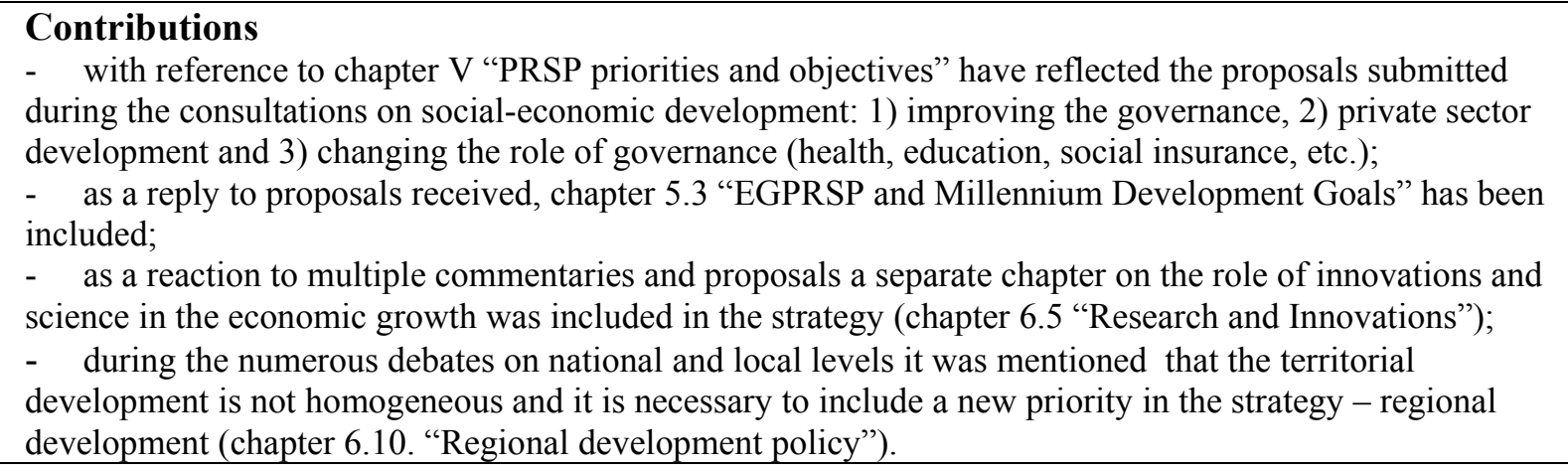

\section{$\underline{\text { Reactions to sector components }}$}

“Public Sector Reform” Strategy

For the strategy's structure it was suggested to create a separate section, dedicated to the issue of fighting corruption in all public structures. Most of public reactions to this strategy came in the form of concrete proposals for actions and measures to be undertaken:

\section{Judiciary}

To ensure independence of the judiciary it is necessary to develop mechanisms regulating the activity of the judge. It was also suggested to create a Magistrates Institute for an ongoing professional training of judges, prosecutors and lawyers. To finalize the legal system Reform component it is necessary to take into account the provisions of the National Plan for the protection of human rights approved by the Parliament, with an emphasis on the enhanced access of social-vulnerable layers to justice. The inclusion in the action plan of the approval of the Law on state guaranteed access to justice, which is a draft at the moment. There should be actions to enforce court decisions in the case of social-vulnerable layers. 
As to the legal education it is necessary to promote actions on legal training of the population. The role of legal science should be determined in the development and enhancement of the legal framework, legal education system and legal practice in general.

\section{Contributions}

- as a result of received proposals the name of the chapter was changed to "Legal Sector Reform" and not judicial, which is a limiting approach;

- another proposal was reflected in the text of the section, to create a National Institute of Justice

(Magistracy) for an ongoing professional training of legal staff (p.263);

- the enhancement of the access of social -vulnerable layers to legal services was emphasized;

- the optimization of study program and education plans for the legal education system (p.273).

\section{Local Public Administration}

It was suggested to create a legal system to clearly regulate financial relations between central and local pubic authorities at delegating competences from the central to the local level. The strategy should be based on regional development concepts. All localities must have strategic plans for short, medium and long-term development.

It is necessary to develop a national plan on the development and financing local infrastructure. Community development centers should be created at the local level, to comprise cultural, sports, educational activities etc. at the local level. Thus, it is suggested to re-institute the positions of youth and sports workers where these lack.

To improve local governance, develop and approve local and national budgets, civil society should be involved and the process should have large media coverage.

\section{Quality of governance}

It is necessary to involve the civil sector, especially economic agents in services provision, as an alternative to state ones. In this sense, it was suggested to provide equal rights to state, public and private schools. In a multinational state, the development of balanced national policies is of vital importance, while respecting the interests and rights of all minorities. The youth should be involved more actively in the political life of the country and in solving existent problems of the society. Is required an improvement of the cooperation process between the public administration and civil society.

\section{Public institutions}

The following was suggested in this area: revision, with a possible cancellation of historical debt of public institutions, to ensure their functionality. Creation of a functional system of continuous development of staff within the public administration.

Reducing the number of paid services provided by pubic institutions, which to a great extent is a hidden taxation of the population and creating an efficient communication system between public authorities and the population.

Efficient maintaining and use of public institutions' goods by providing quality services to the community members.

\section{Conclusions}

- reconfirmation of the principle of decentralization of services and efficient management of public institutions' goods from the central to the local level (p.222); 
- creating an efficient system of continuous training of public servants;

- improving the governance by involving the public in decision-making process especially in relation to

local budgets, their media coverage (p.221, 224);

- establishing the responsibilities of local public administration in relation to central authorities (p.213, 215);

- to increase the fiscal base for local budgets and increase its role is proposed the modification of legislation regarding the improvement of local Taxes mechanism (p.197).

\section{"Private Sector Development" Strategy}

\section{Major problems identified by the public}

Most of public reactions during the debates on the "Private Sector Development" Strategy draft focused on solving the following major issues: 1) instability and complexity of the business environment regulatory framework, 2) administrative control and exaggerated tutelage of business by state bodies, 3 ) high bureaucracy, 4) limited access to financial resources, including to micro-financing and long-term investment credits; 5) difficult access to external markets; 6) persistence of corruption phenomenon.

\section{Essential proposals:}

1. Conducting a regulatory reform that would dramatically change the nature of interaction between the state and the businessman - sole solution against institutional blockings.

2. Simplifying all procedures, not only those for registration but also for account opening, tax accounting, registration as a VAT payer, obtaining licenses and authorizations to remove bureaucratic barriers.

3. Simplifying the fiscal system for small and medium scale enterprises - reducing the number of taxes and fees and decreasing the costs of fiscal administration (some central and local taxes involve administrative costs, which are higher then the taxes themselves). On the other hand, we believe that the Government of Moldova should seriously consider the possibility to reduce the fiscal burden even more, under the regional average, thus, gaining some advantages compared to the neighboring countries.

4. Meliorating investment policies - canceling VAT on import of technologies and equipment, exempting from the payment of re-invested income tax, reducing amortization periods.

5. Improving the system of economic information - creating regional centers of economic information and business consultancy, editing a quarterly bulletin for investors.

6. Facilitating the access of beginning businessman to activities related to training in the field of business administration - providing some specialized training or consulting activities, on specific issues.

7. Consolidating the links of reverse information within the labor force market system - vocational and higher education institutions.

8. To solve the problem of access to long-term bank loans was suggested the facilitation of leasing activities, for the banks to easier attract clients, the former must be exempted from the obligation of payments tracking, using the fund for small business support as a guarantee in obtaining credits.

9. Improving the participatory framework of economic policy - every interested person or institution should have the right to participate in the decision making on economic policy.

10. Introducing the state monopoly on the extraction and use of natural reserves - this will provide an equitable access to the country's wealth.

11. Removing the main contradictions, which exist in the economic policy - for instance, some policies intensify corruption, whereas others have a reverse effect.

12. Improving the country's image internationally - participation at international exhibitions, placing adds in prestigious international magazines. 


\section{Contributions}

- Simplifying all procedures, not only those for registration but also post-registration (accounts opening, tax accounting, registration as a VAT payer, obtaining licenses and authorizations) especially for SME were included (p.291, i);

- Reducing the number of all state control forms, ensure consultancy from the part of fiscal bodies (p.291, ii);

- Simplifying the accounting system (p. 307, iii)

- Informing the population and economic agents about new business opportunities, as well as through opening of specialized information centers, business-incubators, by editing and disseminating magazines, booklet, electronic pages, etc., especially at regional level (p.310, iii);

- Proposals regarding the access of small and medium scale enterprises to financing of activities through micro-crediting lines, loans security, etc. $(310$, ii);

- In priority activities of the component Improving Investment Environment, has been stipulated the creation of conditions for the participation in public debates on issues of business environment that was reflected in the strategy (p. 323, v);

- Another concern of interested parties in the area was the promotion of the country's image internationally through domestic products and services at international exhibitions, publications, etc., including through providing the SME with information of selling markets and access conditions (p. 314, vi, viii, $\mathrm{x}$ );

- Proposals regarding infrastructure development in regions and the rural area as a precondition to attract investments (323, iii);

- Guarantee and protect the intellectual and industrial property rights (p.321, i, 359, i);

- Stimulate banks to offer long term credits $(323, \mathrm{vi})$;

- Sub-chapter 6.4.7 "Creation of the real estate framework" was included;

- Use of special regimes of crediting innovational activities done within small enterprises (360, iii).

\section{“Infrastructure development” Strategy}

Proposed solutions for the improvement of infrastructure may be grouped in several categories.

\section{Technical and technological proposals}

- Initiating new technologies to preserve asphalt (polymeric compound layer).

- Installing meters for the natural gas, water and heating.

- To determine procedures for the energy conservation in dwelling spaces, it was suggested to initiate some experimental projects to test technologies.

\section{Structural proposals}

- Rehabilitating the network of bus stations in raion centres and those in rural centres

- Stimulating the creation of private enterprises in the area of construction, repairs and road maintenance, to catalyse the competition and improve the quality of services

- Initiating a system for the tracking of the quality of all water-supply resources in localities.

\section{Policies proposals}

- Developing the energy market, the competition and eliminating the monopoly in distribution

- Improving state control system over the newly built edifices.

- Implementing the General Urban Plan in all localities of Moldova.

- Creating viable mechanisms for financing investments in infrastructure (state contribution - economic agents - local public administration - consumers) 
- Implementing a tariffs system compliant with the requirements of the market economy with a simultaneous introduction of a viable mechanism for the protection of people with low incomes

- Improving the tariffs policy, through differentiated prices from the social and seasonal aspects

- It was proposed to implement and develop a program for the creation of alternative energy resources, which may cover around $10 \%$ of the country's needs and reduce the energy dependency of Moldova on external sources.

\section{Certain measures related to the environment Strategy objectives were proposed:}

- Establishing a more rigorous control of the Metrology and Standards Department over mineral water bottling and use of water to produce other food products.

- Creating authorized permanently monitored dumps in localities.

- To improve the quality of water in localities' wells, local public authorities may organize an annual contest "The best well".

\section{Contributions:}

- For an efficient use of natural gas, water and heating resources it was proposed to install meters (p. 364, b);

- For an efficient collection of payments for water and energy resources supply it is suggested to develop a tariffs system with the simultaneous introduction of the protection mechanism of people with low incomes (p. 367, v, p. 387, ii);

- The proposal related to housing improvement was reflected in the measures chapter (p. 402, v);

- In the field of using alternative energy means to the existent ones in Moldova's conditions, was included in measures (to increase the share of non-traditional sources in the energy balance of the Republic (solar and wind energy, biogas)) (p.367, i.);

- Many proposals were aimed at energy conservation as an efficient mean of cost reduction and promotion of population information on conservation methods (p. 364, b, ii);

- To rehabilitate the roads has been proposed initiation of negotiations with international financial bodies to include the Republic in European corridor projects (p. 377, vi);

- Actions have been proposed to maintain the roads as efficient as possible to stop their degradation ( $\mathrm{p}$. $377, \mathrm{i})$;

- Has been proposed a large scale application of biological waste water cleaning, stop polluting waters by creating sanitary zones (p. 385, iv);

- Within the national seminar, dedicated to youth problems, has been proposed to intensify the building of "social dwellings" (p. 402, i, p. 398, vi).

\section{“Agri-food sector and rural development” Strategy}

\section{Reactions to the concept}

The NGOs involved believe that little attention has been given to the issue of training in the rural area. Public officials thought that more attention should be given to strategic development plans, a main element for the development of any rural community. Agricultural producers called upon the need to involve the community in the debates regarding normative acts that affect them. To create market economy structures it was shown that tax relieves and the introduction of a unique tax are necessary, state subsides of essential commodities, protection of the domestic producer and export stimulation, creation of the insurance mechanism in agriculture. Some of these proposals coincide with the proposals from the Private Sector Development Strategy. Building of a strong commercial and institutional framework, according to market economy principles. The main emphasis will be on implementation of international quality standards, efficiency and range of products, as well as the entire spectrum of services necessary for the production chain until its selling. 
The participants have also militated for the ensurance of strictly voluntary consolidation of land, and for promotion of information campaigns for farmers in this context: on alternative land lease modes, land exchange, etc. Land consolidation will be done exclusively through free market mechanisms. Will be stimulated the specialization of agricultural enterprises to create optimum size enterprises.

Participants at discussions proposed to create information centres in every locality or commune that will fulfil information functions in agriculture, commerce, and other areas, all of these can be implemented by local NGOs. Has been proposed to create commercial structures that would offer services to agricultural production exporters, to obtain conformity documents recognized in the West.

\section{Proposals related to planned measures}

It is necessary to implement a National Program of Rural Development, which should be concentrated on the specialization of geographical zones in agricultural production and provide incentives to agricultural enterprises through the application of modern technologies. Another proposed measure is the stimulation of the integration and association of agricultural producers and processing enterprises to create a bigger added value.

Other recommendations referred to the institutional framework, like the establishment of a National Agency for Rural Development, ensure the transparency of the Ministry of Agriculture activity (especially in the area of discussions related to laws and programs drafts). Similar measures for transparency improvement have been proposed for other two sector strategies, Public Sector Reform and Private Sector Development.

It is necessary to create favourable conditions for the development of the rural tourism, especially opting for the development of craftsmanship and other non-agricultural activities in the rural area.

Proceeding from the fact that producers face big problems with shipping their production overseas, there needs to be a solution to the transit of goods, especially through Ukraine, at the state level. A continuous development of the existent information and consultation network, to have information on possible sale markets and prices for agricultural production is another option for the consolidation of growth in the rural area.

Special attention should be given to the maximum use of scientific potential owned by Moldova, especially orienting to selection, seeds production, technologies transfers etc. The development of private ventures in the rural area: roads, telecommunications, efficient systems for storing and processing of production waste, potable water-supply systems etc.

Given the fact that Moldova is in a geographical zone with a high risk for agriculture, different modalities have been proposed for estimation and decrease of producers' risks and measures for the restoration of the irrigation system.

Proposals regarding the improvement of the fiscal system in agriculture, to offer support to the agricultural producer through taxation, making it more direct.

\section{Contributions:}

- The proposal to provide subsidies to agricultural producers in priority fields was included in the Strategy (p. 432, p. 453);

- For aspects related to the provision of information, consultancy, training for the rural areas was proposed to attract the potential of the NGOs in this sphere (p. 446, p. 447);

- The proposal on integration and association of agricultural producers in associations and production cooperatives has found its reflection in the strategy (p. 449);

- There were proposals on encouraging the process of specialization of agricultural enterprises and creation 
of farmers' organizations to ensure access to information, markets and production opportunities (p. 449);

- Proposals on cooperation between rural and urban agricultural producers (p.452);

- Proposals related to the development of non-agricultural activities in the rural area (rural tourism, craftsmanship etc.) have found a reflection in the general objective (p. 426);

- An increased attention was paid to the development of infrastructure in rural area (p. 441, p. 446).

\section{Regional development policy}

The economic crisis had a more pronounced negative impact on peripheries. The economic gap between the capital and other regions has increased. At the same time, the political and socio-economic development of the country is affected by the Transnistrian conflict. All these demand a macro-level yet systemic approach for the socio-economic and sustainable development of all territories. Is demanded the support to local public administration bodies in the activities of territories development, simultaneous with allocation of resources and correlation of local development plans with national and sector development programs.

\section{Contributions:}

- Has been accepted the idea to include chapter 6.10. "Regional Development Policy" in the EGPRSP;

- Amongst measures that could contribute to the decrease of inter-regional gap, one of the most important is: improve and develop the infrastructure in localities (transport and telecommunications, roads, gas, utilities) (p. 460, i);

- Development of the small business and increase of its weight in territory $(460$, ii);

- Development of non-agricultural activities (p. 460, iii);

- Creation of the National Agency for regional development (p. 464);

- Facilitate the growth of production and promotion of export from regions (p. 460, v).

“Environment protection and sustainable use of natural resources” Strategy

\section{Conceptual proposals}

In the strategy we should talk about "reducing pollution" instead of "stopping pollution" (unattainable measure within 3 years).

\section{Recommendations for actions and measures by objectives}

To the first objective Reducing the degradation of natural resources (water, forest and soil) and enhancing their productivity a lot of proposals have been made of which we should mention the following: consulting with the population on issues of major interest for the community, hardening sanctions for the violation of ecological legislation, reviewing the methodology of calculating taxes for the pollution of environment and procedures of ecological inspection of cars.

For soils protection it is necessary to provide ecological consultations in agriculture and follow the observance of soil protection technologies, effective application of the law on re-cultivation-forestation of degraded land.

The protection of forest resources, involves actions like the development and support of private forest at the national level. An increase of $20 \%$ in forestation may be achieved by using the slopes, planting trees around water basins, planting green belts along the small rivers (e.g. Raut, Ciuluc). It is necessary to create specially arranged recreation places in forest zones. The positive additional effects will be achieved by planting field protection strips of resistant species (specific for the country's South). 
To achieve the objective "Maintain and improve the quality of the environment as a factor ensuring the nation's health", one of activities will be the destruction and neutralization of toxic substances and waste and appropriate management of domestic waste.

It was suggested to create authorized sites for garbage storage, creation of sarcophaguses for waste, according to modern requirements for the isolation of polluting substances. Separate collection of waste in rural zones and cities because of enormous quantities of accumulating waste and lack of landings that comply with the storage and re-cycling requirements. The strategy should provide mechanisms for the Mayor's office to be able to organize the collection and transportation of garbage, waste, according to a fixed schedule.

Public information and education was suggested as another important direction of activity. We should mention proposals like: organization of meetings with the population to inform on opportunities to use waste and re-cycling; a more active involvement of the population in the liquidation of unauthorized dumps; creating a hot-line for direct and operative information regarding unauthorized dumps.

Prevention and reduction of the impact of natural calamities may be achieved by observing the law in force regarding the prohibition of dwellings on hazardous terrain, investigation and monitoring of all land plots subject to slides, enforcing the barrages of lakes.

Some of the comments related to water sources inventory activities, inventory and marking of polluted water sources and rebuilding water eco-systems.

During the discussion on this strategy there have been ecological solutions for EGPRSP in general and for sector strategies.

\section{Contributions}

- the proposal regarding water sources inventory, quality determination and polluted sources location as well as development of a plan for liquidation of pollution sources (p. 490, ii);

- development of pilot-projects for waste use in rural areas (p. 490, ii);

- the aspect related to the increase of forestation areas brought up during discussions was formulated as well as planting protection forest belts on agricultural land (p. 490, iii);

- Providing ecologic consultancy in agriculture regarding the observance of sole protection technologies, use of fertilizes and pesticides, pasture lad improvement (p. 490, v);

- Investigation and monitoring of land plots subject to land slides, as well as other natural calamities (p. 490, vi);

- A review of taxation procedures of damages caused to the environment (p. 490, vii);

- Improving population access to information, training the population in the ecologic area, increase the level of population participation in decision making on environment (p. 490, viii, 489, viii).

\section{“Education” Strategy}

In reference to professional training, it was proposed to develop the entrepreneurial spirit at youth from the general school; it was suggested to restructure vocational schools, according to the requirements of the current labor market. A similar proposal was made during the discussions on the strategy for the consolidation of the private environment. It was suggested to introduce in general schools the vocational training and development of the entrepreneurship spirit. It was suggested to introduce an objective for the professional training of pupils, following the model of the economic education course developed and offered by the NGO "Junior Achievement". 
It was considered reasonable to introduce the secondary education in the strategy's objectives. The key fields, which need to be considered to ensure the quality in this filed include, development of organizational and management capacity of education institutions (including by decentralization of finances management), human resource management in education (including through the decentralization of professional re-training of managers and professors), enhancement of curriculum and didactical materials (introducing optional subject into school programs), optimization of legislation in view of a better financing of the educational sector and providing incentives to sponsorship activities by the economic agents.

Education co-financing represents one of the main conditions for a better functioning of the system. A real and already implemented solution in the non-formal practice is parents and teaches associations. It is required to develop a regulation for a transparent collection and administration of funds received from parents.

Establishing, at the locality level of committees for coordinating activities between the school, local public authorities, social assistance, and medical assistance for the mandatory feeding of children in every school and supervising children from socio-vulnerable families and families with multiple children. Assure the access of children in extracurricular activities, drawing a particular attention to the rural area - in circles, sports sections etc.

Although the legal framework provides for the existence of private education institutions, they are placed in unequal conditions with the state ones. An example would be that of the requirement towards private institutions that provide education services, to have a statutory fund of 300.000 lei, which is discriminatory and cannot contribute to the development of the private sector in this area, and through this to poverty reduction.

The strategy does not provide for realistic ways of solving the employment problem of young specialists in the education area. As a solution, in order to maintain the staff and improve the quality of management it is suggested to award teachers with a public servant statue and employ directors through contest for a 4 years term. The same is true for all teachers since the quality of education cannot be ensured without a strong motivation.

The strategy does not either provide for the creation of special structures to conduct the quality management. It is required to create a structure independent of the Ministry of Education that would deal with accrediting education institutions. The quality criteria must comprise the quality of the teachinglearning process, evaluation quality, curriculum, manuals quality etc.

\section{Contributions}

- in the education area, one of the successes was the inclusion of vocational education as a priority and its adjustment to the requirements of today's labor market, insomuch as this measure has a great social impact on young people from socially vulnerable families who cannot continue their studies in a different way; also it was proposed to include in the vocational education system children with special educational requirements for their utmost integration into the society (p. 507, vi);

- during the training process, the principle of market requirements correlation with the classified list of specialists from higher education institutions, colleges and polyvalent schools was accepted; a proposal brought up during the debates on Labor Market sector (p. 507, ix);

- in the sense of the community's role growth (local public administration, parents, economic agents, etc.) in school financing, the creation of the appropriate legal framework was suggested (p. 506, i);

- for improved assistance of children with special educational requirements has been proposed the organization of a tracking system for them and creating an assistance services alternative to institutionalization (p. 508);

- the principle of promoting to positions of importance and teachers motivation to be made through a contest (p. 509, vi) 
- the idea of a prioritized allocation of resources for salary raise of employees from the education sphere and the improvement of the material base was proposed and taken over in relation to the issue of a large number of teachers leaving the education system (p. 506, iii, 509, v).

\section{"Healthcare" Strategy}

\section{Reactions to the structure}

The information was too voluminous and hard to analyse and a careful examination of the document was suggested with a more clear and particular explanation of the Strategy components, without duplicating the information.

\section{Proposals to the text}

The situation in this area being well known in general, it is necessary to present as briefly as possible those problems relating to health, which led and continue to lead to poverty. A clear stipulation of priority objectives was suggested.

\section{Conceptual proposals}

A major salary raise of all medical staff was requested, to ensure a decent living and optimum work conditions and knowledge enhancement, through diversification of training methods, including distant learning, modern equipment, creation of an informational health protection system . Health education should become a priority of various state agencies: education, medical and sanitary. It is required to ensure the transparency in the area of pricing for medical services. The role of the local public administration and private medicine as a cornerstone of the national heath system was not adequately reflected.

\section{Reactions to the action plan}

A number of action proposals have been formulated. The most important one is to show the source of financing for every action and the amount. It was suggested to expressly provide for the role of the patient to choose the family doctor, the obligations and rights of the doctor. The single insurance package should be enlarged to include dental care services, treatment of chronic and social diseases. The legal framework of medical insurance should be enhanced and harmonized with the European legislation with the inclusion of the implementation mechanism. Completing the lists of those who benefit from state insurance policies with the representatives of vulnerable social groups (mothers with multiple children, chronically ill etc.) and expending the list of provided services.

The endowment with equipment should be centralized, but carried out subject to the needs and with the agreement of medical and sanitary units' representatives. Every locality should be ensured with at least one car for emergency cases. The State must assume the responsibility to ensure the cardio-patients with necessary medication. The cost of such medications is prohibitive for persons with such pathologies, who need ongoing or a long-time treatment. An alternative assistance is also necessary to people with mental disorders and institutions other than mental homes, as well as the treatment in hospitals in normal conditions, appropriate and optimal to people with severe forms of mental disorders. The creation of emergency stations endowed with adequate space and equipment with a coverage area not larger than 25 $\mathrm{km}$ and a sufficient number of specialized teams (cardiologists, neurologists etc.)

A special attention was given to the mother's and child health by reopening milk kitchens for children from 1 to 3 years, ensure pregnant women with Fe and foliates, educating them in the area of their and children's correct nutrition. 
The intention to create perinatal centres in rural communities was considered absurd. It is necessary to develop some centres at the level of raion centres, endowed with modern medical equipment and welltrained specialists. It is needed to develop individual vaccination plans, subject to the condition of every person and ensure every family with vaccines calendar.

Introducing "health education" classes in the school program with training provided by specialists. Developing some local programs on education and responsibility towards citizen's health, through informative, cultural and sports activities.

Marking polluted water sources and not recommended for consumption is a proposal within the Environment Strategy, which is equally applicable to the health field as well.

\section{Contributions}

- proposals related to the creation of a legal framework to regulate relations between doctors and patients, their rights and obligations (p. 527, i);

- comments on the mother and child health improvement were reflected in the action plan and namely in ensuring children and pregnant women with compensated medications (p. 530, ii);

- the chapter including some measures on fighting psychical sicknesses was also completed (p. 529, ix);

- proposals related to the creation of an informational system for the health care system have been reflected in the strategy (p. 527, v);

- the proposal regarding application of most active measures for fighting socially conditioned sicknesses is taken into consideration and included in objectives (p. 529, ii);

- the consolidation and strengthening of the technical-material base of the health system, endowment of medical-sanitary institutions with modern medical equipment and technologies (p. 527, ix).

“Social Protection, Social Assistance and Labor Market” Strategy

A general comment on this component is the weak coordination of activates aimed at protecting children and families in difficulty, between the Ministry of Education, Ministry of Health and Ministry of Labor and Social Protection and implicitly local public authorities.

Actions proposals for this strategy may be listed as active and passive policies.

\section{Passive policies}

\section{Developing an efficient information mechanism of population able to work}

1. developing an information system that would cover the whole territory of Republic of Moldova, including localities from the rural area;

2. creating a transparent informational system of population able to work;

\section{Promoting social inclusion}

3. creating opportunities for the employment of marginalized persons;

4. stimulating economic agents through fiscal facilities to employ disabled people, supporting the creation of production centers for people with disabilities to produce various traditional artisans and handicrafts within the limits of their capacities and providing substantial facilities for marketing these products

5. creating alternative forms to social services at the community level for lonely elderly citizen, disabled persons, etc, by establishing community centers for social and medical assistance. 


\section{Preventing unemployment among young people}

6. Fiscal incentives to economic agents to employ young people;

7. economic education of youth from the rural area in view of initiating and opening their own businesses;

8. providing some facilities by exempting from the income tax on the first year of activity for young people who started their own business;

9. a form of partnership between the Ministry of Education and MLSP was suggested in order to establish a unique accounting for children aged from 15 to 18 and young people up to 20 years to establish the needs on the labor market, their professional training and directing them to professions in demand on the market. This category should be accounted by NALFE.

10. youth access to higher and vocational education through the offering of long term loans with a small interest rate.

\section{Promoting legal emigration of the labor force}

11. regulating the emigration of the labor force;

12. negotiating agreements with EU countries regarding legal employment

\section{Fighting unemployment through active policies}

13. Organizing labor force fares throughout Moldova

14. creating a center of readjustment and re-qualification of marginalized persons

15. stimulating the diversification of economic activities in the rural area

16. initiating public works

\section{$\underline{\text { Assuring efficient social protection through active policies }}$}

17. indexing revenues and social transfers to the inflation rate and minimum consumption basket

18. reforming the pensions system in agriculture

19. creating the position of a social assistant within the local pubic administration

\section{Improving social protection through passive policies}

20. educating a civic spirit of responsibility towards fiscal obligations and active population's awareness of the need to make payments into the social insurance budget, explaining to the population that subject to the contribution of every person is the size of the pension when the person reaches pension age;

21. developing a deinstitutionalization policy for the handicapped people and getting them closer to the community;

22. developing the job of the personal assistant/caretaker who will provide assistance to a person with disabilities, which will allow this person to be with the family, making the institutionalization unnecessary;

23. developing a policy for the stimulation of families in order to take lonely or abandoned children in their homes to avoid their institutionalization.

\section{Contributions}

- as a response to the situation with pensions payments to people employed in agriculture it was proposed to develop a system to respond to the situation in this area, included in Social Insurance chapter (p. 542, iv, p. 539, i.);

- in the area of pensions provision was proposed their indexation to inflation (p. 535); 
- orienting the social aid to the most vulnerable social layers and develop poverty criteria and official threshold of poverty (p. 552, p. 554 ii, p. 560, p. 105, p. 501);

- creating a system for segments with special requirements such as children and persons with special requirements (p. 556);

- for the de-institutionalization of children and disabled persons was proposed their integration in families (their own or placing them in family type houses) (p. 556);

- the idea of creating community centers for the provision of medical-social services to people with special requirements was supported and accepted (p. 557, p. 564, 556);

- for the chapter Labor Market, the creation of an informational system about employment possibilities, recycling and situation on the labor market was proposed and accepted (p. 579, ii);

- to increase the access of disabled people to the labor market, it was suggested to create fiscal facilities for the economic agents (p. 580);

- extension of best practices on economic education for young people, promoted by a number of NGO's from this field, with an enhanced focus on young people from the rural area (services on initiating and developing own businesses, trainings, information, etc.) (chapter Support and development of small and medium scale enterprises) and other measures for prevention of youth unemployment (p. 591, ii, p. 581).

\section{Implementing, monitoring and evaluating EGPRSP}

During pubic discussions on chapter VIII “Implementing, monitoring and evaluating EGPRSP" interested parties, preponderantly those with experience in above mentioned aspects, like, NGO's networks, local projects of various international organizations made a series of comments, proposals, recommendations and criticism aimed at improving the proposed text.

\section{Essential comments:}

A first general comment on the procedure to finalize the institutional framework for the implementation, monitoring and evaluation of EGPRSP is the need to enhance and finalize the existent institutional framework. A framework that should be followed by a detailed and clear description of attributions, the way of functioning and creation of every component. There is already some experience in this sense, which needs to be analyzed and applied in the future to ensure the continuity principle.

Another concern of interested parties was the lack of links between the national level represented by the National Council for EGPRSP implementation and other components and the local level. In this sense, there is a need to develop a mechanism of interaction between the national and local levels in aspects related to implementation, monitoring and evaluation of EGPRSP. The place and role of NGOs at the raion and local levels are not defined, as well how their activity and contribution will be measured. There should be created an institution/office where any person, organization or institution may express his/her opinion, request information etc.

As to who should exercise the leadership role in the implementation of the strategy, in most cases it was the Government, through ministries and departments, with a distinct role for the Ministry of Economy. This does not exclude the participation of other interested parties in the implementation.

Point 623, which mentions the annual report on monitoring and evaluation "The impact of the Policy on Poverty Reduction in the Republic of Moldova" needs to contain a clear specification on who will make this report: a special unit of the Ministry of Economy.

There was an opinion on the importance to further maintain the Participatory Council as a useful tool of interaction between the Government, civil society and donors. The mechanism of creating and functioning of the council should be improved. 
It is incorrect for the institution responsible for the implementation (Ministry of Economy) to exercise evaluation functions as well. These functions should be exercised by someone from outside the Government, a special body, institution etc. (for ex. the Parliament).

There should be a clear distinction between monitoring and evaluation: (i) monitoring is an internal activity related to the continuous administration of the project, the way the action plans are carried out, whether the budget lines are not exceeded etc. (ii) evaluation is an external activity, which takes place at established periods of time and may be handed over to international consultants. The central role in EGPRSP monitoring must be Ministry of Economy's, which does not have direct implementation responsibilities, but if an evaluation of a 2-3 years of implementation needs to be conducted, this could be done by the Parliament, (institutions that have constitutional responsibilities to monitor the implementation of policies and evaluation of their impact), including the civil society.

In reference to the procedure on creation of the National Council for EGPRSP implementation the principle of parity of interested parties should be observed: central and local public authorities, private sector, civil society and donors. In case of the civil society, its representatives should be delegated by NGOs coalitions or networks with respective experience and potential.

\section{Contributions:}

- as a result of proposals that emerged during consultations, the existent institutional framework was taken as basis, especially the Participatory Council as a mechanism to ensure the participation, which needs to be enhanced and extended to the next level

- interested parties proposed to specify the institution that will be responsible for the elaboration and submission of the report "Policy impacts on Poverty Reduction in Moldova" and namely, the Ministry of Economy

- a general comment related to assuring a link between the local and central level, and as a solution the organization of regional forums where EGPRSP implementation progresses and results of policies monitoring will be discussed at the regional and local levels. 


\section{Mr. Michael Deppler \\ Director \\ European Department}

\section{The International Monetary Fund}

\section{Dear Mr. Deppler,}

On behalf of the Government, please allow me to give my greetings and best wishes to you.

I also want to thank you for supporting Moldova in the most efficient implementation of the Economic Growth and Poverty Reduction Strategy Paper (EGPRSP).

In your letter of June 22 you wrote about the need to ensure a sound macroeconomic framework for EGPRSP implementation, in particular the adoption of a credible state external debt management strategy.

During the development of the EGPRSP, the Government's efforts were directed exactly toward the achievement of this objective and we believe that the results achieved so far are convincing.

Over 2004, the stock of arrears to bilateral and commercial creditors was reduced from \$ 92million to \$23.8 million as of July 1,2004 , while the external debt stock reduced by almost $\$ 106$ million or $14 \%$ compared to the end of the last year. These significant reductions were the result of the regulation of commercial debt to OJSC Gazprom and Hewlett Packard. Obviously, these buy-back transactions have increased the costs associated with the external debt service, since these payments have not been included in the 2004 budget.

Therefore, the only remaining commercial debt in this portfolio are the Eurobonds that were rescheduled in 2002 and the Dresdner Bank loan that was rescheduled in 2003, and that are already included in the MTEF and paid on time according to the agreed schedule.

In the meantime, the Government was consistently servicing the debt to multilateral creditors without external financing during this period of time.

Thus, the only outstanding problem that will have to be addressed in the future is the servicing of the debt to bilateral creditors. These Government's intentions are spelled out in paragraphs 119 and 125 of the MTEF for 2005-07.

Given the importance of the EGPRSP for the future of Moldova and based on the need to ensure a credible basis for the Strategy implementation, the Government of Moldova decided to start interest payments to bilateral creditors, Paris Club members, beginning with July 1, 2004 and keep making these payments during 2005, with the subsequent rescheduling of these debts with the IMF's support, so as to settle all external debt servicing arrears in 2006.

As you know, from August 1, 2003 and until now, the Government is in permanent discussion and communication with its bilateral creditors about the economic and social situation in the country, as well as the possibilities of honoring its obligations. We have already agreed on a new rescheduling for 15 years with some of bilateral creditors, non Paris Club Members, such as Turkey and Romania, which was officially confirmed.

We believe that all these actions clearly demonstrate that the Government is making all efforts to reduce the debt burden with its own financial resources. 
Unfortunately, we cannot now receive written confirmation from the bilateral creditors about the acceptance of arrears accumulation. However, we are firmly convinced, especially following the discussions with the Paris Club Secretariat, that the EGPRSP should not provide for offering financial guarantees by the Government to the creditors and that the resumption of interest payments beginning with July 1, 2004, is an important action showing goodwill.

You are aware that the attached Government decision makes the EGPRSP implementation difficult and directing at this stage any additional funds for servicing principal to bilateral creditors would be to the detriment of the efficient implementation of the EGPRSP and of Moldova, and of our international partners.

We hope that the World Bank and the International Monetary Fund, being a credible partners for Moldova's development, will support us in finding a compromise with the bilateral creditors, persuading them that the decision taken by Moldova is a sign of goodwill, thus providing us the necessary support in the achievement of the Millennium Development Goals, approved by the United Nations Organization member countries, to which Moldova has acceded as well.

We are kindly requesting for your support to our proposal and we count on your assistance in taking a positive decision for joint support with the World Bank of the EGPRSP.

The Government will make the necessary amendments to the EGPRSP and MTEF, as soon as possible, in order to bring these documents in line with the attached Government decision about starting interest payments to bilateral creditors, Paris Club members, beginning with July 1, 2004. See the draft Government Decision on approval of the Addendum to the Economic Growth and Poverty Reduction Strategy Paper 2004-06 and the Medium-Term Expenditure Framework 2005-07 attached.

Yours sincerely,

Vasile Tarlev

Prime Minister

cc: Mr. Shigeo Katsu

Vice-President

Europe and Central Asia Region

The World Bank 
GOVERNMENT OF THE REPUBLIC OF MOLDOVA

\author{
DECISION No. \\ of \\ 2004
}

regarding approval of the Addendum to the Economic Growth and Poverty

Reduction Strategy Paper 2004-06 and the

Medium-Term Expenditure Framework 2005-07

To demonstrate credibility of the Government to external creditors and taking into account the financing gap which would appear as a result of the reflection of all obligations in the sphere of state external debt, full payment of which will be inconsistent with the poverty reduction goal, the Government of the Republic of Moldova DECIDES:

1. The Ministry of Finance will continue communication with external creditors and international financial organizations to reduce the burden of the external debt.

2. Main directions and principles of stabilization of the external debt reflected in paragraph 184 of the Economic Growth and Poverty Reduction Strategy 2004-06 are completed with the following bullet: "Demonstration of good will and credibility of the Government to bilateral creditors by the payment of current interest on bilateral debt starting from July 1, 2004."

3. Paragraph 68 of the Medium-Term Expenditure Framework is completed with the following sentence: "To facilitate this attitude the Government will demonstrate good will and credibility to bilateral creditors by the payment of current interest on bilateral debt starting from July 1, 2004."

4. This Decision shall take effect on the date of its publication.

Vasile Tarlev

Prime Minister

Republic of Moldova 


\section{GUVERNUL REPUBLICI MOLDOVA}

Nr. $1406-720$
Chișinău
GOVERNMENT OF THE REPUBLIC OF MOLDOVA

\section{Domnului Michael DEPPLER, Director Departamentul European}

\section{Fondul Monetar Internațional}

Stimate Domnule Deppler,

În numele Guvernului, Vă salut şi Vă adresez cele mai sincere urări de bine.

De asemenea, Vă aduc mulțumiri pentru dorinţa Dumneavoastră de a susține Moldova în implementarea cît mai eficientă a Strategiei de Creştere Economică şi Reducere a Sărăciei (SCERS).

În scrisoarea din 22 iunie curent Dumneavoastră V-ați expus asupra necesității asigurării unei baze macroeconomice durabile pentru implementarea SCERS, şi, anume, adoptarea unei strategii credibile de gestionare a datoriei externe de stat.

În perioada de elaborarea a SCERS, eforturile Guvernului au fost direcționate anume spre atingerea acestui obiectiv şi considerăm că rezultatele obținute pînă în prezent sînt convingătoare.

Pe parcursul anului 2004 stocul arieratelor față de creditorii bilaterali și comerciali a fost diminuat de la 92 mil. dolari SUA pînă la 23,8 mil. dolari SUA, conform situației de la 1 iulie, 2004, iar stocul datoriei externe a avut o reducere de circa 106 mil. dolari SUA sau o diminuare cu $14 \%$ față de finele anului trecut. Aceste reduceri substanțiale s-au produs în urma reglementảii datoriilor comerciale față de SAD Gazprom şi Hewlett Packard. Evident ca efectuarea acestor tranzacții de răscumpărare au majorat cheltuielile pentru deservirea datoriei externe, deoarece achitările date nu au fost incluse in bugetul 2004.

\section{Ce: Domnului Shigeo KATSU, Vicepreşedinte \\ Europa și Asia Centrală \\ Banca Mondială}

Casa Guvernului,
MD-2033, Chișinău,
Republica Moldova

Telefon: $\quad$ Fax:

+373-2-237795
Government House, MD-2033, Chisinau, Moldova (Rep.) 
Astfel, doar Euroobligaţiunile, restructurate în 2002 şi împrumutul de la Dresdner Bank, restructurat în 2003, care sînt deja incluse în CCTM şi deservirea cărora se efectuează la timp, conform graficului de restructurare convenit, rămîn ca datorii comerciale în portofoliul respectiv.

Totodată, Guvernul a deservit coerent datoriile fata de creditorii multilaterali, neavind finanțare externa în perioada respectivă.

Deci, singura problemă rămîne a fi deservirea față de creditorii bilaterali, care necesită o reglementare pe viitor. Aceste intenții ale Guvernului sînt expuse în paragrafele 119 şi 125 ale CCTM pentru anii $2005-2007$.

Luînd în considerare importanța SCERS pentru viitorul Moldovei şi reieşind din necesitatea asigurării unei baze credibile pentru implementarea Strategiei, Guvernul Moldovei a luat decizia de a începe achitarea dobînzii față de creditorii bilaterali-membrii Clubului de la Paris, începînd cu 1 iulie, 2004 şi continuarea achitării lor pe parcursul anului 2005, cu restructurarea ulterioară a acestor datorii cu susținerea FMI, astfel, încît în anul 2006 să stingem toate arieratele la deservirea datoriei externe.

Cunoaşteți că începînd cu 1 august 2003 şi pînă în prezent Guvernul este în discuție si comunicare permanentă cu creditorii săi bilaterali vizavi de situația economică şi socială a țării, precum şi posibilitățile de onorare a obligațiunilor față de aceştea. $\mathrm{Cu}$ unii din creditorii bilaterali care nu sînt membri ai Clubului de la Paris, aşa ca Turcia şi România, deja s-au atins înțelegeri confirmate oficial privind o noua restructurare pe un termen de 15 ani.

Considerăm că toate acțiunile întreprinse pînă în prezent demonstrează clar că Guvernul depune eforturi depline pentru diminuarea poverii datoriei din surse proprii.

$\mathrm{Cu}$ regret, în prezent este imposibil de a primi o confirmare în scris din partea creditorilor bilaterali privind acceptul acumulării arieratelor. Dar sîntem ferm convinşi, în special, în urma discuțiilor purtate cu reprezentanții Secretariatului Clubului de la Paris, că SCERS nu trebuie să prevadă acordarea garanțiilor financiare creditorilor din partea Guvernului, şi reînceperea achitării dobînzilor de la 1 iulie 2004, este o acţiune importantă și de bună intenție.

Sînteți conștienți de faptul că decizia luată face dificilă implementarea SCERS şi orice direcționare suplimentară la etapa dată a surselor spre deservirea sumei principale față de creditorii bilaterali se va face în detrimentul implementării efective a SCERS, în detrimentul Moldovei şi partenerilor noştri internaționali.

Sperăm că Banca Mondială şi Fondul Monetar Internaţional, în calitate de parteneri credibili pentru dezvoltare a Moldovei, ne vor susţine în găsirea unui compromis cu creditorii bilaterali, convingîndu-i că decizia luată de Moldova reprezintă un semn de bună voință, astfel, oferindu-ne suportul necesar în atingerea Obiectivelor de Dezvoltare ale Mileniului, aprobate de țările-membre ale Organizațiilor Națiunilor Unite, la care a aderat şi Moldova. 
Rugăm respectuos să susțineţi propunerea noastră şi contăm pe suportul Dumneavoastră privind luarea deciziei pozitive de susţinere în comun cu Banca Mondială a SCERS.

Guvernul va aplica în cel mai scurt timp amendamentele necesare la SCERS şi CCTM pentru a aduce aceste documente în conformitate cu decizia luată de a începe achitarea dobînzii față de creditorii bilaterali-membrii Clubului de la Paris, începînd cu 1 iulie, 2004. Proiectul hotărîrii de Guvern privind aprobarea Addendumului la Strategia de Creştere Economică şi Reducere a Sărăciei 2004 - 2006 şi Cadrul de Cheltuieli pe Termen Mediu $2005-2007$ se anexează.

Cu respect,

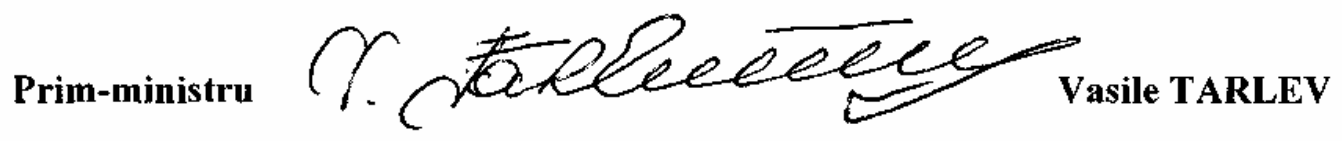




\section{GUVERNUL REPUBLICII MOLDOVA}

HOTĂRîRE nr. $\operatorname{din}$ 2004

privind aprobarea

Addendumului la Strategia de Creştere Economică şi Reducerea Sărăciei 2004-2006 şi Cadrul de Cheltuieli

pe Termen Mediu 2005-2007

Întru demonstrarea bunei credibilități a Guvernului fața de creditorii externi şi ținînd cont de decalajul financiar ce apare în rezultatul reflectărỉi tuturor obligaţiunilor în domeniul datoriei externe, onorarea cărora va fi inconsistentă cu scopul reducerii sărăciei, Guvernul Republicii Moldova HOTĂRĀŞTE:

1. Ministerul Finanțelor va continua comunicarea cu creditorii externi şi organizațiile financiare internaţionale întru reducerea poverii datoriei externe

2. Se completează direcțiile principale de stabilizare a datoriei externe expuse în paragraful 184 al Strategiei de Creştere Economică şi Reducerea Sărăciei 2004-2006 cu sub-punctul următor: „Demonstrarea bunei voințe şi credibilităţii Guvernului fața de creditori bilaterali prin achitarea dobînzii curente la datoria bilaterală începînd din 1 iulie 2004."

3. Se completează paragraful 68 al Cadrului de Cheltuieli pe Termen Mediu cu următoarea propoziţie: „Cu scopul facilitării acestei atitudini, Guvernul va demonstra bună voință şi credibilitatea fața de creditori bilaterali prin achitarea dobînzii curente la datoria bilaterală începînd din I iulie 2004."

4. Prezenta Hotărîre întră în vigoare la data publicării.

Prim-ministru

al Republicii Moldova

VASILE TARLEV 